\title{
Towards a Disciplinary-Conscious New Zealand School Geography
}

\author{
Mike Taylor
}

March 2019

A thesis submitted to Victoria University of Wellington in fulfilment of the requirements for the degree of Doctor of Philosophy. 



\section{Abstract}

This research sought to establish a dialogue between the academic discipline and school subject of geography, by exploring the potential of disciplinary-conscious teaching and learning. Although there have been advocates for utilising the concept of perspectives to develop disciplinary-consciousness (Bliss, 2005; Chalmers, 2003; BOGT, 1999; Puttick, 2013) it is unclear the extent to which that pathway has been navigated in school geography policy and practices (Firth, 2011a; Maude, 2015). Broadly, the focus of my research was underpinned by a 'Futures-3' curriculum stance (Young \& Muller, 2010), in which geography teachers and students were encouraged to engage with the nature of knowledge production in a multi-paradigmatic discipline.

The study drew upon the theoretical energy of Bernstein (1999; 2000), whose sociological analysis of the segmented structure of social science knowledge has congruence with accounts of the development of geographical thought, and therefore helps give direction to the substantive focus of the research problem. Furthermore, Bernstein's articulation of the field of recontextualisation offers further theoretical support for how academic geographical knowledge, such as the concept perspective, is (re)imagined for school geography knowledge.

As my study is mostly focused on the field of recontextualisation, my sequential casestudy design included three distinct phases of empirical inquiry: i) a document analysis of the place and role of the concept of perspectives in curriculum and assessment materials 2001-15; ii) an e-questionnaire of subject specialists; and iii) a Lesson Study inspired collaboration with two teachers and a group of senior secondary students. This latter component of my study was supported by the pedagogical frameworks of Puttick (2013), Hodson (2014) and Moje (2015).

Phase 1 and 2 analysis concluded that the concept of perspective has been recontextualised across multiple documents as a stakeholder framing, which emphasises the views of individuals, groups and organisations, rather than signalling a disciplinary-conscious approach to the subject. Evidence from the geography education specialists suggested 
disciplinary-consciousness had been considered too challenging for teachers and students alike and therefore was unlikely to dislodge the orthodox stakeholder framing. The lesson study collaboration showed, however, that disciplinary-consciousness is not out of the question for students or teachers, and that Puttick's (2013) looking at and looking along conceptual framework is a productive guide for teachers who are starting to provide their students in a basic grounding of paradigms and perspectives influencing geographical thought.

The major implication of this research points towards a recontextualising field in which the social relations within it are structurally configured to make it difficult for a creative engagement with the nature of geographical knowledge to prosper. In this case study, disciplinary-consciousness has been marginalised by subject specialists who are mostly distant from the academic discourses that shape geographic knowledge production. Consequently, curriculum and assessment signalling of perspectives is surface level, and sometimes confusing. Moreover, the prevailing educational discourses that currently shape New Zealand education generate little ‘ideological space' (Bernstein, 1996) for conversations about the variegated nature of geographical knowledge to ferment.

The study concludes with some recommendations for the wide range of actors within the current field of recontextualisation. It is suggested that a collectively aligned response across the sector is required if geography students are to be given the opportunity of exploring different ways of seeing in the construction of geographical knowledge. 


\section{Acknowledgements}

To 'Sacha' and 'Michelle', two teachers prepared to take a risk of trying something new, I offer my gratitude and respect. In a professional environment in which teachers are becoming increasingly swamped by the expectations of their schools, community and wider society, to engage in professional learning at the request of a researcher is a leap of faith: audere est facere!

To the group of Year 12 and 13 students of Ruamoko College and Te Awa High I also offer my humble thanks. Your enthusiastic and thoughtful engagement with the five lessons was great to observe, and it was awesome to see you adapt to unfamiliar surroundings so well. I trust your own educational journeys will be fulfilling, and that you all travel equipped with multiple views.

To my supervisors Drs Bronwyn Wood and Liz Jones. Many thanks for your patience for my drafts, and your critical responses. This has stretched out far too long, but your probing and prodding of what I was trying to say finally got me there.

To my colleagues in the VUW School of Education. Thanks a great deal for your conversations over coffee and cake, whether you are a member of the social science reading group, admin team, or a wider ITE colleague. I am grateful for the Research and Study Leave I have been afforded, and a particular thanks to those of you who took on my teaching load as I absconded for several months to conclude the write up.

Finally, a massive thank you to Katharine, Ella and Ollie. The support of you all has been invaluable. My determination to see this through has been inspired by the examples to study, work and life that each of the three of you have set me. Aroha nui to you all. 


\section{Contents}

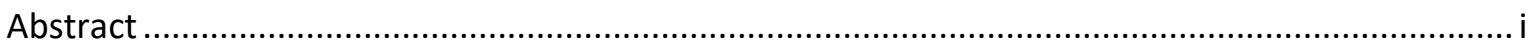

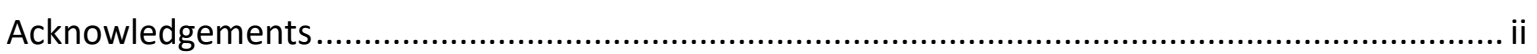

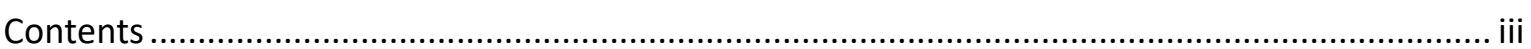

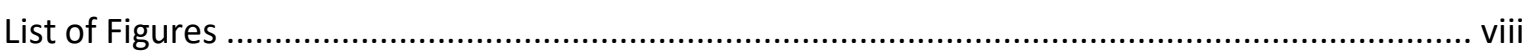

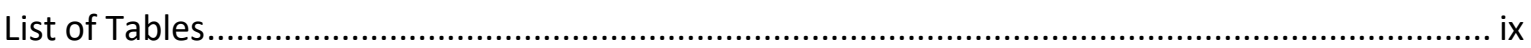

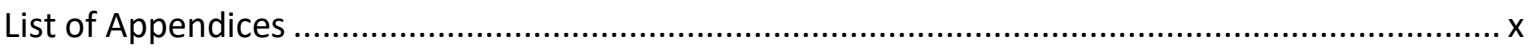

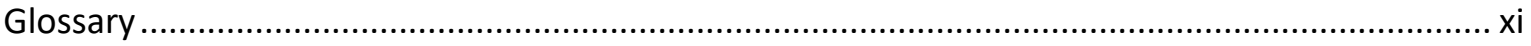

Chapter 1: Why a Focus on Disciplinary-Conscious School Geography? ................................ 1

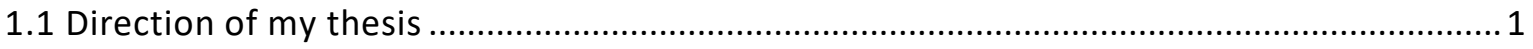

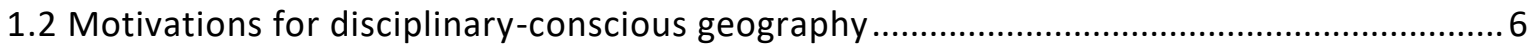

1.2.1 Connecting the school subject and university discipline ........................................... 6

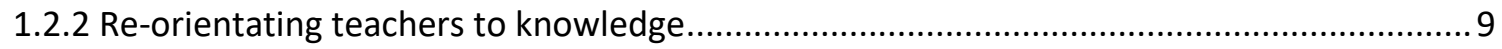

1.2.3 Supporting critical thinking to raise the intellectual challenge.................................... 10

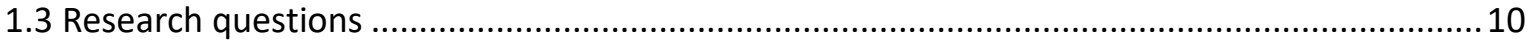

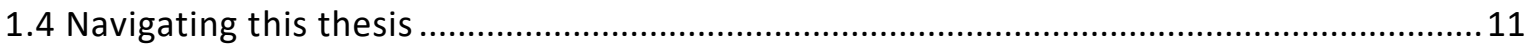

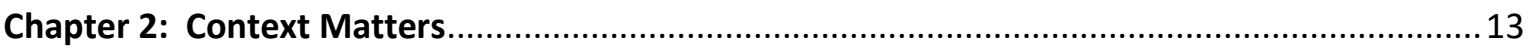

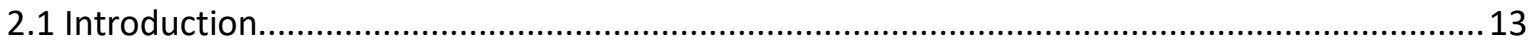

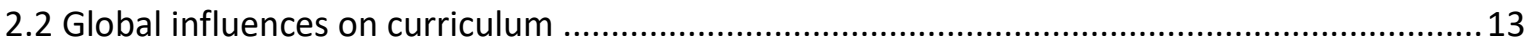

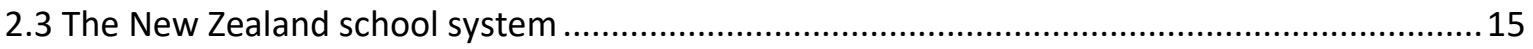

2.3.1 The New Zealand Curriculum ....................................................................... 16

2.3.2 The National Certificate of Educational Achievement .............................................. 17

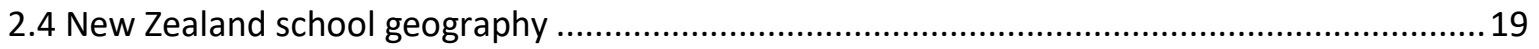

2.5 Subject-specific support for geography teachers ....................................................... 23

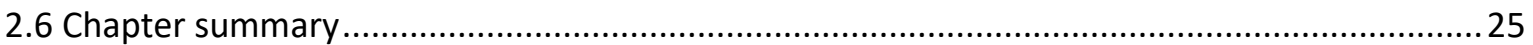

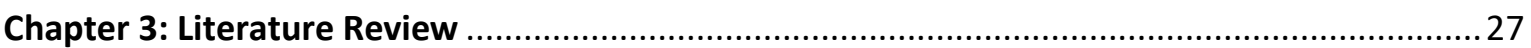

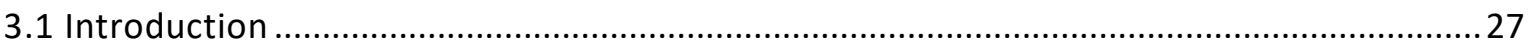

3.2 What is the relevance of disciplinary-consciousness to geography? ...................................28

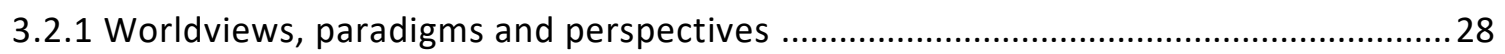

3.2.2 Focusing on paradigms and theoretical perspectives ............................................... 32

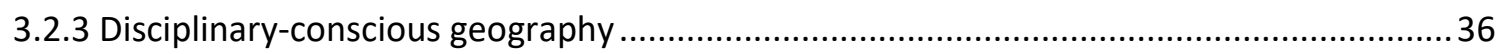

3.3 How have paradigms and perspectives been translated into school geography? .................. 39

3.3.1 Hidden in the background of geography curriculum design.......................................4 41 
3.3.2 Paradigms and perspectives in New Zealand school geography

3.4 How might disciplinary-conscious geography be enacted? ............................................48

3.4.1 Teaching disciplinary-consciousness in school geography.......................................49

3.4.2 Pedagogical direction from other disciplinary-conscious subjects ..............................5 52

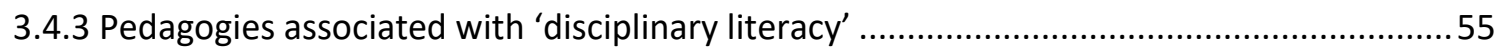

3.5 Summary and rationale for research questions ......................................................... 59

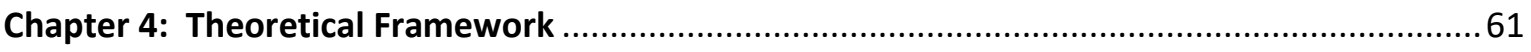

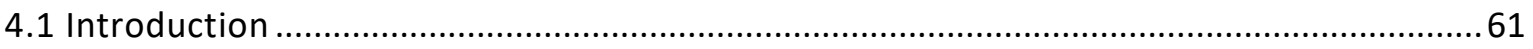

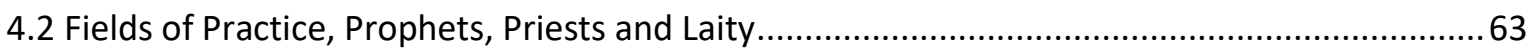

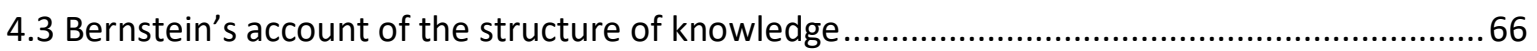

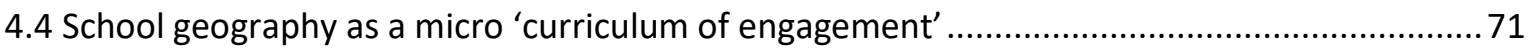

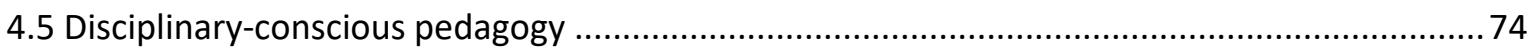

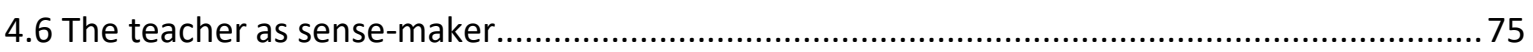

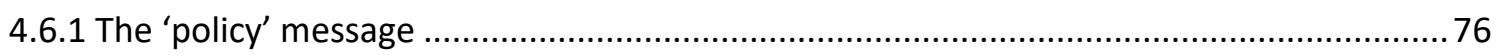

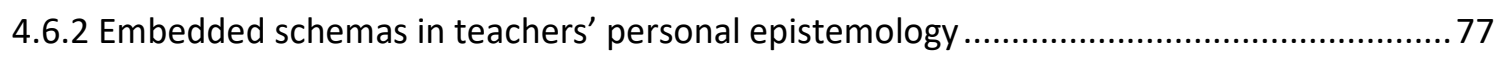

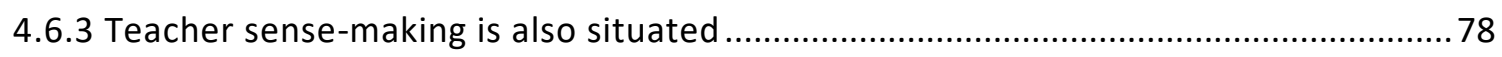

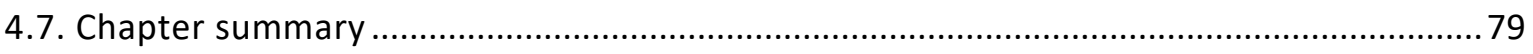

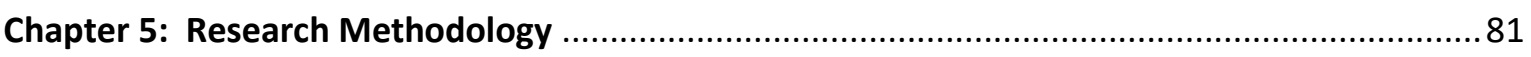

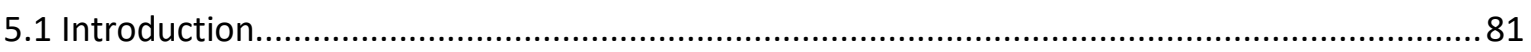

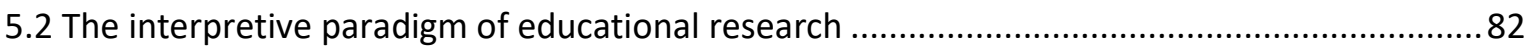

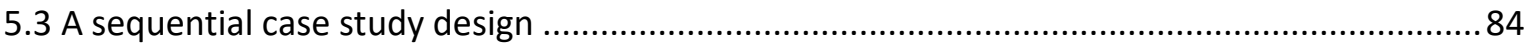

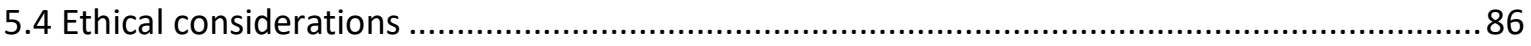

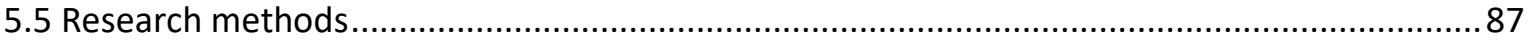

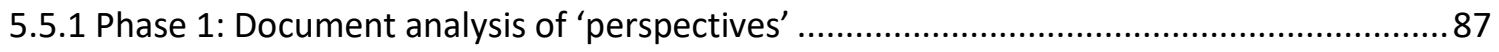

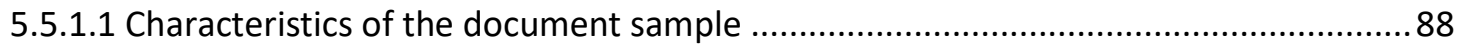

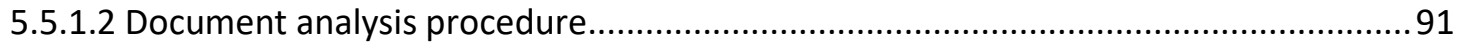

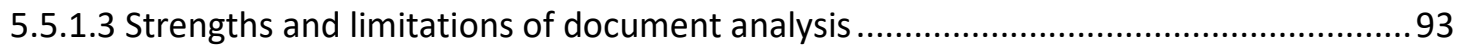

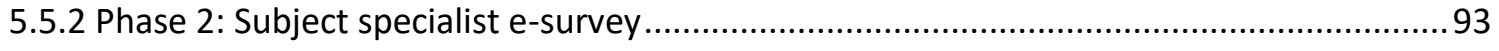

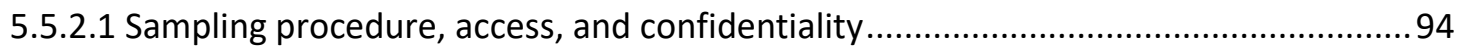

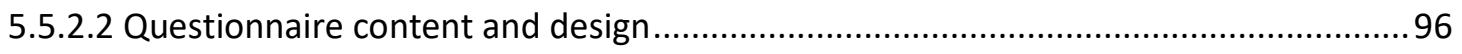

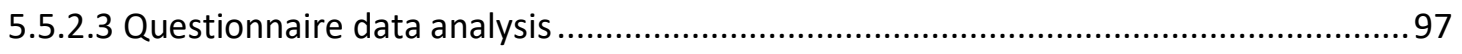

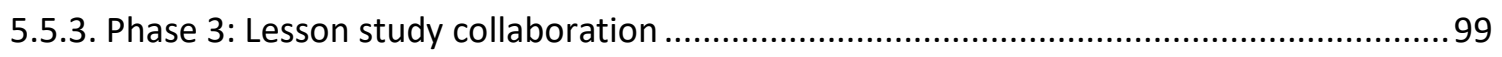

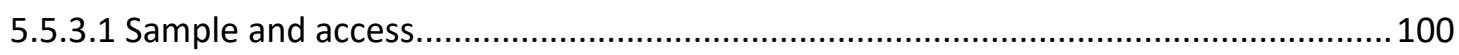

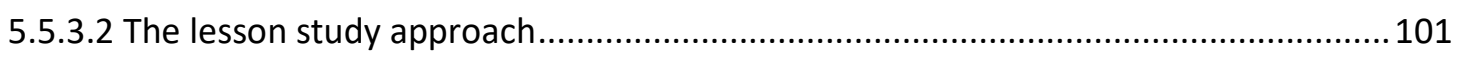




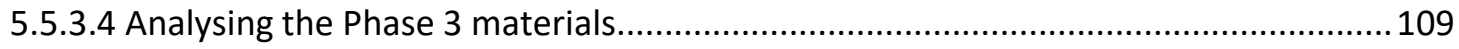

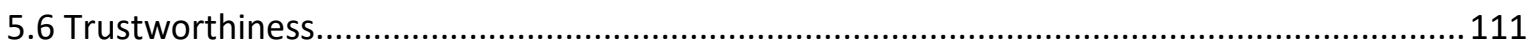

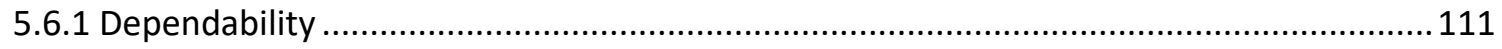

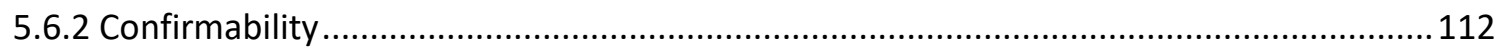

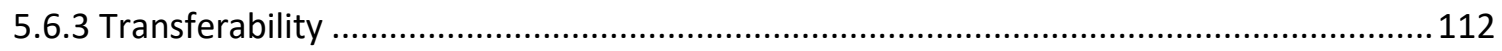

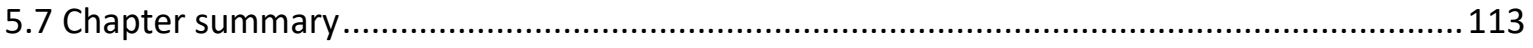

Chapter 6: Curriculum and Assessment Framing of Perspectives.............................................. 115

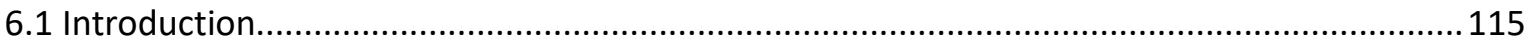

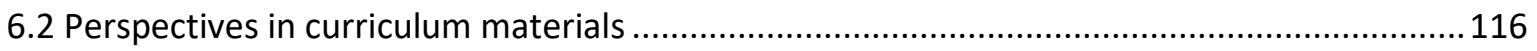

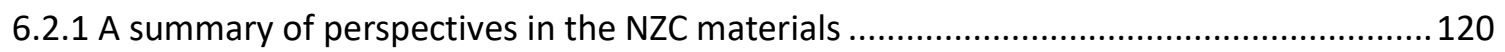

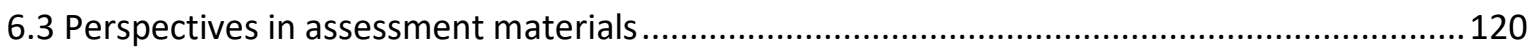

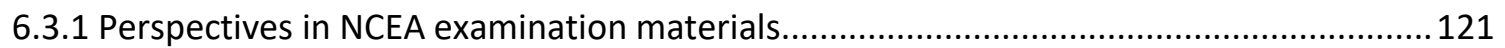

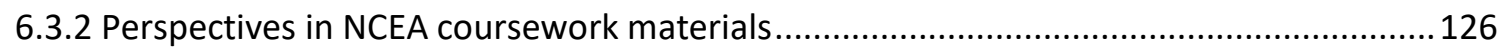

6.3.3 Perspectives in Scholarship Geography Examination Materials .....................................128

6.3.4 A summary of 'perspectives' in assessment materials ....................................................131

6.4 Perspectives in the 2009 social sciences position paper ..................................................... 132

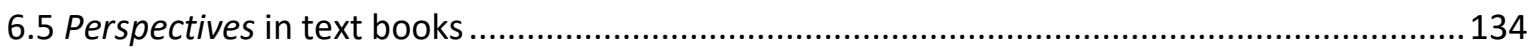

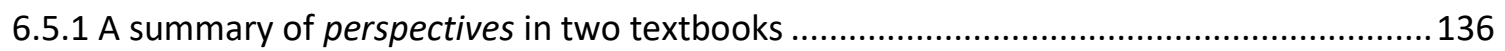

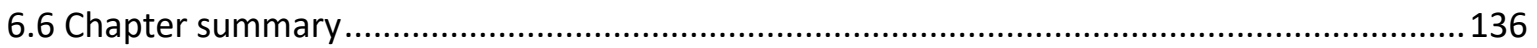

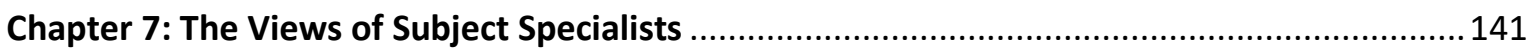

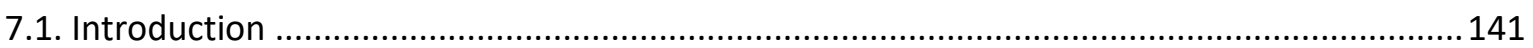

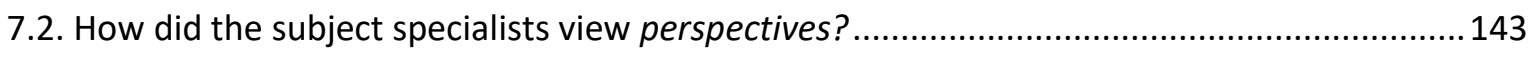

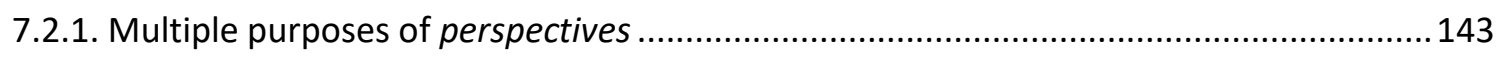

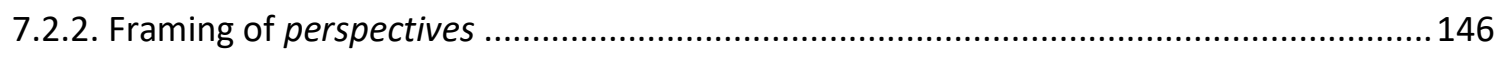

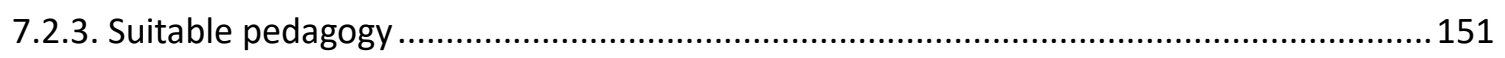

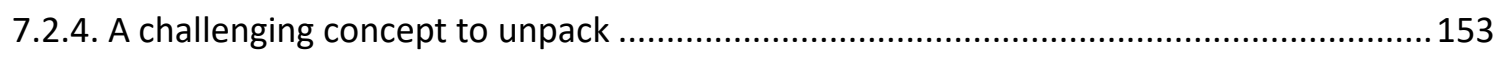

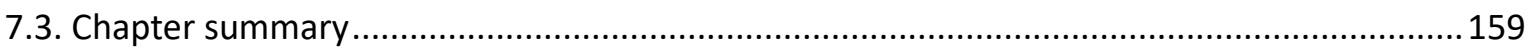

Chapter 8: A Disciplinary-Conscious Lesson Study Collaboration.............................................163

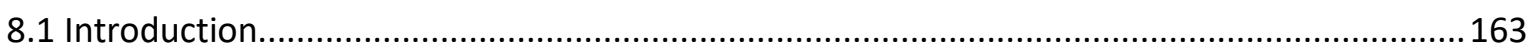

8.2 The 'Studying Cities: Changing Perspectives' programme ...................................................... 164

8.3 A guiding framework for the lesson study collaboration ...................................................... 165

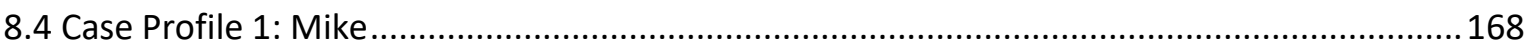

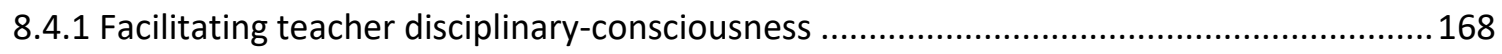




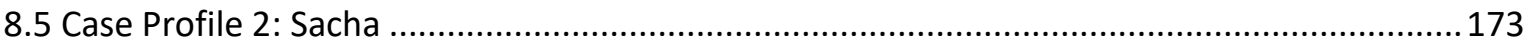

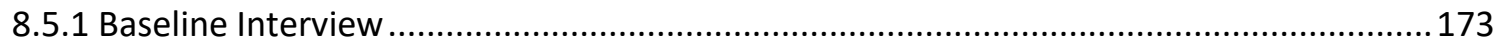

8.5.2 During the lesson study: Reconnecting with the academic discipline ............................175

8.5.3 During the lesson study: Navigating disciplinary-conscious pedagogy............................176

8.5.4 After the lesson study: Applying multiple disciplinary-perspectives ...............................177

8.5.5 After the lesson study: Split-screen framing of perspectives .........................................178

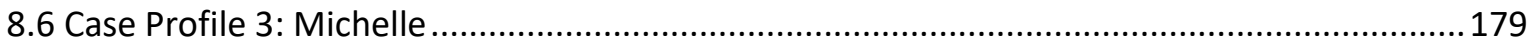

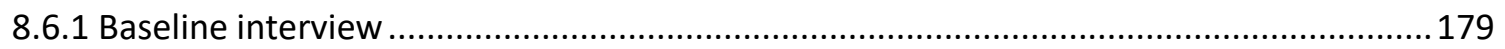

8.6.2 During the lesson study: Reconnecting with the academic discipline .............................180

8.6.3 During the lesson study: Identifying her own disciplinary stance ...................................182

8.6.4 During the lesson study: Wedded to a stakeholder framing ...........................................183

8.6.5 After the lesson study: Valued insights but overwhelmed .............................................. 184

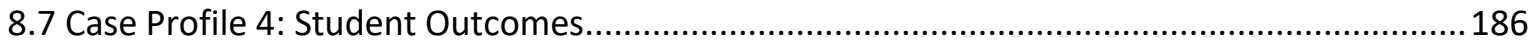

8.7.1 During the lesson study: Quick gains when looking at perspectives ...............................186

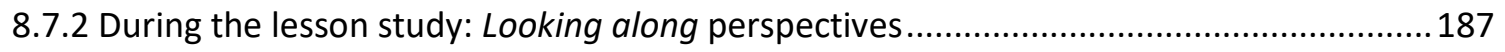

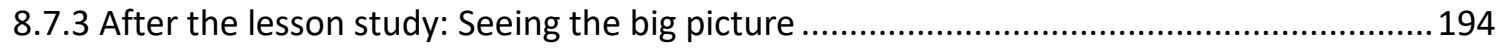

8.7.4 After the lesson study: Analysing specific paradigms and perspectives...........................195

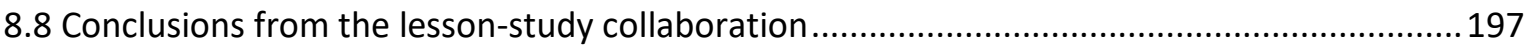

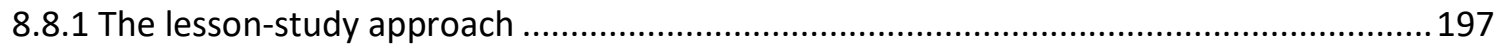

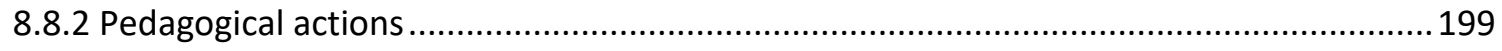

8.8.2.1 Selecting and sequencing paradigms and perspectives.............................................199

8.8.2.2 Knowing when we are teaching disciplinary-consciousness.....................................200

8.8.2.3 Pitching language at student-appropriate levels ......................................................2. 200

8.8.2.4 Planning structured inquiry looking along perspectives..........................................200

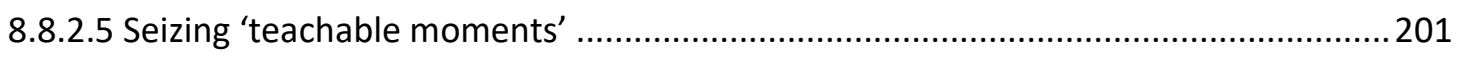

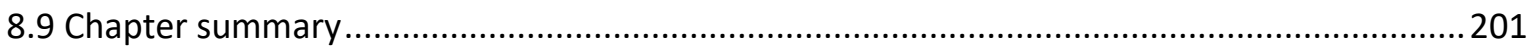

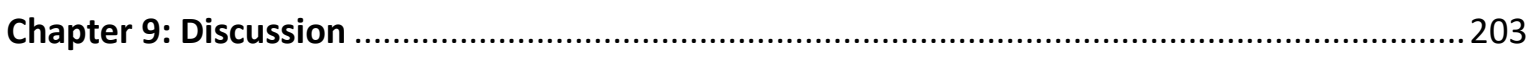

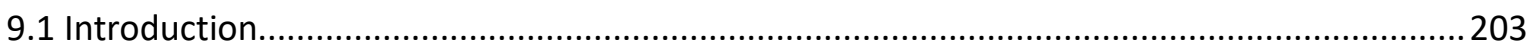

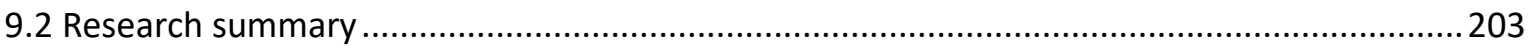

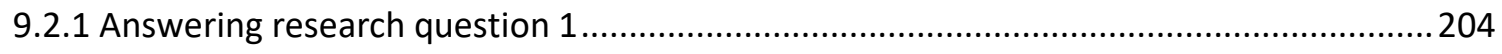

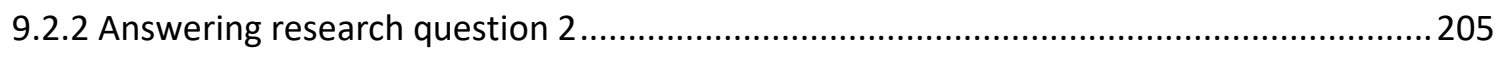

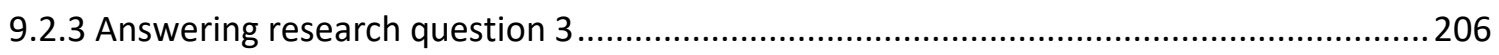

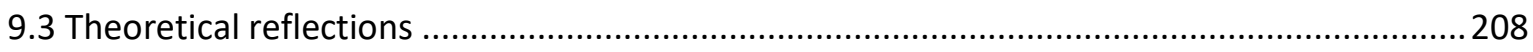




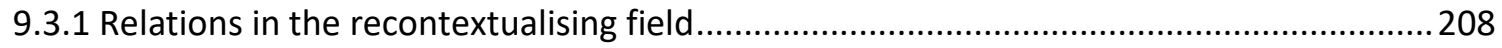

9.3.2 Connecting geography teachers to a Futures-3 Scenario ................................................210

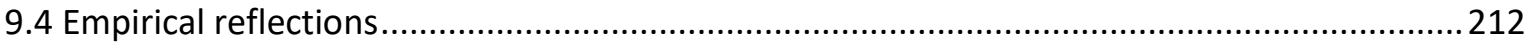

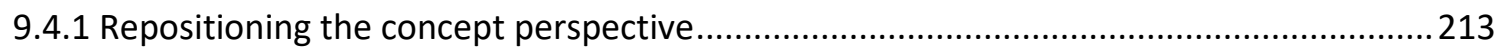

9.5 Reflections on Lesson Study as professional learning.........................................................214

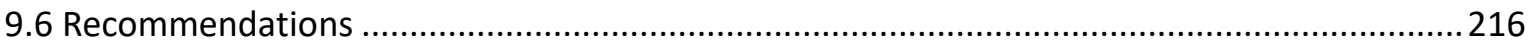

9.6.1 New Zealand Board of Geography Teachers................................................................216

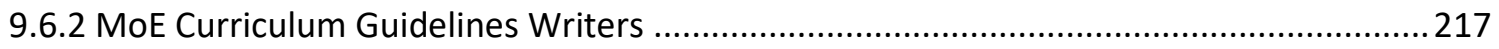

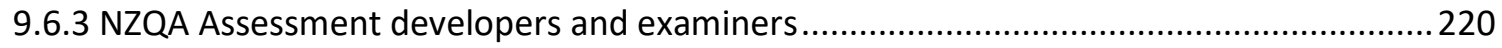

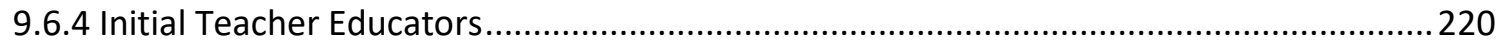

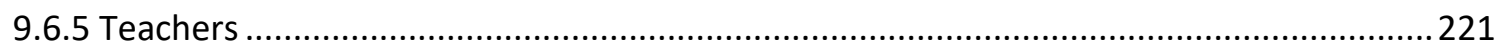

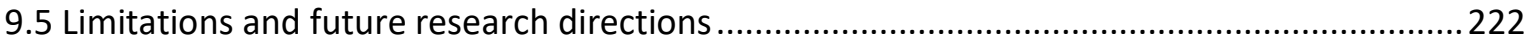

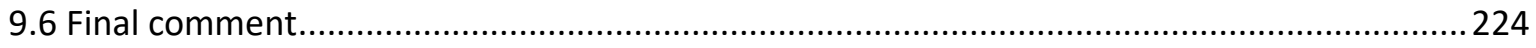

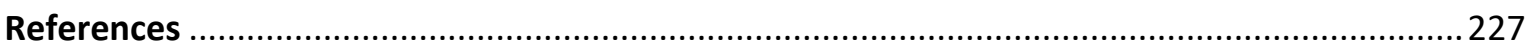

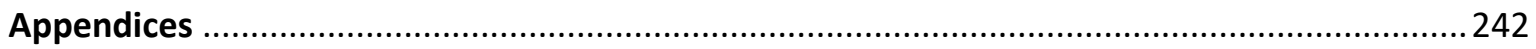




\section{List of Figures}

Figure 2.1: NCEA Achievement Standard prescription ........................................................... 19

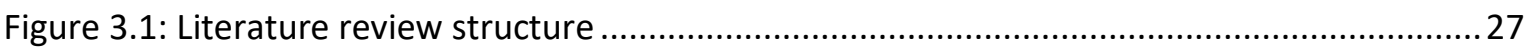

Figure 3.2: The relationship between worldviews, paradigms and perspectives........................... 32

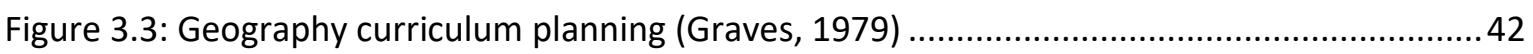

Figure 3.4: Moje's (2015) 4E Heuristic with disciplinary practices ............................................... 57

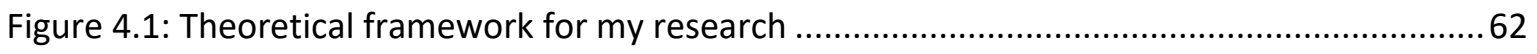

Figure 4.2: Knowledge structures (adapted from Bernstein, 2000) .............................................67

Figure 4.3: Visualising the segmented knowledge structure of geography.................................... 70

Figure 4.4: Three conceptions of knowledge and curriculum ...................................................... 73

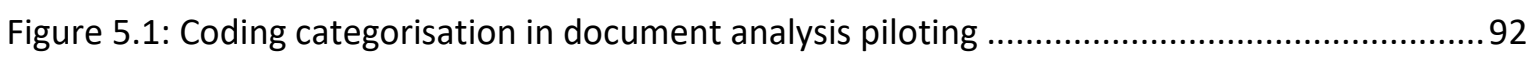

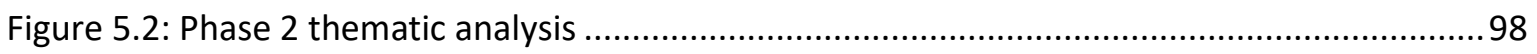

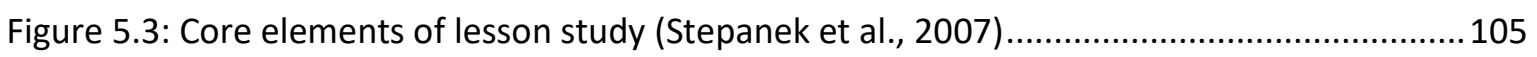

Figure 5.4: Relationship between Phase 3 data sources........................................................... 110

Figure 6.1: A timeline of analysed curriculum and assessment materials ...................................115

Figure 6.2: Three framings of perspectives in New Zealand geography curriculum guides ..........117

Figure 6.3: 'Perspectives' in the senior subject geography curriculum guides (MoE, 2013, n.p.).119

Figure 6.4: NCEA Level 2 'Excellence' exemplar script, 2015 (NZQA, 2016b) ................................124

Figure 6.5: Moderator report on student reflection (source: NZQA, 2015b) ...............................127

Figure 7.1: Subject specialists' perceived importance of different perspectives ........................... 154

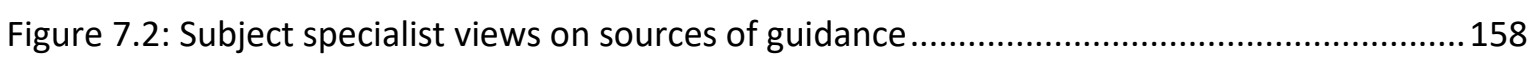

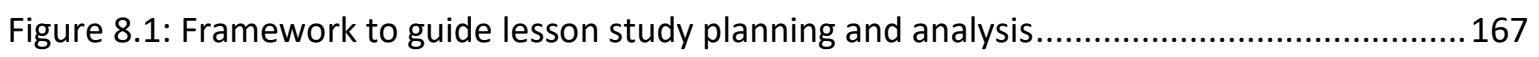

Figure 8.2: Posing questions from disciplinary perspectives (Lesson Study 1) ..............................189

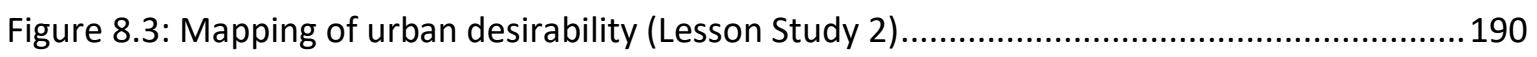

Figure 8.4: Student applications of a spatial science perspective (Lesson Study 2) ......................192

Figure 8.5: Students' recorded interview notes of commuters (Lesson Study 3)..........................193

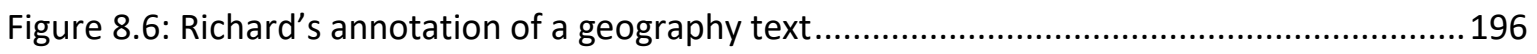

Figure 9.1: Connecting the knowledge debate to classroom practice: A heuristic .......................211

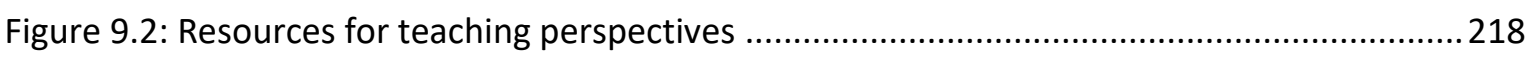

Figure 9.3: A suggested framework for progression in disciplinary-consciousness.......................219 


\section{List of Tables}

Table 2.1: Levels of a typical New Zealand secondary school......................................................... 18

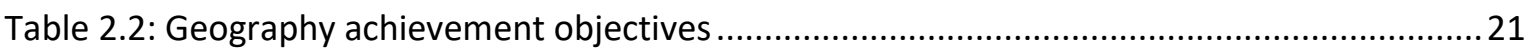

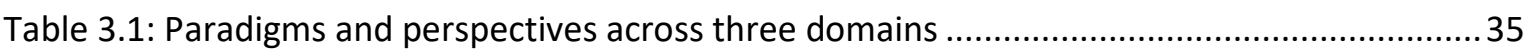

Table 3.2: Approaches to teaching perspectives (adapted from Puttick, 2013)............................. 51

Table 4.1: The pedagogic device (Adapted from Bernstein, 2000; Singh, 2002) ..............................64

Table 4.2: Powerful knowledge in Geography (based on Maude, 2015, 2016) .............................. 74

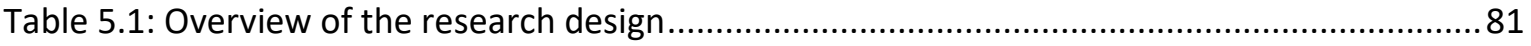

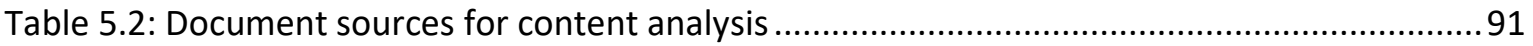

Table 5.3: Question theme and type in Phase 2 questionnaire ........................................................96

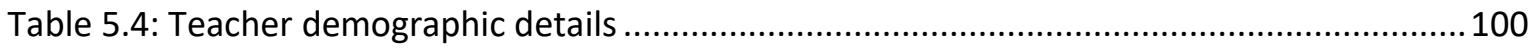

Table 5.5: Rationale for taking a lesson study approach .......................................................... 104

Table 6.1: Assessment materials analysed in Section 6.3 ….................................................... 121

Table 6.2: Perspectives in NCEA Level 2 and 3 examinations (2005-2015) .................................122

Table 6.3: Scholarship examiner commentary on perspectives .................................................129

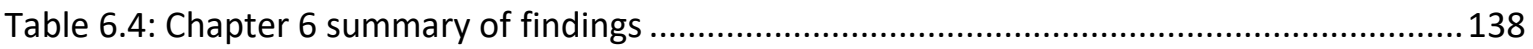

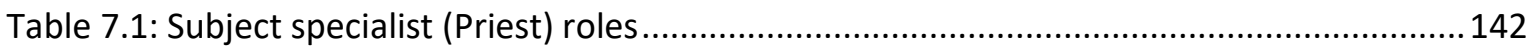

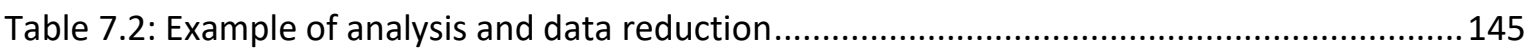

Table 8.1: Studying Cities: Changing Perspectives - Overview of planned lessons......................... 165

Table 8.2: Transcribed extract of student note-writing framework (Lesson Study 1) ...................186

Table 8.3: Student allocation of abstracts according to perspective...........................................187

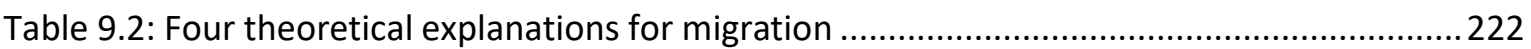




\section{List of Appendices}

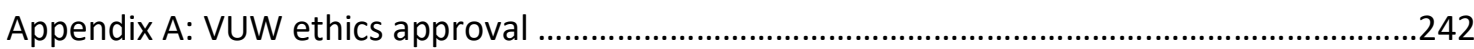

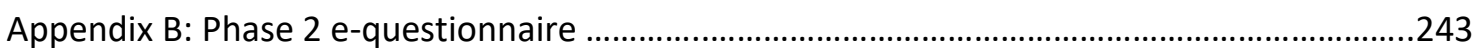

Appendix C: Principal information and informed consent sheets..............................................250

Appendix D: Teacher information and informed consent sheets .............................................253

Appendix E: Teacher baseline semi-structured interview.......................................................257

Appendix F: Student information and informed consent sheets ..............................................259

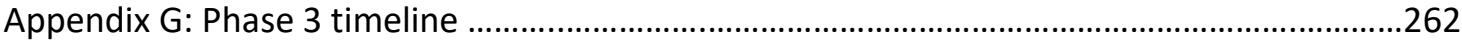

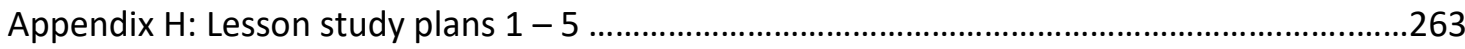

Appendix I: Lesson observation annotation and evaluations ......................................................276

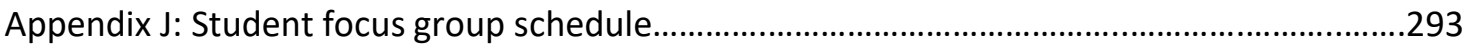

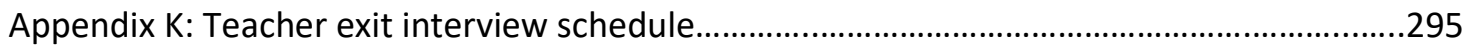

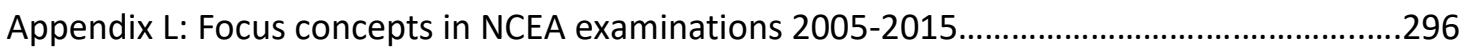

Appendix M: Subject specialist e-survey coding decisions …………………...........................398

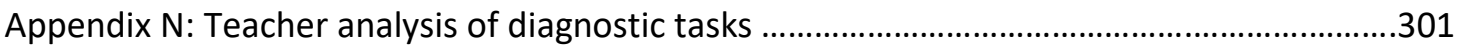

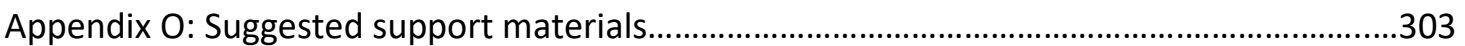




\section{Disciplinary-conscious geography}

\author{
Lesson Study \\ Ministry of Education \\ [MoE]
}

\author{
National Certificate of \\ Educational Achievement \\ [NCEA]
}

\author{
National Geography \\ Curriculum Committee \\ [NGCC]
}
New Zealand Board of Geography Teachers [NZBoGT]

New Zealand Qualifications Authority [NZQA]

\section{Recontextualising Field}

Social Realism
Teaching and learning about paradigms and/or theoretical perspectives as frames of reference from which to sense, interpret, measure or codify geographical phenomena.

A form of practitioner inquiry, in which teachers collaborate in the development and practice of teaching approaches that align to shared goals. Lesson study expects that the participants will also evaluate teacher and student outcomes.

The national administrative organisation responsible for the implementation of the education policy of the government of the day.

The national, standards based qualification for New Zealand senior secondary school students.

A formal group of educators from the tertiary and secondary sector, and Department of Education, operational 1978-1989.

The national subject association for geography teachers, aimed at supporting quality teaching and learning in geography classrooms, raising the profile of geography for students, and promoting links between educational sectors.

The organisation responsible for the administration of New Zealand's qualifications framework, established by the Education Act 1989.

A Bernsteinian term (2000) that identifies the sites and agents responsible for the re-working of academic knowledge into school knowledge. Divided into the official recontextualising field [ORF], inhabited by the State and the pedagogic recontextualising field [PRF], inhabited by examiners, professional development providers, and text book authors.

A position on the social objectivity of knowledge, which argues for turning teacher and student attention to powerful disciplinary knowledge through a 'curriculum of engagement'. 


\title{
Chapter 1: Why a Focus on Disciplinary-Conscious School Geography?
}

\author{
Geography teachers need to engage with questions about the production and nature of \\ knowledge if they are to enable their students to make sense of how geography helps them \\ to make sense of the world. An aim of geography education should be to develop school \\ students' understanding of the nature of geographic knowledge. This has never really been \\ an explicit aim of geography education. (Firth, 2011a, p. 154)
}

\subsection{Direction of my thesis}

The key aim of this research was to close a gap between the academic discipline and school subject of geography by taking an explicit disciplinary-conscious approach to teaching and learning. By disciplinary-conscious, I mean a creative engagement with the paradigms and perspectives that have underpinned the production of geographical knowledge throughout the second half of the 20th Century. This involved taking a 'way of seeing approach' (Hay, 1987), with an overt theoretical stance to geographical knowledge. This is appropriate given the etymology of 'theory' is the Greek word 'theoria', which means 'to see' (Aitken \& Valentine, 2014). My specific approach was to utilise the key geography curriculum concept of perspectives as a small, yet expansive, portal for geography teachers and students to view their "sprawling, horizontal, rich but unruly discipline" (Lambert, 2013, p. 93).

In order to explore how school geography might become disciplinary-conscious, the research objectives were two-fold: (i) to examine the current and possible curricular recontextualisation of perspectives in school geography; and (ii) to explore how a disciplinary-conscious approach to perspectives impacted on teachers and senior school students. The research connected with the social realist concern about the reduced status of knowledge in schools (Young \& Muller, 2010), and to this end the major theory which informed this research was Bernstein's (1999) theorisation of the segmented structure of social science knowledge. Further Bernsteinian (1996; 2000) influence came in the form of 
his theorisation of how academic knowledge is reimagined, recast and relocated as school knowledge in the field of recontextualisation. Furthermore, pedagogically focused interventions from Puttick (2013), Hodson (2014) and Moje (2015), contributed insights to how teachers might realise a disciplinary-conscious approach to teaching geography. In total, there were three empirical phases of my research in which I: (i) analysed curriculum and assessment messaging of the concept 'perspectives'; (ii) elicited the views of a group of geography subject specialists about the role of perspectives; and (iii) engaged in a collaborative lesson study sequence to develop teachers' and students' disciplinaryconsciousness.

While debates about paradigmatic shifts and theoretical perspectives have generated considerable attention related to the production and nature of geographical knowledge in academia over the last four decades, theoretical developments of knowledge have been in the background of geography curriculum design and peripheral to the teaching of school geography (Chalmers, Keown, \& Kent, 2002; Firth, 2013; Morgan, 2002; Puttick, 2013; Rawding, 2013; Winter, 2006). The problem at the heart of this study is that thinking about the nature of geographic knowledge is not something that has been at the forefront of teacher practice or student learning.

In the field of geographical knowledge production itself, where university researchers and scholars debate developments in the discipline, the theoretical focus on geography has been met with some resistance. For example, the president of the Association of American Geographers pointedly suggested:

a significant part of the quest for geographic knowledge has been detoured by attempts to understand the latest "ism" rather than advancing geographic knowledge - i.e. geographers have focused on perspective rather than substance and in doing so have wasted much effort in internecine conflict and criticism

(Golledge, 2002, p. 2)

The somewhat pejorative label of 'ism' notwithstanding, it is my view that Golledge's decoupling of perspectives and knowledge is problematic. This is because perspectives shape the kinds of questions asked, information gathered, analysis undertaken, and conclusions reached by geographers. At a deeper level than substantive knowledge, 
geography $\underline{i s}$ being advanced by explicit attention to the theoretical basis of knowledge production. What is unclear for the secondary sector, is whether teachers have the capacity or inclination to support their students to explore diverse forms of geographic knowledge production in age-appropriate ways.

By focusing on the concept of perspective in a disciplinary-conscious sense, the direction of this thesis is different to accounts which aim for a unified geographic perspective. For example, MacLeod (2014), explains that the geographic perspective is akin to using a telescope comprised of several concepts: environment, process, pattern, interaction, and sustainability. According to Macleod, all these concepts are part of the geographic telescope, but changing their relative position within the telescope might emphasise different aspects of the phenomena being studied. While I believe this is an appropriate approach for young learners as they form rudimentary understandings of geography as a subject, my approach for senior secondary school students was, however, rather different. This is because the aim of my study was to engage with an array of different 'telescopes' that have shaped geographical knowledge rather than just one.

To extend MacLeod's metaphor, the Hubble telescope is instructive here, as it orbits the Earth high above the gas and pollutant filled atmosphere, allowing it to see space better than telescopes on Earth. While telescopes have a history traced to Galileo in 1609, the legacy of the 30-year-old Hubble is significant, with the Chandra X-ray, Planck Observatory, and Kepler mission some of the dozen or so space telescopes which have set their sights on quite different aspects of the universe since the 1990 Hubble launch. These more recent telescopes are very different in aim and operation than Hubble, although are clearly a part of the same family of space telescopes.

Similar to space telescopes, the academic discipline of geography has experienced rapid developments in a short period of time. Geographic thought throughout the second half of the $20^{\text {th }}$ Century became increasingly diversified as geographers developed new lenses to see the world afresh (Cresswell, 2013; Gregory \& Walford, 1989; Johnston \& Sidaway, 2004). Like new theoretical developments in geography, space telescopes did not result in the demise of 'inferior' predecessors: their aim was different as they sought to shed light 
on new questions. And so too have a range of paradigms and perspectives jostled for attention in the discipline of geography, resulting in debates that have been described as providing a much more "lively and stimulating subject area" (Bassett \& Short, 1989, p. 189). The invigoration that these paradigms and perspectives have brought to bear on the discipline were captured by Ian Hay's (1987) assertion that:

If we are to gain a better comprehension of our social world, it becomes a necessity then to scrutinise the quality of our (pr)isms and also to be aware of the nature of the (pr)ism through which our conceptions of the world are passed. (p. 2)

In New Zealand school geography, the focus on perspectives as a tool for raising disciplinary-consciousness originally surfaced in the New Zealand Board of Geography Teachers' (1999) position paper, ideas from which were soon incorporated into further guidelines provided to teachers at national assessment-focused professional development workshops in 2001. These guidelines identified a range of '-isms' (specifically, scientific empiricism, positivism, feminism, new cultural and Māori geographies) with the stated intention that:

In teaching Geography to students in secondary schools we are particularly interested in differentiating between different 'theoretical' perspectives. That is, we want students to know about how knowledge about the world is organised and understood from different points of view. (Miller, 2001, p. 10)

In the same guidelines it was also declared, however, that engaging with theoretical perspectives was "not every body's cup of tea" (Miller, 2001, p. 11). The 'take it or leave it' approach of this final statement was hardly a clarion call for teachers to integrate theoretical perspectives into their teaching practice in thoughtful and engaging ways.

The disciplinary-conscious focus of my research places learning about geography, rather than learning geography at the centre. If that sounds like tautology, then I hope the following distinctions from the geography classroom help. Typically, the focus on knowledge in senior secondary school geography centres around acquisition of substantive knowledge (factual and conceptual) and procedural skills (Schwab, 1978). For example, based on New Zealand's 2016 Kaikōura earthquake, students might learn that Waipapa Bay experienced up to five metres of coastal uplift as well as develop deeper conceptual 
knowledge about Kaikōura's physical, social, environmental and economic vulnerability in relation to the location of multiple complex fault systems. Furthermore, this substantive knowledge might be interwoven with procedural skill development, in which students annotate maps, interpret aerial images, and analyse first person accounts of the earthquake and its aftermath.

While this approach described above is the longstanding orthodoxy, it may provide unintended consequences if students come to view geographical knowledge as inert, rather than a contested space of ideas. Returning to the 2016 Kaikoura earthquake, on what basis do we trust acquired knowledge and understanding about changes to Waipapa Bay's coastal environment? What do we have to learn about observation and measurement in order to understand how the Waipapa Bay environment changed so dramatically? Who produces the legitimate theories on the causes of earthquakes or how to mitigate vulnerability? What does an 'objective' view of earthquakes limit us to knowing? How do we know what we know in geography, and how has this knowledge come to be? If a rounded picture of the development of geography is to be acquired, these questions suggest that learning about geography requires attention to the production of knowledge: in the week following the Kaikōura tremor there were claims about the influence of a supermoon $^{1}$ (Edens, 2016; Wright, 2016), pronouncements on the causes of earthquakes from an evangelical worldview (Strongman, 2016), while the 'triangle of life' vied for legitimacy with advice to 'drop, cover, hold' (Ministry of Civil Defence \& Emergency Management, 2016). In short, when learning about how knowledge is produced it allows geography to become visible as an object of study (Firth, 2011b).

To summarise the direction of my thesis, my curiosity lay in the possibility of developing a deeper connection with geographical knowledge if senior secondary students were encouraged to explore the development and nature of geographical knowledge itself. As the etymology of geography is literally writing the world, a disciplinary-conscious stance has the potential to illuminate how geographical writing is produced in quite different

\footnotetext{
${ }^{1}$ Although NASA has recently borrowed the term 'super-moon' from the discourse of astrology, this borrowing should not be inferred as a bridge between the concepts and theories of scientific and astrological knowledge production.
} 
ways and for quite different purposes. Yet there is very limited empirical research that focuses on geography curriculum and pedagogical development in New Zealand schools. Having now outlined the general direction of my thesis, in the remainder of this introductory chapter, I identify three key motivations for my research focus.

\subsection{Motivations for disciplinary-conscious geography}

Broadly, this study is motivated by my commitment to subject specialism, despite the contemporary western zeitgeist, in which there has been an erosion of trust in specialist knowledge (Durkin, 2018; Rabin-Havt, 2016). Rather than reify geographical knowledge, however, I seek to explore disciplinary-consciousness in recognition that "the problem of the teacher is to pass on a body of knowledge in such a way that a critical attitude towards it can also develop" (Peters, 1967, p. 19).

\subsubsection{Connecting the school subject and university discipline}

A disciplinary-conscious approach to teaching and learning geography is potentially a pathway towards helping teachers address longstanding observations that school and university geography have little in common (Butt \& Collins, 2013; Goudie, 1993; Rawling, 2001; Stannard, 2003). Yet, while academic knowledge is an important source of material, other forces also impinge on the development of school subjects (Deng \& Luke, 2008). Consequently, some subjects may have high fidelity with the academic discipline in a parent-child like relationship, other subject-discipline relationships may be discontinuous, (i.e., no obvious relationship), while other subject-discipline relationships are in a dialectic relationship with one another (Stengel, 1997). By establishing a stronger connection between school and university geography through paradigms and perspectives, it is tempting to assume a top-down, parent-child relationship between the discipline and the subject. However, because I anticipate the recontextualisation of ideas for the school setting, in which choices about selection, pacing, and design of activity take place, the relationship between academic geography and school geography is dialectic, in acknowledgement that:

Subjects connect us to a range of intellectual traditions, but are also shot through 
with arguments about how to make sense of the world. Young people need grounding in both. Acquiring knowledge, developing understanding and practising significant 'ways of seeing' contribute to the capability of people to function in society.

(Lambert \& Morgan, 2009, p. 155)

As attention to paradigms and perspectives has traditionally been the preserve of tertiary education, I have had to ask myself whether it is realistic or desirable to expect senior secondary students to engage with the diverse foundations of geographic knowledge. Although debates about different geographic perspectives have created considerable attention in academia, the presence of such arguments have been peripheral to the teaching of school geography.

Moreover, there is consensus that school geography knowledge is largely presented from an absolutist/positivist perspective of knowledge (Brooks, 2006; Firth, 2013; Puttick, 2013; Winter, 2011). I see this broadly mono-theoretical characteristic of school geography, as one example of what Goudie (1993) lamented was the 'great divide' between the university and school geography. By exploring the nature of geographic knowledge production in an explicit sense, students may be supported to develop an intellectually honest representation of the pluralistic outlook of the contemporary discipline, and thereby 'bridge the divide' between school and university geography (Butt \& Collins, 2013), while becoming more equipped as social scientists and citizens (Lambert \& Morgan, 2009).

I am, however, very mindful of authors such as Goodson (1988), Stengel (1997), and Deng and Luke (2008), who concur that school subjects are not simply watered down representations of the academic discipline. As Thomas (1973) reminded a geography teaching readership over four decades ago:

it does not automatically follow that innovations which have been incorporated into university geography should necessarily be incorporated into geography at school level, as the basic concern of the latter must be the education of the child rather than the further development of geography as an academic discipline.

(Thomas, 1973, p. 72) 
Thomas' distinction between the subject and discipline foreshadowed Stengel's (1997) model of subject-discipline relationships, which proposed that some of these relationships can be discontinuous. As Rawling's (2001) detailed examination of the subject-discipline relationship in England from 1980-2000 indicated, discontinuity was a strong feature:

The school curriculum and higher education curriculum have become separate components, each influenced more by the socio-political contexts of their production and by the need to address government priorities than by any sense of a common disciplinary base. In higher education, diversity is the picture... at school level, geography has become a relatively static vehicle for social and educational purposes.

(Rawling, 2001, p. 166)

Rawling's statement summarises well a situation that I currently relate to in the New Zealand setting. Many of the key foci of contemporary New Zealand school geography can be traced back to curriculum development of the 1970s and 80s (Chalmers, 2005), while curriculum development narratives in the last decade seem to give more attention to student need and the development of generic competencies than they do to exploring the nature of geographical knowledge (see, for example, Baldwin, 2012).

While I acknowledge there are traditional differences in the purposes of academic disciplines (i.e., knowledge production) and school subjects (i.e., knowledge acquisition), if the relationship between the two were completely severed, it would raise the question of how specialised knowledges could ever be reproduced (Muller, 2009). I appreciate that most senior secondary school students who study geography do not progress to universities, let alone become professional geographers. Yet, I apply Moje's (2015) observation to my focus on disciplinary-consciousness as:

not about producing new members of the disciplines (although it surely will produce some new members, and perhaps some from a range of diverse backgrounds), but about providing all students with the opportunity to understand how disciplines work and to raise questions about the trustworthiness of disciplinary knowledge. (p. 259) 


\subsubsection{Re-orientating teachers to knowledge}

A second motivation for my study is a reorientation of teacher focus, which has, for the last two decades been encouraged to focus on the 'how' of teaching rather than the 'what' (Young, 2008; Young \& Muller, 2010). This pedagogical narrative has been driven by powerful discourses from the global policy arena in which teacher quality has been promoted as the greatest 'in school' factor to raise student achievement (Hattie, 2008). The prioritising of pedagogy, and several other external narratives that have emerged in the context of globalised, market driven education systems has, according to several critics, led to a marginalisation of constructive debate about the place and role of knowledge as a central internal curriculum resource (Lambert, 2014; McPhail \& Rata, 2016; Wood \& Sheehan, 2012; Young, 2008). I hope that my reorientation to knowledge may help teachers not only ask 'is this knowledge meaningful and authentic for my students?' but also, 'what are the meanings this disciplinary/subject knowledge gives my students access to?' (Yates \& Millar, 2016). By doing so, the focus charts a more balanced route between the bipolar constructs of 'student-led' and 'knowledge-led' schooling.

As a component of the re-orientation to knowledge, in the last five years a lively debate about the characteristics of powerful knowledge has ensued, described as "the most significant debate to emerge within the geographical education community for many years" (Slater, Graves \& Lambert, 2016, p. 189). The debate originated in England, and has had significant influence on recent Australian geography curriculum development (Maude, 2015). New Zealand school geography has not, however, featured in that debate. Maude's (2018) recent description of powerful geographical knowledge included giving students "some power over their own geographical knowledge...know something about the ways knowledge is created, tested and evaluated within geography, and about geographical reasoning" (p. 183). I am, therefore, motivated by exploring the extent to which disciplinary-consciousness can give students such power over their own geographical knowledge.

A reorientation to knowledge has the potential to support teachers and senior secondary students to engage with geography's disciplinary eclecticism. While much disciplinaryconscious research compares contrasting subjects, such as natural science, history and 
literature (see, for example, Goldman, 2012; Hipkins, Johnson, \& Sheehan, 2016; Moje, 2015), the challenge for geography teachers is revealing to their students the very different foundations of knowledge within geography itself. This variegated nature of the discipline is captured well by Firth's (2011b) observation that “Geography and Geographers are differentiated from the inside out...Geography is a multi-paradigmatic discipline and geographers work with different concepts of scientific knowledge and its development" (p. 299). Consequently, my focus is on theoretical pluralism rather than advocating a specific paradigm, although I do empathise with the position of educators such as Huckle (1983), who has lamented that schools have largely ignored the social re-constructive paradigm. I hope that this 'neutrality' is not interpreted as an abrogation of commitment, as enabling teachers and their senior secondary students to explicitly explore strengths and limitations of a range of paradigms and/or theoretical perspectives is the launch pad to widen their ways of seeing.

\subsubsection{Supporting critical thinking to raise the intellectual challenge}

A final motivation for my research centres on my view that a disciplinary-conscious stance towards school geography may challenge the perception that geography is an intellectually impoverished school subject (Cresswell, 2008). Anecdotal conversations with New Zealand geography teachers indicate that many of the brightest students are turning their back on geography as a senior school option, as part of the wider fall in students enrolled in senior geography classes (NZQA, 2018). A focus on disciplinary-consciousness might help raise the bar of thinking levels. Thus, disciplinary-consciousness is not for the purpose of reifying knowledge but developing critical attitudes towards it (Bruner, 1960; Peters, 1967). The need for students to be critical consumers of knowledge if they are to successfully navigate a complex world may require not only an understanding of broad differences across disciplinary structures, but, in the case of geography, attention to the quite different ways of seeing within the subject itself.

\subsection{Research questions}

As will unfold in the following chapters, and noted early on in this chapter, the potential for disciplinary-consciousness was signalled to New Zealand geography teachers at the 
cusp of the new millennium (NZBoGT, 1999). This spurred my first research question, from which two others emerged. While I will explore theoretical and empirical literature, as well as the New Zealand educational context that relates to these questions over the following chapters, I state them here to crystallise my research direction for the reader:

- $\quad$ To what extent have curriculum and assessment materials signalled a disciplinary-conscious orientation to perspectives, since the publication of the 1999 NZBoGT position paper?

- How do geography curriculum and assessment specialists view the value, place and role of perspectives in New Zealand senior secondary school geography?

- What are the outcomes of a lesson study collaboration focused on developing teachers' and students' disciplinary-consciousness?

\subsection{Navigating this thesis}

Reflecting that all educational research problems are shaped by contingencies of the setting, in Chapter 2 I present some of the broader trends that have shaped New Zealand school geography education over the last three decades. This will give the reader a sense of the wider socio-cultural context in which this study was conducted, with particular attention to the forces that have shaped school geography curriculum development in New Zealand, and the support of its subject specialist teachers.

Chapter 3 is a review of literature that focuses on the place and role of disciplinary perspectives in geography education. The chapter is divided into three distinct parts: (i) the relevance of disciplinary-consciousness to geography; (ii) disciplinary perspectives as translated to the school geography curriculum; and (iii) disciplinary perspectives as enacted in classrooms. There has been substantial commentary on the need for geography education to expand its disciplinary gaze in the last forty years, although there are few empirical studies connected to what this might look like in the classroom. For this reason, this chapter also draws upon literature from other school subjects that might offer helpful signposts for disciplinary-conscious teaching and learning. It is from this literature review that I present the rationale for my research questions. 
In Chapter 4, I present the theoretical framework for this study. The purpose of this framework is to provide an intellectual map for the direction of my research. This begins by drawing upon Bernstein's (1999) theory explaining the structure of knowledge within the field of production. I then focus on the field of recontextualisation, and the multiple sites in which academic knowledge is translated to subject knowledge. This chapter also draws upon frameworks for teaching in a disciplinary-conscious fashion, especially in terms of teaching theoretical perspectives (Puttick, 2013) and disciplinary literacy (Moje, 2015).

In Chapter 5, I present the case study design of my thesis, which includes ethical considerations, and methods used to collect and analyse data. This chapter is a window into how I have approached the three empirical phases of this research, which include document analysis, an e-questionnaire and a collaborative lesson study sequence exploring disciplinary-consciousness.

Chapters 6-8 present the analysis of each phase of research. In Chapter 6 I report an analysis of over 60 curriculum and assessment documents that signal the concept of perspectives. From this analysis I was able to identify three quite different framings of the concept, of which a disciplinary-conscious framing was limited. In Chapter 7, I present the analysis of an e-questionnaire, submitted by a group of geography subject specialists, to explore the potential for a disciplinary-conscious approach to perspectives. Chapter 8 is an analysis of teacher and student outcomes generated by a lesson study approach to disciplinary-conscious geography.

In Chapter 9, I draw together the evidence from the three empirical phases in order to discuss the implications of my research. This includes recommendations to some of the actors who influence New Zealand school geography's field of recontextualisation. This chapter also presents the prospect for further directions in this strand of research. 


\section{Chapter 2: Context Matters}

\subsection{Introduction}

In this chapter I outline some of the key factors that have shaped the conditions of the New Zealand education scene and the geography curriculum. My focus is on curriculum and knowledge, and I begin by connecting broad international curriculum trends with the New Zealand direction. After this, I give an account of some of the key aspects of New Zealand school geography and end the chapter with a focus on professional learning and development [PLD] for specialist geography teachers.

\subsection{Global influences on curriculum}

The idea that education needs to respond to a world being reshaped by technology and globalization is widely accepted. Under the auspices of the Organisation for Economic Cooperation and Development [OECD], a global project entitled Definition and Selection of Competencies: Theoretical and Conceptual Foundations (OECD, 1997), argued for the connection of educational outcomes with the needs of the international economy. According to this report, if economic growth was to be successfully driven by educational outcomes, a transformational shift would be required in schools, as:

although cognitive skills and knowledge - as explicitly transmitted through traditional school programs - are important education outcomes, the reflection on competencies cannot be limited to such elements. Both labour market behaviour and current research on intelligence and learning indicate the importance of non-cognitive factors such as attitudes, motivation, and values.

(Rychen \& Salganik, 2003, p. 5)

The DeSeCo project marked a period of curricula transformation for some OECD countries, as they developed 'competency' and ' $21^{\text {st }}$ century skills' based curricula. Typical attributes of these curricula, of which New Zealand was an enthusiastic and early adopter (see Section 2.4), was a commitment to cross-disciplinary ideas such as critical thinking, creativity, communication, problem solving, collaboration, self-management, entrepreneurship, and civic literacy. The OECD vision was a reimagining of rapidly transforming post-industrialised economies to hyper-connected, competitive, innovative, knowledge economies (see, for example, OECD, 2009). Such was the 'common sense' and 
prevalence of the vision of economic transformation through market liberalism, that it has been argued that 'this future image is not just a scenario, but simply 'the future': a matter of fact that we have to face, adapt to and anticipate" (Pauw, 2015, p. 311).

The view of knowledge as a process rather than a product, is an important conceptual shift to help prepare future generations for an interconnected global economy (Gilbert, 2005). Knowledge-as-a-process is a constructivist view, with great applicability to the psychology of learning: it holds that knowledge is subjective, actively created by re-organisation of mental schema and is fundamentally tied to the knower. A constructivist view of knowledge presents a strawman argument that school knowledge is traditionally 'fixed' and 'accepted', conveniently ignoring the fact that the creation of knowledge in disciplines "occurs within intellectual communities and according to processes of scrutiny, doubt, criticism and refutation" (McPhail \& Rata, 2016, p. 58). Nevertheless, the constructivist view of knowledge seeped out from its Vygotskian learning theory origins about 'how' knowledge is created, into debates about 'what' knowledge is important. International publications stressed the need for 'competency-based curricula', and ' $21^{\text {st }}$ century skills' that would support the human capital required to support a rapidly globalising economy (Dobbins, 2010).

By the mid-2000s, countries such as New Zealand, England, Australia, Scotland, South Africa and Canada had developed $21^{\text {st }}$ century skills type curricula, in which knowledge was no longer the central driver of curriculum development. Rather, instrumental external drivers, such as the global economy, student-diversity, and civic competence were central to curriculum discourses (Wood \& Sheehan, 2012). This situation resonates with Firth's (2013) observation of "the neglect of disciplinary knowledge in recent years, both in curriculum policy and in classroom practice that has followed from such policy" (p. 63).

The marginalisation of knowledge in many of these international curriculum was exacerbated by 'concept-led' approaches to subjects, which left out the detail of content in favour of broad outcomes-based statements for teachers to flesh out the detail (Milligan \& Wood, 2010). Today, it is not uncommon to hear the refrain in school staffrooms that the 
New Zealand Curriculum [NZC] is 'world-leading' for the relative freedom it offers teachers, although Sinnema and Aitken (2013) do provide a note of caution:

There are compelling arguments for and against increased flexibility and reduced prescription. Flexibility acknowledges teachers' professional autonomy; it increases their sense of control, and therefore, commitment and satisfaction; and it enables responsiveness to local needs and interests. But flexibility increases workload because it diminishes the value of, and market for published resources; it presupposes expertise in curriculum that may not be widely [or] evenly spread. (pp. 128-9)

To lend empirical weight to claims that knowledge has been marginalised in national curricula, Priestley and Sinnema (2014) compared the presence of knowledge in the NZC and the Scottish national curriculum, before and after their most recent iterations. They concluded that:

This empirical analysis partially supports the claim that these curricula have downgraded knowledge - they have greatly reduced the specification of content, de-emphasised the importance of knowledge in relation to other aspects (skills, competencies, etc.), and failed to provide explicit guidance on processes to the practitioners charged with developing them. (Priestley \& Sinnema, 2014, p. 71)

Notably, in the last five years, South Africa, England and Australia have developed new curriculum with detailed statements of expected knowledge progression. As we will see in the following section, however, New Zealand's constructivist-based approach to curriculum development shows little signs of abating.

\subsection{The New Zealand school system}

Since the Tomorrow's Schools reforms of the late 1980s, New Zealand schools have operated on a self-management model of organisation. Each school is led by parentalcommunity elected Board of Trustees, charged with governance of operations such as financial sustainability, building maintenance, employment matters and curriculum provision in order to meet nationally formulated administrative and educational goals (Fiske \& Ladd, 2000). The Tomorrow's Schools reforms marked a break from the post-war Keynesian approach to welfare provision, in which education was required to respond to a 
number of economic, cultural, educational and political changes which impressed themselves on New Zealand society in the 1960s and 70s. For example, fiscal crises precipitated the Treasury to recommend aggressive bureaucratic cost-cutting, while the globalising influences on the labour market generated a demand for the education system to become more responsive to developing the skills required for the emergence of a knowledge economy (Dobbins, 2010). While neo-liberal ideologies of competition and choice were promulgated by the New Zealand Treasury in the early-mid 1980s as the 'answer' to perceived Department of Education inefficiencies and waste, Openshaw's (2009) historical analysis of the Tomorrow's Schools reforms suggests they were at the "end of a continuum" of diverse voices demanding significant educational realignment, including "Māori radical groups, feminists, radical academics, conservative pressure groups, [and] cost conscious politicians...” (p. 15). While Openshaw's analysis stresses the complexity of public policy making, and cautions ascribing too much influence to neoliberal discourses, New Zealand was an enthusiastic adopter of new-public management discourses in the immediate lead-up to and aftermath of the Tomorrow's Schools reforms, characterised by the introduction of school competition, devolution from inefficient bureaucracy and marketisation (Fiske \& Ladd, 2000).

The election of the fifth Labour-led government in 1999 saw, in rhetoric at least, a softening of the neoliberal discourses, as a third-way politics approach sought to balance economic growth with democratic citizenship (Codd, 2005). Nevertheless, the framing of education in terms of human capital tended to encourage discourses and practices of individual performativity, credentialisation, and competition throughout the first decade of the $21^{\text {st }}$ Century (Dobbins, 2010). Thus, New Zealand's education policy was a response to the economic and social imperatives of a small trading nation in a globally connected society. As such, New Zealand education policy has been firmly informed by a specific, and relatively unchallenged, geographic imagination over the last three decades (Morgan, 2013).

\subsubsection{The New Zealand Curriculum}

The first national curriculum framework emerged shortly after the managerial focus of the Tomorrow's Schools reforms noted in the previous section. This managerial focus was 
manifest in the nature of the new framework, which represented a shift from inputs and educational processes to outcomes and products (Codd, 2005). The establishment of the New Zealand Curriculum Framework (MoE, 1993) was a shift away from a nationally prescribed knowledge-rich syllabi, in favour of an outcomes based framework, light on detail and oriented to essential learning areas (e.g. social sciences) rather than specific subjects. The manifestation of this policy through further curriculum revision in 2007 was the emphasis of generic competencies and ' 21 st century skills' underpinned by 'learningto-learn', and 'personalised learning' discourses, in keeping with the ideas of the OECD introduced earlier. Also emphasised in the New Zealand Curriculum (NZC) (MoE. 2007) are values, pedagogy, student agency, and community partnerships, while subject content prescription remains largely absent.

The current iteration of the $N Z C$ is the statutory framework that sets national directions and offers guidance for the establishment and review of school curriculum. Rather than prescription, the $N Z C$ is predicated on an outcomes-based curriculum design that provides guidelines and autonomy to schools, so that they can create curricula that reflect the needs of their community. As Openshaw (2009) has noted, the assumption of more direct government monitoring of achievement and national priorities while still offering schools increased curricula autonomy has created a "paradoxical process" (p. 171), and is one of many manifestations of competing ideologies inherent in 'third-way' inspired policies in the New Zealand education system (Codd, 2005). Sinnema (2016) also reminds us that the autonomy offered to teachers by the general permissiveness of the $N Z C$, is inevitably constrained by system conditions, which include qualification imperatives, drivers for 'excellence' and 'equality' of student achievement, and local capacity found across teachers and schools (p. 978).

\subsubsection{The National Certificate of Educational Achievement}

In the final three years of secondary school, student learning is based on levels 6-8 of the $N Z C$, and achievement is credentialised by the National Certificate of Educational Achievement [NCEA] levels 1-3 qualifications, comprising a modular system of internally (school based, nationally moderated) and externally (national exams) assessed Achievement Standards (see Table 2.1). Results in these qualifications are annually 
published by the Qualifications Authority [NZQA], and enthusiastically reported by sections of the media as part of a league-table approach to public accountability (Wylie, 2013). The NCEA qualification is currently under review, as concerns about the fragmentation of knowledge, assessment driving the curriculum, and teacher and student workload have become widely recognised (MoE, 2018a).

Table 2.1: Levels of a typical New Zealand secondary school

\begin{tabular}{|c|c|c|c|c|c|}
\hline Student Age & $\begin{array}{l}\text { School } \\
\text { Year } \\
\text { Level }\end{array}$ & $\begin{array}{l}\text { NZ } \\
\text { Curriculum } \\
\text { Level }\end{array}$ & $\begin{array}{l}\text { NCEA } \\
\text { Qualification } \\
\text { awarded }\end{array}$ & & $\begin{array}{l}\text { Social Science } \\
\text { learning }\end{array}$ \\
\hline $17-18$ & 13 & 8 & 3 & \multirow{3}{*}{$\begin{array}{l}\text { Senior secondary } \\
\text { school }\end{array}$} & \multirow{3}{*}{$\begin{array}{l}\text { Optional } \\
\text { subjects e.g., } \\
\text { geography, } \\
\text { history, } \\
\text { economics }\end{array}$} \\
\hline $16-17$ & 12 & 7 & 2 & & \\
\hline $15-16$ & 11 & 6 & 1 & & \\
\hline $14-15$ & 10 & $4-5$ & & \multirow{2}{*}{$\begin{array}{l}\text { Junior secondary } \\
\text { school }\end{array}$} & \multirow[t]{2}{*}{ Social studies } \\
\hline $13-14$ & 9 & $3-5$ & & & \\
\hline
\end{tabular}

The general lack of guidance to teachers of the knowledge content of subjects in the $N Z C$, helps explains why the subject specific Achievement Standards of the NCEA qualification have become defacto curriculum guides for many teachers of senior secondary school subjects (Hipkins et al., 2016). School subject knowledge and skills are assessed by a suite of up to 5-8 Achievement Standards at each of the three levels of senior secondary school. Schools and students are given flexibility to choose their selection of Achievement Standards, and each standard gives guidelines on the content to be assessed.

Figure 2.1 is an example of the level of prescription in a NCEA Level 2 Achievement Standard 'Demonstrate geographic understanding of an urban pattern'.

The long shadow of assessment has impacted on senior secondary school teaching and learning for decades, but in the current context, modularised chunks of learning can be assembled in packages that are driven less by knowledge, and more by the interests and 
motivations of learners, employers, or accountability pressures ${ }^{2}$ (Fastier, 2016). It may be the case that these discourses are outweighing the influence of knowledge, in the shaping of teacher curriculum making practices. This has potential to manifest along social class lines, as illustrated in the recent Auckland Herald strapline "While wealthy white students study science and Shakespeare, their poorer brown peers are more likely to be learning to make coffee or operate a grill" (K. Johnston, 2016).

\section{Figure 2.1: NCEA Achievement Standard prescription}

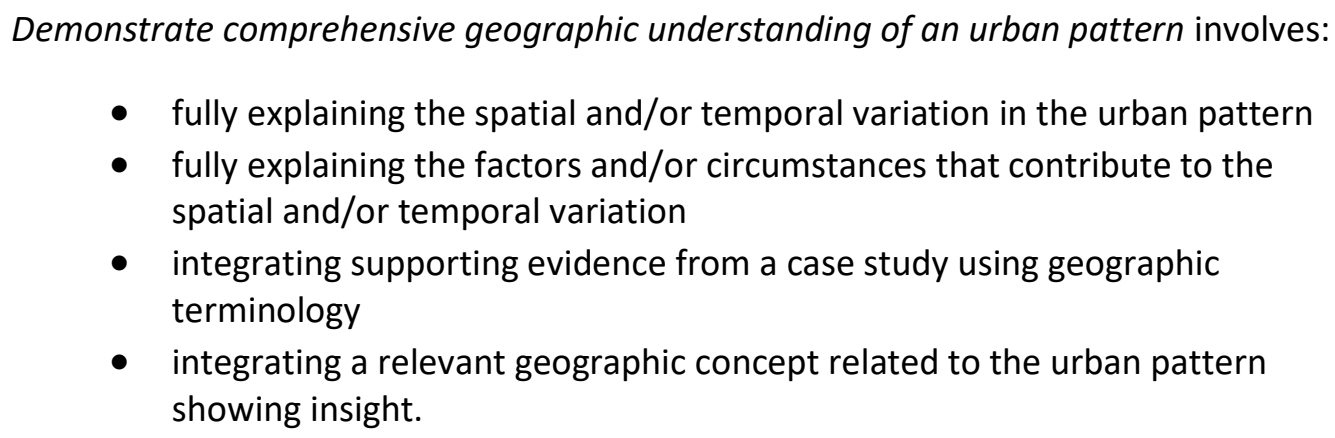

- integrating supporting evidence from a case study using geographic terminology

- integrating a relevant geographic concept related to the urban pattern showing insight.

Urban pattern refers to the spatial and/or temporal variation created in a city.

Factors and/or circumstances may include elements, processes, events, and perceptions that contribute to the pattern.

Examples of urban pattern that may be studied include crime, transport networks, education networks, gentrification, urban sprawl, and retail development.

\subsection{New Zealand school geography}

Despite the longstanding presence of geography in New Zealand secondary schools, its popularity is by no means assured: it is a long time since the hey-days of the early 1980s when over 28,000 students took Form 5 (Year 11) geography (Department of Education, 1987). Based on publicly available data, in 2017 there were approximately 10,000 Year 11 geography students, 7,000 at Year 12 and 7,500 at Year 13 (NZQA, 2018). The decline in numbers at Year 12 is often explained as being the impact of high achieving students

\footnotetext{
${ }^{2}$ Accountability measures impacting on senior secondary school teachers were exacerbated in 2012 by the Better Public Service school leaver target of 85\% achievement at NCEA Level 2 (Ministry of Education, 2012b), revoked in May 2018.
} 
selecting three natural sciences at the expense of geography. Although there is a small rebound in Year 13, anecdotal reports suggest that almost one in four Year 13 geography students are taking the subject for the first time. From 2013-2017, the rate of decline in geography Achievement Standards being assessed was over twice the rate of general decline in the Year $11-13$ cohorts (NZQA, 2018).

Geography is a constituent subject of the social science learning area in the $N Z C$. The overarching rationale of school social sciences is that students should: develop knowledge and skills to enable them to: better understand, participate in and contribute to the local, national and global communities in which they live and work; engage critically with societal issues; and, evaluate the sustainability of alternative social, economic, political and environmental practices.

(MoE, 2007, p. 30)

The social science emphasis of geography is further influenced by the 'social inquiry' approach that is advocated as "an integrated process for examining social issues, ideas and themes" (MoE, 2008, p. 2) for all the constituent social science subjects, seeking to "promote conceptual, critical and reflective thinking in students (and teachers)" (p. 8). Notably, one aspect of social inquiry encourages teachers to engage students with viewpoints, values and perspectives as they develop their substantive knowledge base.

New Zealand school geography has a strong "what is where, why there, and why care?" flavour (Gritzner, 2002). It focuses on phenomena in natural and cultural environments, processes responsible for their spatial variation, and the consequences and decisions that evolve from interaction between people and their perception of the environment. The top line of achievement objectives in Table 2.2 is strongly oriented to a positivist perspective of geographical thought, in which a natural and cultural world external to the knower can be observed, mapped and analysed. The lower line of achievement objectives implies a humanistic orientation, in which geographic thought focuses on how people respond to the world as they view it through the filter of their own culture ${ }^{3}$ (MoE, 1990).

\footnotetext{
3 'Culture' being used in a broad sense that may refer to one or more of ethnicity, age, gender, location, or heritage etc.
} 
Reflecting an outcomes-based curriculum approach, the $N Z C$ is providing geography teachers with a framework of transferrable achievement objectives that are in effect 'conceptual understandings' or 'big ideas' that frame geography programmes. Whether teachers are aware of the theoretical orientation of these achievement objectives is not clear. For example, Baldwin's (2012) appraisal of the opportunities of the $N Z C$ states that "the nature of geography can be interpreted in different ways, but the $N Z C$ provides a framework through the achievement objectives and related geographic concepts." (p.213). Baldwin's avoidance of how exactly the nature of geography is interpreted differently, seems to indicate that she sees the New Zealand curriculum as the key starting point for teachers, uncoupled from the academic discipline. This is consistent with Firth's (2011a) observation that "what geography teachers have primarily worked with for the last two decades is not the subject matter of the academic discipline, but the subject-matter of the school subject" (Firth, 2011a, p. 154).

Table 2.2: Geography achievement objectives (adapted from MoE, 2007)

\section{Level 6}

(Year 11, aged 15/16) (Year 12, aged 16/17) $\quad$ (Year 13, aged 17/18) Students will gain knowledge, skills, and experience to:

understand that natural and cultural environments have particular characteristics and how environments are shaped by processes that create spatial patterns.

understand how people interact with natural and cultural environments and that this interaction has consequences. understand how the processes that shape natural and cultural environments change over time, vary in scale and from place to place, and create spatial patterns. understand how people's perceptions of, and interactions with, natural and cultural environments differ and have changed over time. understand how interacting processes shape natural and cultural environments, occur at different rates and on different scales, and create spatial variations. understand how people's diverse values and perceptions influence the environmental, social, and economic decisions and responses that they make.

The current concept-led approach of the New Zealand Curriculum (MoE, 2007) has meant that there has been a movement away from 'paradigms' as markers of the essence of geography. The concept-led approach prioritises seven key concepts: environments, processes, patterns, interaction, change, perspective, and sustainability, which the geography curriculum guides state are 'directly derived' from the six achievement objectives (MoE, 2015). My emphasis of the key concepts in Table 2.1, does indeed show 
that most of the seven key concepts are directly embedded in achievement objectives, although 'sustainability' is absent and 'perspective' has become 'perception'. This semantic detail might not appear significant to the layperson, but as will unfold later in my thesis, this is an immediate signal of ambiguity between the concepts of 'perception' and 'perspective'.

As Robertson, Morgan and Kriewaldt (2017) observe, the vagueness of the achievement objectives are not particularly useful for planning, and, they pointedly remark that "There is no public record or account of the 'research' or discussions that informed the writing of these "statements." (p. 9). The existence of expansive consultation and geography curriculum debate, such as that experienced during the National Geography Curriculum Committee [NGCC] years (see Chapter 3), seems to be a feature of a bygone era (Chalmers, 2005).

While there are opportunities for students to create geographical knowledge through research assignments at each level of the senior school, these opportunities are typically circumscribed by assessment imperatives that implicitly promote a positivist view of geographical knowledge production. Progression in these research assignments is framed by the level of independence through which students work (with direction; guidance; consultation) and through a Bloom (1967) inspired taxonomy (describe; explain; analyse). If this approach is to remain, then such learning opportunities are fertile territory for the nature of empiricism and positivism to be explored. More radical change might allow for research assignments to draw upon a wider range of paradigms and perspectives.

Notably, the most significant curriculum change in the last two decades - Geographical Information Systems [GIS] - has been spurred by school access to technological development and arguments based on student interest, pedagogical innovation and vocational value (Eddy \& Olsen, 2011). Eddy and Olsen (2011) give an enthusiastic account of GIS development in school geography driven by pioneer teachers in the mid1990s, although it was not until its validation in newly developed NCEA Achievement Standards that GIS has become more common in senior geography classes (NZQA, 2016c). Developments in GIS certainly challenge teachers to keep up to date with their 
skill base, and it is an empirical question (beyond the scope of this thesis) whether GIS teaching and learning will extend beyond the traditional positivist matrix of measurement, control and prediction. It may be that the introduction of GIS offers a platform in which disciplinary-conscious questions about the strengths and limitations of empirical and positivist philosophies are posed. Alternatively, increased GIS may result in students becoming "puzzle solvers within a paradigm, rather than investigators of the paradigm itself" (Morgan, 2012, p. 64).

\subsection{Subject-specific support for geography teachers}

The creation of the Ministry of Education in 1989 marked the closure of the Department of Education's Curriculum Development Unit which employed geography (and other) subject specialists with theoretical and experiential credentials. Also in 1989 the NGCC, which contributed valuable curriculum development debates between the tertiary and secondary geography educators (see next chapter) was disbanded (Chalmers, 2005). The closure of the Geography Resource Centre at Christchurch Teachers' College and the reduction to few subject specialists in school support advisory services are further markers of the decline in curriculum focused support for secondary school geography teachers. While there have been Ministry of Education funded national subject facilitators for geography in 2007 and from 2012-14, these sporadic moments punctuate a general decline in subject specific PLD provision that has been keenly observed by the Tomorrow's Schools Independent Task Force (2018) consultation report.

In the last twenty years, the domain of PLD has been shaped by a 'third sector' which mediates between the state and the school market through highly flexible networks comprised of think tanks, 'edu-preneurs', social enterprises, and educational management organisations ${ }^{4}$ in collections of public-private networks and partnerships (O'Neil, Duffy, \& Fernando, 2016). An important aspect of these 'third sector' actors is that they are not simply service providers at arm's length from the Ministry of Education but have become much more influential in their ability to participate in policy framing. Alignment between policy framing advice from third sector actors and concomitant PLD provision is an

\footnotetext{
${ }^{4}$ Cognition Education (Auckland) and Core Education (Christchurch) are two EMOs that teachers are likely to be familiar with.
} 
inevitable strategy of the business models at the heart of many of these providers. Consequently, 'third-sector' policy input and PLD focuses tend to address cross-cutting curriculum priority areas. Although some 'third sector' curriculum development projects in the social science domain exist, it is notable that recent examples ${ }^{5}$ have been targeted at primary and intermediate school aged children rather than the much smaller market of senior secondary students.

Teachers are faced with a wide choice of PLD themes, yet in a 2015 national survey $32 \%^{6}$ of New Zealand secondary school teachers reported that PLD had not focused sufficiently on implications for their own curriculum learning area (Wylie \& Bonne, 2016). The same survey also reported an increase in the number of teachers accessing helpful subject specific advice from outside their own school - an increase from $37 \%$ in 2012 to $46 \%$ in 2015. In a context of general decline of senior school curriculum PLD support, geography teachers increasingly rely on local networks of subject association support in their regions and, for some, the biennial social science conference, Facebook connections, and commercial providers of classroom resources. The majority of this activity is spread across functional concerns (i.e., training) of teaching (Zeichner \& Gore, 1990). With little curriculum specialist capacity in the MoE itself, there have been intermittent efforts to fund senior subject professional development using a peer-to-peer approach. In 2007, a pilot funding agreement between the MoE and Post Primary Teachers' Association [PPTA], provided a network of 'Senior Subject Advisers' [SSAs] to provide just-in-time support to teachers across the country, with a particular focus on embedding the NCEA assessment reform. The SSAs, of whom there were three specialising in senior geography, were experienced teachers seconded from schools, and had high credibility with their peers (Taylor, Yates, Kinsella \& Meyer, 2011). Despite the pilot being well received by classroom teachers, industrial negotiations between the government of the day and the PPTA meant the SSA pilot was discontinued the following year. Since then, regular assessment focused 'best practice' workshops have been provided on a regional basis by NZQA geography moderators, while from 2012-14 national senior social science advisers

\footnotetext{
${ }^{5}$ See, for example, http://maorihistory.tki.org.nz/ and http://www.learnz.org.nz/naturalhazards183

${ }^{6}$ Based on a sample of 1, 777 professionals. Of these, $22 \%$ were grouped as social science, arts or commerce learning area teachers.
} 
were hosted by the Auckland, Canterbury and Otago University school support service providers, of whom two were geography specialists.

The lack of subject specific PLD has been further exacerbated by the 'Investing in Educational Success' policy, which has established school 'Communities of Learning/ Kāhui Ako'. These Kāhui Ako are formal networks of local schools, tasked with improving outcomes for learners. As most of the Kāhui Ako are comprised of a single secondary school and feeder primary/ intermediate schools, it follows that there is little chance of this PLD mechanism to focus on the senior secondary school curriculum. Instead, many of the publicly available Kāhui Ako initiatives on the MoE website, are focused on the transition between the primary/ intermediate years and secondary school. According to the Ministry of Education (2018b), 700 contracted PLD providers were accredited by the Ministry of Education and working in 2000 schools, yet few, if any, of these are geography education specialists. Thus, while PLD opportunities present to teachers, especially in the four national priority areas of pāngarau/maths, pūtaiao/science, reading and writing, and digital fluency, geography specific PLD is unlikely to be a feature of Kāhui Ako activities.

The description in this section highlights a clear pattern of declining subject specific PLD expertise, which is largely the downstream effect of the market-led approach to provision. As a relatively niche teaching area, geography teaching expertise is diffused. It is an open question whether a peer-to-peer approach, driven by small numbers of committed volunteer teachers, are able to provide national PLD or likely to have the capacity to seriously consider how to approach geography education beyond what is currently expected to meet current norms of senior secondary geography achievement.

\subsection{Chapter summary}

In this chapter I have outlined influences, both international and domestic, which have led to an environment in which subject knowledge has been marginalised in senior high school geography. This is important to my study, because disciplinary-consciousness requires that teachers creatively engage with what it means to 'know' in geography. While teacher connection with academic geography does not appear to be strong, a wider system context 
of little expert subject support also raises questions about the capacity for teachers to develop deeper understandings and practices connected to theoretical perspectives in geography. With this in mind, in the following chapter I explore extant literature to build a picture of previous research focused on developing a disciplinary-conscious stance towards knowledge, with particular emphasis on the concept of 'perspectives' in school geography. 


\section{Chapter 3: Literature Review}

\subsection{Introduction}

The structure of my literature review is driven by three overarching questions and is grouped across eight themes (see Figure 3.1).

\begin{tabular}{|c|c|c|}
\hline $\begin{array}{l}\text { What is the relevance } \\
\text { of disciplinary - } \\
\text { consciousness to } \\
\text { geography? }\end{array}$ & $\begin{array}{l}\text { How have paradigms and } \\
\text { perspectives been } \\
\text { translated into school } \\
\text { geography curriculum? }\end{array}$ & $\begin{array}{l}\text { How has disciplinary- } \\
\text { consciousness been } \\
\text { enacted? }\end{array}$ \\
\hline $\begin{array}{l}\text { 1. Worldviews, paradigms and } \\
\text { perspectives }\end{array}$ & $\begin{array}{l}\text { 1. Curriculum design and } \\
\text { paradigms }\end{array}$ & $\begin{array}{l}\text { 1. Lessons from other } \\
\text { disciplinary-conscious } \\
\text { curriculum areas }\end{array}$ \\
\hline $\begin{array}{l}\text { 2. Focusing on paradigms and } \\
\text { theoretical perspectives }\end{array}$ & $\begin{array}{l}\text { 2. Worldviews, paradigms and } \\
\text { perspectives in New Zealand } \\
\text { and Australian school } \\
\text { geography }\end{array}$ & $\begin{array}{l}\text { 2. Pedagogies associated with } \\
\text { 'disciplinary literacy' }\end{array}$ \\
\hline $\begin{array}{l}\text { 3. Disciplinary-conscious } \\
\text { geography }\end{array}$ & & $\begin{array}{l}\text { 3. Teaching disciplinary- } \\
\text { consciousness in school } \\
\text { geography }\end{array}$ \\
\hline
\end{tabular}

Figure 3.1: Literature review structure

To identify literature that focused on the place and role of paradigms and perspectives in secondary school geography, I initially conducted searches through a range of international and local geography education journals. These journals were: International Research in Geographical and Environmental Education (International Geographical Union); Teaching Geography (UK); Geography (UK); Geographical Education (Australia); The Geography Teacher (USA); New Zealand Journal of Geography (1969-2004); and New Zealand Geographer. From relevant research identified in these seven journals I used a snowball technique which took me to other academic journals, books, and chapters in edited collections, particularly for those bodies of literature that go beyond the boundaries of geography education. This literature was analysed thematically to create the review below. 


\subsection{What is the relevance of disciplinary-consciousness to}

geography?

As noted in Chapter 1, geography and geographers have been described by Firth (2013) as "differentiated from the inside out" (p. 299). In this section I start from a broad view of knowledge differentiation by focusing on three key terms: worldviews, paradigms, and perspectives. I then provide an argument for why I limit my definition of disciplinary-consciousness to focus on paradigms and perspectives. Finally, in this first section of my literature review, I draw upon literature which presents geographical knowledge as disciplinary-conscious.

\subsubsection{Worldviews, paradigms and perspectives}

Since Platonic/Socratic thinking, knowledge has been perceived as truth (i.e., knowledge as an object) or gateway to truth (i.e., knowledge as a process). Yet how such truths or truthfulness are produced and represented has been the subject of philosophical, and more specifically, epistemological debate, ever since. For thousands of years, knowledge served authoritarian and theological purposes and was disseminated as 'Truth'. Reaction against religious ways of knowing eminated from the canonical empiricists, such as Berkely, Locke and Hume, who, with different degrees of emphasis, asserted that all knowledge was derived from experience. This period of philosophical thought was the beginning of the uncoupling of knowledge and faith, as according to these philosophers, knowledge was located in the realm of human perceived experience. The impliction of the empiricist school of thought was that knowledge could never be certain in light of a posteriori sensory impressions that generate new perceptions. The underlying epistemological principle of this empirical worldview was that such knowledge conformed to the nature of phenomena/objects (Atherton, 1999).

Immanuel Kant's The Critique of Pure Reason, published in 1781, inverted the epistemology of the empiricists by arguing that cognition "is occupied not so much with the objects but rather with our mode of cognition of objects insofar as this is to be possible a priori" (p. 11-12, my bold emphasis). That is, Kant's idea was that knowledge was not ensconced in an object waiting to be revealed, but that very basic structural features of the world (i.e., space, time, and causal relations) were artefacts of our subjective cognitive faculties. As it is very difficult to make choices about what to measure, describe or 
evaluate independently of theory, Kantian thinking is an important early signpost to this thesis as it introduced the idea that when knowledge is produced, it is not limited to sensory experience, but also shaped by pre-existing conceptions about the world:

Reason must approach nature with the view, indeed, of receiving information from it, not, however, in the character of a pupil, who listens to all that his master chooses to tell him, but in that of a judge, who compels the witnesses to reply to those questions which he himself thinks fit to propose (Kant, 2000, p. 8).

While many of the canonical philosophers contemplated different pathways to knowledge, it was $19^{\text {th }}$ Century German philosopher Friederiche Nietzsche who first articulated a theory of the futility of such an exercise. His theory of perspectivism was a challenge to the notion that 'true' knowledge was accessible at all. Nietzsche's perspectivism held that all knowledge was an approximation which was derived from the different angles of inquiry from which an object is observed. Rather than hoping to find true knowledge, Nietzsche espoused a view from multiple angles:

There is only a perspectival seeing, only a perspectival 'knowing'; and the more affects we allow to speak about a matter, the more eyes, different eyes, we know how to bring to bear on one and the same matter, that much more complete will our 'concept' of this matter, our 'objectivity' be (Nietzsche, 1887/1998, p. 12).

Nietzsche's perspectivism was a hugely influential anchor for the relativism and antiessentialist worldviews of the late $20^{\text {th }}$ century post-modern philosophers, albeit there remain contrasting views on the extent of Nietzsche's nihilism (Reginster, 2001). As a forerunner to the post-modern rejection of meta-narratives, to my mind, perspectivism falls into the bind of self-refutation. That is, if there is no truth, how can we accept the concept of perspectivism as a truth? Nevertheless, as Nietzsche's perspectivism brings to attention pluralism, it is a huge asset to the social sciences.

These ideas opened up new approaches to theory and the social sciences. Although mid$20^{\text {th }}$ Century social sciences sought to develop law like generalisations (at least through Economics), universalist stances to the social world have largely been rejected. What differs, is the extent to which different philosophies reject universal, objective truth. 
In Nietzsche's case, his perspectivism seems to be over-socialised; that is, following the subjectivity of perspectivism we are able to reduce knowledge to over seven billion truths. My stance, however, recognises disciplinary knowledge, not as individual interpretation, but "collectively evolved products of the human mind that gain a level of autonomy and warranted objectivity through critical scrutiny in public arenas" (Popper, 1978, cited in McPhail, 2016, p. 308).

The usage of worldview, paradigm and perspective have made their way into common social science discourse. A search of the International Encyclopedia of the Social Sciences [IESS] found the following definitions for 'worldview', 'paradigm', and 'theory'?

a) [Weltanshauung/worldview] is a comprehensive conception or theory of the world and the place of humanity in it. It is an intellectual construct that provides both a unified method of analysis for and a set of solutions to the problems of existence.

b) A paradigm is a template, model, or framework...within the philosophy of science, a paradigm is a general but distinct worldview or theory.

c) [Theory is] any attempt to systematize and explain certain phenomena...Different theories are often offered as competitors. As a result, disciplines often tend to be identified more with their explanatory approaches than with specific areas of interest.

(IESS, 2008a, 2008b; 2008c)

The definition from the IESS of a worldview is explicitly derived from Kant's Weltanshauung, as a way of thinking and acting in an integrated, unified way. Borrowing a geographic metaphor, Aerts et al. (2007) describe worldviews as "like geographic maps, which help us find our way and act coherently in this world" (p. 7). To emphasise just how broad in scope a worldview 'map' might be, I draw attention to Mead's (1975) identification of the several elements of a worldview: ontology (nature of reality); epistemology (nature and sources of knowledge); cosmology (beliefs about origin of life, especially humans); teleology (beliefs about the meaning of the universe); theology (beliefs about existence of and nature of God); anthropology (beliefs about people in general and oneself in particular); and axiology (values and ethical systems that guide

\footnotetext{
7 'Theory' was chosen as a proxy, given that 'theoretical perspective' yielded no direct search hit.
} 
action). Such an all-encompassing concept is interesting, but the cognitive load of so many elements would present challenges for teachers and students (Aitken, 2006).

Coming from a top-down view, Vidal (2008) also suggests that a worldview is an allencompassing philosophy, but differentiates paradigm by defining them as "grand level theory" subsumed by the broader worldview. For example, Vidal's proposal of a unifying scientific worldview, draws together three 'grand-theories' that are analogous to the paradigmatic level of thought: systems theory, problem-solving, and evolution (as a general theory of change). As will be explored in greater depth in Chapter 4, paradigms are strongly connected to Kuhn's (1962) sociological study of science, which proposed that paradigms are a disciplinary matrix of understanding, shared by a community of researchers.

In contrast to the general consensus of what constitutes a worldview and paradigms, I am mindful that the there are multiple definitions and usages of the term 'perspectives', And there are so many perspectives that one can take! Distinct languages that one may use are distinct perspectives; distinct logics are distinct perspectives; distinct theories are distinct perspectives; distinct devices, techniques, and methodologies are distinct perspectives; distinct knowledge bases are distinct perspectives; distinct value systems are distinct perspectives; distinct people whom one admires, loves, or hates engender different perspectives (Sadegh-Zadeh, 2012, p. 808).

Narrowing my focus from the extensive list above, I draw upon Crotty's (1998) definition of theoretical perspective as: "A way of looking at the world and making sense of it. It involves knowledge, therefore, and embodies a certain understanding of what is entailed in knowing, that is, how we know what we know" (p. 8). By focusing on how we know what we know, theoretical perspectives are deeply connected to knowledge production because they shape the questions that are asked, methodologies used, and conclusions derived.

My understanding is that worldviews and paradigms are largely about relations with abstract ideas, while theoretical perspectives have a closer connection to the empirical world. Theoretical perspectives are subsumed by paradigms, which are themselves unified by worldviews. Therefore, differences between these terms suggests a matter of 
scale; that is, the scope of each term suggests a distinguishable hierarchy (Figure 3.2). In the education literature (for paradigms and perspectives are foundational, and therefore cross disciplinary domains) Denzin \& Lincoln (2018) differentiate paradigms and perspectives as:

...paradigm as a basic set of beliefs that guide action. These beliefs can never be established in terms of their ultimate truthfulness. Perspectives in contrast, are not as solidified or as well unified as paradigms, although a perspective may share many elements with a paradigm, for example a common set of methodological assumptions or a particular epistemology (p. 97).

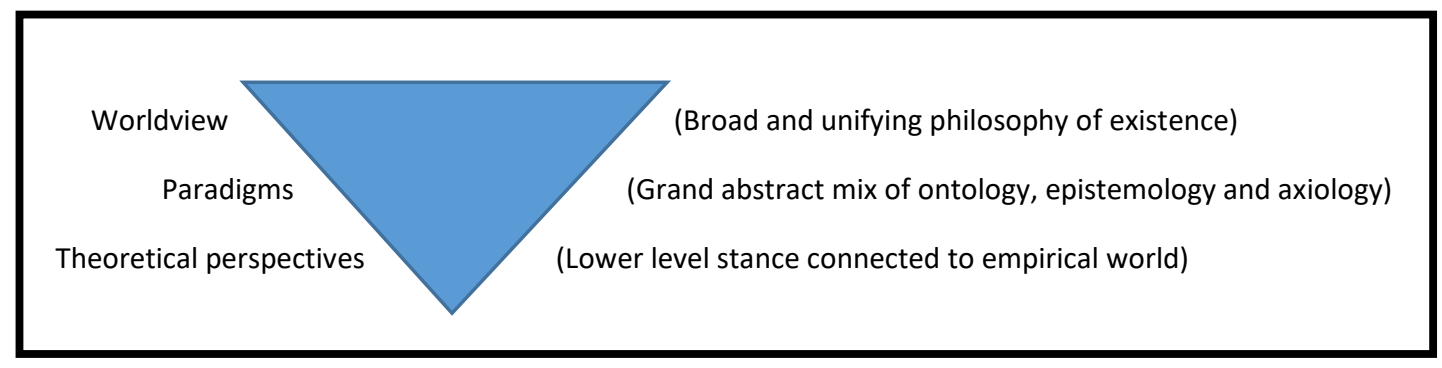

Figure 3.2: The relationship between worldviews, paradigms and perspectives

Having drawn upon literature which shows overlap, yet also important differences, between the three terms, in the next section I describe why the terms 'paradigms' and 'theoretical perspectives' became important to my study of disciplinary-consciousness in geography.

\subsubsection{Focusing on paradigms and theoretical perspectives}

Whereas worldviews seek to unify through synthesis, paradigms and theoretical perspectives are reflective of the deeply contested field of knowledge production in any domain. Put another way, paradigms and theoretical perspectives constitute a metaphorical centrifugal force on disciplines, as competing ontologies ('nature of reality'), epistemologies ('how we know what we know') and axiology ('statements of values') compete to shape knowledge production. Consequently, as increasingly diverse theories of knowledge are employed, disciplines become increasingly fragmented over time. By giving attention to paradigms and/or theoretical perspectives, I elevate disciplinary- 
consciousness from the analytical to the critical. That is, by focusing on the contested nature of geographical knowledge, the development of a critical disciplinaryconsciousness potentially enables students to consider the affordances and limitations of different approaches to the production of geographical knowledge. This is necessary across the whole curriculum, but because of geography's disciplinary heritage, could also be important for geography itself.

The origin of the term paradigm is associated with Thomas Kuhn (1962), who posited that 'normal' science takes place within a community of researchers who have a shared disciplinary matrix, or 'paradigm', of understanding. Kuhn further posited that during periods of paradigmatic stability, progress in science was cumulative, as researchers explored discrepancies between the expectations of the paradigm and empirical evidence. He also argued, however, that such normal paradigmatic phases came under existential threat at times during which new questions arose that could not be addressed by orthodox approaches. According to Kuhn, tumultuous phases of scientific revolution took place as the discipline entered a period of crisis in which members of the scientific community began to question the intellectual framework they were working in, leading to "a proliferation of compelling articulations, the willingness to try anything, the expression of explicit discontent, the recourse to philosophy and to debate over fundamentals" (Kuhn, 1962, p. 27). Kuhn labelled these revolutionary periods as 'paradigm shifts'. These radical movements were ways of thinking and doing, divorced from the orthodoxy, that were "sufficiently unprecedented to attract an enduring group of adherents" (p. 10).

Such paradigm shifts bore witness to emerging investigative possibilities for the "redefined group of practitioners to resolve" (Kuhn, 1962, p. 10). Thus paradigm shifts, such as the Copernican Revolution or the early $20^{\text {th }}$ century shift from Newtonian to quantum mechanics, occurred when the research community rejected the old intellectual framework and adopted the concepts and tools of the new. Kuhn's (1962) account of the sociology of science indicated iterative characteristics, as what was once avant-garde established itself as normal science, before that too came under scrutiny and challenge. 
The implication of Kuhn's sociology of science, is that a discipline has great change potential: it is in a constant state of becoming (Morgan, 2002). If a discipline is understood as an epistemic community of learners who seek to defend and reject ideas associated with the production of knowledge, then awareness of the type of work by the community members is also important. As such, a focus on the 'knower' is also important in order to understand how the 'known' came to be, especially if we are to accept that knowledge evolves from a collective enterprise, within the wider socio-cultural milieu. Paradigm shifts are relatively rare in the history of science, but even during periods of 'normal science', a plurality of theoretical perspectives develop to shed new light on the world.

The applicability of 'paradigm shifts' to the development of geography is, however, problematic. Unlike the Kuhnian view of scientific revolutions, there is broad consensus that geography has diverse theoretical languages which exist side-by-side, rather than any one usurping another in revolutionary style (Aitken \& Valentine, 2014; Cresswell, 2013). Rather, the development of geographical thought has been more akin to the acceleration and stagnation of different paradigms. Indeed, Johnston (1996) argues that developments in geographical knowledge production were mostly a product of generational change, as young scholars took new research pathways as they questioned the orthodoxies of their intellectual forerunners. While the early $20^{\text {th }}$ Century environmental determinism of Ellen Semple certainly became quickly moribund in academic circles, positivism, critical theory, and post-modernist are likely to feature in contemporary university geography departments.

This is what Firth (2011b) meant in his description that "Geography and Geographers are differentiated from the inside out...Geography is a multi-paradigmatic discipline and geographers work with different concepts of scientific knowledge and its development" (p. 299). Maton (2014), in his appraisal of the diversity of social science knowledge production, suggested that Kuhnian 'revolutionary science' is more akin to the 'normal science' knowledge growth in the social science domain. In a similar vein, Aitken and Valentine (2014) argued that "the linear narrative of the development of unified paradigms thus falsely creates a sense of sequential progress when consensus is rarely complete or 
stable" (p. 3). It is this feature of geographical development that I would like school students to explore. Therefore, my focus is not to inculcate students in any single paradigm, but to explore a range of paradigms and perspectives as they sit cheek-by-jowl with one another.

To reinforce the broad range of paradigms and theoretical perspectives, Table 3.1 names a series of theoretical perspectives that shape knowledge production in education, (urban) geography, and the social sciences. Following Lather's (2006) categorisations, I have

Table 3.1: Paradigms and perspectives across three domains

\begin{tabular}{|c|c|c|c|c|}
\hline & $\begin{array}{l}\text { Paradigm of } \\
\text { Prediction }\end{array}$ & $\begin{array}{l}\text { Paradigm of } \\
\text { Understanding }\end{array}$ & $\begin{array}{l}\text { Paradigm of } \\
\text { Emancipation }\end{array}$ & $\begin{array}{c}\text { Paradigm of } \\
\text { Deconstruction }\end{array}$ \\
\hline $\begin{array}{l}\text { Theoretical } \\
\text { Perspectives } \\
\text { in Education } \\
\text { (Lather, } \\
\text { 2006, p. 37) }\end{array}$ & Positivist & $\begin{array}{c}\text { Interpretive } \\
\text { Naturalistic } \\
\text { Constructivist } \\
\text { Phenomenological } \\
\text { Ethnographic } \\
\text { Symbolic } \\
\text { interaction }\end{array}$ & $\begin{array}{c}\text { Critical } \\
\text { Neo-Marxist } \\
\text { Feminist } \\
\text { Critical race } \\
\text { theory } \\
\text { Praxis-oriented } \\
\text { Frierian } \\
\text { participatory } \\
\text { Action research } \\
\text { Gay \& Lesbian } \\
\text { Theory } \\
\text { Critical } \\
\text { ethnography }\end{array}$ & $\begin{array}{l}\text { Post structural } \\
\text { Postmodern } \\
\text { Queer theory } \\
\text { Discourse } \\
\text { analysis } \\
\text { Post colonial } \\
\text { Post-Fordism } \\
\text { Post-humanist } \\
\text { Post critical }\end{array}$ \\
\hline $\begin{array}{l}\text { Theoretical } \\
\text { perspectives } \\
\text { in Urban } \\
\text { Geography } \\
\text { (Pacione, } \\
\text { 2009, pp. 24- } \\
\text { 32) }\end{array}$ & $\begin{array}{c}\text { Environmentalism } \\
\text { Positivism } \\
\text { Behaviouralism }\end{array}$ & $\begin{array}{l}\text { Humanism } \\
\text { (including } \\
\text { ethnography and } \\
\text { the 'social } \\
\text { construction' of } \\
\text { urban space) } \\
\text { Managerialism }\end{array}$ & $\begin{array}{l}\text { Structuralism } \\
\text { (inc. Marxist, } \\
\text { gender, ethnicity) } \\
\text { Moral philosophy }\end{array}$ & $\begin{array}{l}\text { Postmodernism } \\
\text { (inc. queer theory) } \\
\text { Post-colonialism } \\
\text { Transnationalism }\end{array}$ \\
\hline $\begin{array}{l}\text { Broad } \\
\text { perspectives } \\
\text { across the } \\
\text { social science } \\
\text { literature } \\
\text { (Huff, 2009, } \\
\text { p. 121) }\end{array}$ & $\begin{array}{c}\text { A logical } \\
\text { (positivist) } \\
\text { Instrumental } \\
\text { (pragmatic) }\end{array}$ & $\begin{array}{c}\text { Multiple, } \\
\text { embracing } \\
\text { (constructivist) } \\
\text { Change (historical) } \\
\text { Optomistic } \\
\text { (realist) } \\
\text { perspective }\end{array}$ & $\begin{array}{c}\text { Suspicious, } \\
\text { emancipating } \\
\text { (critical) } \\
\text { Alternative } \\
\text { standpoint } \\
\text { (feminist) }\end{array}$ & $\begin{array}{l}\text { Playful or ironic } \\
\text { (postmodern) }\end{array}$ \\
\hline
\end{tabular}


juxtaposed Pacione's (2009) and Huff's $(2006)^{8}$ lists of influential theoretical perspectives within the four broad paradigmatic divisions of knowledge categorisations, which, according to Lather, principally seek to predict, understand, emancipate or deconstruct. The significance of this table to my study, is that both paradigms and theoretical perspectives are terms that allow students to explore the contested nature of geographical knowledge by focusing on its social development, underlying assumptions and implications for methodological practices. The focus on paradigms and perspectives support my definition of disciplinary-consciousness as used in this thesis: the teaching and learning of paradigms and theoretical perspectives as frames of reference from which to sense, interpret, measure or codify geographical phenomena.

\subsubsection{Disciplinary-conscious geography}

Differing views on the theoretical foundations of knowledge have, and continue to, influence the field of geographical knowledge production. Hartshorne's (1939) work is widely considered to be the first in depth exploration of the ontology and epistemology of the modern discipline, although rapid developments in the following decades expanded his distinctions between 'areal definition', 'regional' and 'systematic geography'. For example, the 1950s heralded the 'new' geography, infused with quantitative methodologies designed to explain the world in terms of law-like generalisations based on discovery of objective realities. The 'new' geography was given impetus by rapidly expanding computational ability in university departments, while such developments were deeply political in their attempts to gain legitimacy as a scientific endeavour (Cresswell, 2013; Johnston \& Sidaway, 2004)

The drive to make geography more scientific may account for other threads of disicplinary development being supressed. For example, Wright's (1947) work was an attempt to challenge geography as the preserve of scholars, given that geographical sense making:

extends beyond the core area of scientific geography or of geographical knowledge as otherwise systematized by geographers. Taking into account the whole peripheral realm, it covers the geographical ideas, both true and false, of

\footnotetext{
${ }^{8}$ My selection of these three international scholars reflects their eminent standing in their respective disciplinary domains.
} 
all manner of people - not only geographers, but farmers and fishermen,

business executives and poets, novelists and painters, Bedouins and Hottentots.

(Wright, 1947, p. 12)

There has been a renewed interest in Wright's work as a seminal contribution to the history of the intellectual development of geography, with historians of geography such as Koelsch (2003), Keighren (2005) and Papotti (2014) in agreement that Wright's work was an antecedent to the development of the perception research that geographers engaged with from the 1960s. Wright's work influenced geographers such as Cole (1973), whose focus was on understanding the world as interpreted by the views, values, and actions of a wide range of social actors, all of whom have vested interests, to greater or lesser degrees, in their natural and cultural environments:

each of us views the world for a brief span of time, as if it were through a keyhole. Each of us, because of being born and living at a given time and in one or a few places only, sees the world differently. Instead of one monolithic geography there are currently at any given time some 3,000 million geographies of the world.

(Cole, 1973, p. 240)

This period of humanist disciplinary development in the 1960s and 70s, sought to reassert the human experience of place and space in order to better understand the world. Humanism rejected the natural science ontology that there is a real world external to the observer, instead focusing on the subjectivities that develop peoples' connectedness to place (Ley, 1977). As a note of reference to my study, use of the term 'lens' evokes Lowenthal's (1961) seminal introduction to humanistic geography which concluded that, "The surface of the Earth is shaped for each person by refraction through cultural and personal lenses of custom and fancy" (p. 260).

Humanist geography's focus on individual's perception are categorically different to my focus on paradigms and perspectives of the discipline. They may well be related, however, because as Ley (1977) argued, if perception is to be applied in geography, then it also required being applied to geography, and by doing so, developing disciplinaryconsciousness: 
The end point, and perhaps most important conclusion of perception studies, is to lead the geographer to turn the analysis back onto his [sic] own cognitive categories, his own unquestioned presuppositions...the need then is for geographic methodology to become reflexive, encompassing within its paradigm the conduct of man [sic] the scientist as well as man the geographic agent; only with such selfconsciousness may some of the hidden and taken-for-granted values of the practicing scientist be brought to light (Ley, 1977).

Despite the humanist tradition offering an alternative to the positivist tradition before it, some geographers identified the need for the geographies of power relations to be emphasised (e.g., Harvey, 1973). Consequently, 'radical' geographies, including historical materialist (Marxist), feminist, and indigenous perspectives emerged in the late 70s and through the 1980s (Gregory \& Walford, 1989). These critical perspectives emerged with a commitment to social re-construction in the wake of increasing social inequalities and injustices. More recently, in the late 1980s and through the 1990s, postmodern geographies came to the fore. The postmodern crisis of representation rejected the modernist assumption of 'truths' (inherent in all three previous paradigms), and meta-narratives were rejected in favour of a focus on the myriad differences and chaotic arrangements that influence place and space (Massey, 1995; Peet, 1998; Thrift, 2008).

Foreshadowing the teaching theme of cities in the lesson study phase of my research, I am particularly drawn to Haggett's extended metaphor for the dynamic development of the subject.

Geography today represents an amalgam in which the legacy of past ideas remains strongly embedded but current thinking is still being worked out. In some respects it resembles a city with districts of different ages and vitalities. There are some long ago established districts dating back a century ago and sometimes in need of repair; areas which were once fashionable and are so no longer, while others are being rehabilitated. Other districts have expanded recently and rapidly; some are well built, others rather gimcrack. If we use the city metaphor, then geography has extended beyond its medieval walls to form a sprawling conurbation with other subjects.

(Haggett, 1983, cited in Fien \& Gerber, 1988) 
Debate about the production of geographical knowledge continues to the present, such that geographical knowledge is produced in ways that see traditionally incompatible paradigms and perspectives coming together. Two good examples of this 'coming together of cultures' are Blue and Brierley's (2016) critical geomorphology and Kwan's (2002) adoption of GIS to serve the feminist geography research agenda. In both these papers, the advance in knowledge is the bringing together of paradigms and perspectives traditionally viewed as incompatible with one another. These recent examples of innovative research serve to reinforce the inherent dynamism of geographic knowledge production, and cause me to reflect on how such disciplinary-consciousness might translate to the school subject.

Now that I have explored examples of literature that demonstrate geography's disciplinaryconscious nature, I move to literature that identifies how paradigms and perspectives have been translated into the school geography curriculum.

\subsection{How have paradigms and perspectives been translated into school geography?}

In this section I review literature that is focused on the place and role of paradigms and perspectives in school geography curriculum. The disciplinary diversity outlined in the previous section, is somewhat mirrored by Hirst's description of geography as a 'field' of knowledge:

these [fields] are not concerned, as the disciplines are, to validate any one logically distinct form of expression. They are not concerned with developing a particular structuring of experience. They are held together simply by their subject matter, drawing on all forms of knowledge that can contribute to them.

(Hirst, 1974, p. 46)

Hirst made no specific case for whether school curriculum should be populated by disciplines or fields, but he was sure that the complexity of geography was largely derived from the need to understand the contributing disciplines.

While Hirst (1974) advocated an academic rationalist curriculum organised around 'forms of knowledge' to buffer education from 'the predilections of pupils, the demands of society, or the whims of politicians" (p. 32), the period in which he wrote was marked 
by a suspicion of traditional knowledge as it was seen to contribute to social reproduction (Young, 1971). For example, Postman and Weingartner (1971) argued that if students were to learn about authentic issues, that it was necessary for schools to "abandon the abstraction that is called a 'subject"” as "the 'subject' is given. It is there" (p. 81). Postman and Weingartner's argument was, in part, a challenge to schools to weaken the classification of boundaries, whereby knowledge could be constructed subjectively in response to what they saw as authentic, cross-disciplinary problems. Lambert (2013), however, took a directly opposite view on the nature of knowledge and the subject: "Geography is not just 'there'. It has been, and continues to be, created by disciplined human effort. To be able to draw from this resource, teachers need, in some way, to be engaged with it" (Lambert, 2013, p. 92)

Lambert's position is similar to other authors (e.g. Firth, 2011a; Young, 2008) who align with social realism. Social realism rejects a relativist powerplay between different philosophical (social constructivist) positions and asserts that objective knowledge has its social basis in the academic communities of scholars, whose role it is to develop robust knowledge that can reliably explain the world. Nevertheless, social realism demands a critical stance towards the fallibility of knowledge as new ideas are developed in the field of knowledge production (Bernstein, 1996). The implications of this theoretical approach for geographical knowledge is that it cannot be left entirely up to whims of societal change to shape what is regarded as important knowledge - but that it must be independent from the context in which it is produced. Therefore, the logical conclusion is that social realist approaches require induction into different ways of knowing. Such induction may be through inspection of paradigms and perspectives, yet as my next section shows, teachers have traditionally been distant from the influence of paradigms on curriculum design. My own position has been influenced by social realist ideas, as I hold to the idea that disciplinary-conscious geography requires students to engage with the strengths and limitations of the perspectives and paradigms that have developed to produce geographical knowledge. I expand on this idea through the concept of 'curriculum of engagement' in the following chapter. 


\subsubsection{Hidden in the background of geography curriculum design}

The idea that geography curriculum are implicitly infused by paradigms is well documented by Graves' (1979) model of curriculum planning (see Figure 3.3). This model was an early attempt to fuse curriculum and geographical theory together in order to present curriculum planning as a dynamic process rather than a static prescription. Of particular significance to this thesis is Graves' early positioning of 'paradigms of geography', which, as Figure 3.3 indicates, are influenced by researchers, typically in universities. As Figure 3.3 shows, the chosen paradigm will influence the aim of a geographical education (Box 3), and the selection of content (Box 4) would also echo the paradigms chosen. The three paradigms Graves listed, however, should not be read as the last word on paradigms or disciplinary perspectives. Indeed, Graves (1979) suggested that aerial differentiation was a relic of by-gone geography, and that school geography would be better served by ecosystem or spatial perspectives. Graves' model is also dated in a more fundamental sense, at least for the New Zealand setting. The division between the (national) curriculum (Boxes 1-4) and school course (Box 5) speaks of a past era in which there was still significant central control over the prescription of a geography curriculum. In the contemporary New Zealand setting, I suggest that the loci of control over boxes two to four are now with schools, given the high level of autonomy schools presently have (Sinnema, 2016). My thesis is predicated on the assumption that bringing paradigms and perspectives of geography from the background to the foreground is required if teachers are to develop a disciplinary-conscious approach to school geography.

The process of embedding paradigms and perspectives in school curricula required development and Slater (1981) provided some stimulus for geography curriculum design. She agreed with Graves that a monolithic theoretical view was to be avoided, especially given the rapid developments that she characterised as a "relay in viewpoints" (p.6). Although Slater used the term 'viewpoint', it is clear that she had paradigms in mind when she stated: "One viewpoint cannot encompass, explain, codify, represent satisfactorily, the totality, the wholeness of human experience whether this is in relation to people and environment or any other focus of investigation" (p. 7). Consequently, Slater offered a series of questions that would be useful to both central curriculum designers as well as teachers, when considering which paradigm to shape the school geography experience: 


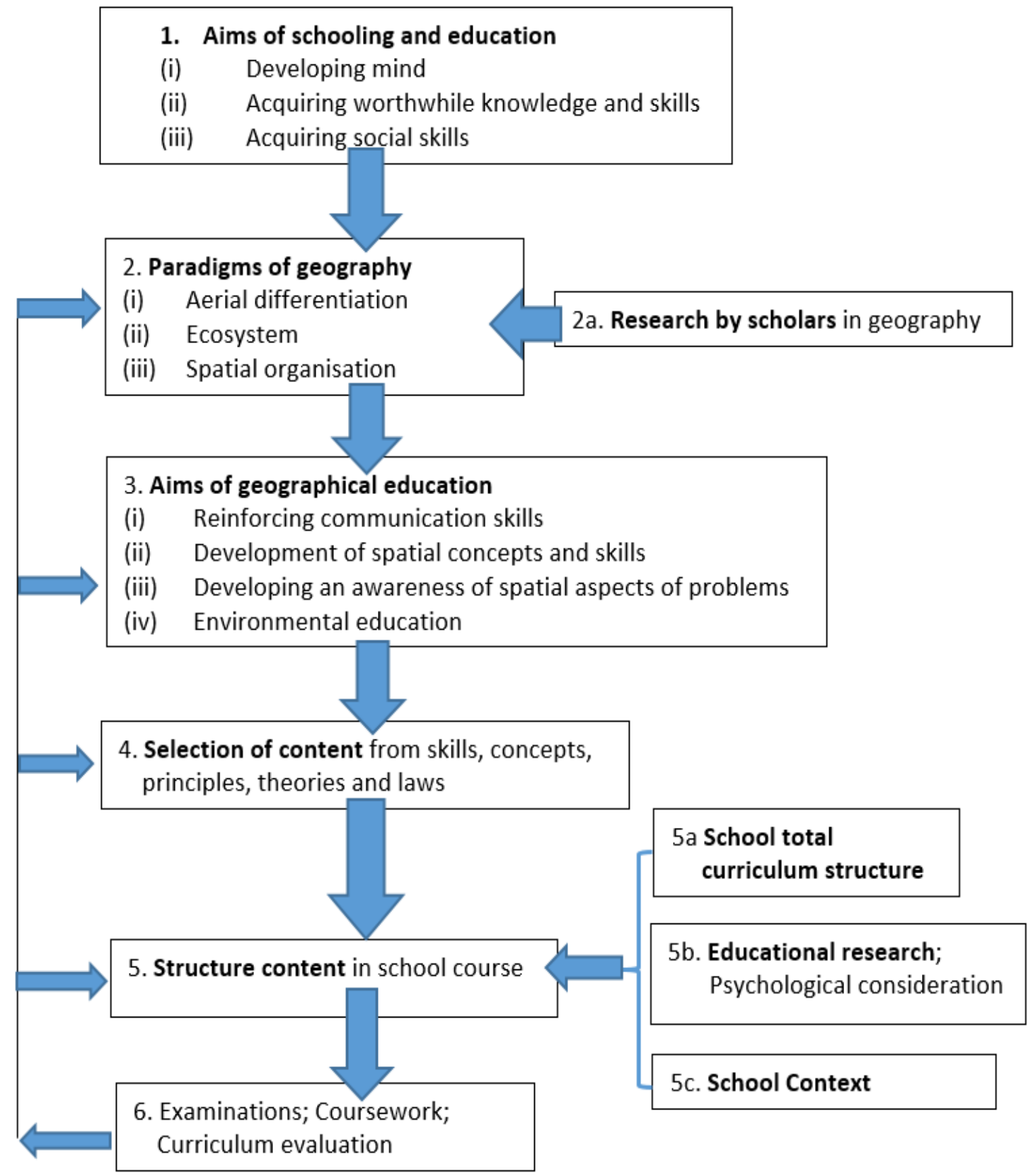

Figure 3.3: Geography curriculum planning (Graves, 1979)

1. Is the viewpoint significant to the subject? student? society?

2. Does it raise issues students will probably need to consider now and in the future?

3. Is the viewpoint appropriate to the students who will be exposed to it?

4. Is it likely to motivate interest and application?

5. Does it connect with student experience?

6. Does it relate to societal concerns and needs?

7. Does it contribute to a balanced view of the subject? (Slater, 1981, p. 9) 
Slater highlighted the recontextualisation process well, as her set of questions connected to students and society as much as they did to the subject. This exemplifies that when knowledge from the academy is translated into school subject material, it is shaped by a number of factors, rather than simply passed down in its original form.

\subsubsection{Paradigms and perspectives in New Zealand school geography}

It is my view that, in the New Zealand context, paradigms and perspectives have also been hidden in the background of geography curriculum design, albeit this has been punctuated by calls for teachers to have greater consciousness of disciplinary developments.

The first national syllabus for geography was a product of the National Geography Curriculum Committee [NGCC] period in the 1970s and 80s, which involved sustained debate concerning the changing geographic paradigms of knowledge and their role in curriculum development (Astle, 1987; Bartlett, 1983; Cant, 1982; Forer \& Owens, 1979; O'Malley, 1977; Slater, 1983; 1987b). Highlighting the rapid disciplinary development of the era, a comment by an anonymous NGCC participant to committee colleagues was reported to be: "Do not worry if you have missed the bus with the latest geography paradigm. The next one will be here shortly" (Cant, 1982, p. 11).

In the context of paradigm proliferation in the 1970s and 80s, the overall tenor of the New Zealand literature at this time was that school geography should, as a minimum, be aware of the developments in the academy. Writers commented on the influence of positivism on school geography in the 1970s "with its emphasis on systematics, models and statistics" (Bartlett, 1983, p. 7), despite it also being clear that this was "a phase which is still active in university geography but which certainly is not the current growth point" (Forer \& Owens, 1979, p. 4). Not everyone, however, was quite as convinced that the scientific 'quantitative revolution' had permeated schools to the extent that it had influenced universities. For example, while O’Malley (1977) recognised that new frontiers of teaching geography required exploration, he pointed to the inadequacy of supporting curriculum guidance, which meant "the majority of teachers were totally unprepared and ill-equipped to teach" (p. 3) the new, scientifically-oriented geography. 
The NGCC-era literature is also of significance to my focus on disciplinary-consciousness, because of its attention to the increasing number of theoretical perspectives used by geographers in response to the critiques of earlier work. For Ian Hay (1987), it was not only geographical phenomena that required inspection, but also the nature of the paradigms and theoretical perspectives through which phenomena and processes were perceived. Hay (1987) noted that "imperfections in earlier (pr)isms of thought were, in part, the prompts for more crystal blends and cuts" (p.7). NGCC members advanced a number of these blends and cuts in their provocations about future directions in school geography, such as Bartlett's (1983) focus on interpretive and social justice oriented geographies and Astle's (1987) focus on structuralism, "with its emphasis on capitalism and the contemporary issues/problems associated with this mode of production, which is part of a radical, political economic phase of geography in the 1980s" (p. 7). Ultimately, the debate about perspectives during the NGCC syllabus developments was no quirk of fate. It reflected the disciplinary-consciousness of syllabus developers that sought to keep a relationship between school geography and the academic discipline (Slater, 1987a).

Despite New Zealand's protracted NGCC literature, however, there was scant evidence of geographic paradigms in the final draft geography syllabus guidelines adopted by teachers in the early 1980s. In response to O'Malley's criticism concerning the absence of overt paradigms in an early iteration of the draft syllabus, the chair of the NGCC offered this rationale, which I quote at some length:

NGCC has given careful thought to the role of paradigms in the teaching of geography...We were, in fact, under considerable pressure to adopt one or other of the paradigms which were current in universities and teachers' colleges in the 1970s. We resisted that pressure for the following reasons:

(a) paradigms, like content, are such an important part of the component of the programme that they should be selected by those who design the school programmes

(b) paradigms, like educational theories, have a limited lifespan...we do not wish to fossilise school geography... 
(c) teachers are themselves reared on paradigms...to give a central position to a single paradigm taught by one or two universities would have placed the majority of teachers and many schools and regions at a disadvantage.

(Cant, 1982, p. 11)

The absence of explicit paradigms in the proposed New Zealand geography syllabus was not about the devaluing of paradigms per se, but at which stage in curriculum making they should emerge. Although Graves' (1979) influential curriculum planning model indicated paradigms were an early design influence of the espoused curriculum, the NGCC stance, for the New Zealand setting, suggested that it should be teachers who consider paradigms as part of their localised curriculum making.

After the NGCC debates there was little empirical evidence of teachers taking up the challenge of designing school geography programmes in line with developments in the discipline. Longhurst and Peace's (1993) advocacy for taking feminism from the lecture halls of universities to school geography classrooms was furthered by Nairn's (1997) postgraduate study which explored the gendered participation of geography classrooms. Ultimately though, Nairn's work employed a gendered perspective applied to an educational problem: geography classrooms were the setting, but it was gendered exclusion/inclusion that was the object of study, rather than geographical knowledge itself. Gale's (1996) Master of Social Science thesis was a rare example of a teacher's consciousness of the social-reconstructionist paradigm. Her work used a framework informed by Treaty of Waitangi principles to analyse interviews about the place of Māori culture and perspectives in school geography and social studies. While this thesis clearly marked an interest in disestablishing a western epistemological basis in curriculum terms, the focus did not extend to teacher practice.

The most significant attempt to bring paradigms and perspectives to the attention of the New Zealand Geography teaching community was the New Zealand Board of Geography Teachers [BoGT] (1999) position paper entitled Future Directions of Geography education and Assessment for 2001 and Beyond. The position paper signalled that school geography would benefit from exploring developments in universities where there was "increasing attention to the philosophy of geography - theorising about what counts as 
geography and critiques of the underlying assumptions of geographic thought" (p.15). The position paper was written by a collaboration of tertiary and secondary sector geography educators in response to the development of the forthcoming NCEA qualifications for 16-19 year olds, and recognised that the geography syllabus developed through the 1970s and 80s by the NGCC "needs to be revised to bring it into line with current geographic thinking and approaches" (p. 3).

Attention to perspectives was one of five aims of school geography in the position paper: "To help students understand the range of perspectives that exists as people utilise and interact with the physical and human environment, and as they carry out geographic investigations" (NZBoGT, 1999, p. 8, my emphasis). In this statement, and throughout the remainder of the document, there is a clear division of the use of perspectives between what the position paper identifies as i) social and cultural geography perspectives; and ii) geographers' perspectives and approaches to the study of the environment (p. 25). According to the position paper, socio-cultural perspectives "would focus on the role of space, place and culture in relation to: different groups...social issues... aspects of daily life...historical legacies". In contrast, geographer's perspectives would focus on "student's ability to use a range of approaches beyond the socio-cultural approaches mentioned above. Approaches such as systems, regional systematic, behavioural etc...” (p. 25). The BoGT position paper offered some suggested outlines for what would be currently recognised by geography teachers as the Geography Achievement Standard matrix (NZQA, 2014a). Of note, the socio-cultural approach to perspectives was included across all three NCEA levels, while the geographer's perspectives approach was limited to the final year as a 'comparative geographic approaches' achievement standard. Crucially, however, the comparative geographic approaches idea for assessment was not adopted into the NCEA geography matrix.

Since the intervention of the BoGT position paper, disciplinary-consciousness has received intermittent attention in New Zealand school geography education literature. Following on from the 'geographical approaches' advocated by the 1999 NZBoGT position paper, one of the more explicit disciplinary-conscious projects was Peace's (2001) report of an online Masters-level accredited qualification that was to support practising teachers to teach 
critical geographies in their programmes. Of the five modules in the course, one was entitled The Changing Face of Geographical Thought, which was designed to introduce teachers to the potential of emerging theoretical perspectives for secondary school teaching. Although Peace (2001) believed that the online medium would facilitate access to new ideas and overcome time pressures facing teachers, she concluded that attention to critically informed geographies was a marginal practice at best. To begin, attracting teachers to subscribe to the course was extremely challenging. Peace suggested that postgraduate qualifications favoured by teachers tended to focus on leadership roles rather than subject-specialist curriculum theory. Furthermore, the practising teachers reported that constraints of curriculum and assessment imperatives limited their opportunities to incorporate critical geographical perspectives.

In another response shortly after NZBoGT position paper was published, Chalmers, Keown and Kent (2002) advocated deep ecology and post-Fordist perspectives as representative of new developments in the discipline. The authors drew parallels across New Zealand and English contexts to argue that teachers should keep up to date with developments in theoretical perspectives. Their commitment to a plurality of paradigms and/or perspectives was highlighted in their statement that "we believe positivist social science has an important role, but that teachers and researchers need to be clear about the limits of the perspective they adopt, and versatile with respect to the perspectives they are prepared to consider" (p. 317). Bliss (2005) added to the potential for versatility of perspectives with her account of scientific, environmental and indigenous perspectives. Her approach took a distinctly postmodern look: "geography recognizes the plurality of groups and seeks to deconstruct dominant mono cultural discourse (that tends to serve the elite and mainstream majority) by empowering 'other' voices and their ways of knowing and seeing" (p. 229). Taken together, the Chalmers et al. (2002) and Bliss (2005) papers certainly broaden disciplinary horizons, although neither paper extended to what this might look like in practice.

The infusion of Māori concepts into New Zealand school geography has become an expectation (MoE, 2013a). Such a progression can be traced to the 1999 NZBoGT position paper, which argued that "Maori Geography is currently not accepted as of equal status to 
Western Geography” (p. 22). The position paper acknowledged that thinking about approaches to Māori geography required more development, and the Māori concepts are typically in support of the stakeholder conception of perspectives. That is, a concept such as maanakitanga might be used to exemplify the tangata whenua of local marae who opened their doors to displaced people in the aftermath of the Christchurch earthquakes (Lambert, 2014). This is quite different from a kaupapa Māori approach to geographic research, in which manaaki ki te tangata ${ }^{9}$ may shape the way that research is conducted with participants (Smith, 2006). Māori perspectives, like other disciplinary-conscious perspectives influence ways of doing geography.

Beyond this literature, I was curious about the extent to which disciplinary-conscious approaches had been recontextualised in New Zealand curriculum documents. Consequently, my first research question asked: To what extent have curriculum and assessment materials signalled a disciplinary-conscious orientation to geography, since the publication of the 1999 BoGT position paper? Looking beyond the documents, I also wanted to know how the concept of 'perspectives' was viewed by subject specialists such as curriculum advisers, professional development providers and examiners who have had input into the types of documents I analysed in Phase 1. For this reason, my second research question asked: How do geography curriculum and assessment specialists view the value, place and role of perspectives in New Zealand senior secondary school geography? I answered this in Chapter 7.

\subsection{How might disciplinary-conscious geography be enacted?}

In this final section I focus on approaches to teaching disciplinary-conscious geography. I would like to note from the start of this section that my definition of disciplinary-conscious geography, which gives explicit attention to the paradigms and perspectives, may not be the only way that disciplinary-consciousness is conceptualised. For example, the considerable literature on geographical enquiry, may be considered to be disciplinaryconscious because it has a focus on learning by doing geography (see, for example, Roberts, 2003, 2013). The literature on teaching approaches that align with the social-

\footnotetext{
${ }^{9}$ Sharing, hosting, and being generous to the participants of research
} 
reconstructionist approach to geography is also aware of developments in the discipline (and society) (see, for example, Fien \& Gerber, 1988; Huckle, 2002), although I contend that these authors seek a paradigm shift in school geography rather than disciplinaryconsciousness in the pluralistic sense that I am exploring. My focus on perspectives, however, was a deliberate attempt to operationalise one current aspect of the New Zealand curriculum that held potential to enhance disciplinary-conscious geography. For this reason, I use perspectives as a pedagogical and curriculum thinking tool. So, what does the literature say about explicitly teaching paradigms and/or perspectives?

\subsubsection{Teaching disciplinary-consciousness in school geography}

Tim Cresswell's call for greater intellectual rigour in the school subject at senior levels led him to conclude that:

I see no reason why students should not arrive at university with a basic understanding of philosophy of place...formulated through pre-existing geographical imaginations... [thinking] in this way provides students with the tools to get beyond the specifics of a particular case study and to approach any number of 'real world' geographies imaginatively and thoughtfully... In my experience it is also an enlivening and stimulating endeavour that attracts students to a discipline that too often seems to consist of counting cars at crossroads. (Cresswell, 2008, p. 139)

Cresswell suggested that spatial science, humanist, and critical interpretations of place were not beyond the grasp of senior secondary students. I take these three paradigms of knowledge to connect to Cresswell's notion of "pre-existing geographical imaginations". This is because such imaginations have previously been developed by the collective intellectual work of scholars and academics in the domain of knowledge production.

Empirical research in school geography education that focuses on the explicit teaching of disciplinary perspectives is rare. As I established earlier in this literature review, much of the disciplinary-conscious literature focused on paradigms and perspectives is advocacy/ curriculum focused, rather than pedagogically instructive. Literature on teaching about the development of geography seems confined to motivating undergraduate students to explore what Keighren, Abrahamsson and della Dora (Keighren, Abrahamsson, \& della Dora, 2012) memorably termed the 'roots and routes' of geography. According to these 
authors, the pedagogical benefits of inducting students into some of the classics or canons of geography were:1) a common intellectual vocabulary; 2) a shared understanding of what geographers have in the past concerned themselves with; and 3) an indication of how contemporary trends in the discipline follow (or react against) those which have gone before (Keighren et al., 2012). What this study did not provide were some fine-grained descriptions of strategies, that could perhaps be modified to school level.

The most significant direction towards the explicit teaching of theoretical perspectives was Puttick's (2013) conceptual framework in which he made the distinction between looking at and looking along theoretical perspectives. In his words, looking at geographical perspectives was to "stand outside the perspective, provide a detached account of it, and consider its methods, substantiation procedures, and the kinds of conclusions the perspective makes it possible to reach" (p. 358). Puttick contrasted this with looking along perspectives, which involved submersing students in ways-of-doing geography that are illustrative of those theoretical perspectives. Looking along a perspective, according to Puttick's analogy, is viewed in terms of a "participant, inhabited, personal, committed knowledge". Different strategies suggested by Puttick for looking at and looking along perspectives are shown in Table 3.2. While Puttick (2013) suggests that both approaches in his conceptual framework are legitimate, the weight he gives to the looking along approach suggests that he sees more authenticity in students being given the opportunity to doing geography as well learning about geography.

The utility value of Puttick's (2013) conceptual framework for my study is not to determine whether I should take either the looking-at or looking-along approach to perspectives. Given that the aim of my study was to take a disciplinary-conscious approach, I imagine that both conceptions may have value to my collaboration. Indeed, in terms of looking at perspectives, I find Puttick's (2013) caution an important aspect to consider in preparation for our lesson study collaboration:

Looking at and explaining different geographical perspectives to students may be a challenge for teachers. Knowing the terms to use, illustrations to draw upon and developing suitable resources that are understandable by students, yet do not oversimplify the perspective, is a hard task. It tests the extent to which we understand these different knowledges (p. 359). 
Table 3.2: Approaches to teaching perspectives (adapted from Puttick, 2013)

\begin{tabular}{|c|c|c|}
\hline & Characteristic & Possible teaching strategies \\
\hline $\begin{array}{l}\text { Looking } \\
\text { at a } \\
\text { perspective }\end{array}$ & $\begin{array}{l}\text { Looking at geographical } \\
\text { perspectives is to stand } \\
\text { outside the perspective, } \\
\text { provide a detached account of } \\
\text { it, and consider its methods, } \\
\text { substantiation procedures, } \\
\text { and the kinds of conclusions } \\
\text { the perspective makes it } \\
\text { possible to reach. }\end{array}$ & $\begin{array}{l}\text { - Comparative study between perspectives } \\
\text { - Analysis of assumptions and premises } \\
\text { - Analyse what counts as evidence }\end{array}$ \\
\hline $\begin{array}{l}\text { Looking } \\
\text { along a } \\
\text { perspective }\end{array}$ & $\begin{array}{l}\text { Looking along geographical } \\
\text { perspectives is seen in terms } \\
\text { of participant, inhabited, } \\
\text { personal, committed } \\
\text { knowledge. Involves seeing } \\
\text { the perspective from the } \\
\text { 'inside'. Looking along a } \\
\text { perspective is to be immersed } \\
\text { in it, and breathing its air. }\end{array}$ & 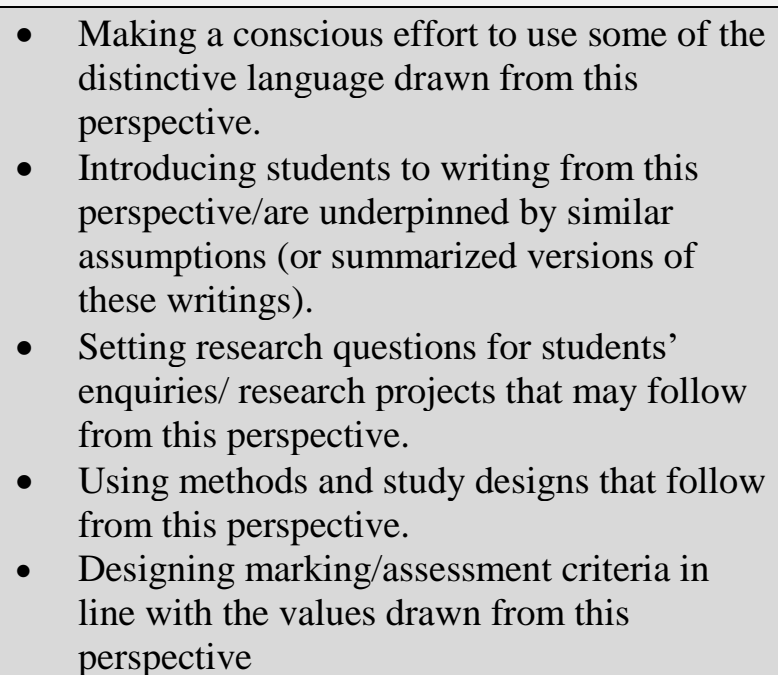 \\
\hline
\end{tabular}

If a comparative approach between perspectives is to be taken, it may require a much more concerted study of geographical thinkers. Recently, for example, Vernon (2016) asked whether a philosophical approach to school geography should encourage students to explore the ideas of key geographical thinkers. Vernon's query is not, however, for purposes of establishing a geographical canon in the academic rationalist vein, but to explore the contested, dynamic evolution of a discipline that is shaped by the agency of actors working at the frontiers of knowledge production. Vernon's (2016) engagement with Bernsteinian theory on the structure of knowledge invokes a pertinent question for this thesis: "to what degree and in what ways can we (or should we) represent geographyas-philosophy in the classroom (i.e. as a 'way of thinking')?" (p. 102). Vernon also goes on to ask, should senior secondary students "be equipped with a basic grounding in 
particular authors and paradigms?" (p. 102). Vernon did also caution, however, "How does one ensure one avoids the trap of teaching simply geography plus epistemology, rather than geography shaped by its epistemology?” (p. 103). In this respect I think she is aligning herself to Puttick's (2013) metaphorical looking along a perspective.

\subsubsection{Pedagogical direction from other disciplinary-conscious subjects}

One school subject to turn to for direction on disciplinary-conscious teaching is that of science. Internationally, and in New Zealand, the theory and practice of teaching the Nature of Science $[\mathrm{NoS}]$ has established a significant body of literature that focuses on student learning science, about science, and doing science (Abd-El-Khalick \& Lederman, 2000; Hodson, 2014). In this section I examine some of this literature to consider possibilities that may be useful to geography teaching.

Within the multiple threads of research associated with NoS, the knowledge development in science emphasis is similar to the focus of this thesis. This is because this thread is focused on studies which encourage students to learn how knowledge in science is developed in socio-historical contexts, so that they learn to see science as a constantly developing culturally determined system of knowledge (De Putter-Smits, 2012). Hodson (2014) refers to this goal of science education as learning about science, in which the aim is for students to develop an understanding of the characteristics of scientific inquiry, the socio-cultural milieu that surrounded the origin of important scientific theory, ways in which the scientific community self-regulates, and the development of linguistic conventions in the development of scientific claims.

Hodson (2014) suggests a range of strategies, such as biographies and autobiographies, movies, internet searches, role-playing and debating can be used successfully in learning about science. What is particularly useful to this study is that Hodson does not see learning about science as a monolithic focus but gives plenty of examples of the many scientific sub-cultures in which the focus, questions asked, and methods utilised are quite different. Is this all too much for school students? Studies in this learning about science vein all present empirical evidence of teachers' concerns that subjective and socio-cultural aspects of science are considered better delayed for older students (Akerson, Buck, Donelly, Nargund-Joshi, \& Weiland, 2011; Leden, Hansson, Redfors, \& Ideland, 2015) 
While a great deal of the NoS literature focuses on the characteristics of scientific testing, more explicit philosophical approaches have been written about. For example, Eflin, Glennan and Reisch (1999) recommend some 'dos and do nots' when considering the '-isms' of science in classrooms. These include ignoring the (strawman) failings of positivism in preference for a focus on empiricism, especially in relation to measurement and experimentation; avoiding debates about realism, and assuming a naïve realist view as appropriate for school education; introduce students to Kuhnian thinking, in particular competing paradigms, and how theoretical commitments and social issues influence the development of science; avoid confusing students with the psychological, epistemological and metaphysical issues associated with social constructivism / relativism. The value of this paper speaks to the need for carefully circumscribing the extent to which a disciplinary -conscious approach might be taken with a group of senior students: aspirations must be met with pedagogical realities.

More recently, theoretical perspectives have also emerged in senior secondary literature classrooms. For example, Appleman (2009) focuses on theoretical perspectives as a lever for students to question the ideologies inherent in literature texts, from the classics to contemporary media. Appleman notes that, in the American context, terms such as Marxist and Feminist theory are so politically charged that reframing them as 'social class theory' and 'gender criticism' might be fruitful. Her focus on post-colonial theory and literary deconstruction (post-modern theory) recognises the intellectual challenge of teaching literary theory, but she argues that multiple perspectives on a singular text can help students of all abilities broaden their understanding of literature with wider views of their world. In Australia and New Zealand, the development of new curriculum and assessment standards has also given English Literature teachers the opportunity to explore theoretical perspectives with their senior secondary students. The guidance of the emerging literature suggests that there is a need to upskill teacher capability to understand the nature of different perspectives as well as explore suitable pedagogies (Evans, 2017; Schroor, 2017). 
Across my review of these geography, science and English Literature authors I identified a range of approaches in which there was agreement about what teachers and students may need to do:

- Select appropriate perspectives (Puttick, 2013; Sazama, 2015; Isaac, 2017)

- Identify key concerns and themes of the perspective (Puttick, 2013; Hodson, 2014; Isaac, 2017)

- Introduce key theorists/scholars (Hodson, 2014; Sazama, 2015; Isaac, 2017)

- Explore historical, social and political context that gave rise to perspectives (Hodson, 2014; Isaac, 2017) i.e. contextual-cultural values

- Consider ontological, epistemology, axiological components and methodological connections (Puttick, 2013; Hodson, 2014; Sazama, 2015)

- Analyse and/or use language features of perspectives (Hodson, 2014; Puttick, 2013; Isaac, 2017; Moje, 2015)

- Evaluate what counts as data (Puttick, 2013; Hodson, 2014; Moje, 2015)

- Compare and contrast issue/phenomena through different perspectives (Puttick, 2013; Isaac, 2017)

- Set research questions and use inquiry methods that reflect perspective (Puttick, 2013; Hodson, 2014; Moje, 2015)

I certainly take from literature that the Goldilocks Principle needs to come into play regarding what is 'just right' in introducing school aged students to paradigms and perspectives. The emerging literature makes it clear that theoretical perspectives have multiple layers of meaning that requires considerable unpacking and clarification in the minds of teachers if they are going to be translated into engaging, motivating and substantive learning for students.

One further avenue for a disciplinary-conscious approach to teaching has emerged through the Theory of Knowledge [ToK] course of the International Baccalaureate Diploma Programme. Targeted at students of 16-19 years of age, ToK is a course designed to develop student understanding of knowledge and the process of knowing. While there are elements of philosophy in the course, the goal of ToK, is to explore collective areas of specialist knowledge communities as well as personal tacit ways of knowing such as 
instinct and intuition. Bergeron and Rogers (2015) used a mixed methods design to investigate the impact, perceptions, and implementation of the TOK course in IB schools worldwide. Quantitative survey data were analysed from 1,534 participants and focus groups with 33 TOK teachers were conducted in Australia, The Netherlands, and the United States. A strong thread of the findings was the improvements teachers felt they had in their own critical thinking and interdisciplinary understanding, as well as the connections that students were perceived to make between academic disciplines. It was clear from Bergeron and Rogers' report that teachers were very positive about the opportunity to teach ToK, albeit the self-selecting sample might not give a fully balanced view. While ToK is designed to explore knowledge production, the structural set up means it is difficult to know whether IB students are likely to receive much teaching about the development of geography, per se.

To summarise the literature from other subject domains, it is clear that engagement with theoretical orientations to knowledge has been taken up by teachers in a number of curriculum subjects. Nevertheless, the literature is also clear that this is considered challenging territory by teachers. Indeed, overall, the NoS literature is striking in terms of how long its ideas have been advocated, but how limited its integration into science education pedagogy has been (Hodson, 2014). This certainly makes me aware of the breadth and depth of work required for a disciplinary-conscious approach to geography to flourish.

\subsubsection{Pedagogies associated with 'disciplinary literacy'}

In the United States, 'disciplinary literacy' is a body of literature that particularly looks at how students come to understand and practise the differences between the substantive, procedural and syntactic knowledge of discipline infused curricula. The disciplinary literacy literature is underpinned by a student maturation point of view, as its proponents argue that after the focus of basic functional literacy in the primary/elementary years, and metacognitive literacy in the middle school years, that high school students should focus on developing knowledge of and skills with the linguistic codes, technical vocabularies and discourse practices that support epistemic understandings and routine practices of a discipline (Moje, 2008, 2015; Shanahan \& Shanahan, 2008). This is why writers 
sometimes uses 'disciplinary literacy' and 'adolescent' literacy interchangeably, which: becomes a matter of teaching students how the disciplines are different from one another, how acts of inquiry produce knowledge...this [is] the generation of an epistemically grounded curriculum and pedagogy, or one in which students come to understand that knowing how knowledge is produced is as important as access to the knowledge itself. (Moje, 2008, p. 103)

It seems to me that there is considerable overlap between the aims of disciplinary literacy and the work of British geography educators who have been at the forefront of arguing for student entitlement to geographical knowledge in a subject-led curriculum (Firth, 2011a; 2013; Lambert, 2011; 2014; Morgan, 2002; 2005). Furthermore, U.S. disciplinary literacy advocates and British geography educators both point towards the large scale failure of working class students to be inducted into disciplinary thinking, which prevents them from following educational pathways that are likely to improve social mobility (Lambert, 2014; Moje, 2007).

Gabriel and Wenz (2017) recently highlighted three distinct pedagogical approaches towards disciplinary literacy and associated instructional practices from their review of over 200 articles describing literary instruction in content-area classes. The first approach they termed 'disciplinary-specific strategy instruction', and focused on student needs to read and write texts 'like a scientist' or 'like a historian'. The authors suggest that textbooks are not ideal for such purposes, because they tend to present knowledge as settled, and so teachers need to be able to select disciplinary texts in order that students can explore 'author voice'. This is aligned to the idea of purposeful reading explicated by Sazama (2015) in the context of literary theory. Furthermore, according to Gabriel and Wenz (2017), teachers need to be able to model disciplinary features, such as pointing out what makes texts distinctly scientific or historical in their argumentation styles or in the presentation of data. The second pedagogical approach highlighted by Gabriel and Wenz was to include 'general-strategy instruction', to support students' overall literacy. Instructional practice to support this might be to choose a range of texts (written, multimedia, cartoons, diagrams etc.) in order that students are not stymied by an overreliance on written text. More generic practices such as annotation and summarisation, and the use of graphic organisers will also help learners. The importance of generic literacy 
practices is also made by researchers who claim that disciplinary literacy should not replace functional literacy, but co-exist in senior secondary schools, especially given the large number of high school students still working towards basic levels of proficiency (Faggella-Luby, Graner, Deshler, \& Drew, 2012; Heller, 2010). The third approach advocated by Gabriel and Wenz (2017) was to encourage students practising being the disciplinary specialist. The manifestation of this is to engage students in enquiry with the intention that text engagement will connect to the purpose of the stage of the enquiry with which they are engaged. A strategy suggested by Gabriel and Wenz is the idea of engineering 'teachable moments' at points in which students have a need to know.

Moje (2015) has recently presented a heuristic for teachers seeking to explore disciplinary literacy practices. The first dimension of the heuristic emphasises that teachers should engage students in the practices of the discipline through deliberate inquiry. Such is the importance of this aspect of her framework, that she presents it as the core of her model (see Figure 3.4). Significantly, while Moje views disciplinary inquiry as specific to a specialised community, she contends that all disciplines have the same overarching inquiry practices: asking questions or framing problems; working with data of some type; reading

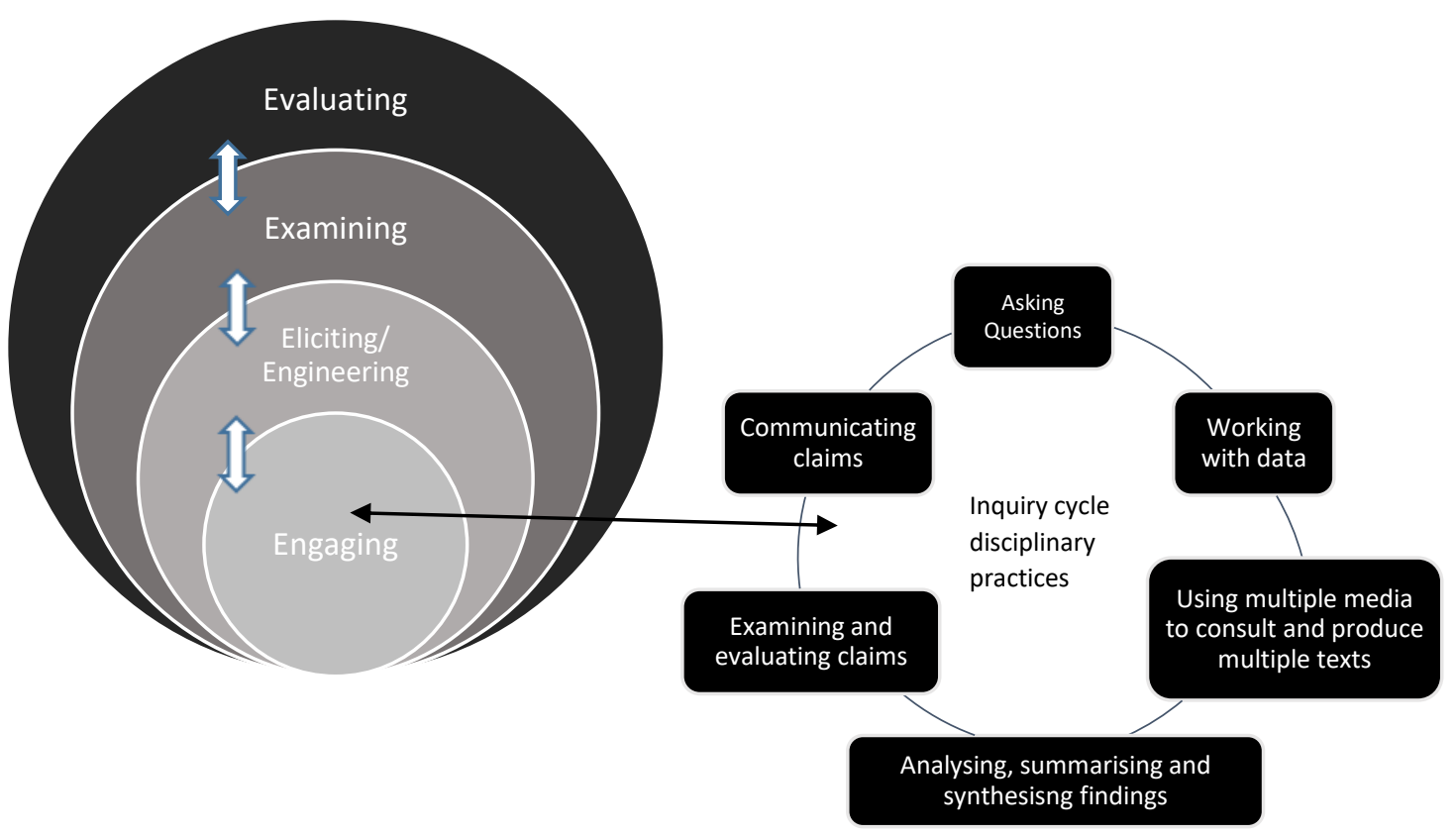

Figure 3.4: Moje's (2015) 4E Heuristic with disciplinary practices 
and writing a range of texts; recording, analyzing, and synthesizing data; and communicating their findings. Offering pragmatic advice to teachers, Moje suggests inquiry practices should be the framework for unit planning and that daily lessons regularly focus on one or more of these practices, such as question posing or working with data.

The eliciting/engineering aspect of Moje's heuristic suggests that deliberate acts of teaching are required to help support students with a range of strategies so that students can make meaning about ways of engaging in the inquiry practices. Moje (2015) gives examples of what many would see as generic literacy type strategies, for disciplinary reading, writing, discussion and debate, technical vocabulary extension strategies that "should sit within disciplinary inquiry practices that both apprentice learners into these specialized, private domains and provide purpose and audience for young people" (p. 267).

The examine component of Moje's heuristic focuses on the meanings and ways in which words, phrases, and symbols are used in a discipline, so that students can learn about why members of a disciplinary community read, write, and talk in particular ways. This, according to Moje, "makes clear to students that the disciplines are human constructions, with social and cultural norms, rather than merely bodies of knowledge to be digested" ( $p$. 268). Working on disciplinary discourses also provides opportunities for students to question whose interests are served by the language of a particular perspective that is being adopted.

In the final part of Moje's (2015) heuristic, evaluating gives students the opportunity to consider why disciplinary perspectives serve a useful purpose, or in some contexts, why they do not. Evaluative conversations once again make explicit how disciplinary perspectives shape and are shaped by knowledge production.

All the strategies in this chapter are helpful to my study because they offer pedagogical direction to unpack a prospective disciplinary-conscious approach to geography. The list offers advice on what is already done by some teachers as well as aspects which may break 
new ground. I used this framework to help me design the lesson study phase of my empirical research (see Chapter 8).

\subsection{Summary and rationale for research questions}

In this chapter I have reviewed literature to examine the place and role of paradigms and perspectives in school geography as an expression of what I have termed a disciplinaryconscious approach to the subject. My review of the literature has indicated that New Zealand school geography has tended to follow the Graves' (1979) model of curriculum design, in which the influence of paradigms and/or perspectives are hidden in the background, several steps removed from the concerns of teachers. However, that model is a relic of centrally planned syllabus, which is no longer the case in the New Zealand Education setting (see Section 2.4). If school geography is to become disciplinaryconscious then teachers may need to give more time and energy to questions of "what are the characteristics of geographical knowledge?' and 'which theorists, under what social conditions, contributed to the development of geographical knowledge?'

Examples were noted from other subjects, such as Science and English Literature, that are developing disciplinary-conscious approaches. A parallel body of literature known as 'disciplinary literacy' has also emerged in the last decade, from which geography teachers may find inspiration to engage with their multi-paradigmatic subject. The disciplinary literacy literature is, however, characterised by studies in which differences between subject-area epistemologies are at the forefront. This study will see whether such disciplinary variety can be studied through the single subject lens of geography.

Absent from the literature are empirical studies of teacher and student engagement with paradigms and perspectives as an expression of greater disciplinary-consciousness towards geography (Firth, 2013; Vernon, 2016). In highly devolved education systems, in which teachers are charged with producing programmes of learning with little in the way of prescription, how teachers and students explicitly focus on geographical knowledge is not well documented. Thus, my over-arching quest is to determine the role and potential of the concept perspectives to move towards disciplinary-conscious New Zealand school geography. 
My overall conclusion following this literature review is that my research would benefit from exploring how disciplinary-consciousness might permeate New Zealand school geography at different levels of recontextualisation. Given the NZBoGT (1999) position paper advocacy that school geography should become more attuned to disciplinary developments in the universities, it prompted my initial research question focused on whether this trajectory had been revealed in the literature. The question became:

To what extent have curriculum and assessment materials signalled a disciplinaryconscious orientation to geography, since the publication of the 1999 NZBoGT position paper?

My second question focused on a small group of individuals, whose role in recontextualising the curriculum and assessment materials is likely to heavily shape the potential for disciplinary-conscious school geography. Although my previous question established a 'base-line' of how perspectives is framed in curriculum and assessment materials, my second phase sought to understand why this was the case:

How do geography curriculum and assessment specialists view the value, place and role of perspectives in New Zealand senior secondary school geography?

Finally, in recognition that there was a significant gap in empirical studies focused on disciplinary-conscious outcomes for teachers and their students, my third question asks:

What are the outcomes of a lesson study collaboration focused on expanding teacher and students' disciplinary-consciousness?

Having reviewed the literature focused on paradigms and perspectives in the context of curriculum and enactment, I now propose a theoretical framework to guide my research journey. 


\section{Chapter 4: Theoretical Framework}

\subsection{Introduction}

In keeping with the geography education theme of this study, my theoretical framework acts as a map or travel plan to guide my research. As will become apparent, I do not tie myself to a single theoretical idea, but rather weave together ideas to create a coherent framework in the tradition of a research bricoleur (Denzin \& Lincoln, 1998).

The theoretical framework I present in this chapter is influenced by my own stance from the outset. Perhaps it is not surprising, given my professional history as a specialist subject teacher of geography, that I put great store in disciplinary fields of inquiry that offer the conceptual frames and analytical tools to help people make sense of their world. However, although my advocacy of subject specialism locates me in a liberal humanist tradition of education this should not be interpreted as a call for a return to a Gradgrind-esque approach to curriculum and practice, nor a cultural restorative tradition by which geographical knowledge is presented in a static and lifeless way (Rawling, 2001). On the contrary, knowledge is necessarily in a constant state of refinement and, sometimes, rejection, by a host of key actors, who are themselves shaped by broader socio-cultural influences (Morgan, 2002). Yet such social mediation of knowledge does not justify an 'anything goes' position towards what might be included in a school curriculum, but strengthens the ability for knowledge to provide warranted claims as an approximation of 'truth' (Young \& Muller, 2007). Thus, my position connects with recent social realist accounts of the nature of knowledge, more of which I will outline in this chapter.

Figure 4.1 is designed to help readers connect the key theoretical elements that inform my study. In broad terms the theoretical framework consists of two fields of practice: the field of knowledge production (typically found in research focused institutions) and the field of recontextualisation (Bernstein, 1996; 2000). Understanding the field of knowledge production is important to geography teachers, because it is from here that knowledge about the key actors and developments in geographical knowledge can be drawn (Vernon, 2016). Nevertheless, as I shall outline in Section 4.2, it is the field of recontextualisation in which much of this research is located, as this is where intellectual knowledge is translated 
into educational knowledge, represented in curriculum documents, textbooks, and assessment prescription.

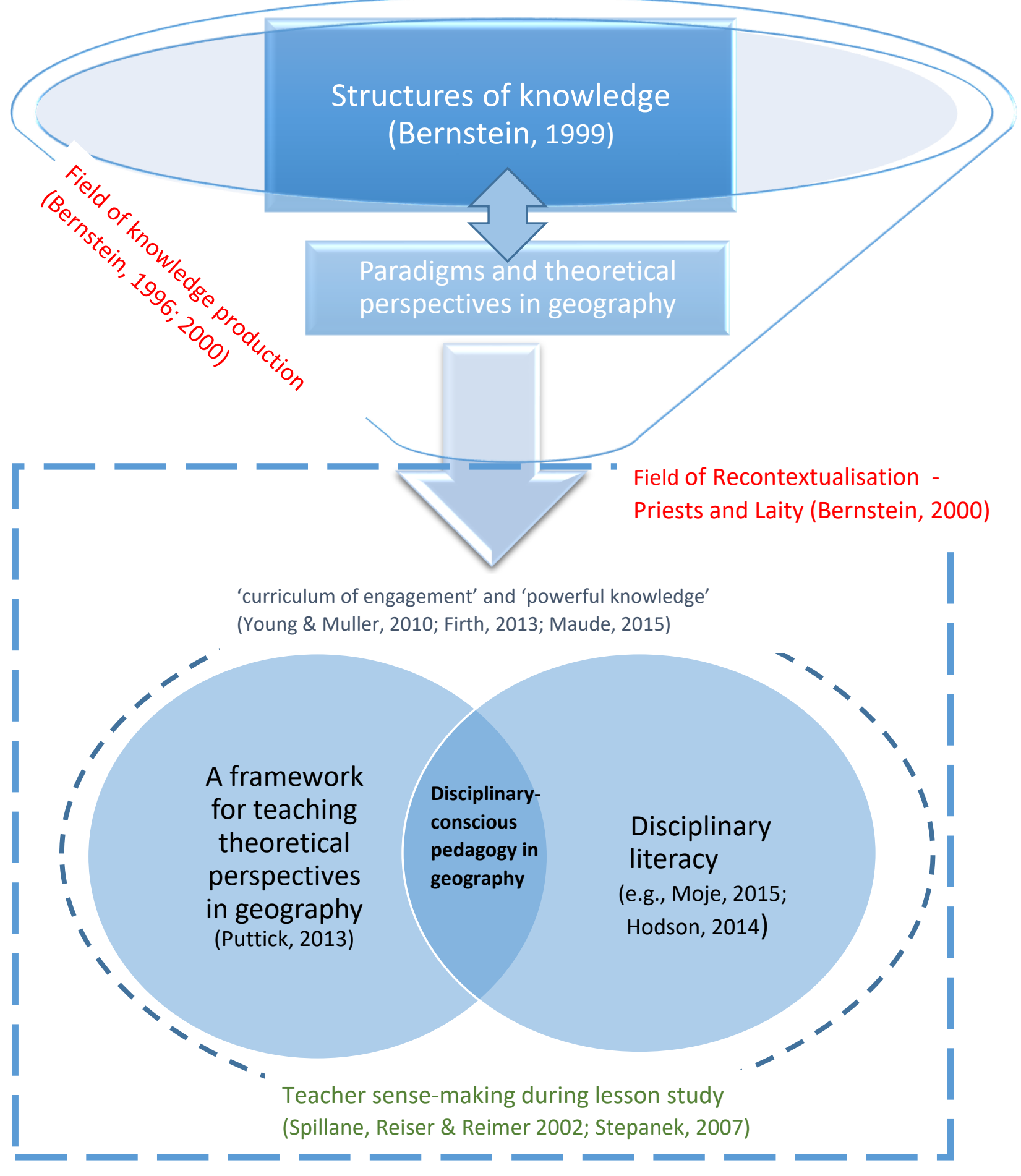

Figure 4.1: Theoretical framework for my research 
Embedded within the field of knowledge production is Bernstein's (1999) theorisation of the structures of knowledge. As will unfold in this chapter, this theorisation helps explain the role of paradigms and perspectives in the field of knowledge production.

Embedded within the field of recontextualisation, I draw upon Firth's (2013) notion of a 'curriculum of engagement' and apply it to the single subject of geography. I do not stop at the level of curriculum, however, because this thesis also has a particular focus on how disciplinary-consciousness might be enacted by teachers. Thus, the recontextualisation of knowledge from the field of knowledge production must take place first through curricula representations before being further shaped by the pedagogical work of teachers.

Because my research is at a micro-scale level of recontextualisation, Figure 4.1 also shows that my theoretical framework is given direction by specific pedagogical frameworks that have a strong disciplinary-conscious focus (Puttick, 2013; Hodson, 2014; Moje, 2015). The final aspect of my theoretical framework focuses on teacher sense-making, in which, I draw upon a framework proposed by Spillane, Reiser and Reimer (2002) to give theoretical power to the process of interpreting curriculum messaging.

For the remainder of this chapter, I explain the key aspects of each element of my theoretical framework, while drawing attention to their relevance for my research. I begin by first distinguishing between the field of knowledge production and field of recontextualisation, as within each of these are significant actors, whose practices will be the focus of my empirical work.

\subsection{Fields of Practice, Prophets, Priests and Laity}

The focus of my research enables me to locate aspects of my study within and between specific fields of practice in what Bernstein (2000) called the 'pedagogic device': a model to help explain the processes by which intellectual, expert knowledge is recontextualised into knowledge for schools. 


\begin{tabular}{|c|c|c|c|}
\hline Field & Field of Practice \& Actors & Typical Sites & 'Rules of the game' \\
\hline Intellectual & $\begin{array}{l}\text { Production } \\
\text { Prophets } \\
\text { e.g. Scholars such as E.W. Burgess, } \\
\text { Yi Fu Tuan, David Harvey etc. }\end{array}$ & $\begin{array}{l}\text { Universities/research } \\
\text { organisations }\end{array}$ & $\begin{array}{l}\quad \text { Distributive rules } \\
\text { (i.e. power relationships } \\
\text { within and between networks } \\
\text { of scholars) }\end{array}$ \\
\hline \multirow[t]{2}{*}{ Educational } & $\begin{array}{l}\text { Recontextualisation } \\
\text { Priests e.g. Curriculum guideline } \\
\text { writers; Education Review office; } \\
\text { (Official recontextualising field) } \\
\text { AND } \\
\text { Examiners; Text book writers; } \\
\text { professional development providers; } \\
\text { Initial teacher educators; teachers } \\
\text { (Pedagogical recontextualising field) }\end{array}$ & $\begin{array}{l}\text { Curriculum } \\
\text { documents, textbooks, } \\
\text { journals, Sites of } \\
\text { teacher education, } \\
\text { position papers }\end{array}$ & $\begin{array}{l}\text { Recontextualising rules } \\
\text { (i.e. discourse from } \\
\text { intellectual field altered as } \\
\text { related to other discourses } \\
\text { that compete for space in the } \\
\text { educational endeavour) }\end{array}$ \\
\hline & $\begin{array}{l}\text { Reproduction } \\
\text { Laity } \\
\text { Teachers and Learners }\end{array}$ & $\begin{array}{l}\text { Teaching and learning } \\
\quad \text { (classrooms, } \\
\text { fieldtrips, assessment) }\end{array}$ & $\begin{array}{l}\text { Evaluative rules } \\
\text { (i.e. what counts as valid } \\
\text { curricular content) }\end{array}$ \\
\hline
\end{tabular}

In Bernstein's (2000) religiously couched terms, academics and scholars are viewed as 'prophets' for their ability to see into the unknown and 'think the unthinkable'. These prophets generate the knowledge structures and substantive knowledge of their disciplinary field. The distributive rules govern who has access to what knowledge and under what conditions in such settings: explicit 'rules of the game' such as qualifications and tenure are likely to be part of the distributive rules, although orientation to new theories and/or methodologies may also enhance access to specific fields of production. As much of my study focuses on recontextualisation rather than knowledge production, a focus on paradigms and perspectives speaks to ideas from the field of production.

Moreover, the relationship between the fields of practice is hierarchical, as recontextualisation cannot happen unless knowledge production has occurred. I do note, however, Puttick's (2015a) contention that, in England, chief examiners have come to dominate the work of teachers and attitudes of students to such an extent that their role is as much prophet as it is priest. 
As the literature established in Chapter 3, a school subject is not simply a mirror image of the academic discipline, thus the field of recontextualisation is the site at which intellectual, disciplinary knowledge is transformed to educational knowledge. As Table 4.1 shows, there are a host of specialised 'priests' who participate in the field of recontextualisation, operating across what Bernstein (1996) labelled the Official Recontextualizing Field (ORF) and the Pedagogic Recontextualising field (PRF). The ORF is the formal representation of knowledge by the State, typically in the form of a national curriculum document. The PRF, represents the work of a range of priests who are also in a position to shape the development of school knowledge, such as examiners, text book authors and professional development providers. In a world saturated by social media I consider the priests of geography education to be thought of as 'influencers'.

Across the ORF and PRF, disciplinary knowledge is 'curricularised': some material from the field of production will be selected while some will not; other material will be relocated and/or refocused; and educational discourses related to the purposes of education and theories of teaching and learning may also be appropriated in the field of recontextualisation. Consequently, educational knowledge is more than just the intellectual knowledge from the field of production, as there is always "a place for ideology to play" (Bernstein, 2000, p. 9) when several discourses come together.

Bernstein (1996) considered the relationships within the recontextualising field to be significant, not least because new approaches emerged from the tensions that existed between the constituent actors between the ORF and PRF:

Both fields may well have a range of ideological pedagogic positions which struggle for control of the field. And these positions in the Official and Pedagogic Recontextualizing Fields may well be opposed to each other. Thus the relative independence of the latter from the former is a matter of some importance.

(Bernstein, 1996, pp. 117-118)

In this respect, I understand the pedagogic device to be a conversation between structure and agency, as it simultaneously stresses the relationships between the fields of practice, as well as indicating who is 'playing the game' in the recontextualisation of knowledge. 
Puttick (2015b) helps give concrete detail to the abstraction of Bernstein at this level of 'recontextualisation', by identifying teachers' different degrees of recontextualisation of sources such as Google, YouTube, exam specification websites, textbooks and news websites. On his continuum of five degrees of recontextualisation, the least recontextualised sources are those presented to students substantially unchanged (1 degree), while 3 degrees of recontextualisation involved sections of sources copied and reformatted, and 5 degrees when sources became "an indistinguishable part of teachers' embodied subject knowledge" (p. 29).

The final field of the pedagogic device is the field of reproduction, namely that arena in which curriculum is transformed into pedagogic practice by the interactions of the laity whose task is to reproduce the knowledge. This act is done by students, who are subject to the evaluative rules of examinations and classroom evaluation. There may also be some teachers who see themselves as 'deliverers' of geography education, although it is very difficult to envisage teachers not in some way recontextualising knowledge, even if it has been through prior iterations of translation.

Now that I have given a brief overview of key actors responsible for recontextualisation of knowledge, I return to the field of knowledge production to explore the intellectual knowledge that is at the heart of the recontextualisation process in this research. To do so I draw upon another of Bernstein's helpful theorisations, this time, of the structure of knowledge itself.

\subsection{Bernstein's account of the structure of knowledge}

In the last decade of his life, Bernstein's work took a turn to the properties of knowledge and how this was translated in school settings for purposes of pedagogy. One thread of this work, and of deep importance to my theoretical framing, was a detailed exploration of the structure of disciplinary knowledge.

A helpful starting point to explore Bernstein's (1996) structure of knowledge was his distinction between horizontal and vertical discourses (see Figure 4.2). Horizontal 
discourses were, according to Bernstein (1996), 'everyday' knowledges that are "local, segmental, context dependent, tacit, multi-layered, often contradictory across contexts but not within contexts" (p. 170). Such horizontal discourses are learned from experience and related to specific events. While student experience can be used as a pedagogical lever, horizontal discourses are not a strong basis for curriculum provision because they fail to systematically organise a conceptual framework for understanding the world.

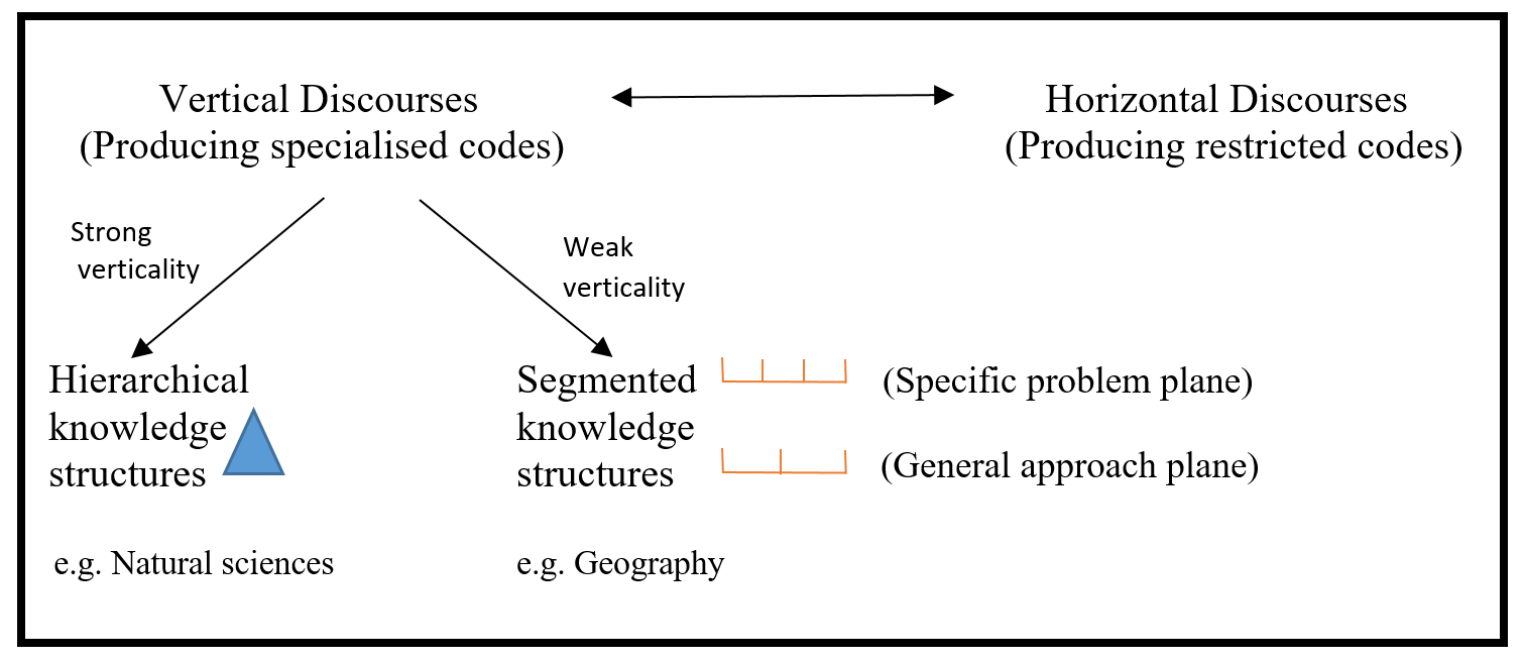

Figure 4.2: Knowledge structures (adapted from Bernstein, 2000)

In contrast, vertical discourses are context independent, specialised languages that generate elaborated codes of abstraction. According to Bernstein's theorisation, domains with disciplinary coherence are structured by vertical discourse. Bernstein identified that vertical discourses comprise two types of knowledge, of relatively 'strong' and 'weak' verticality which either take:

the form of a coherent, explicit, and systematically principled structure, hierarchically organized, as in the sciences $\boldsymbol{o r}$ it takes the form of a series of specialised languages with specialised modes of interrogation and specialised criteria for the production and circulation of texts, as in the social sciences and humanities. (p. 159)

Strong 'verticality' is explained by Bernstein (1996) as the capacity of hierarchical knowledge structures to develop theories and laws which integrate knowledge at lower levels of understanding. Bernstein used Physics as his case example of hierarchical 
knowledge structures, and visually displayed the knowledge structure as a triangle. This visualisation expressed the increasing explanatory sophistication at the apex, as greater generality and abstraction is achieved by subsuming the large number of empirical phenomena at the wider base of the knowledge structure (Bernstein, 1999).

According to Bernstein (1999) however, segmented knowledge structures with 'weak verticality' do not have the same levels of integrative capacity. For my thesis, I apply Bernstein's (1996) abstraction of segmented knowledge structures as "a series of specialized languages, each with its own specialized modes of interrogation and specialized criteria" (p. 172). Bernstein typically uses the term horizontal knowledge structures, sometimes describing them as segmented structures. I am choosing to use segmented knowledge structures in order that the reader does not confuse these (of, say, specialised social science knowledge) with horizontal discourse (of everyday, experiential knowledge). Thus geography is not structured by an integrating code of increasing levels of abstraction, but by a collection code, in which additional specialised languages are added. The addition of 'new voices' in the development of geography (refer to Section 3.2.3) in the second half of the $20^{\text {th }}$ Century is why geography is an excellent example of a collection code.

Of particular importance to my study, is that Bernstein (2000) recognised that because of the indirect relation between the abstraction of disciplinary thought and the empirical world, gaps or spaces are created where there is always the potential for alternative discourses to develop:

I want to suggest that this gap or space can become (not always) a site for alternative possibilities, for alternative realisations of the relation between the material and immaterial...the site for the unthinkable, the site for the impossible...the meeting point of order and disorder, of coherence and incoherence. It is the crucial site of the yet to be thought." (p. 31)

My reading of Bernstein is that these sites of the 'yet to be thought' are a combination of both the substantive focus and the theoretical approach to geography. This seems to be confirmed by Bernstein's distinction between the General Approach Plane (GAP) and a Specific Problem Plane (SPP): 
The GAP plays an analogical role to general theory in hierarchical knowledge structures. The GAP is a space where meta languages are produced which attempt to provide the basic orientation, a language of description and the rules of its use, which legitimize how phenomena should be understood and interpreted...the second discursive plane [SPP] is produced by empirical study of particular problems or areas. (Bernstein, 2000, p. 173)

The distinction between the SPP and GAP is fundamental to my study, as it is my contention that a disciplinary-conscious approach requires far greater attention to the GAP than is typically the case in school geography, which tends to focus on topics. This is especially the case if students are to become more critically aware of the strengths and limitations of geographical knowledge production.

The GAP reflects what Bernstein (2000) calls 'meta-languages', which are added to the field of geography over time. As Muller (2009) has noted, with each additional language comes a "fresh perspective, a new set of questions, a new set of connections, and apparently new problematic, and most importantly a new set of speakers... because these languages are incommensurable, they defy incorporation” (p. 70). As noted in Chapter 1, there are examples of innovative research that aim to integrate some of these so-called incommensurable languages, but for the purposes of disciplinary-conscious school geography, focusing on perspectives provides me a way to explore teacher and student learning about 'additional' meta-languages in geography.

To highlight my application of Bernstein's theorisation to geography, I have used geographical examples in Figure 4.3. In this example, spatial science (with a realist ontology and objective epistemology) and feminist (relativist ontology and subjective epistemology) perspectives are examples of two 'incommensurable languages' on the general approach plane. The SPP is also segmentally structured, but by languages associated with specific problems (e.g., the language of cities includes 'agglomeration'; 'gentrification'; 'suburbanisation' etc.). Put another way, Bernstein's 'general approaches' (i.e. paradigms and perspectives) reflect the transitive dimension of geographic knowledge and are called upon to act as 'telescopes' to view the intransitive objects of study in the SPP, such as migration, globalisation, urbanisation or climate change. According to 
Bernstein, the specialised language from the GAP "may cut across a series of problems or the same problem may be described by different specialized languages in the GAP" (Bernstein, 2000, p. 174).

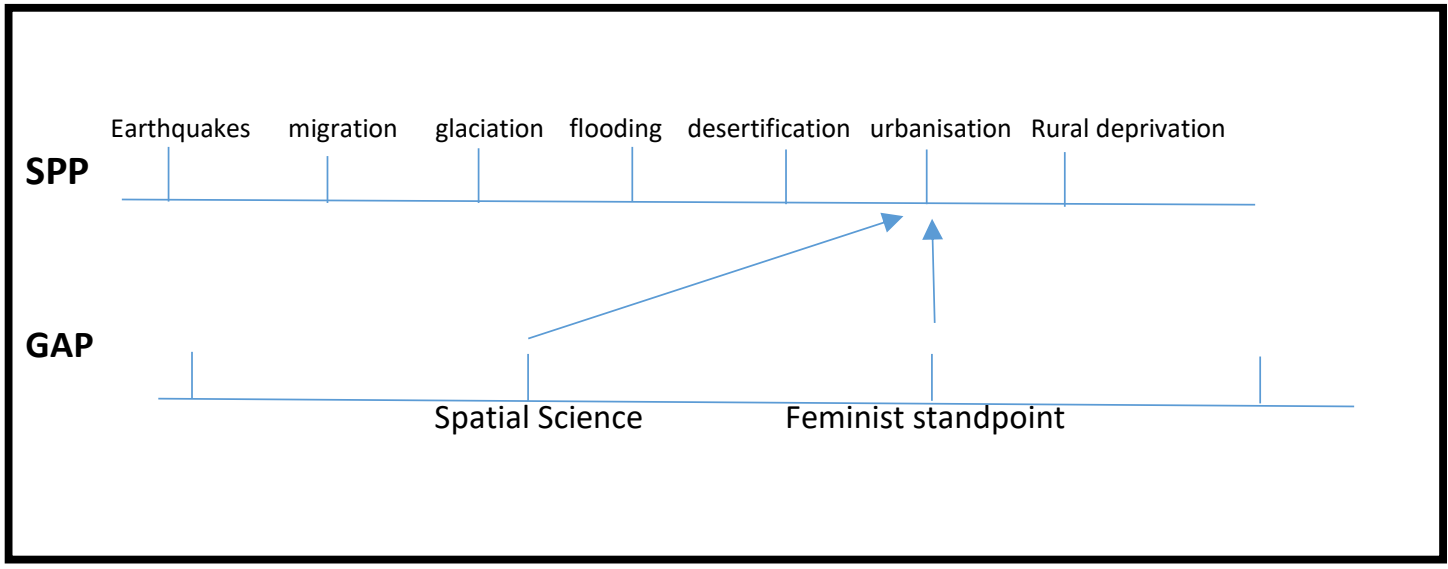

Figure 4.3: Visualising the segmented knowledge structure of geography

Following Figure 4.3, a spatial science approach might effectively map the proliferation of favela (shanty town) development on the edge of Brazilian cities but tell us very little about the experiences of people living in such places. A feminist standpoint perspective, however, may seek to examine the powers that shape the experiences of women living in such places. ${ }^{10}$ In both of these examples, the difference in what Bernstein calls the 'general approach' of the segmented structure is underpinned by very different assumptions about the nature of knowledge, which generate quite different methods of inquiry. My aim in this study was to expose teacher and student learning to a broader range of perspectives in order that the variegated nature of geographical knowledge could be explored.

Now that I have presented the theoretical influences behind the relationship between knowledge production and perspectives, the remainder of this chapter explores theoretical influences related to school curriculum and pedagogy.

\footnotetext{
${ }^{10}$ As post-modern approaches took hold of academic geography, feminist standpoint theories lead to increasing segmentation of languages as the intersections of, inter alia, socio-economic status, ethnicity, sexuality, age, and dis/ability were explored.
} 


\subsection{School geography as a micro 'curriculum of engagement'}

Firth (2013) identifies the "curriculum of engagement" (p.64) as a subject based curriculum which emphasises the structure of knowledge and challenges students to explore the nature of disciplinary knowledge. Rather than applying this concept to an entire curriculum experience, I am working on the assumption that geography's theoretical breadth has enough latitude for the concept to be applied to this single school subject.

Firth's curriculum of engagement concept draws heavily from Young and Muller's (2010) work, which seeks to present social realist theory as a counterpoint against both traditionalist and progressive conceptions of knowledge. For example, Maton (2014) describes a social realist view of knowledge as, "[a]gainst positivism, knowledge is understood as inescapably social and historical but, against constructivism, knowledge is not reduced to social power alone, as some knowledge claims have greater explanatory power than others" (p. 11, my emphasis). Social realist accounts point out that in contemporary education policy, curriculum and pedagogy have become blurred, leading towards 'constructivism' extending beyond its Vygotskian origins as a learning theory, to imbue conceptions of curriculum and knowledge itself (Maton, 2014b; McPhail \& Rata, 2016; Young, 2008). In a constructivist education environment, knowledge is rejected as a product in favour of a process that can perform to meet the needs of the 'knowledgeeconomy' (see, for example, Gilbert, 2005). Consequently, as described in Chapter 2, catering for ' $21^{\text {st }}$ century learners' has resulted in knowledge becoming relegated in curriculum policy and procedural approaches such as 'learning to learn', 'key competencies', 'inquiry learning' and 'student-centeredness' have been foregrounded instead. Furthermore, constructivism understands knowledge as a power struggle between dominating and subordinated groups. My focus on theoretical perspectives does speak to the social production of knowledge, but also that different perspectives are independent from the discourse of the knower, as represented by their respective strengths and limitations.

The curriculum of engagement concept is Firth's (2013) manifestation of what Young and Muller (2010) call a Futures 3 [F3] educational scenario, which is their response to the underlying problems of traditionalist (F1) and constructivist (F2) curriculum (see Figure 
4.4). The problem of both traditional and progressive accounts of knowledge, according to Young and Muller (2010), is what they view as an 'epistemological dilemma', in which knowledge is either considered an immutable truth to be discovered ('under-socialised'), or alternatively as an arbitrary construct that is no more than a reflection of societal power relations ('over-socialised). The educational dilemma that arises from this epistemological dilemma is the emergence of 'unpalatable' curricula: academic-rationalist types of curriculum [F1] or generic-skills based curriculum [F2] in which the differences in powerful disciplinary knowledge are rendered invisible to the student.

In Figure 4.4 I have used a visual metaphor to convey that the social realist Futures-3 scenario bridges the ontological and epistemological binaries of the Futures-1 and Futures2 scenarios. A key tenet of the social realist F3 view aligns with Pring's (2015) appraisal of the enduring power of disciplines, not because they somehow maintain their privilege by vested social interests (a Futures-2 critique of Futures-1), but because:

These 'bodies of knowledge' are the theories, propositions and explanations which have accumulated through enquiry, criticism, argument and counter argument. They are what have survived testing and criticism. They are, as it were public property. Indeed, their credentials depend on them being open to public challenge and refutation. (Pring, 2015, p. 99)

Embedded in 'curriculum of engagement' is Young's (2008; 2009; 2013) concept of powerful knowledge. ${ }^{11}$ Young argued that subjects which draw upon the disciplines offer the most reliable intellectual apparatus for students to make sense of their world. Furthermore, these powerful knowledges are, Young (2009) argued, the province of specialist teachers in schools, the implicit argument being that specialist teachers are intellectuals and given the chance to stimulate students engagement with such powerful knowledges. According to Young, every-day experiences cannot offer the platform for powerful knowledge to develop, because that form of knowledge is context-dependent and does not access the opportunities for conceptual transfer (i.e. context independence) that the structures of powerful knowledge are able to provide.

\footnotetext{
${ }^{11}$ Not to be confused with 'knowledge of the powerful' which was a construct of early 1970s socialconstructivist arguments, of which Young was originally a key advocate! His turn to social realism is a reevaluation of the advantages that access to disciplinary-infused school subjects bring young people.
} 


\begin{tabular}{|l|l|l|l|}
\hline & $\begin{array}{l}\text { F1: Absolutist/ } \\
\text { Positivist orientation to } \\
\text { knowledge }\end{array}$ & $\begin{array}{l}\text { F3: Social Realist } \\
\text { orientation to knowledge }\end{array}$ & $\begin{array}{l}\text { F2: Social constructivist } \\
\text { orientation to knowledge }\end{array}$ \\
\hline Ontology & $\begin{array}{l}\text { Reality is based on 'truths' } \\
\text { which exist independent of } \\
\text { what is thought about it. }\end{array}$ & $\begin{array}{l}\text { Reality exists independent of } \\
\text { human thought, but human } \\
\text { perception shapes that reality. }\end{array}$ & $\begin{array}{l}\text { Reality is constructed by the } \\
\text { situatedness of people. }\end{array}$ \\
\hline Epistemology & $\begin{array}{l}\text { Objective: Knowledge is } \\
\text { immutable, transcendental } \\
\text { and certain. What we know is } \\
\text { mimetic to reality. }\end{array}$ & $\begin{array}{l}\text { Objective judgementalism: } \\
\text { Knowledge has emergent powers, } \\
\text { yet is fallible, and regulated by } \\
\text { systematised critique. }\end{array}$ & $\begin{array}{l}\text { Relativist: All knowledge is socially } \\
\text { produced and therefore of equal } \\
\text { standing. What we know is } \\
\text { interpretation. }\end{array}$ \\
\hline $\begin{array}{l}\text { Typical } \\
\text { Curriculum } \\
\text { 'Canonical' texts } \\
\text { representing the best } \\
\text { knowledge humanity has } \\
\text { accumulated over time. } \\
\text { Strong boundaries between } \\
\text { subjects. }\end{array}$ & $\begin{array}{l}\text { Curriculum of engagement } \\
\text { Subject based curricula emphasises } \\
\text { challenging students to explore the } \\
\text { nature of disciplinary knowledge. }\end{array}$ & $\begin{array}{l}\text { 21 st Century Progressive } \\
\text { 'Skills'/ 'competency' based as no } \\
\text { knowledge is more important than } \\
\text { others. Integrated curricula are } \\
\text { promoted (weaker classification). } \\
\text { Learning rather than knowledge } \\
\text { emphasised. }\end{array}$ \\
\hline
\end{tabular}

Figure 4.4: Three conceptions of knowledge and curriculum (Adapted from Firth, 2013, and Young \& Muller, 2010)

In an operationalisation of powerful knowledge (see Table 4.2) Maude (2015) has identified five broad types of powerful knowledge to "give young people intellectual abilities that they are unlikely to learn from their everyday lives" (p. 18). My research into disciplinary-consciousness connects specifically with the third of Maude's (2015) powerful knowledge types: "Being critical of knowledge and the authority on which it is based" (p. 22). As Maude indicates, this focus is important because "students need to know something about the ways knowledge is developed and tested in geography...this is about being able to answer the question: how do you know?, an underdeveloped area of geographical education" (Maude, 2015, pp. 22-23). While reflecting on the origins and date of source material is a reasonably common feature of school geography, a disciplinary-conscious approach extends this strand of Maude's powerful knowledge framework. By exploring paradigms and perspectives, it allows students to engage with the 
strengths and limitations of how knowledge is produced allowing for disciplinaryconsciousness to complement Maude's (2015) meta-cognitive intention.

Table 4.2: Powerful knowledge in Geography (based on Maude, 2015, 2016)

\begin{tabular}{|c|c|}
\hline Powerful knowledge type & Description \\
\hline 1. Meta-concepts & $\begin{array}{l}\text { Knowledge that provides students with 'new ways of thinking } \\
\text { about the world' }\end{array}$ \\
\hline $\begin{array}{l}\text { 2.Analytical and substantive } \\
\text { concepts }\end{array}$ & $\begin{array}{l}\text { Knowledge that provides students with powerful ways of analysing, } \\
\text { explaining and understanding }\end{array}$ \\
\hline $\begin{array}{l}\text { 3. Being critical of knowledge and } \\
\text { the authority on which it is based }\end{array}$ & Knowledge that gives students some power over their own learning \\
\hline 4.Issues-based knowledge & $\begin{array}{l}\text { Knowledge that enables young people to follow and participate in } \\
\text { debates on significant, local, national and global issues }\end{array}$ \\
\hline 5.General knowledge & Knowledge of the world, of the 'capes and bays' variety. \\
\hline
\end{tabular}

\subsection{Disciplinary-conscious pedagogy}

To help frame the pedagogical aspect of my research, I bring together the work of key authors focused on disciplinary-conscious approaches to teaching and learning discussed in the literature review: Puttick's (2013) framework for teaching theoretical perspectives; Hodson (2014) learning about science; Moje (2015) disciplinary literacy; and Sazama (2015) and Isaac (2017) literary perspectives/theory. Following my exploration of some of the very practical suggestions that these authors have offered in Chapter 3, the key aspects that I focused on to think about approaches to teaching were:

- Select from range of perspectives (Puttick, 2013; Sazama, 2015; Isaac, 2017)

- Identify key characteristics of the perspective (Puttick, 2013; Hodson, 2014; Isaac, 2017)

- Introduce key theorists / scholars and explore historical, social and political context that gave rise to perspectives (Hodson, 2014; Sazama, 2015; Isaac, 2017)

- Analyse and use language features of perspectives (Hodson, 2014; Puttick, 2013; Isaac, 2017; Moje, 2015)

- Develop aspects of geographical inquiry (e.g. posing questions, collecting, analysing, and communicating data) aligned with a perspective (Moje, 2015; Puttick, 2013) 
By focusing on pedagogy, my attention to perspectives and paradigms as a manifestation of geography's segmented knowledge structure takes me to a rather different focus than the extant debates about school geography and its relationship with knowledge. My rationale for teachers getting to grips with paradigms and perspectives is because it adds to the foundational architecture of the development of the subject, which is necessary (albeit not sufficient) to support young people to make sense of the multiple ways of seeing that have developed in the discipline.

\subsection{The teacher as sense-maker}

My theoretical framework is circumscribed by attention to the teacher as sense-maker. This is because I am focusing on how geography teachers come to understand a curriculum policy message about developing students' understanding of theoretical perspectives in relation to the production of geographical knowledge. To do this, I draw upon the work of Spillane, Reiser and Reimer (2002), who offer a sense-making framework, based on several years of mathematics curriculum and pedagogy implementation research, that described how implementing agents are likely to interpret changes in their behaviour in response to the interaction between: (i) the policy message; (ii) embedded schemas in teachers' personal epistemologies; and (iii) the situated context. The sense-making framework, is therefore, attentive to both top-down and bottom-up perspectives: because the policy messages and the manner in which policy documents represent the messages are influential in implementing agents' understanding of them... [and] also implementing agents' scripts or schemata, coupled with their situations, are fundamental constituting elements in the sense making process.

(Spillane et al., 2002, p. 420)

According to its authors, the sense making framework complements traditional interpretations of policy implementation which tend to focus on factors such as implementers' wilful avoidance of policy directives, lack of individual capacity or lack of resources. Spillane et al. (2002) contend that a more nuanced understanding of individual sense making is required to recognise that policy implementers 'at the street level' have a genuine intent to engage with policy changes. The framework recognises, however, that there is a complex suite of personal and social cognition factors that increase or lessen the 
chance of individuals "to think differently about their behaviour, prompting them to raise questions about their existing behaviour and encouraging them to construct alternative ways of doing business" (p. 421). In the following sections I outline aspects of the three broad elements of the sense-making framework.

\subsubsection{The 'policy' message}

Policy messages are produced through multiple sources (Aitken, 2006). As I have previously described, the first clear statement towards explicit disciplinary-consciousness towards geographical knowledge was presented in the 1999 BOGT position paper. This curriculum policy message has been filtered to current online geography curriculum guides (see MoE, 2013c), although it is unclear how transparent this message is through the wide range of curriculum and assessment materials available to teachers. Consequently, the messaging of perspectives as a tool for disciplinary-consciousness is the focus of my first phase of empirical research. With policy messages emanating from different sources, the chance for differences in interpretation were reasonably high.

Spillane's (2004) research stresses the importance of the wording of policy messaging to influence sense-making. His work suggests that all policy needs a rationale to be communicated in order that implementing agents can see beyond the surface features. This may be enhanced by framing the policy with explicit attention to implementing agents' pre-existing schemata about the policy. Spillane et al. (2002) identify some of the tensions in messaging of policy, with particular emphasis on offering general principles and specific examples. More abstract communication can offer deeper messages about the intention of the policy, but can also be "very susceptible to being understood in superficial and idiosyncratic ways" as a result of teachers' existing schema (p. 416). Spillane et al. (2002) question the efficacy of one sentence statements of goals, but also point out that accompanying essays or vignettes to illustrate the reform ideas are not commonly available.

A further tension that Spillane (2004) highlights is the need to avoid signalling so much dissonance that it triggers rejection. The Goldilocks Principle of getting it 'just right' matters, in the sense that teachers need to see the problems in their current practice in order 
for accommodation of practices rather than assimilation. Developing the dissatisfaction in their own behaviour is a necessary lever for reinterpretation of one's practices, but if the policy message is too negative then teacher's self-affirmation will likely lead to critique of the policy.

\subsubsection{Embedded schemas in teachers' personal epistemology}

No teacher is a tabula rasa. Rather, Spillane et al. (2002) point towards the embedded knowledge and beliefs borne through experience that act as a lens through which interpretations are made. Therefore, according to these authors, sense-making is not a simple process of encoding but the "active attempt to bring one's past organisation of knowledge and beliefs to bear in the construction of meaning from present stimuli" (p. 394). When cognitive knowledge structures bring related concepts together to make sense of the world, individuals develop schemas which help make sense of the complexities of everyday phenomena. The way in which these schemas become deeply embedded, especially as they tend to conserve pre-exiting views of the world (i.e. Piaget's concept of assimilation), leads to development of hard to change 'scripts' about how the world works. The role of experience in the practical world of teaching also produces tacit knowledge, which may be at odds with new policy messages.

On the development of schema, fuelled by obdurate knowledge, beliefs, experience and frames, Spillane et al. (2002) suggest two significant policy implementation implications. First, is that when confronted by new ideas, the conserving role of pre-existing schema means that implementing agents see new ideas as familiar ones. Secondly, new ideas can be integrated without significant restructuring of schema. Consequently, teacher cognition can look for 'low-hanging fruit' by honing in on superficial features of the policy initiative without grasping some of the deeper fundamental reasons for the policy.

Following on from the significance of history in sense-making, individual cognition is not solely determined by embedded schema, but shaped also by emotion. Past policy initiatives may have produced adverse emotional responses as teachers failed to decipher abstract and unclear policy messages leading to anxiety, confusion and 
frustration. Policy direction often has impact on teaching and learning, which seeps into implementing agents self-image as teachers (Spillane et al., 2002). Emotional responses to reform can lead to cherry picking of ideas that confirm to teachers' emotional bias to reform (either positive or negative), while preservation of self-image may similarly have either positive or negative outcomes on policy sense-making.

\subsubsection{Teacher sense-making is also situated}

The range of meetings that teachers attend, whether in a school subject-department, with a wider group of subject specialists from other schools, universities, and/or industry, or in informal social media networks, are likely to develop social cognition. That is, while knowledge and belief schemas are important from an individual cognitive perspective, activity structures can help give insight to social interaction (Spillane et al., 2002). Sensemaking is distributed in the interactive web of agents (including teacher-student interactions) and allows for insights to emerge that might otherwise have been invisible if only an individual cognition approach were taken to sense-making research. Like individual cognition, situated contexts have multiple dimensions and implications, to which I now turn.

Situated cognition suggests that teachers can benefit from their frequent and ongoing deliberations with other teachers and subject experts, while also using material resources or artefacts to support deliberations. Remaining isolated tends to lead to the superficial changes described in Section 4.6.2. There is no guarantee, however, that a situated network will produce the desired policy implementation outcomes. Given the social nature of situated cognition, language is the chief medium through which new ideas are discussed, which is hindered by the imprecision of the tool (Spillane et al., 2002). Teachers can use the same policy language to represent ideas that do not align with the policy.

Emotions and values also permeate social sense-making processes. The opportunity to network is in itself well regarded by teachers, who value the appreciation and acknowledgement that participation in these networks may bring. However, the strong personal ties and shared belief and values that can be seen to unify social groups can also be barriers to open dialogue (Spillane et al., 2002). The bonds of friendship and 
collegiality can lead to avoidance of disagreement and conflict, which may well be the stimuli required to consider alternative ideas required for greater alignment to policy initiatives. It is clear therefore, that if difficult conversations are to be valued between colleagues, suitable levels of trust need to be developed between the implementing agents.

Situated cognition also emerges from practice. As detailed by Spillane et al. (2002), action can precede understanding, as well as be driven by understanding. This is of particular pertinence to the lesson study phase of my research, which by its design, is a practice driven approach to PLD from which understandings may emerge (see Chapter 5). In this way I am following Spillane et al.'s (2002) contention that the system for providing sense making support is as critical as the content of the message: "there is a critical need to structure learning opportunities so that stakeholders can construct an interpretation of the policy and its implication for their own behaviour" (p. 418).

\subsection{Chapter summary}

The substantive focus of my study is connected to a disciplinary-conscious geography that echoes the social realist view of a Futures 3 'curriculum of engagement' in which students are challenged to explore the nature of disciplinary knowledge (Young \& Muller, 2010; Firth, 2013). To be able to differentiate between paradigms and perspectives, and in keeping with a social realist view of knowledge, teachers need to know something about the development and structure of geographical knowledge. I have advanced Bernstein's $(1999,2000)$ account of segmented knowledge structures as a strong theoretical idea to hang the focus of my research, not least because he articulates the General Approach Plane, upon which paradigms and perspectives clearly map.

My theoretical framework necessarily also draws upon ideas more closely related to the classroom level. Therefore, I have drawn upon Puttick's (2013) conceptual model for looking-at and looking-along a perspective, which gives some specific pedagogical guidance for geography teachers contemplating taking an explicit approach to teaching about the development of geographical thought. Conscious that Puttick's model is a ground-breaking intervention on the enactment of disciplinary-conscious geography, I 
have, nevertheless, also drawn upon a wider number of models through which to analyse the lesson study phase of my research.

Finally, my theoretical framework has also drawn upon a model of teacher sense-making (Spillane et al. 2002). The attraction of this model was because it attended to the policy signal - which I explore through a document analysis of curriculum and assessment materials - as well as the cognitive processes (individual and social) that influence teachers' understandings and reactions to those policy signals.

In the next chapter I present the methodology of my research. 


\section{Chapter 5: Research Methodology}

\subsection{Introduction}

In this chapter I present the methodological account of my study which explains the overall design approach and the related methods utilised. The study used an exploratory sequential design, framed around a case study of implementing a disciplinary-conscious approach to teaching and learning geography. An overview of the key questions and the methodological approach taken are presented below (Table 5.1).

Table 5.1: Overview of the research design

\begin{tabular}{|c|c|c|}
\hline Sequence & Focus Research Question & Key methodological approach \\
\hline Phase 1 & $\begin{array}{l}\text { To what extent have curriculum and } \\
\text { assessment materials signalled a } \\
\text { disciplinary-conscious orientation to } \\
\text { perspectives, since the publication of } \\
\text { the } 1999 \text { BoGT position paper? }\end{array}$ & $\begin{array}{l}\text { Document analysis of } \\
\text { 'Perspectives' in the Official } \\
\text { Recontextualising Field. } \\
\text { Conclusions triangulated across } \\
\text { multiple source documents. }\end{array}$ \\
\hline Phase 2 & $\begin{array}{l}\text { How do geography curriculum and } \\
\text { assessment specialists view the value, } \\
\text { place and role of disciplinary } \\
\text { perspectives in New Zealand secondary } \\
\text { school geography? }\end{array}$ & $\begin{array}{l}\text { E-survey of geography education } \\
\text { specialists' views of 'perspectives' } \\
(n=12) \text {. Conclusions triangulated } \\
\text { across participants. }\end{array}$ \\
\hline Phase 3 & $\begin{array}{l}\text { What are the outcomes of a lesson } \\
\text { study collaboration focused on } \\
\text { expanding teacher and students' } \\
\text { disciplinary-consciousness? }\end{array}$ & $\begin{array}{l}\text { A lesson study collaboration with } \\
\text { two teachers of explicit } \\
\text { disciplinary-conscious teaching } \\
\text { Conclusions triangulated across: } \\
\text { 1) Lesson planning recordings } \\
\text { 2) Teacher Interviews } \\
\text { 3) Lesson observations } \\
\text { 4) Student focus groups }\end{array}$ \\
\hline
\end{tabular}

In this chapter I first give the background theory of the interpretive paradigm of qualitative research and why this is a suitable approach for this study. I then give an explanation of the study as a bounded sequential case-study of the implementation of disciplinary- 
conscious geography teaching and learning. These two aspects combined give the broad research tradition in which this study is located, after which I focus on the research methods I employ in different phases of the research. The range of research methods involved in the three phases of empirical data collection and analysis are varied, including document analysis, a questionnaire survey, semi-structured interviews, naturalistic planning meetings and observations of teachers and students explicitly exploring disciplinary perspectives in a sequence of lessons.

\subsection{The interpretive paradigm of educational research}

An interpretive approach was adopted for this study. This was because the investigation focused on a problem of curriculum representation and teaching practice, in which I explored how geography teachers and their students might explicitly engage with a disciplinary-conscious approach to teaching and learning. In such an interpretive process the researcher must share the frame of reference of the subject and come to understand the individual's interpretation of the world if they are to make sense of their actions (Cohen, Manion, \& Morrison, 2003). Different lines of sight can lead to alternative interpretations, hence the need for a rich description in which my own role and impact is acknowledged. The data in this study are predominantly qualitative, with language playing a key role as an instrument through which the world is represented and constructed. Qualitative research of the type found in this study gives insights into, and understanding of, people's behaviour rather than describing universal truths that are typically found in research of positivistic character (Cohen et al., 2000; Robson, 2002). Creswell's (2009) definition of qualitative research presents the process for exploring and making sense of the meanings that individuals or groups ascribe to a social problem:

The process of [qualitative] research involves emerging questions and procedures, data typically collected in the participant's setting, data analysis inductively building from particular to general themes, and the researcher making interpretations of the data. The final written report has a flexible structure. Those who engage in this form of inquiry support a way of looking at research that honours an inductive style, a focus on individual meaning, and the importance of rendering the complexity of a situation (Creswell, 2009, p. 4). 
Philosophical beliefs underpin the qualitative framework of this study, which shape my view of the world and how I act upon it. According to Denzin and Lincoln (2000), this means that I am effectively "bound with a net which contains [my] epistemological, ontological and methodological premises [which] may be termed a paradigm or an interpretive framework" (p. 19). This is, of course, the idea of paradigms and perspectives that I am also exploring at the school level. In terms of this educational research I assume a realist ontology (there is an external reality of policy messaging and teacher collaboration), a subjectivist epistemology (the participants in the research co-create understandings) and a largely naturalistic (meetings and classroom interactions) set of methodological procedures.

In broad terms, this research is a social realist account. I justify my view on this by making the distinction between my view of reality (ontology) and how I seek access to that reality (epistemology). Ontologically, my research assumes a realist orientation, positioning the policy documents, teacher meetings, and subsequent lessons as objective 'facts'. They existed and were not merely arbitrary words. While objective documents such as curriculum and assessment guidelines undoubtedly exist, individuals who have situated views of the world write them. Moreover, the people who read such documents also make subjective interpretations of such documents. Furthermore, and crucially for epistemological clarity, as the researcher I am the primary instrument of data collection. Thus, qualitative methodologies require that I identify my key "personal values, assumptions and biases that might influence the research process at the outset of the study" (Creswell, 1994, p. 163).

As noted in Chapter One, I have a history of teaching geography, as well as working for an organisation with a commitment to Initial Teacher Education. This means that a sense of 'objectivity' - a key tenet of positivist research - is subject to immediate scrutiny. My current position on the New Zealand Board of Geography Teachers and active involvement in a provincial geography teachers' association also signals my commitment to working with geography teachers. As such, I am well positioned to work with participants to understand their beliefs, opinions, and practices in the implementation of theoretical perspectives in the teacher education context (Creswell \& Plano Clark, 2011). 
Nevertheless, I also entered the study with a range of assumptions and biases, which may cloud my own vision. For example, and as also noted in Chapter One, I have been concerned with the recent constructivist trends that seem to have marginalised teacher discussion about the nature of geographical knowledge.

Methodologically, my approach relied on the use of multiple sources of information to explore and understand realities, ultimately as they appeared in the natural setting of teacher lesson planning and classroom interactions. This is in keeping with the view expressed by Patton (2002) who argued that qualitative research primarily utilizes three methods of collecting information, namely: "in-depth, open ended interviews, direct observation and written documents" (p. 4). The subjectivity of these different sources of data provided different meanings, therefore, my task was to discover the meanings attached to that information and to reassemble them. Thus, for a study invested in understanding participants' perceptions and experiences regarding the recontextualisation of disciplinary perspectives in school geography, a critical interpretive stance was appropriate.

\subsection{A sequential case study design}

Case-study design is an approach widely used in education research to illuminate problems of practice. Merriam (2001) described case study as "intensive descriptions of a single unit or bounded system" (p. 19), and although Gerring (2007) similarly defined case study as "the intensive study of a single case where the purpose of that study is - at least in part - to shed light on a larger class of cases" (p. 20) he also acknowledged the "definitional morass" (p. 17) of the appellation 'case study' in the wider research literature. Yin (2014) whose influence on the case study field spans four decades, offers a two-fold definition of case study, which includes: 1) the scope of a case study: an empirical, in-depth enquiry of a contemporary phenomenon, in which the boundaries between phenomenon and real world context are not clearly delineated; and 2) the features of a case study - in which variables of interest are greater than number of data points; multiple sources of evidence are required to triangulate; and theoretical frameworks used to guide data collection and analysis (p. 16-17). 
The bounded nature of this study was centred on a disciplinary-conscious approach to teaching and learning geography, through the recontextualisation of the key curriculum concept of 'perspectives'. The 2001 start date of the case study was not long after the publication of the NZBOGT position paper in which a disciplinary-conscious approach was first mooted, and also the year in which all senior geography teachers who attended national PLD workshops would have received the NZQA published notes about theoretical perspectives. The lesson study series was conducted in 2015, and therefore was a suitable endpoint of analysed materials. ${ }^{12}$

All three phases of empirical research were embedded into the case study (Grünbaum, 2007), so that I had three distinct units of analysis: curriculum and assessment materials; geography education specialists; and the lesson study collaboration comprised of teachers and students. This makes clear the notion that although the bounded case-study might be a focus on the singular, the evidentiary base upon which my research design was based is plural (Gerring, 2007). In Phase 1, I explored how perspective has been communicated to teachers in curriculum and assessment materials, and Phase 2 focused on geography education specialists' views of perspectives. The third phase explored teaching Year 12 and 13 students about urban geography in a disciplinary-conscious way. This unit of analysis was structured diachronically (Gerring, 2007, p. 27), as embedded within the lesson-study collaboration were multiple observations of teacher and student activity over time. As this aspect of the curriculum design was based in the pedagogical recontextualising field, I was also able to draw upon the specifics of the teachers and their students to exemplify the overall case study. I had initially intended to present case profiles (Simons, 2014) for individual students as well as the teachers, but over the course of the research it became clear that there would not be enough data from individual students to present a robust enough case profile. For this reason, I presented the student findings as a single group. This, in part, also influenced the decision to conduct a student focus group at the conclusion of the research, rather than conduct individual interviews. The case profiles of the two teachers did not detract from the fact that "The program is still the main focus of analysis, but, in exploring how individuals play out their different roles

\footnotetext{
${ }^{12}$ Any 2016 examiner reports analysed related to 2015 student assessments.
} 
in the program, we get closer to the actual experience and meaning of the program in practice" (Simon, 2014, p. 459).

By focusing on small numbers of participants, I was not seeking generalisability, but following much case study research I sought in-depth understanding from the particular. I drew upon the case study methodology literature that asserts that generalisations can be derived from small-scale qualitative studies in the form of 'fuzzy' generalisations (Bassey, 1999), theoretical generalisations (Stake, 1995), reader generalisability (Merriam, 1998) and analytic generalisations (Yin, 2003).

\subsection{Ethical considerations}

The proposed research involved confidential data and various ethical considerations at multiple levels. While the data carried some risks to privacy, minimal potential harm to individual teachers and students existed in this proposed research. This is because the project gathered data from human participants responding to interviews and focus-groups as well as collected evidence on teacher practices and student outcome data during the lesson study series. It was essential therefore, that participants had the ability to comprehend the implications of giving their consent (Rapley, 2007), while understanding that the lesson study was an effort to enhance and deepen geography teaching and learning experiences.

The Victoria University of Wellington Human Ethics Committees (VUWHEC) reviewed my research proposal to ensure that my work met all statutory and ethical guidelines involving human subjects (see Appendix A, HEC approval \#20841). In my original proposal, this focused on the lesson study component of my research. After my Phase 1 document analysis, however, I judged that simply giving an account of the current positioning of the key concept of 'perspectives' in curriculum and assessment would not suffice. I also needed to hear from geography educators responsible for influencing curriculum and assessment and what scope there was for developing disciplinaryconsciousness in the future. Therefore, I submitted an amendment to my original ethics application in order to develop the e-survey to this influential group of geography educators (Phase 2, Table 5.1). 
For the Phase 3 lesson study, and in line with existing practice of VUW Human Ethics Committee, consent forms were distributed first to Te Awa High and Ruamoko College principals, then Sacha and Michelle (pseudonyms), and finally the Year 12 and 13 students who were potential participants in Phase 3. These consent forms establish confidence that all ethical issues are considered and addressed to protect the privacy of those involved; the confidentiality of the data; the cultural safety of all participants; and to protect against the potential for harm that may arise from research involving human participants.

Confidentiality was required at all times. In terms of reporting, pseudonyms are used to conceal personal and school identities. Some students offered their own pseudonyms, which have been used, while others indicated they were happy to have any name assigned to them.

\subsection{Research methods}

This section outlines a range of specific tools designed to collect data pertinent to the research questions. In the tradition of interpretive qualitative research these methods are largely oriented to the written and spoken word as the sources of information. In order to assist the reader, the research methods are presented in order of the three phases of the overall research design. Within each phase I not only detail the data collection methods but also methods of analysis.

\subsubsection{Phase 1: Document analysis of 'perspectives'}

This section specifically addresses the first research question: Since the publication of the 1999 BoGT position paper, to what extent have curriculum and assessment materials signalled a disciplinary-conscious orientation to perspectives?

To remind the reader, the position paper Future directions of Geography education and assessment for 2001 and beyond (NZBoGT, 1999) was the first overt statement which recommended an approach to the concept of perspectives in both a socio-cultural sense in which the focus would be "...on the role of space, place and culture in relation to different groups..." (p. 25) and a disciplinary-consciousness, which supports "developments in approaches and methodologies in geographic study consistent with those currently used by academic and professional geographers" (p. 19). An assumption of the Phase 1 research 
was that if teachers were to be clear about a disciplinary-conscious approach to geography, then curriculum messages should, as much as possible, use unambiguous words and phrases, while the use of definitions, examples or explanations should make the distinctions of usage as clear as possible (Spillane et al., 2002).

In order to analyse the signalling of perspectives to teachers, I took a curriculum content analysis approach. Content analysis is an umbrella term for a range of procedures to study the content and themes of written or transcribed texts, in my case materials associated with New Zealand's official geography curriculum and assessment materials. The assumption of content analysis is that texts can reveal cultural forms of expression, which means that content analysis is concerned with social reality (Bos \& Tarnai, 1999). In this study, I was particularly keen to see the way(s) in which perspectives were framed. To this end, the content analysis aimed at differentiating among the various meanings of 'perspective' in curriculum and assessment materials, treating the concept as a homograph (Insch, Moore, \& Murphy, 1997). In order to make a judgment on the signalling of perspectives to teachers, it required examination of multiple source documents available to teachers. The scope and characteristics of these documents is described in the following section.

\subsubsection{Characteristics of the document sample}

During this phase, I initially surveyed 131 curriculum and assessment documents to analyse framings of perspectives, of which 61 were included in the final analysis. I based the initial sample of documents on the following selection criteria:

- Publicly available (currently on the internet or included in widely disseminated materials to geography teachers).

- Published between 2001-2015. The start date corresponded with NCEA materials made available to teachers before the introduction of the qualification. The end date corresponded with the year in which the empirical component of this thesis was conducted.

- Focused on Year 12-13 geography. The reason for excluding Year 11 materials was because the introductory level of senior geography curriculum and assessment focuses on basic viewpoints and values continuum rather than the more complex concept of perspectives (NZQA, 2015c). 
As the $N Z C$ is a document brief on detail, the curriculum document analysis included the web based New Zealand curriculum guide: geography ${ }^{13}$ (MoE, 2013c). These resource materials are 'second tier' support of the $N Z C$, designed to help teachers make informed curriculum decisions. In addition to these curriculum guides, the analysis included senior school assessment standards and associated materials as high stakes assessment in the senior secondary school is widely considered as de facto curriculum (Hipkins et al., 2016). Indeed, the vast majority of documents related to national qualification assessment standards. The modularisation of senior school assessment meant that I not only scrutinised each standard, but I also viewed examinations, exemplar answers, and examiner reports associated with each standard. While perspective is one of several key concepts assessed in school geography, it was clear that certain achievement standards regularly focused on the concept, while others did not. This helped me to clarify which particular assessment materials to include/exclude.

The initial document sample also included Scholarship assessment materials. Geography scholarship is awarded to the top 3\% of the Year 13 geography cohort who sit the examination, representing the 'best of the best' in student achievement (Chalmers, 2015). The high stakes scholarship examination demands application of skills and concepts derived from the two broad Year 13 achievement standards. A key feature of the Scholarship performance standard is that students should apply the concept of perspectives in their answers, which makes these documents a valuable component of the overall analysis. The initial collection of documents also extended to 'Top Scholar' ${ }^{14}$ exemplars published every second year since 2009. Annual Scholarship assessment reports were also selected, as these are a valuable source that act as a dialogue between chief examiners and teachers about aspects of student performance.

By including publicly available authentic exemplars of student work (for example, 'Excellence' standard work at NCEA level 2 and 3, and 'Top Scholar' exemplars), I could

\footnotetext{
${ }^{13}$ The web-based geography guidelines include links external to the website. Where these links are specific to perspectives I have included them in my document analysis, as I take their inclusion on the geography curriculum guides webpage as endorsement of their contents.

${ }^{14}$ The Top Scholar award is presented to the individual whose scholarship examination answer is considered to be the 'best of the best'.
} 
analyse how meanings of perspectives were legitimised, through the availability of high quality scripts. Such materials are important signposts for teachers, as they provide concrete examples of evidence that add detail to the more abstract language of NCEA achievement and Scholarship performance standards.

The remainder of documents were either background information or materials designed to be used as direct pedagogical supports in their classrooms. Examples of the former include the guidance notes on perspectives included as a (minor) part of NCEA implementation notes (Miller, 2001) and the more recent social science position paper (Mutch, Hunter, Milligan, Openshaw, \& Siteine, 2009). Examples of the latter included contemporary geography textbooks. Although text book material presents ideas that have been transformed from academic knowledge, I considered these to be of potential value, especially as publishers typically see it as a virtue to align textbook materials to what is valued in examinations (Lee \& Catling, 2015). It is worth noting that my sample of curriculum and assessment materials are not likely to be exhaustive, as it is entirely possible that there were local resources produced by teachers over a decade ago that I have not been able to access in the way that nationally available resources were.

After identifying potentially useful documents outlined above, I then narrowed this down by identifying those which explicitly included content focused on perspectives or the closely related perception. In this sense, the document sample was purposive, because I focused attention on documents that were able to provide material for analysis. Table 5.2 below shows the distribution of documents included in the content analysis. 


\begin{tabular}{|l|c|}
\hline \multicolumn{1}{|c|}{ Document } & $\begin{array}{c}\text { Number of source documents } \\
\text { selected for analysis }\end{array}$ \\
\hline New Zealand curriculum (2007) & 1 \\
\hline Geography teaching and learning guides (2013c) & 1 \\
\hline NCEA Level 2 \& 3 examinations (2005-2015) & 20 \\
\hline $\begin{array}{l}\text { NCEA L2 \& L3 internal and external achievement } \\
\text { standards (Based on 2013 Matrix) }\end{array}$ & 8 \\
\hline NZQA Approved L2 \& L3 internal assessment resources & 4 \\
\hline NCEA student exemplar answers (2012-2015) & 9 \\
\hline Scholarship performance standard & 1 \\
\hline Scholarship assessment reports (2005-2015) & 10 \\
\hline Top Scholar exemplars (2009;2011;2015) & 3 \\
\hline NCEA guidance notes (2001) & 1 \\
\hline Social Sciences Position Paper (2008) & 1 \\
\hline Geography text books (2011;2013) & $\mathbf{6 1}$ \\
\hline \multicolumn{2}{|c|}{ TOTAL } \\
\hline
\end{tabular}

\subsubsection{Document analysis procedure}

A key decision to make when undertaking content analysis was to determine the unit of analysis, or the basic unit of text to be classified (Krippendorff, 2004). 'Perspective' is clearly a singular word, its presence allowing me to identify parts of texts that required analysis. Since the message I examined about perspectives was varied, using words as units did not seem to be a reasonable choice: if I were to focus simply on the word I might limit myself by not analysing closely related phrases or sentences. Therefore, I chose the analysis to take place at the sentence level (Krippendorff, 2004). The fine-grained nature of sentence level units of analysis was achievable because the majority of documents focused on perspectives were relatively short. For example, examination questions were often only two or three sentences long, examiner reports typically gave a paragraph to perspectives, while the longer documents (at 3-4 pages in length) were manageable.

I took a deductive coding process to classifying the units into categories (Denscombe, 2007). Specifically, because I was testing the signalling of the messages about perspectives in relation to the 1999 NZBOGT position paper, I used this as a baseline to code two framings: 'stakeholder perspectives' [SP], and 'Disciplinary theoretical perspectives' [DTP]. The basis of coding these categorisations highlighted some key words. For 
example, words such as 'individuals', 'groups', 'organisations', 'perception', and 'decision-making' commonly appeared in the sentences that were SP categorised. For the DTP categorisation, words such as 'geographers', 'research', 'knowledge', 'disciplinary' and 'philosophical' typically appeared in wider sentence structures. The coded categories were piloted against a piece of text (see, for example, Figure 5.1), before I proceeded to code the selected sample of documents.

This required multiple readings of sentences to be certain that I had not missed text that was related to the idea of perspective and to ensure that the coding was accurate. I discovered through the pilot process, however, that although a 'best-fit' classification approach was mostly achievable, that some sentences required coding as 'ambiguous' [A], when perspectives could not be easily coded as SP or DTP. Equipped with this [A] code, as I analysed each sentence unit I was mostly able to make single classification calls of 'best fit', rather than be troubled by a great deal of uncertainty in each coding decision (Insch et al., 1997).

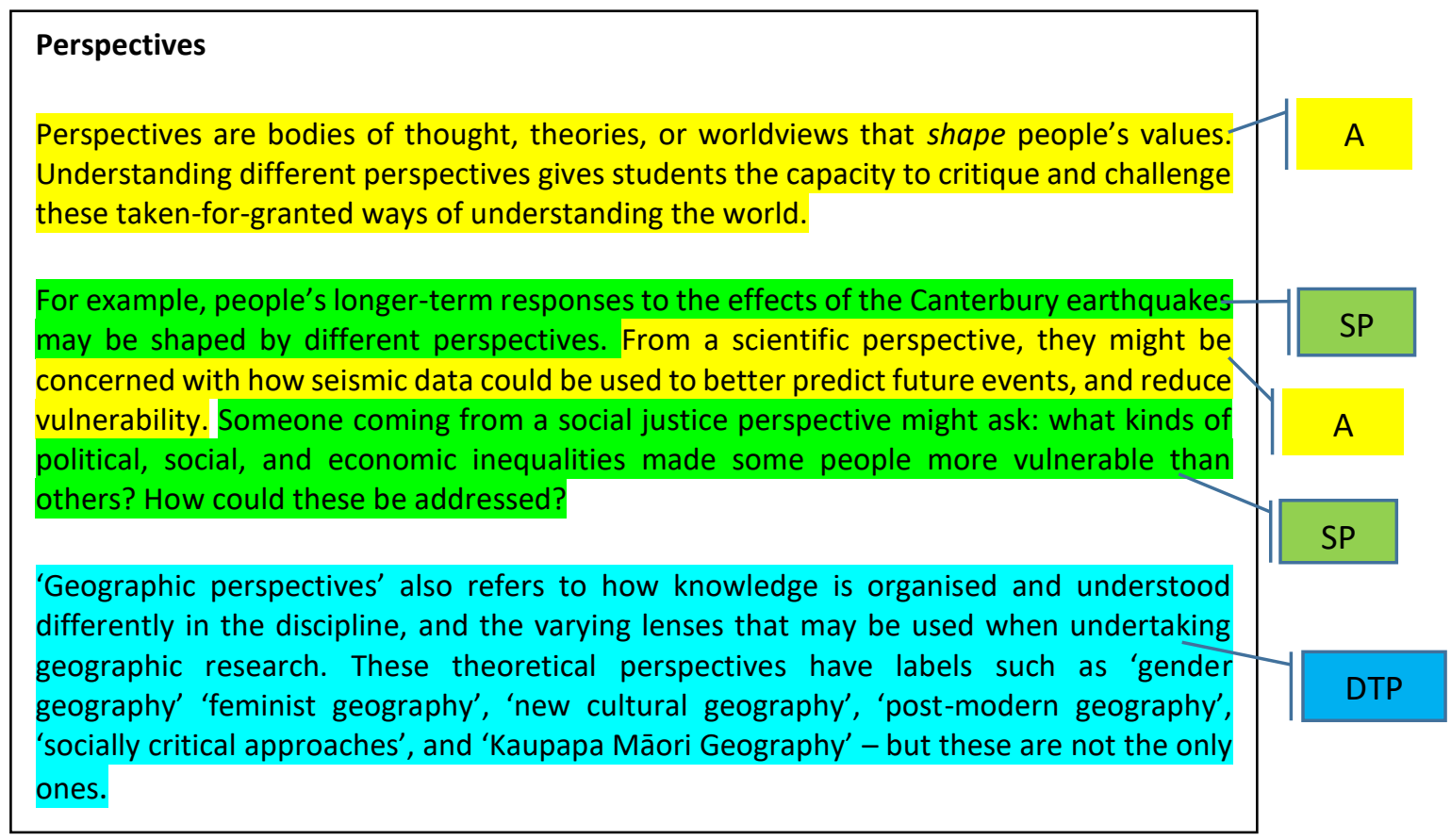

Figure 5.1: Coding categorisation in document analysis piloting 


\subsubsection{Strengths and limitations of document analysis}

While quite labour intensive, the sentence unit of analysis was appropriate for the types of document I was dealing with. Most of the documents were economical in their phrasing, because they had a pedagogical imperative to be succinct for student consumption (e.g., examination questions or textbook explanations). Even the more detailed resources for teachers (e.g., teaching and learning guidelines) were reasonably succinct, presumably because of the need to be digested quickly by busy professionals. In retrospect, if paragraphs were the unit of analysis, not too much would have been lost, although there were some examples in which different messages about perspectives were contained in the same paragraph. Therefore, the sentence unit of analysis allowed for identification of such nuances contained in paragraphs.

The perils of being overly constrained by a deductive approach to content analysis became apparent through one aspect of my analysis, in which there was an example of a (recurring) NCEA Level 2 examination question that clearly sought to assess student epistemological understanding. Yet in all bar one case, the question avoided explicit connection to the concept of perspectives, tending to focus on the analytical concept of 'measurement'. This drew my attention to the fact that simply focusing on the words perspectives and perception was in itself not always enough to guarantee that I had analysed all content about the nature of geographical knowledge. This precipitated repeated reading of the documents for messaging that was related to the nature of knowledge, but was not explicitly connected to the terms 'perspectives' and/or 'perception'. It transpired that it was only the NCEA Level 2 examination that had an epistemological focus without connection to the word 'perspectives'.

The findings of this first phase of the study are presented in Chapter 6 .

\subsubsection{Phase 2: Subject specialist e-survey}

My second research question was focused on the potential for disciplinary-conscious New Zealand school geography, and therefore necessitated a wide coverage of subject specialists who have influenced curriculum and assessment in geography. The question asked: How do geography curriculum and assessment specialists view the value, place and role of perspectives in New Zealand senior secondary school geography? 
I assumed that, because curriculum ideas are contested, negotiated, and mediated, that the variety of roles in the official recontextualising field may present different views on both the normative messaging of the concept 'perspectives'. The list of specialist roles I identified included: curriculum advisers/writers; exam writers and markers; internal assessment moderators; text book authors/resource writers; initial teacher educators; and professional development providers. The rationale for selecting such a group of educators was that such specialists are heavily invested in geography education and are likely to represent a group from where curriculum maintenance, change or modification is likely to originate. These were Bernstein's (1996; 2000) 'priests', responsible for the recontextualisation of knowledge in school geography education. Furthermore, such is the small size of the geography teaching community, that many of these specialists are also practising geography teachers in secondary schools. The intent of this questionnaire was to elicit views of the current role of 'perspectives' in school geography as well as the potential for developing a more disciplinary-conscious orientation to geographical knowledge production.

\subsubsection{Sampling procedure, access, and confidentiality}

A purposive sampling procedure identified 24 potential geography educators. Cohen, Manion and Morrison (2003) view purposive sampling as a means by which researchers can handpick cases to be included in the sample on the basis of their judgement as 'knowledgeable people'. In this regard, my interest in perspectives - especially its 'geographical approaches' orientation - required an engaged audience who were able to comment on matters of interest to me. This was not an exhaustive list as it was limited by my own knowledge and access to such people.

The ease of gaining access to the purposive sample varied significantly. An email to the NZQA, the employer of contracted exam writers and internal assessment moderators, confirmed that they had a policy of not making public the identity of exam writers in order to minimise possible exposure to disgruntled students and/or teachers. Clearly this policy meant that face-to-face interviewing was not going to be granted; thus a mechanism that allowed me to reach a difficult to access population under the cover of anonymity would be required (Cohen et al., 2003). A web-based questionnaire was decided as a suitable 
mechanism. An online questionnaire itself is not, however, sufficient to achieve anonymity. This is because the request to complete the survey needs to be distributed. Therefore, I contacted two NZQA managers with responsibility for examination and moderator oversight and asked their permission to forward the survey link to potential participants. The criteria for determining which individuals be contacted was also shaped by the document analysis in Phase 1, and encompassed:

- Geography scholarship exam writer and chief examiner;

- Geography NCEA Level 2-3 exam writer(s) and panel markers;

- Geography NCEA Level 2-3 internal assessment moderator(s);

The NZQA managers agreed that they would send the survey consent forms to the individuals with oversight for geography. Any returns from these individuals would be redirected through the managers so that anonymity could be secured.

The school geography education is a small community in New Zealand and thus accessing all other potential participants of the Phase 2 survey (other than those at NZQA) was achieved by sending a direct e-mail. This approach to accessing individuals meant that while their confidentiality was to be maintained throughout the research process, their anonymity to me was not.

All participants received a brief introductory email with a web link and password to access the actual survey. This approach is advocated in the e-survey literature as an effective means of attracting a purposive sample (Lumsden, 2007). The link took participants to a welcome page that outlined more fully the purpose of the survey, as well as online ethics information which outlined the confidential nature of returns and data aggregation assurances (see Appendix B). All potential respondents were informed that submission of a questionnaire was taken as acceptance of the informed consent agreement between the researcher and the participant. It is to the content of the questionnaire and the technical aspects (such as layout and presentation) that I now turn. 


\subsubsection{Questionnaire content and design}

The questionnaire was designed to establish the ways in which specialist geography educators interpreted the concept 'perspective'. The survey comprised of 13 questions, half of which requested detailed open-ended responses. The majority of the designed questions (see Table 5.3) explored the subject specialists' views on perspectives, and can be seen in full in Appendix B.

Table 5.3: Question theme and type in Phase 2 questionnaire

\begin{tabular}{|c|l|c|}
\hline Question & \multicolumn{1}{|c|}{ Theme } & Response Type \\
\hline $1 \& 2$ & Significance of concept & Multi-choice \& open \\
\hline 3 & Guidance on perspectives & Likert \& open \\
\hline $4-6$ & Pedagogy: application and progress of perspectives & Open \\
\hline 7 & Relevance of perspective types & Likert \\
\hline 8 & Disciplinary focus & Open \\
\hline 9 & Role Identification & Check \\
\hline 10 & Role specific responses to perspectives & Open \\
\hline 11 & Disciplinary focus & Percentage \& open \\
\hline 12 & $\begin{array}{l}\text { Approximate division between stakeholder and } \\
\text { epistemic orientations to perspectives }\end{array}$ & Open \\
\hline 13 & Final comments & \\
\hline
\end{tabular}

Question seven of the questionnaire included a list of 22 possible perspectives, derived from NCEA examinations over the last decade, as well as local and international literature (Bliss, 2005; Chalmers, Keown \& Kent, 2002; Gale, 1996; Hicks, 2013; Huckle, 2002; Morgan, 2002). Two questions (Q8 and Q11) were explicitly directed towards the disciplinary orientation of geographical knowledge to explore the extent to which the possibility of a disciplinary-conscious approach was considered viable. This included, in Question 8, a definition of the disciplinary stakeholder framing of perspectives in the MoE (2013b) Curriculum Guides.

The design of the online survey followed advice that longer online surveys should be broken into sections rather than being a lengthy 'scrolled' environment, and that careful use of different question types can give the appearance of a shorter survey (Lumsden, 2007). I was particularly keen to make sure that the survey design would communicate effectively on a range of electronic devices, as increasing portability is a feature of the 
digital world in the last decade (Godwin-Jones, 2008). For this reason, I used the Qualtrics platform (www.qualtrics.com), which has a convenient function that allowed me to preview the survey design on both computer/tablet and mobile phone screens. I also applied skip logic to certain questions, in order that people were not being asked questions that were not relevant to them. The skip logic is shown in Questions 2 and 10 of the survey design in Appendix B.

While Likert-type responses tend to be very quick for respondents, it was necessary to minimise a fatigue factor in question 7. Consequently, in this question I was able to randomise the order of 'perspectives' to prevent those at the end of the list receiving less considered attention than those higher up the list (Cohen et al., 2003).

In order to test the reliability of the survey instrument, on both content and technical matters, I piloted the online questionnaire with two experienced geography teachers not involved in this research. The pilot included asking each of the teachers to assume three different roles, so that they could take different pathways as shaped by the skip logic. I asked each of the pilot teachers to time their completion of the survey, while:

i) simultaneously noting any question(s) that they did not understand;

ii) noting any questions that seemed not to follow on from previous questions;

iii) identifying any malfunctioning of question types; and

iv) noting any design features that hindered completion of the questionnaire. Feedback from the piloting teachers resulted in four adjustments: rewording of two questions for more clarity, a reduction in the text to read on question eight, and an adjustment to the skip logic of one question.

\subsubsection{Questionnaire data analysis}

Analysis of the questionnaire data varied depending on the nature of the question I asked. Where I analysed quantitative data, I limited operations to frequency counts. This was because statistical interpretation was not relevant given the small size of the purposively chosen group. As a result, I used Excel spreadsheet to analyse the quantitative data, which enabled me to quickly calculate frequency statistics as well as construct graphs to display the data. 
Where analysis focused on qualitative responses from the participants, I drew upon the thematic analysis approach of Lichtman (2010) and the 'grounded' approach of Charmaz (2006). Both of these researchers emphasise the inductive nature of analysis, in which meaning is achieved by moving from the particular to the more general conceptual category. To this end, I identified and synthesized information present in the data, with the goal of condensing large amounts of raw data into a more digestible format. Lichtman advocates a 'Three Cs' framework for qualitative research in which coding was categorised before being grouped as concepts (see Figure 5.2). Lichtman's framework breaks the coding process down into six steps and emphasises the extremely iterative nature (don't be misled by the linearity of my diagram) of coding. Charmaz (2006) has less steps in her process of open coding, code creation, and the determination of axial coding, yet it presents a very similar inductive process from the particular to the general.

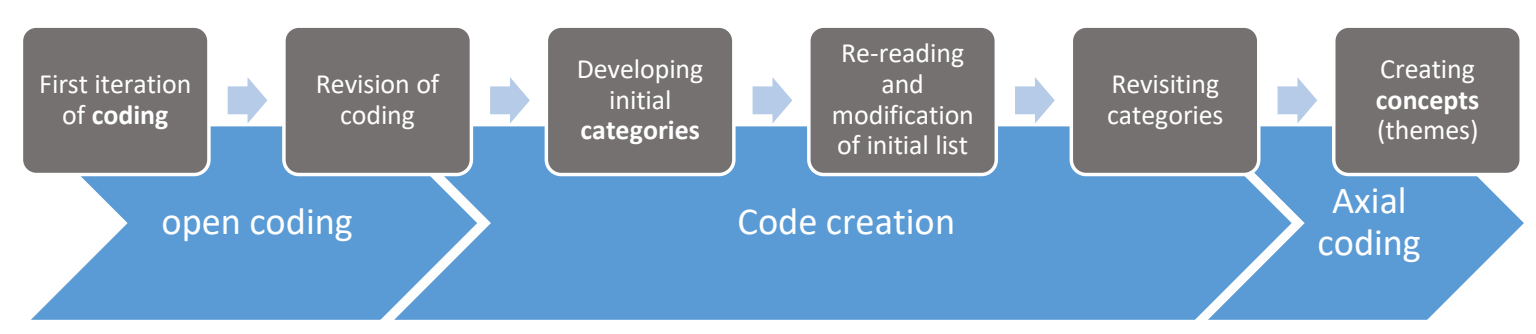

Figure 5.2: Phase 2 thematic analysis (adapted from Lichtman, 2010 and Charmaz, 2006)

Following the approaches of Charmaz (2006) and Lichtman (2010), in the first step of my coding process, I took a line-by-line approach in which I categorised ideas as words or phrases. I read and reread the responses to questions, which helped me identify some important ideas, around which I could name an initial or 'open code'. Initially the coding was done by hand, but such was the amount of recoding (step 2) that I imported the qualitative questionnaire responses into QSR International's Nvivo $10^{\mathrm{TM}}$ software to manage coding and recoding in a more efficient manner. The ability to move snippets of text to different child-nodes and quickly ensure I had not double coded statements made the process far quicker and likely more reliable than doing it by paper. This was especially important as I went backwards and forwards making revisions during the second step of open coding. For the third step, the coding process was informed by Lichtman's (2010) direction that "when organising your codes, it is your task to decide the most informative 
or logical manner of sorting. You need to determine from the data what meaning you think can be found" (p. 200). In this third step, I clustered the initial codes (or what Nvivo terms 'child nodes') into categories of codes (parent nodes). This step was messy as there were multiple iterations of categorising, deleting and modifying the evolving code categories. In the third step, some of the initial codes were re-named, and then allocated and reallocated to the categorisations as I went back and forth reading the questionnaire responses in a constant comparison technique (Glaser \& Strauss, 1967). The fifth step was the firming up of categories. At this stage none of the categories were removed in their entirety, but a few categories combined or changed in title to form themes. In the sixth and final step the overarching conceptual themes were revisited to see whether they reflected the meaning attached to the original questionnaire responses (Lichtman, 2010). This is analogous to Charmaz's definition of axial coding, the purpose of which is "to bring the data back together again into a coherent whole after the researcher has fractured them through line-by-line coding" (p. 186). The data in Phase Two was presented in tabulated form in order to show the relationship between statements from the participants, code categorisation and axial coding. The findings of this second phase of the study are presented in Chapter 7.

\subsubsection{Phase 3: Lesson study collaboration}

My final phase of research explored my collaboration with two teachers to design and teach a sequence of lessons in a disciplinary-conscious fashion. Phase 3 was very much a 'testing of the idea' approach, as the literature that advocated disciplinary-conscious geography was not supported by any empirical evidence. Therefore, my question was: What are the outcomes of a lesson study collaboration focused on expanding teacher and students' disciplinary-consciousness?

Phase 3 was a study of teacher collaboration to teach disciplinary perspectives to a group of senior secondary school students in a five lesson program. I took what I understood as the contradictions and limitations of the understanding of perspectives and worked with the teachers to see if we could re-imagine perspectives from a stakeholder framing towards a disciplinary-conscious orientation. Before I could undertake this phase, however, I needed to recruit teachers and students to this aspect of the study. 


\subsubsection{Sample and access}

In order to develop this third phase of research, a purposive sample of teachers was sought, defined by the teachers having a) previously been involved in collaborative professional learning environments; b) capacity to meet regularly with each other; and c) having Year 12 or 13 geography students to work with. Criterion b) limited the potential sample of schools to a restricted geographical region, as data collection needed to be managed around the researcher's and participating teachers' work commitments, so that collaboration could be facilitated as smoothly as possible. The focus on Year 12 and 13 was driven by the literature and the findings of Phase 1 which suggested that perspectives was a concept likely to be engaged with by Year 12 and 13 students rather than those in a foundational Year 11 geography course.

After ethics approval from the VUW Human Ethics Committee was granted (see Appendix B), I gave a short outline of the intentions of my proposed research at a local geography teachers' meeting, after which three teachers expressed an interest in being involved with their students. Subsequent discussions with each of the three potential participants led to two suggesting further interest and one declining. The Principals of Te Awa High and Ruamoko College were sent information about the proposed study (see Appendix C). Once informed consent was given by the principals, this was the signal to obtain official informed consent (Appendix D) from the two teachers, whose details are given below.

Table 5.4: Teacher demographic details

\begin{tabular}{|c|c|c|}
\hline & Sacha & Michelle \\
\hline Age band & $30-40$ & $30-40$ \\
\hline Gender & Female & Female \\
\hline $\begin{array}{c}\text { Teaching } \\
\text { experience }\end{array}$ & $5-9$ years & $10-15$ Years \\
\hline $\begin{array}{c}\text { School } \\
\text { Extra } \\
\text { responsibility }\end{array}$ & Department leader & Faculty management \\
\hline
\end{tabular}

Before we began our lesson study planning meetings, I conducted individual baseline interviews with Sacha and Michelle to establish their views on geographical knowledge broadly and the concept of 'perspectives' more specifically (see Appendix E). The interviews were digitally recorded, transcribed, and member checked for accuracy and 
amendments by Sacha and Michelle (Lincoln \& Guba, 1985). The baseline interviews were semi-structured in nature, which was a way of eliciting detailed responses from both interviewees, while having the flexibility to follow lines of inquiry that emerged during the interview process (Cohen et al., 2003; Denscombe, 2007). This meant that questioning, probing and listening were fundamental to my interviewing approach which was constantly in tension with the time limit set on the baseline interviews outlined in the ethical consent process. I was also aware of Simons (2014) advice that "paying attention to the silences and what they mean, you can get closer to the meaning of participants' experiences. It is not always what they say" (p. 462). At the same time, I was aware that I did not want Sacha or Michelle to feel they were being tested in the baseline interviews - it was early in the research process, and the establishment of the intended collaborative exercise could soon unravel if either of them had felt that I was being judgemental about their knowledge and understanding.

Access to students was facilitated through Sacha and Michelle. I intended that students of the two teachers should be able to participate in the perspectives lessons without pressure to feel they had to be participants in the research. Therefore, details of the research were only given at the conclusion of the first workshop session, rather than before it. Those students who agreed to participate in the research gave a written copy of their informed consent back to their teachers before the second workshop session (Appendix F). Parental consent was not required as all students were older than 16 years. In total, 13 students (nine boys and four girls) submitted an informed consent form. Seven of these students were from Te Awa High and six from Ruamoko College.

\subsubsection{The lesson study approach}

Lesson study is located in the broader field of practitioner research; it is a highly collaborative approach to professional learning, in which outcomes for both teachers and their students are the principle focus of professional knowledge building (Lewis, Perry, Friedkin \& Roth, 2012). A lesson study approach has been described by Dudley (2015) as a 'forensic examination of classroom teaching and learning because of the close attention it is designed to give to real learning in naturalistic settings such as classrooms. The lesson study approach aligns with broad notions of participant observation. Cohen, Manion and 
Morrison (2011) describe non-participant observers as standing "aloof from the group activities they are investigating and eschew membership" (p. 297). As part of the lesson study inspired approach, however, I was an active participant, which included a) collaboratively planning a programme of lessons; b) teaching and observing of student outcomes during each lesson; c) analysis of student learning and modification and design of subsequent lessons.

While lesson study is an increasingly international endeavour, its origins are located in the longstanding tradition of Japanese primary and middle school teachers making their practice public as part of their professional development (Fernandez, 2002). Lesson study is derived from the words jugyou (instruction, lessons, or lesson) and kenkyuu (research or study). Lewis, Perry and Murata (2006) note that the central tenet of the many variations of lesson study that have developed over a hundred year history have at their core the common principle of "observation of live classroom lessons by a group of teachers who collect data on teaching and learning and collaboratively analyze it" (p. 3). It is clear from accounts of the origins of lesson study, that in the Japanese context, it was largely used for the development of mathematical and science curriculum learning; a trend that continued with its diffusion (Xu \& Pedder, 2015). Despite the popularity of lesson study in Japan and subsequently China, it has only been since the late 1990s and early 2000s that the West has paid much attention to what is a Japanese state school professional development norm (Lewis, 2015). Bringing a lesson study inspired approach to geography education in New Zealand is a novel aspect of this research.

While Stepanek et al. (2007) have catalogued some of the nuanced differences between lesson study and other practitioner focused collaborative approaches, such as 'study groups', 'curriculum development' and 'peer coaching and mentoring', the uniqueness of lesson study may be somewhat of a fallacy, given the many features it shares with other forms of practitioner inquiry. Yet, while action research and practitioner inquiry can be quite a personal exploration of practice, lesson study promotes the idea of public lessons, in which audiences of fellow teaching professionals observe the interaction between teachers and students (Lewis \& Tsuchida, 1998). The reduction of professional isolation is also promoted by lesson study's commitment to teachers collaborating in the development 
of teaching approaches that align to shared goals. Furthermore, lesson study expects that the planners/ observers will also spend time evaluating teacher and student outcomes. Drawing upon themes from lesson study literature, I identified four key reasons for the suitability of a lesson study approach for the third phase of my research design: 1) it is concept specific; 2) lesson study supports critical team centred professional development through lesson plan design; 3) lesson study is flexible, adapting to the contingencies of context; and 4) it is efficient for time poor teachers (see Table 5.5).

All three planning sessions were audio recorded and transcribed into a template that included a line number and a margin for field notes to also be transcribed next to the relevant passage of the meeting. For these long transcriptions, I made use of a transcription service provider. The quality of the service was questionable: clearly voice recognition software had been used and a lack of technical language meant I spent a considerable amount of time 'data cleaning'. This also involved the removal of off-task discussion which tended to increase after the second hour of meetings. Only once this was done did I send the transcripts to Sacha and Michelle to check for accuracy and clarifications.

A key feature of the collaborative phase was that each lesson study would be conducted after the normal school day, at a venue in Wellington City that was neutral to Te Awa High and Ruamoko College. This was a major example of the approach responding to the contingencies of context: it was agreed by the teacher participants that an 'after-hours' setting would minimise the impact of the senior secondary school assessment regime, which is known to strongly regulate teacher decision making and student motivation (Wylie, Hipkins, \& Hodgen, 2008). In short, the after-hours, off-site setting aimed to avoid the student question "Is this in the test?". Furthermore, because the lesson study collaboration would include students from two different schools, both Sacha and Michelle were keen that cognitive outcomes would be supplemented with positive participatory and affective outcomes. 
- Lesson study offers microanalysis of learning around specific concepts; it is content focused

(Dudley, 2015; Lewis, Perry \& Hurd, 2009; Stepanek et al., 2007)
The specific focus is the New Zealand geography curriculum's key concept of 'perspectives'. In effect I aimed to take a concept-led focus to support teacher and student engagement with the segmented nature of geographical knowledge. If thinking about foundational geographical knowledge along philosophical lines was "not every body's cup of tea" (Miller, 2001), I anticipated putting the taste to the test.

Lesson plan design has very high face validity for professional practice of teachers. A 'heads-together' approach might break down uncertainty about related concepts, and develop a norm where ownership of student learning (successful or otherwise), belongs to the group. Moreover, evaluating the lessons through the frame of the student learning, allows for criticality without the focus being overly centred on the performance of the teacher. It was my aim to create conditions that may enhance both support and critique through positive emotional conditions of situated cognition.

- Lesson study has flexibility in its design, allowing for the contingencies of context to shape its manifestation

(Fernandez, 2002; Lewis, Perry \& Murata, 2006; Perry \& Lewis, 2009; Stepanek et al., 2007; Xu \& Pedder, 2015)

- Lesson study can be efficient and effective for time-poor professionals

(Dudley, 2015; Pedder, 2015; Stepanek et al., 2007)
For this study I drew upon two teachers in the lower North Island and a group of Year 12 and 13 students who self-selected to participate in a sequence of lessons about 'Perspectives on Cities'. While I understood that the first three planning meetings would enable us to develop impetus for the first two lessons, our busy work schedules meant that planning in between lessons was achievable over the internet.

I was aware that both teachers had professional responsibilities that suggested a short-intensive collaborative experience was more likely to be engaged with and that the approach might be able to provide visible outcomes for themselves and their students reasonably swiftly.

Stepanek et al. (2007) have presented the core elements of lesson study as nested as shown in Figure 5.3. The 'Habits of Mind' aspect is the high-level outcome and aligns well with the nature of situated cognition described in Spillane et al.'s (2002) framework of sense making. The big idea of our lesson study was 'Perspective' although with its many layers of meaning, we expected more 'big ideas' to emerge, whether it be through the detail of 
our teaching/instruction, the goals of lessons, or student learning. The content of the lesson study approach was designed around the theme of cities and urbanisation. The first reason for making this decision (before Sacha and Michelle had agreed to participate) was that, in the second decade of the $21^{\text {st }}$ Century, over $50 \%$ of humanity now live in cities, while urbanisation processes are felt across the entire globe, making this a key geographic issue. As a consequence, many of the existential issues facing humanity are deeply embedded in the choices and decisions associated with city life (Bridge \& Watson, 2013; Pacione, 2009). The second reason for choosing this theme was that it was a topic that is typically taught in Year 12 geography classes and had recently been a context for the geography scholarship examination (NZQA, 2014d). I was conscious that choosing content for the lessons that would have high face validity for both teachers and students would potentially increase participation rates.

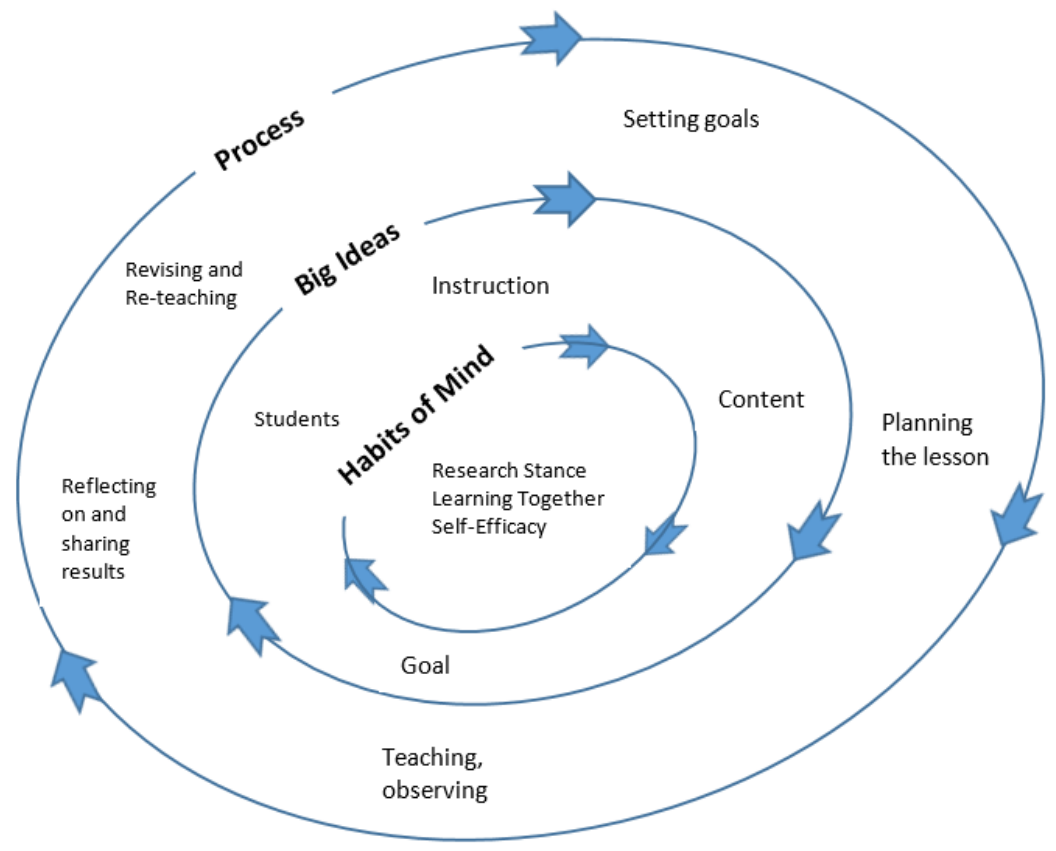

Figure 5.3: Core elements of lesson study (Stepanek et al., 2007)

To give the reader an impression of the lesson study approach, the following paragraphs are based around the central elements of our lesson study process (i.e. the outer circuits of the Stepanek et al. (2007) model - see Figure 5.3). 


\subsection{Setting goals}

The overall goal was driven by the research agenda of Phase 3 of the study, which was to see how Sacha, Michelle and I planned and taught a disciplinary-conscious approach to geography. In this context, Sacha, Michelle and I met for three half day planning meetings, during which we agreed on objectives for each lesson:

i. To understand that knowledge of cities can be shaped by a [named] perspective;

ii. To analyse a [named] perspective; and

iii. To apply a [named] perspective to an aspect of urbanisation/cities.

It was anticipated that these three objectives would be applicable to each of the lessons, irrespective of which disciplinary perspectives we chose as the substantive focus of each lesson.

\subsection{Planning the lesson(s)}

Working collaboratively with Sacha and Michelle, a programme of five lessons was planned and taught to the Te Awa High and Ruamoko College Year 12 and 13 students. The spread of the planning meetings, and all the other aspects of the Phase 3 approach are given in a timeline in Appendix G. For detail of the lesson plans and material presented to students in those lessons, see Appendix H. The shared ownership of this planning stage was important, because it meant that whichever role was taken in the actual lesson (i.e., teacher or observer), all three of us had a strong sense of ownership of what we were attempting to do. The planning of lessons not only involved the selection and pacing of activities, but also discussions about the content matter, and student needs.

The planning for the first two lessons took place during the three half day planning sessions, while the subsequent three lessons were planned collaboratively online, after the previous lesson analysis. We recognised that this approach enabled us to be responsive to the previous lesson, but also that the depth of discussion about the content of the lesson was not as in-depth as our earlier face-to-face meetings. 


\subsection{Teaching, observing and debriefing}

The teaching and observing was shared between the three of us. There was an imbalance in the number of lessons taught, as I was the teacher for the first three, followed by Sacha and Michelle teaching one each. Following the student learning focus of the lesson study approach, the two observers who were not teaching used a template to record observations and contributions (written and oral) of student work rather than focus directly on teacher actions and utterances (Stepanek et al., 2007). Following the practice described in the literature, we chose to focus on three students each lesson, although took the opportunity to record verbal interactions or photograph work of other students which captured our interest. Appendix I gives an example for our modified observation/ evaluation sheets. Observation was of behavioural engagement, looking for signs of verbal interaction, body language, interaction between peers or between student and teachers. If a focus group student contributed to class discussion, a summary was noted by an observer. The outcome of focus student work was documented either in prose or, sometimes, a digital image was taken. On one occasion in the third lesson study, the creation of poems and raps were unfortunately not captured digitally, because the volume of the microphone was not turned up.

Stepanek et al. (2007) suggest that built into the teaching phase is a debrief of the instruction and learning with the students. While we took the opportunity for students to reflect on what they were learning and ask questions, we chose not to include a specific debrief session with the students as a matter of course. In this respect we let the act of teaching guide us for student feedback, rather than commit to a 'cookie-cutter' lesson plan recipe.

\subsection{Reflecting on and sharing results}

Immediately after each lesson session, the three of us produced an observation/analysis sheet that was a composite of our observations and reflections. A key aspect of this reflection material was to consider what seemed to have worked and what could have been improved, based on the evidence we collected from each of the three individual focus students. Having images of student work on mobile devices allowed our discussions to be driven by artefacts. It was anticipated that there would be three key focus students for the 
duration of the teaching, but the reality of absences, meant that over the course of the five lessons, there were six students who were focused on by observers. While Richard was ever present as a focus student, the other five were a focus student for either two or three lessons. This was a limitation to our tracking of students but reflected the naturalistic environment of the collaboration, in which we had no control over the students' own time constraints and availability over a five-week period.

\subsection{Revising and re-teaching}

The revision and re-teaching of the lesson was centred on the idea of 'disciplinary perspectives' rather than the specifics of, for example, 'spatial science' or 'humanistic geography'. This was a reflection of the limited amount of time we had for the lessons, and in no way presupposed that each of the lessons could not have been improved in some way before moving on to a subsequent disciplinary perspective. Consequently, what we attempted to do was take our understanding from one lesson and try to make improvements to the next lesson, albeit the specific disciplinary perspective would differ.

\subsubsection{Exit interviews and focus group discussions}

An opportunity for Michelle, Sacha, and their students to reflect on their sense-making of disciplinary perspectives during the lesson study process, was facilitated 10 weeks after the conclusion of the collaboration (see Appendix J). I considered this period long enough to judge whether teachers and students had internalised some of the 'big ideas' of the collaboration and was also concerned to have this data collection completed by the end of Term 3. This is because it would take very understanding participants to take time out from the first three weeks of Term 4 to be interviewed, as this is generally considered a period of cramming for upcoming senior school public examinations in New Zealand. As it happened, the messiness of school life did have considerable impact on my exit interview of the Ruamoko College students. Although all six students were asked by Michelle to attend, only John and Ardie turned up to the focus group discussion, which meant I was unable to collect data from the girls in this group. Given that all the girls had attended three of the five lesson study lessons, there perhaps was not the affective commitment to the project at this stage that there might have been for students who were always present. Furthermore, the focus group discussion (see Appendix K) was quite 
difficult to conduct in the first 10 minutes, as despite my attempts at prompts, both boys were reasonably brief in their replies. Although John eventually became more actively engaged, Ardie was less forthcoming. I judged that this was because he felt he had less of a grasp of the big ideas than John. subsequently, I engaged him in the dialogue by directing my questions specifically to him.

Although the teacher exit interview schedule comprised several set questions, the order in which they were asked differed in both interviews. This was because I was conscious of the need for the exit interviews to flow in order for both Sacha and Michelle to be comfortable critiquing aspects of our work. Spillane, Reiser and Reimer (2002) have noted that when teams of teachers work in collaboration, their collegiality can hinder selfcritique. I felt that this more the case with Michelle than Sacha, although with some prompting both were confident enough to lightly critique our approach.

\subsubsection{Analysing the Phase 3 materials}

There were four groupings of data that informed the Phase 3 analysis:

i. Baseline semi-structured interviews of Michelle and Sacha before the lesson study collaboration began, to elicit personal epistemological orientation.

ii. Planning meetings, lesson plans and materials, and observation/evaluation sheets generated during the lesson study collaboration;

iii. Products of student work during the lessons;

iv. Exit interviews of Michelle, Sacha, and each group of students from Te Awa High and Ruamoko College;

The relationship between these different data sources is shown in Figure 5.4.

Interviews and planning meetings were all transcribed verbatim into Microsoft Word ${ }^{\mathrm{TM}}$ documents. A column on the right-hand side of each document was established on to which I transferred field notes and time stamps in approximate five-minute intervals. On the left-hand side, a column contained line numbers. While the time bound nature of the baseline and exit interviews meant the dialogue was 'on-task', the much longer planning meetings (typically three hours in length) produced enormous transcripts of over 70 pages 
in length. Therefore, as part of the cleaning up process of the transcript (fixing typos; relistening to sections when we talked over each other) I deleted chunks of text from the transcript that were clearly 'off-task'. In retrospect I wish I had made this decision as I transcribed, because the stop/start nature of the transcription process meant that it was a very labour intensive process for the planning meeting dialogue to be transcribed.

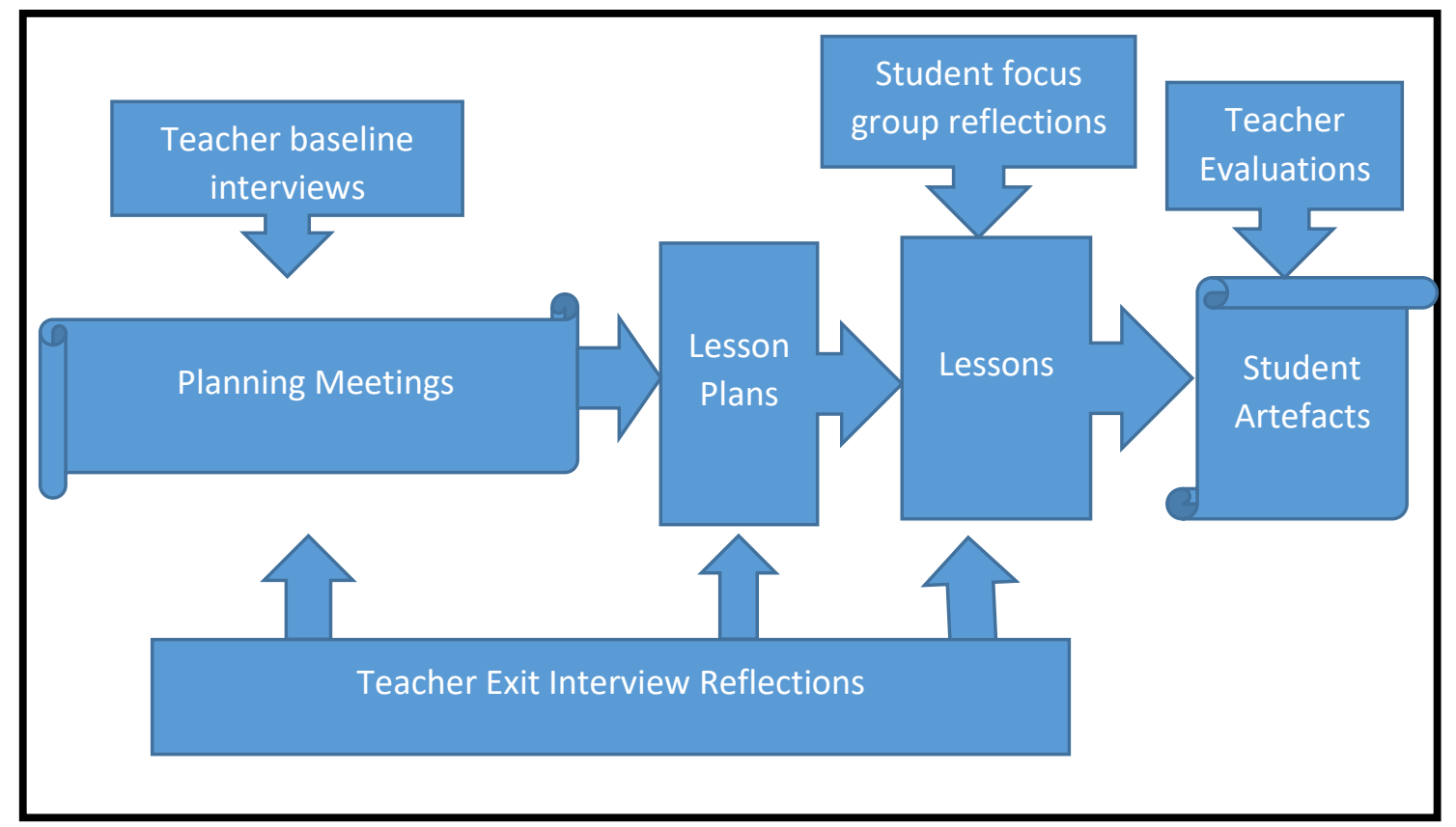

Figure 5.4: Relationship between Phase 3 data sources

My analysis in this phase was especially informed by some of the strategies identified in the literature, particularly those presented by Puttick (2013), Hodson (2014) and Moje (2015). For each of the four cases (Myself, Sacha, Michelle and the group of students) I analysed baseline interviews, planning meetings, and exit interviews/focus group discussion using a constant comparison technique (Strauss \& Corbin, 1998) with attention to the affordances and challenges that our collaborative work presented. Given the findings of Phase 1 and 2 I was also interested to chart learning that could be characterised as disciplinary conscious. Consequently, I looked for statements or examples of work that showed evidence of: i) Identifying perspectives (low level); ii) analysing perspectives (intermediate level); and iii) applying perspectives (high level), and framed them in a chronological order of before, during, and the lesson study experience. 


\subsection{Trustworthiness}

Trustworthiness of a study poses the question "to what extent can we place confidence in the outcomes of the study? Do we believe what the researcher has reported?" (Maykut \& Morehouse, 1994, p. 145). Lincoln and Guba (1985) argue that qualitative studies need to establish the trustworthiness of their claims through careful attention to research design and methods used. Their suggestions for considering trustworthiness are the focus for the following sections, specifically in relation to the concepts of dependability, confirmability, and transferability.

\subsubsection{Dependability}

The dependability of this study is premised on the notion that a clear pathway of processes and decisions made about the method can be tracked throughout the duration of the research. Throughout this research, documents, transcripts of interviews, survey responses, have been coded and retained to provide a chain of evidence or 'audit trail' (Guba \& Lincoln, 1989). This coding documentation (see Appendix L) will allow readers to judge the trustworthiness of the outcomes by being able to track the coding work from its inception to its conclusions. The dependability of the research also includes an account of my role as the researcher, which I have paid particular attention to in the Lesson Study component of this chapter, including relevant ethical considerations.

Dependability is an auditing process that examines the research processes to make sure they are sound (Lincoln \& Guba, 1985). I strengthened dependability through a number of strategies, including by piloting my e-survey questions, and using some observation and evaluation templates in our lesson study collaboration from published teacher guideline resources (Stepanek et al., 2007). This allowed me to make alterations before I used these tools in the field. The Lesson Study audit trail to help produce thick description of methods of data collection and analysis, as well as Sasha and Michelle's checking of transcripts, also helped to support the dependability of the study. 


\subsubsection{Confirmability}

Confirmability has been achieved through the explicit account of methods used during the research process. This has sometimes included using multiple sources and methods as a form of triangulation to strengthen confirmability. For example, in the Phase 1 document analysis, confirmability was enhanced by the selection of a range of sources. Taken together, the breadth of sources presented a comprehensive picture of the way that perspectives were being signalled to teachers. Similarly, in the Lesson Study collaboration, semi-structured interviews, transcripts of planning meetings, and lesson observation debriefs gave stronger confirmability of outcomes than if only one of those sources had been subject to scrutiny. Increasing the empirical breadth through the three phases of the case study offer what Flick (1998) suggested is a "strategy that adds rigour, breadth, complexity, richness and depth to any inquiry" (p. 230).

As my personal subjectivity infused my research, this required a reflexive stance in order that my own biography, beliefs and prejudices are recognised as likely to shape, yet not over-influence the analysis and conclusions of the research. My findings do not simply 'emerge' but I am an active agent in the production of knowledge, influenced by my personal background of life experiences and choice of an interpretive lens through which I have studied the phenomena in this study. Thus in Chapter 1 I declared my motivations for this research to help give the reader a sense of my stance in this research.

\subsubsection{Transferability}

Researchers from the interpretive paradigm consider transferability to be a more suitable term than generalisability, whereby extensive and careful descriptions are given in order that he reader can apply "the study to their own situations" (Lincoln \& Guba, 1989, p. 242). Stake (2000), writing about case-study, suggests that 'naturalistic generalisation' enables the reader to take findings from one study and apply them to understanding another similar situation. Thus, the relatively small numbers of participants were because of a focus on depth rather than attempting to generate generalised claims supported by statistical probability. Thus Denscombe's (2007) assertion that the "question becomes 'To what extent could the findings be transferred to other instances?' rather than 'To what extent are the findings likely to exist in other instances?"” (p. 299). 


\subsection{Chapter summary}

In this chapter I have presented an account of a three-phase, sequential case study research design, to explore the role and potential of using the concept of perspectives to develop a disciplinary-conscious approach to school geography. The chapter documents a range of methods of data collection and analysis, which include content analysis of curriculum and assessment documents, an e-survey of school geography specialists, and a lesson study collaboration of explicitly teaching disciplinary perspectives in relation to urban geography. The chapter also discusses ethical considerations and my role as the knowledge producer of this study.

The following three chapters represent the findings from my analysis of these three phases of research. 


\section{Chapter 6: Curriculum and Assessment Framing of Perspectives}

\subsection{Introduction}

In this initial empirically focused chapter, I present the results of a content analysis of curriculum and assessment materials to determine the extent to which the concept of perspectives has been framed in a disciplinary-conscious approach. In essence, this analysis is an example of the message signalling function of curriculum to which teachers pay particular attention when any sort of change is necessary. Analysing how curriculum and assessment representations of perspectives "enable or constrain implementing teachers' sense-making is pivotal from a cognitive perspective" (Spillane et al. 2002, p. 416) and requires attention to not just the key idea, but the way in which the message is communicated.

Figure 6.1 is a timeline of the period in which the curriculum and assessment materials I reviewed originated. The analysis is based on documentation from 2005-2016, although I have also included NZBoGT (1999) and the NCEA statement on perspectives (Miller, 2001) on the timeline as points of reference. The earliest assessment materials I

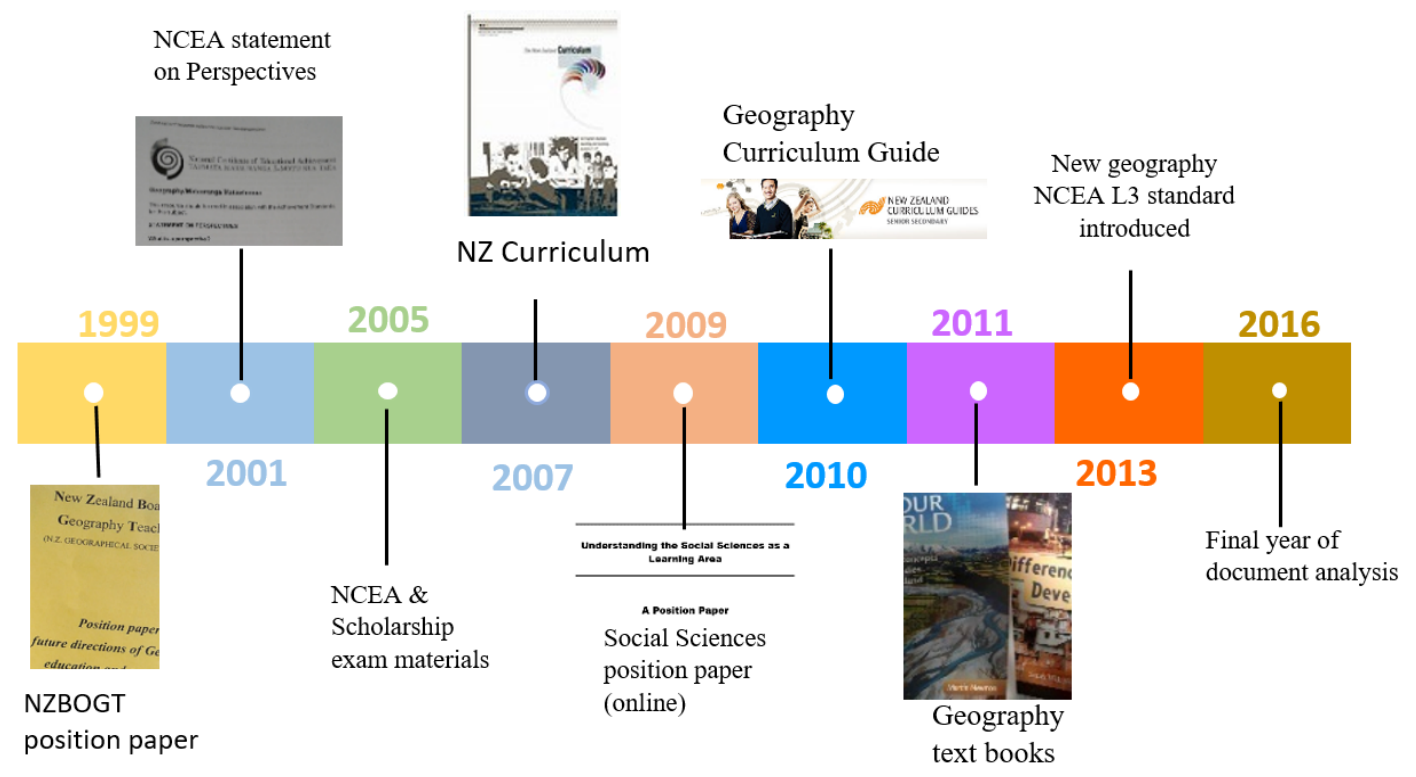


reviewed were from 2005 and the latest in 2016 as these were based on 2015 examinations, which was the year in which the three phases of this research were conducted.

\subsection{Perspectives in curriculum materials}

Broadly, my analysis of curriculum materials revealed three framings associated with the term perspectives. Figure 6.2 is a visual representation of these three different framings, which I have termed: (i) stakeholder perspectives; (ii) boundary maintenance perspective; and (iii) disciplinary-conscious perspectives.

The most common notion of perspectives in the Geography Curriculum Guide was the stakeholder framing which, as Figure 6.2 shows, emphasised people, groups, and organisations as the subjects of study. Such a stakeholder framing is also emphasised through the social inquiry methodology advanced in the social science learning area statement of the NZC, which states that students should be encouraged to "explore and analyse people's values and perspectives" (MoE, 2007, p. 31). Two of the four Level 7 and 8 geography NZC achievement objectives certainly signal the stakeholder framing:

- How people's perceptions of, and interactions with, natural and cultural environments differ and have changed over time

- How people's diverse values and perceptions influence the environmental, social, and economic decisions and responses that they make (MoE, 2007, n.p, my emphasis)

The second framing of 'perspectives' suggested by the geography curriculum guides, and which I have called boundary-maintenance, is presented by a direct link from its webpages to the National Geographic's Geographic Perspective: Content Guide for Educators

(Brown \& LeVasseur, 2006). This framing states that:

Geographers employ both a spatial perspective and an ecological perspective that enable them to ask questions about how humans interact with their physical surroundings...Geography uses an interdisciplinary and generic spatial perspective that may be broadly applied to anything distributed across Earth space. The geographer is therefore free to examine all relevant information in order to make an informed prediction or decision. (Brown \& LeVasseur, 2006, p. 2) 
In this framing, the object of study is not the individual, group, or organisation, but geography and geographers. The National Geographic framing of perspectives particularly emphasises how geography is different to other disciplines/subjects. Use of 'the geographic perspective' and attention to the 'uniqueness' of geography, is underscored by the cartoon in which the geographer examines a cityscape, as an artist, scientist, economist, and political scientist stand by (see Frame 2, figure 6.2).

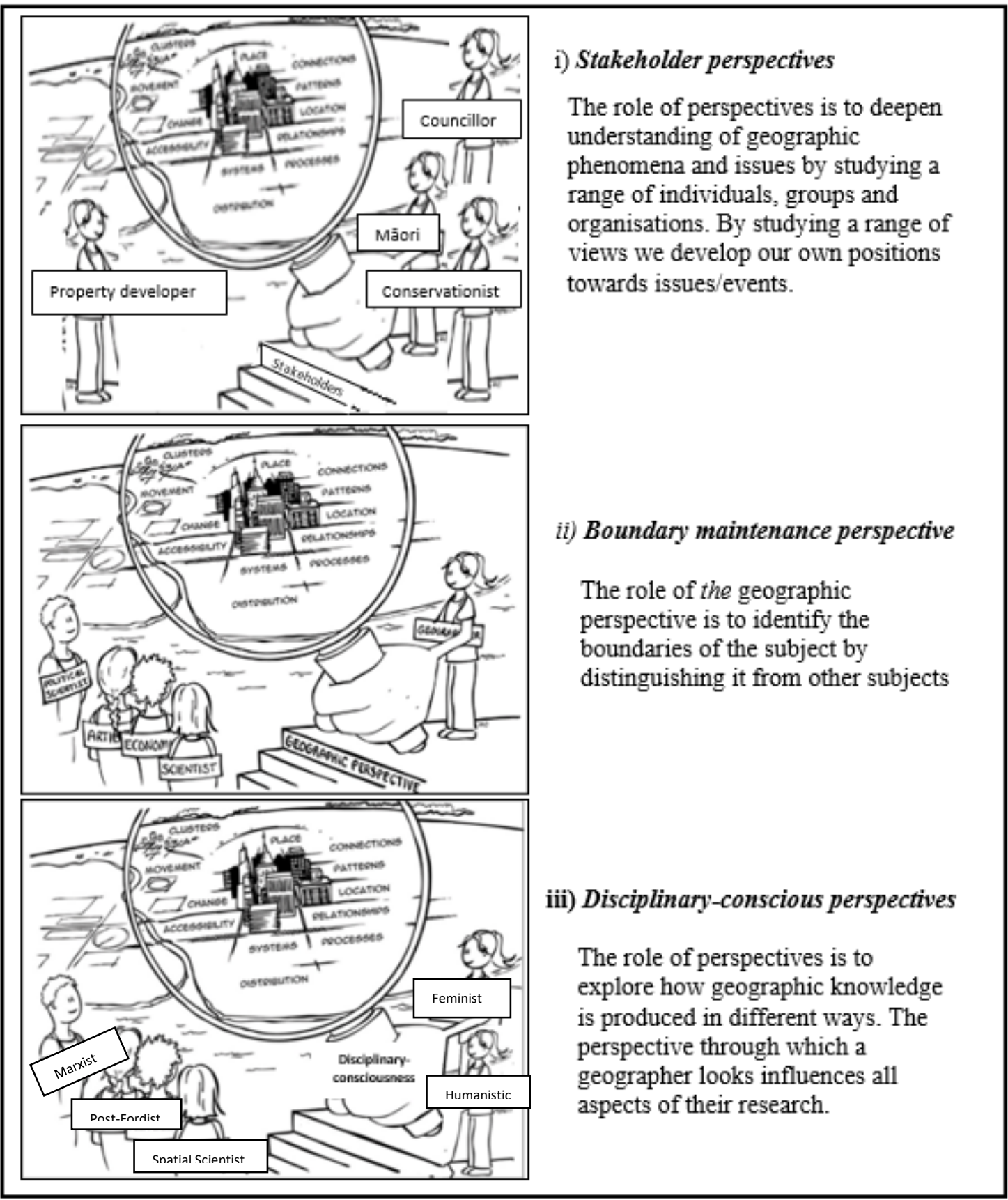

Figure 6.2: Three framings of perspectives in New Zealand geography curriculum guides

(Framing 1 and 3 cartoon adapted from Frame 2, Brown \& LeVasseur, 2006) 
The change from 'perspective' to 'perception' could quite quickly be passed off as a matter of semantics. That explanation cannot, however, be levelled at the senior secondary geography curriculum guides, which are very careful to differentiate between perception and perspective as distinctly separate, albeit related, concepts (see Figure 6.3). As the conceptual distinctions in the curriclum guides show, perception is related to what people think about geographical environments, whereas perspectives are much broader worldviews that shape the values that underpin viewpoints people have about geographic phenomena, places and/or events. In this curriculum material there is an attempt to give 'perspective' a more theoretical edge than 'perception', albeit it appears that the perspectives are applied to individuals and groups rather than providing insight into the production of geographical knowledge (MoE, 2013). The point of the geographic perspective is to offer subject boundary maintenance, albeit acknowledging its interdisciplinarity.

The third framing of perspectives in the curriculum guide is disciplinary-conscious, as it also highlights ways through which geographers (rather than individuals, groups and organisations) interpret the world to generate geographic knowledge. The key difference with the previous framing is that this framing suggests that students should explicitly explore a plurality of theoretical perspectives in geography:

'Geographic perspectives' also refers to how knowledge is organised and understood differently in the discipline, and the varying lenses that may be used when undertaking geographic research. These theoretical perspectives have labels such as 'gender geography', 'feminist geography', 'new cultural geography', 'post-modern geography', 'socially critical approaches', and 'Kaupapa Māori Geography' - but these are not the only ones. (MoE, 2013)

This aspiration to engage with theoretical pluralism is made explicit by the naming of disciplinary perspectives such as 'feminist geography' and 'new cultural geography', echoing NZBOGT (1999) and Miller (2001). These geographic perspectives are epistemically infused theoretical frames, shaped by academics as members of communities of knowledge production, who are themselves shaped by the institutional norms of scholarly practice and wider socio-political influences. 


\section{Perspectives}

Perspectives are bodies of thought, theories, or worldviews that shape people's values. Understanding different perspectives gives students the capacity to critique and challenge these taken-for-granted ways of understanding the world.

\section{Values}

Values are deeply held beliefs about what is important and desirable in relation to environments or geographic issues. Understanding values can help explain why people have certain perceptions or hold particular viewpoints. There are different kinds of values, such as moral, social, cultural, aesthetic, and environmental.

\section{Perceptions and viewpoints}

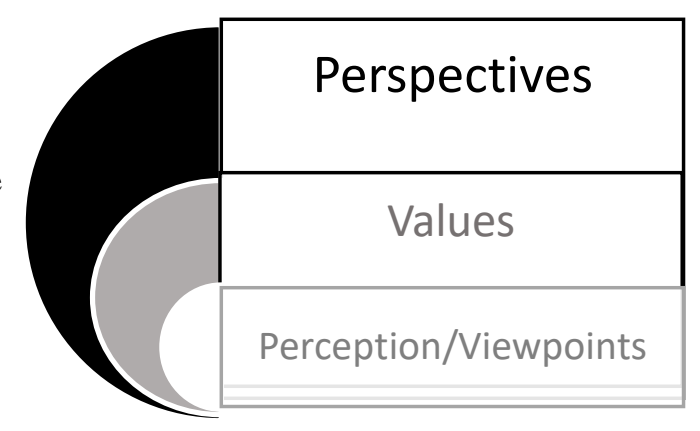

The way in which people view and interpret environments (perceptions) or what they think about geographic issues (viewpoints), are usually the result of their background, experiences or involvement with environments or issues. People's perceptions and viewpoints can, and often do, change over time.

Figure 6.3: 'Perspectives' in the senior subject geography curriculum guides (MoE, 2013, n.p.)

According to the Geography Curriculum Guide (MoE, 2013b), exploration of geographic perspectives helps students explore "how knowledge is organised and understood differently in the discipline, and the varying lenses that may be used when undertaking geographic research" (n.p.). This framing is less about the perspectives of all-manner of people and more about geographical knowledge as an object of study (Firth, 2011b). That is, explorations of disciplinary-conscious perspectives may develop students' understandings about the theoretically variegated nature of geographical knowledge. This is the clearest contemporary signal that aligns with the intent of the BOGT position paper. It is this third framing that is the explicit message to geography teachers that exploring the nature of geography as an object of study should also be revealed to students in order that they can understanding the meanings that geographical thought help them access. Nevertheless, this framing was outweighed by the other two framings and, as will unfold, not greatly supported by messaging in other curriculum and assessment materials. 


\subsubsection{A summary of perspectives in the NZC materials}

In relation to the NZBOGT (1999) position paper, there is some attention to disciplinaryconscious perspectives, although the stakeholder perspective framing is given significantly more attention. Therefore, while perspectives appear well embedded in New Zealand school geography, it is particularly through an issues-based approach in which inquiry learning is advocated. Another framing, which I have called the boundary maintenance perspective, is also evident in the teaching and learning guidelines. While this is a useful construct to distinguish geography from other subjects, for senior students it is rather a monolithic representation of geography that verges on being intellectually dishonest: disciplinary-consciousness explicates that geography and geographers are hugely differentiated in their approaches (Firth, 2011b). An unanticipated outcome of this analysis was Figure 6.2, which I hope, with acknowledgement to the original, allows the reader to crystallises the difference in the framings I identified in this first round of document analysis.

Given these different framings of perspectives outlined in curriculum and assessment materials, I proceeded to examine the extent to which the messaging of perspectives is evident in other curriculum and assessment documents, as these have significant signalling influence (Spillane et al., 2002) for teachers of senior secondary school students.

\subsection{Perspectives in assessment materials}

In this section I draw upon the framing of perspectives in assessment materials from 20052015. As noted in Chapter 5, these assessment documents are signals of curriculum as they offer a level of prescription detail not present in the $N Z C$ or the online curriculum guides. There are several assessment documents that are made publicly available online each year, by the Qualifications Authority (see Table 6.1). The significance of these documents is that they offer signposts to geography teachers about what is being successfully learned (and presumably, therefore, taught). As the NCEA comprises modularised 'internal' teacherassessed coursework and 'external' public examinations, the analysis comprises documents from both these assessment approaches. In this analysis, the greater number of NCEA geography examination materials reflects that the internal (coursework) materials have been published more recently. The documents I drew upon were restricted to NCEA 
Level 2 and 3 assessment materials, because these assessments are aligned with the Level 7 and 8 geography Achievement Objectives (refer to Section 2.5). In addition to the NCEA assessment resources, I also analysed Scholarship examination resources, which not only represent the highest level of academic achievement in geography in the New Zealand school system, but for the last decade have included perspectives as an integral aspect of the examination.

Table 6.1: Assessment materials analysed in Section 6.3

\begin{tabular}{lll}
\hline NCEA Examination & NCEA Coursework & Scholarship Materials \\
Materials & Materials & \\
\hline Exam questions & Moderator comments & Scholarship annual examiner report \\
Exemplar answers & $\begin{array}{l}\text { Achievement Standard } \\
\text { notes }\end{array}$ & Top Scholar exemplar scripts \\
\hline
\end{tabular}

\subsubsection{Perspectives in NCEA examination materials}

To begin my analysis I first identified the conceptual focus of all the NCEA Level 2 and 3 examinations over the 2005-15 period (see Appendix M). As the summary of examination questions shows in Table 6.2, this helped me identify the NCEA Level 2 and 3 exams which focused either explicitly or implicitly on the use of perspectives and/OR perception. I found that while perspectives is commonly assessed in secondary school geography examinations, there was an uneven distribution across levels and within exams over the 2005-2015 period. At NCEA Level 2, perception was most commonly examined in the Natural Landscape exam (eight times over an 11 year period) and a mix of perception and perspective at NCEA level 3 in the applied concepts and skills exam (six times). The NCEA Level 2 Differences in Development exam included perceptions/ perspectives three times, although, as I will describe later, there is evidence from this exam that disciplinaryconsciousness is implictly connected to a commonly posed examination question.

Despite Table 6.2 showing a clear orientation to stakeholder perspectives, (a framing settlement), when I examined the selected examinations in greater detail, I found that there was definitional ambiguity in the language of exam questions. For example, although the Natural Landscapes examinations were exclusively linked to the stakeholder perspectives (see Table 6.2), the language used across eight years included people's appraisal, 


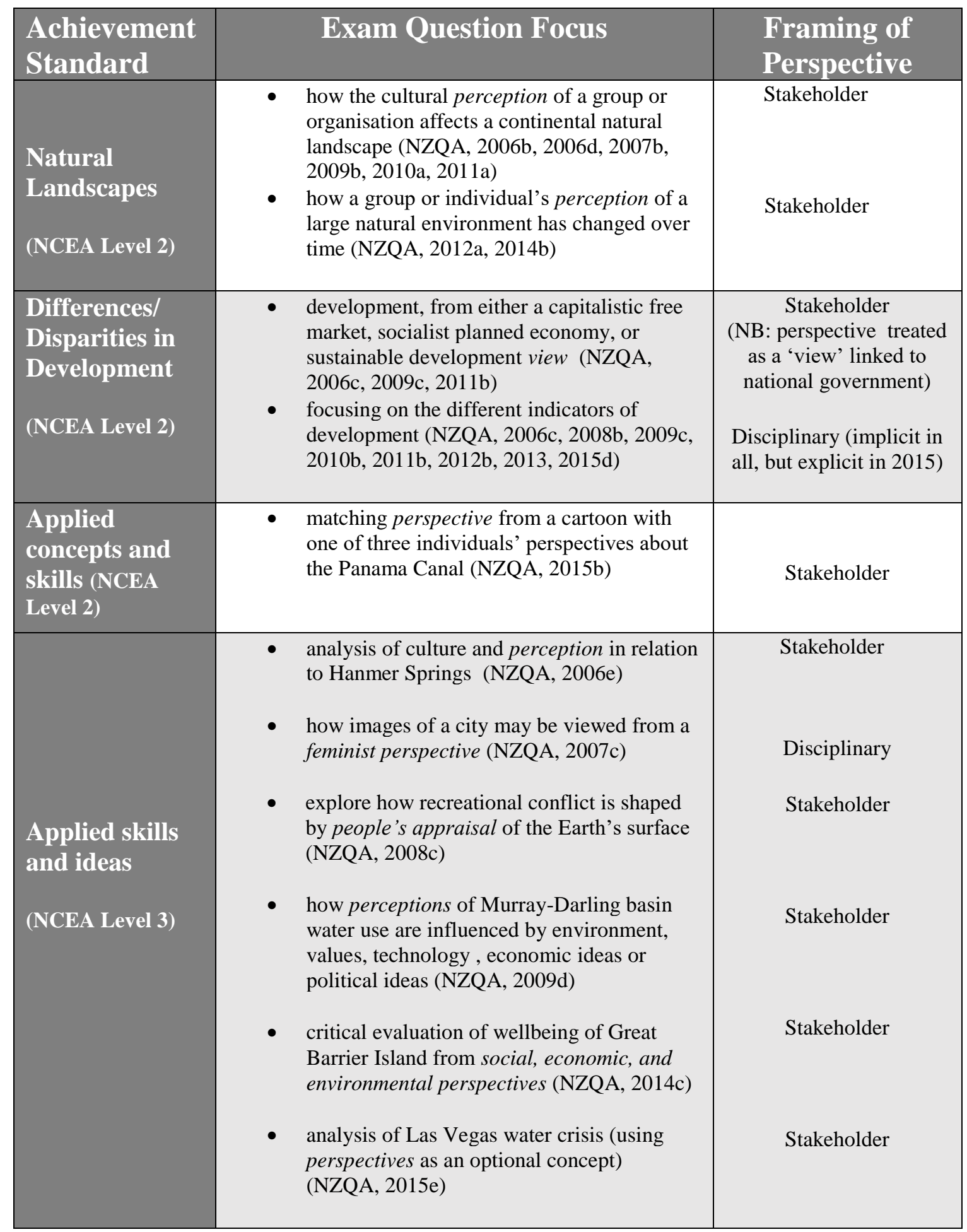

perceptions and perspectives. Using the terms perception and perspective synonymously is a contradictory signal to teachers in light of the careful attempt to distinguish between both terms in the geography curriculum guide (refer to Figure 6.3). 
The three occasions in which perspective was explicitly a focus in the NCEA Level 2 Differences in Development examination $(2006,2009 \& 2011)$ was through a focus on different worldviews of development, typically capitalist, socialist-centrally planned or sustainable development. On these occasions, the use of 'worldviews' was separated very clearly from individuals' perceptions, although the concept did remain connected to stakeholders (i.e. national governments) as subjects of study rather than, say, the influence of these worldviews on geographic thought. Therefore, although these exam questions were a movement towards something much wider than individual viewpoints and values, disciplinary-consciousness was still not the focus.

The content analysis also revealed, however, that the NCEA Level 2 Differences in Development examination had a re-occurring and overtly epistemological slant for seven of eight exams in the 2005-15 period, despite not being explicitly connected to the concept of 'perspective'. Rather, it was common in this exam to test understanding of how development can be evaluated through different indicators of development (see Table 6.2), which by its nature orientates students towards epistemology. This has typically focused on objective and subjective indicators and the strength and weaknesses of using them to measure and codify development. For the first time, however, the 2015 Differences in Development examination, did make explicit connection to perspectives. However, as discussed below, the potential to signal disciplinary-consciousness was not leveraged to its full potential, because of a weak choice of student exemplar.

In the 2015 Differences in Development student exemplar, which are released to guide teacher knowledge and practice, 'prespective' [sic] was used as a synonym for a 'wider view' of human development measurement. That is, according to the student, the Human Development Index gives a broader view (or, in the student's words, a "better picture") than any single indicator of development. This is not incorrect. What I suggest, however, is that in this case, 'perspective' is used in a vernacular sense, rather than being utilised to show disciplinary-consciousness. Moreover, the definition given to perspectives was not related to geographical knowledge as the object of study (see Figure 6.4). If that definition were to be re-imagined as "perspectives influence the questions that geographers ask, how 
Read the geographic concept below and refer to it when answering this question.

\section{Geographic Concept}

Perspectives involve people's viewpoints (what they think). Viewpoints are influenced by people's values (deeply held beliefs about what is important or desirable).

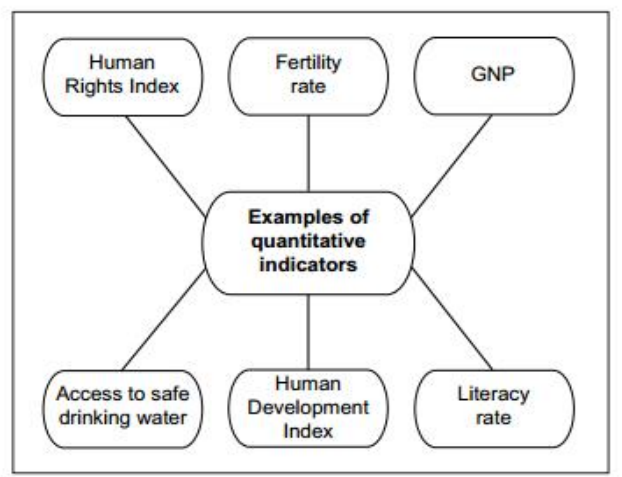

Fully explain the usefulness of quantitative indicators as a way to measure the development in at least TWO case study areas.

Space for planning is provided on page 3 .

In your written answer on pages 3,4 , and 5 , you should:

- use geographic terminology

- $\quad$ use the geographic concept of perspectives

- integrate comprehensive supporting case study evidence.

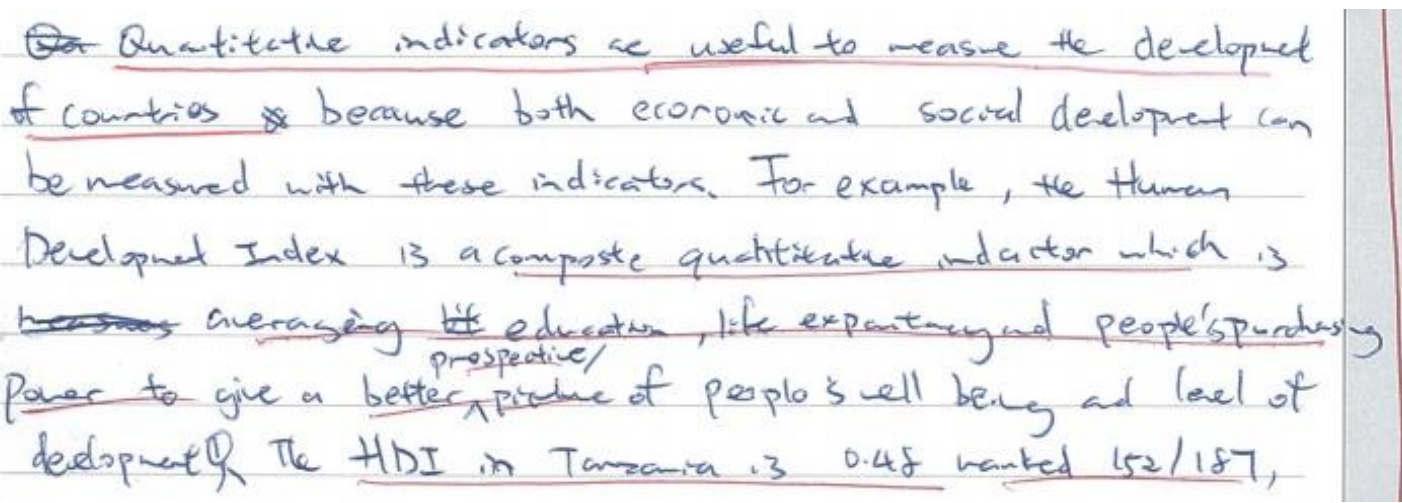

Figure 6.4: NCEA Level 2 'Excellence' exemplar script, 2015 (NZQA, 2016b)

they collect and analyse data and make conclusions. Geographers' understandings of phenomena and events are shaped by their disciplinary perspective" it might elicit a rather different response. ${ }^{15}$ For example, in this particular exam, the student might have explored empirical perspectives, by highlighting how quantitative indicators allow for efficient

\footnotetext{
${ }^{15}$ Assuming, of course, that teachers have taught about indicators of development in a disciplinary conscious way.
} 
comparisons between case study areas and are also useful for showing change in those areas. Alternatively, the student might have explored positivist perspectives, by commenting on how indicators can be used to make predictions and generalisations. I do not lay the problem at the door of either the student or the examiner for choosing this script. This is because the disciplinary un-conscious, colloquial use of the term perspective is in keeping with the definition of perspective given in the exam question. There were many other fine reasons for selection of this script as a model of 'excellence', but the example did little to signal to teachers a notion of perspective that goes much beyond equating it with the low-level idea of 'viewpoints'. I also note that the NCEA Level 2 Applied Skills and Concepts exam included perspectives explicitly for the first time in 2015, although its 'match a quote with a person' question also treated perspective synonymously with viewpoint/perception. These examination examples are, therefore, an example of reaping what has been sowed in the official recontextualising field.

At NCEA Level 2, although perspective was examined in the Natural Landscapes exam eight times, these exclusively used the stakeholder framing. The focus on indicators of development in the Differences in Development exam certainly opened an epistemological doorway (see later), although seven of the eight examples were implicit, and did not mention the term perspectives. Perspectives was far more likely to appear in the NCEA Level 3 applied skills exam (six times) than the Level 2 version (once), which on one hand suggests it was considered a higher-level concept, albeit all bar one of these utilised the stakeholder framing.

In 2007 the NCEA Level 3 applied skills and concepts examination asked candidates to comment on photos depicting parts of Christchurch city from a feminist perspective, with a precursory statement that "Cities can be viewed as gendered, that is, parts of a city can be viewed as masculine and other parts viewed as feminine" (NZQA, 2007c, p. 6). The question received a negative response from at least one family through the media, although the rejoinder from academics justified this as legitimate, if challenging, geography (Brooker, 2007). The examiners' report, however, chided teachers that despite plenty of advance warning, "it was very apparent that many candidates were unaware of this requirement and subsequently unprepared" (NZQA, 2008a, p. 4). Feminist geographies 
have not appeared in any other examinations at Level 3 since, and following the 2007 NCEA Level 3 skills and concepts exam, perception or economic, social or environmental perspectives have become the standard requirement. The 2007 examination was the most concerted effort to introduce disciplinary-consciousness into NCEA Level 3 examinations, yet poor student performance seems to have given little encouragement for successive examinations to tread a similar pathway.

\subsubsection{Perspectives in NCEA coursework materials}

Disciplinary-consciousness was also weakly signalled to teachers in internal assessment materials. For example, in a piece of work awarded 'Excellence' the commentary from the moderator states that "This student has fully explained how the values and perceptions held by the NZRCA led to their response. The student shows depth of understanding by explaining how the strength of other lobby groups influences the perception of NZRCA" (NZQA, 2015a, p. 2, my emphasis). The stakeholder focus was unequivocal.

As noted in Figure 6.2, disciplinary-conscious perspectives are taken to be the lenses through which geographical research is undertaken. Yet there is little expectation of disciplinary-consciousness in relation to methodology signposted in any of the research focused achievement standards at NCEA Levels 1-3. For example, in NCEA Level 3 research, students are expected to critically evaluate the research process through a discussion of alternative research methods and their implications (NZQA 2012). Despite the potential, there is no mention of the role of perspectives shaping alternative research methods. The level of critique expected assumes an implicit positivist research paradigm, rather than having the opportunity to explore how the research might have been approached from a different paradigm or perspective. This echoes Morgan's (2012) observation that students may become "puzzle-solvers in a paradigm rather than questioning the paradigm itself' (p. 64).

In recent years, the NZQA has published moderator annotations of student coursework. Similar to the exemplar scrips from examinations, these materials are designed to give teachers direction. In Figure 6.5, the student critique of their research recognised that a questionnaire seeking residents' impressions of Rotorua congestion points, could be 
augmented by objective people counts. While the first sentence is a focus on different methods, the second sentence is strongly suggestive of an epistemological understanding of the differences in the nature of evidence. The moderator comment focuses on different methods, missing the opportunity that two different paradigms drive such methods: a humanist perspective in which a questionnaire explores 'sense of place' and an empiricistscientific perspective that seeks to measure an 'objective reality'. To my mind, this was an opportunity lost by the NZQA coursework moderator to present a clear signal to teachers about the connection between methods and theoretical perspectives underpinning geographical knowledge production.

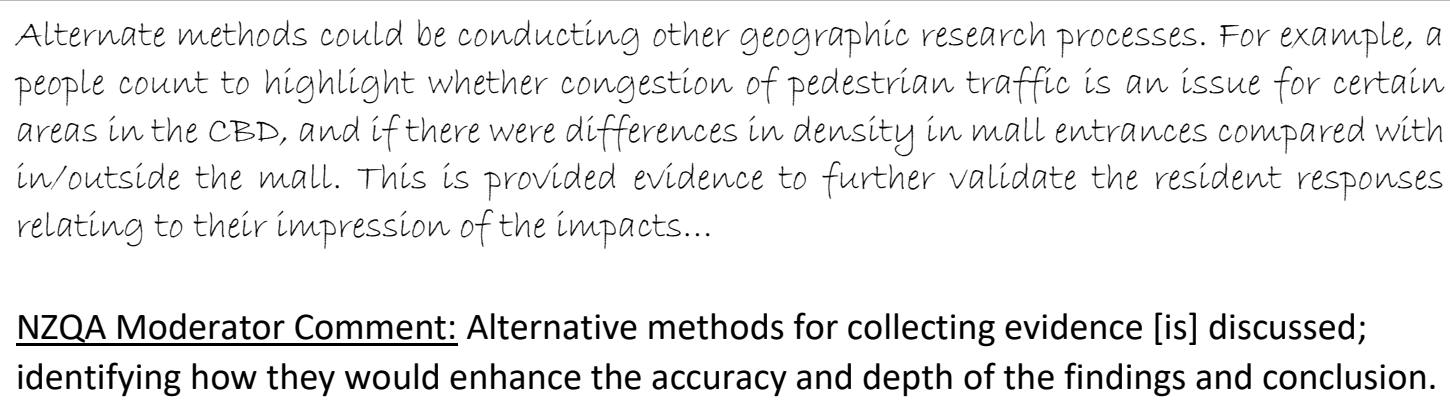

NZQA Moderator Comment: Alternative methods for collecting evidence [is] discussed; identifying how they would enhance the accuracy and depth of the findings and conclusion.

Figure 6.5: Moderator report on student reflection (source: NZQA, 2015b)

Since 2013 a new NCEA Level 3 achievement standard (Analyse a significant contemporary event from a geographic perspective) was added to the suite of internal assessments. This standard defines a geographic perspective as "a spatial dimension and the interaction between people and the environment" (NZQA, 2012, p. 2). Thus this achievement standard orientates perspective towards boundary maintenance, in this case taking both a 'spatialist' and 'interactionist' view of geography (Walford, 1996). The key point here, is that the geographical perspective was a given, rather than a contestable idea with which to engage students (Firth, 2011b). As such, although there is an underlying view of geography to this achievement standard, it certainly does not direct teachers to strongly consider a range of theoretical perspectives when they select their event.

Taking into account the limited extent to which disciplinary-consciousness has been signalled in the last decade of NCEA assessment, I now turn to scholarship level materials, 
with the possibility that disciplinary-consciousness have been 'saved' for the most capable of New Zealand's geography students.

\subsubsection{Perspectives in Scholarship Geography Examination Materials}

Scholarship examinations are the highest level of school qualification, that seek to reward the most academically able students (since 2005 the top 3\% of the NCEA Level 3 cohort). Only a small number of students choose to do these exams every year in addition to their NCEA qualifications. It is explicitly referenced in the Scholarship exam prescription that students will "incorporate a range of different ideas and perspectives to present a supported argument" (Ministry of Education, 2012a). The nature of scholarship exams is such that the questions are open-ended, and so the wording of the questions does not necessarily explicitly mention perspectives. For this reason, my analysis of perspectives in Scholarship drew upon Assessment Reports written by the Scholarship Examiner and was supplemented by Top Scholar scripts published on the NZQA website.

A summary of the attention given to perspectives by the Scholarship examiner in Assessment Reports, 2005-2015, is presented in Table 6.3. For ease of interpreting the summaries, I have highlighted the commentary that identifies disciplinary-conscious, stakeholder, and boundary maintenance framings of perspectives in different colours. Two major themes arose from my analysis of these scholarship examiner reports. The first theme was that the scholarship reports accepted a broad range of what counts as a perspective. Variations in how perspective was accepted by the Scholarship examiner was well illustrated by the extracts of 'successful answers' in the 2005 scholarship assessment report, which noted both disciplinary theoretical perspectives and stakeholder perspectives as examples of good answers: Geographers as scientists with "dispassionate outside expertise" were side-by-side with the personal perspectives of floodplain inhabitants (NZQA, 2006a, p. 6). In this case disciplinary-consciousness was aligned to a positivist framing, although this was in no way signalled in the examiner report. Furthermore, the representation of geographers as 'value-free' scientists is a very contestable axiological statement. 


\begin{tabular}{|c|c|}
\hline Year & Summary of commentary \\
\hline \multirow[t]{3}{*}{2005} & $\begin{array}{l}\text { Noted that there are no easy guidelines or exemplars to follow in case of perspectives. Also } \\
\text { noted that some candidates examined the idea of perspectives when used in academic } \\
\text { studies. Suggested a need to distinguish perspectives from, but relate them to, perception, as } \\
\text { many candidates regarded both synonymously. }\end{array}$ \\
\hline & $\begin{array}{l}\text { Offered extracts from "successful answers" in which perspectives were seen as: } \\
\text { Views and opinions of English and Bangladeshi perspectives on flooding/ local council } \\
\text { working from a regulatory perspective/ personal perspectives of riverside dwellers (x2) }\end{array}$ \\
\hline & "Geographer as scientist who was a "dispassionate outside expert..." \\
\hline 2006 & $\begin{array}{l}\text { Stated that best candidates understood how perspectives shape and influence the views and } \\
\text { opinions people and groups have about events, issues, and questions. Clash between } \\
\text { conservation and economic priority views was recognised by successful candidates. Less } \\
\text { successful answers included discussion of a range of views and opinions rather than deeper } \\
\text { perspectives. Suggested that why people had views and opinions required consideration of } \\
\text { "attitude and philosophy". }\end{array}$ \\
\hline 2007 & $\begin{array}{l}\text { Successful answers included perspectives where views of people directly impacted by } \\
\text { desertification were compared with views of national and international agencies. Although } \\
\text { implicit, emphasis was on difference between humanist and scientific perspective } \\
\text { (emphasised by reproduction of a student extract). }\end{array}$ \\
\hline 2008 & $\begin{array}{l}\text { Best performing candidates able to differentiate between viewpoints and perspectives. } \\
\text { Candidates not achieving scholarship had prepared in-depth material about perspectives, but } \\
\text { used it when not relevant to answer. }\end{array}$ \\
\hline 2009 & $\begin{array}{l}\text { Scholarship students showed correct understanding of perspectives provided in resources, } \\
\text { whereas students who did not achieve included non-relevant perspectives. }\end{array}$ \\
\hline 2010 & No comments specific to perspectives. \\
\hline 2011 & $\begin{array}{l}\text { Candidates awarded Scholarship with Outstanding Performance understood the nature and } \\
\text { scope of the discipline of geography to support the answers and identified relevant } \\
\text { perspectives in their discussions. }\end{array}$ \\
\hline 2012 & $\begin{array}{l}\text { Stated that candidates generally understood the different perspectives that "arise out of ways to } \\
\text { reduce poverty across the globe." }\end{array}$ \\
\hline 2013 & Candidates were able to explain geographic perspectives on who should benefit from mining. \\
\hline 2014 & $\begin{array}{l}\text { Many candidates failed to include reference or discussion about perspectives. Stated that } \\
\text { candidates should be aware of the differences between perspectives and point of view. }\end{array}$ \\
\hline 2015 & $\begin{array}{l}\text { Successful candidates understood how different people or organisations had different } \\
\text { perspectives on the challenges facing agriculture. Named social and environmental } \\
\text { perspectives. Noted, however, that many candidates failed to include reference or discussion } \\
\text { about perspectives. Like previous year stated that candidates should be aware of differences } \\
\text { between perspectives and point of view. }\end{array}$ \\
\hline
\end{tabular}

Key: Disciplinary-conscious $=$ red $;$ Stakeholder $=$ green $;$ Boundary maintenance $=$ blue

The 2005 Scholarship Assessment report also noted that "some candidates examined the idea of perspectives when used in academic studies" (NZQA, 2006a, p. 6). Significantly, however, there was no indication of how favourably this engagement with scholarly knowledge production was viewed by the examiner, as the note was not connected to 
specific exemplars of successful answers. Furthermore, in the 2005 NZQA scholarship report the examiner directed teachers to the 1990 geography syllabus where they could find "perspectives of different groups of people in relation to a global or local issue" (see Table 6.3). Such advice unequivocally promotes stakeholder perspectives. In the 2016 Scholarship examiner report it was noted that perspectives required exploration of "the attitude and philosophy"(NZQA, 2007a, p. 5) that shaped views and opinions, but there was no elaboration of what this might mean.

My review of the publicly available geography 'Top Scholar' ${ }^{16}$ scripts shows that 'what counts' as perspectives also varied. For example, the 2015 Top Scholar script justified the most significant challenges facing agriculture through broad sustainability, economic and demographic perspectives. In contrast, the 2011 Top scholar assessed the likely effectiveness of solutions to solve the global water scarcity crisis through technocentric, behavioural and market method approaches. These latter perspectives were more theoretical than the thematic terms of 'social', 'economic' and 'environmental' perspectives. In 2009, the depth of knowledge about a single perspective proved compelling: the Top Scholar used a capitalist perspective to shape his/her analysis of the global food crisis which analysed cheap (biofuel) solutions, urban sprawl, increasing food prices and price controls. Although this script did not show a range of theoretical perspectives, it was a fine example of synthesising a number of themes around the dominant mode of production. There is evidence, therefore, that disciplinaryconsciousness exists in the upper echelons of student achievement, which raises the question of whether it can be accessed by students with less lofty aspirations.

The second major theme of the scholarship examination reports is that there was regular feedback to teachers that students needed to distinguish between perception/viewpoints and perspectives (NZQA, 2006a, 2007a, 2009a, 2015f, 2016a). For example, for 2005 the examiner noted that "there are no easy guidelines or exemplars to follow for perspectives" (NZQA, 2006a, p. 6) and that there was a need to distinguish perspectives from, but relate them to, perception, "as many candidates regarded both perception and perspective as the

\footnotetext{
${ }^{16}$ The Top Scholar prize for geography is awarded annually to the individual student whose Scholarship examination is judged to be the highest standard.
} 
same thing" (p. 6). A similar message was noted in the comments of the 2015 Scholarship assessment report which stated that "Candidates should be aware of the differences between perspectives and points of view" (NZQA, 2016a, p. 2). Note that while this confusion was for geography students, these assessment reports are a dialogue between the scholarship examiner and teachers.

\subsubsection{A summary of 'perspectives' in assessment materials}

My analysis of perspectives in assessment materials indicates negligible orientation to disciplinary-consciousness, with a few rare exceptions, especially in studies of development and scholarship. In contrast, the signalling of stakeholder framing of perspectives were most common in assessment materials. As Table 6.2 showed, the stakeholder framing was evident in five of the six years in which the concept was examined in the NCEA Level 3 Applied Skills examination, 2005-15. The NCEA Level 2 Natural Landscapes exam exclusively emphasised stakeholder perspectives in eight exams over the same period.

In contrast, the only significant evidence of the nature of disciplinary knowledge was in the Level 2 Differences in Development examination. Typically, however, the questions in this exam focused on the substantive concepts of 'objective and subjective indicators of development' rather than explicit connection to the concept of perspectives. The notable exception was in 2015, where the students were asked to connect measurement of development with the concept of perspective. As my analysis highlighted, however, (refer to Figure 6.4) an 'Excellence' script exemplar did very little to signal to teachers how indicators of development are useful empirical referents that would support a broader positivist view of development.

My analysis of examiner reports suggested that where disciplinary-consciousness may have been necessary, student exemplars profiled as 'Excellent' produced thin expressions. According to a Level 3 chief examiner, the inclusion of feminist perspectives as a lens through which to view Christchurch was poorly prepared for by students, and by inference, their teachers (NZQA, 2008a). Furthermore, this rare foray into disciplinaryconsciousness, appears to have reduced the will for subsequent examiners to introduce 
alternative theoretical perspectives. Little wonder, therefore, that in a 'what is assessed is what gets taught' environment (Hipkins et al., 2016), geography teachers are likely to remain wedded to the stakeholder framing of perspectives.

The recurring advice from the geography scholarship examiner(s) to teachers over the 2005-15 period was that many students were failing to distinguish between perspectives and viewpoints. Given that the design of scholarship examinations is to reward sophisticated thinking, the analysis casts doubt on whether even top students (and, by extension, their teachers) are becoming disciplinary-consciousness or are falling back on the relative safety of viewpoints/perceptions and broad socio-cultural, economic and environmental themes. While there was some evidence of disciplinary-consciousness indicated in some of the 'Top Scholar' examples, these were, by definition, the exceptions rather than the rule.

\subsection{Perspectives in the 2009 social sciences position paper}

In the context of a period of national curriculum review, from 2005-8 a group of five nationally recognised social science education experts wrote Understanding the Social Sciences as a Learning Area: A Position Paper which, in addition to providing an account of the history of the development of the social sciences in New Zealand schools, also sought to define important terms and concepts (Mutch et al., 2009). In their brief appraisal of geography as a constituent subject of the social sciences, the 2009 position paper authors recognised the 1999 NZBoGT position paper as an "in-depth critique" of school geography in the 1970s and 80s, but also acknowledged that suggestions in the position paper led only to "minor changes to the syllabus via the development of the geography achievement standards for the NCEA qualifications"17 (Mutch et al., 2009, p. 28).

Perspectives was stated as one of the key terms of the social sciences, although the authors were careful to identify different applications in different subjects:

\footnotetext{
${ }^{17}$ The most visible of these changes that suggest a recontextualisation of 'new paradigms' of geography, was the incorporation of a list of Māori concepts to be applied to geographical contexts in NCEA assessments.
} 
The term perspective is used in different ways across senior social science disciplines. For example, in history, perspective means the lens through which someone interprets actions, experiences and the points of view of others. This may be influenced, for example, by a person's ethnicity, age, gender or socio-economic status. In geography and senior social studies "perspective" means a generally accepted body of thought, synonymous with "world view", "theoretical framework" and "paradigm" - such as feminist, ecological or socialist world views.

(Mutch et al., 2009, p. 9)

It is clear that some work was being done here to signal disciplinary-conscious geography, especially with the inclusion of 'paradigm', although it should be noted that there was no mention of this term in the Geography Curriculum Guides written since the release of the position paper. The statement distinguishes geography's use of perspectives from history, which unsurprisingly perhaps, has a strong orientation to the stakeholder framing. Elsewhere in the position paper, the authors also acknowledged theoretical debate in the parent disciplines that influenced earlier social science curriculum development in the 1990s:

In the decade from the late 1980s to the late 1990s, scholars used postmodern and post-structural perspectives about the nature and goals of knowledge to question the mainstream paradigms and assumptions of the social science tradition...Matauranga Māori and the scholarly body of writing around the centrality of the Treaty of Waitangi informed indigenous, bicultural and cross-cultural perspectives and methodologies that have influenced social sciences contexts for learning (Mutch et al., 2009, p. 20).

The last three words of this passage (i.e. "contexts for learning") seems to align with the Bernsteinian $(1996 ; 2000)$ 'specific problem plane'. That is, students have studied issues in society raised by biculturalism. This does not, however, give any clues about whether teachers or students should explicitly engage with the general approach plane or, more specifically, indigenous epistemologies.

Notwithstanding the references to theoretical perspectives, very little of the 2009 Social Science position paper connected perspectives with disciplinary-consciousness. The following statement about geography: "Students learn how people perceive, represent, 
interpret and interact with places and environments" (p. 28) is clearly oriented to how people see the world differently, but it is open to the reader whether this is applied to geographers in the field of knowledge production (i.e. the geographical approaches framing) or to individuals, groups and organisations (i.e. the socio-cultural stakeholder framing).

\subsection{Perspectives in text books}

The final area I turn to examine signalling of perspectives is in textbooks. In New Zealand, local textbooks are used to support curriculum and assessment aims directly, and are widely used by teachers. In this section, I analyse the signalling of perspectives in two widely available geography text books. Informed by my previous analysis of assessment materials I purposively chose two relatively recent texts: the first is Our World: Geography concepts and case studies for New Zealand Students (Newton, 2011) and the second is Differences in Development NCEA Level 2 (Wakeford, 2013). The first text was chosen for its inclusion of perspective as one of the seven key concepts in New Zealand school geography, which was a stated feature of the textbook. The second text was chosen in light of my analysis of NCEA examination materials, which showed that there was a strong opportunity for empirical perspectives to be explored through the commonly assessed idea of indicators of development (see Section 6.3.1 earlier).

In terms of the placing of perspectives, there is a subtle difference between the two texts. Newton's (2011) text takes the approach of illustrating perspective as one of the seven key concepts of the current $N Z C$. Indeed, each chapter in the entire text is structured around one of the seven key concepts from the $N Z C$, including a definition and followed by three case studies that illustrate the concept in action (Newton, 2001, p. 6). In effect, Newton is positioning perspectives as an organisational key concept in the same way that 'process', 'environment' and 'pattern' are (Taylor, 2008). In Wakeford's text, however, perspectives is noticeably absent in the box labelled 'key geographic concepts' (Wakeford, 2013, p. 2). Instead, Wakeford organises her textbook around a social inquiry approach (MoE, 2013) in which perspectives is a lens through which other concepts are viewed. For example, in a box labelled 'Exploring values and perspectives' a question posed is "How important is sustainability in the process of development?" (p. 2). 
The differences above notwithstanding, both texts explicitly advance the stakeholder framing of perspective:

The perspective that people have is influenced by their values, previous experiences, culture and identity. Perspective is influenced by who people are and where they come from. (Newton, 2011, p. 95).

Perspectives are often linked to support for, or opposition to an issue. They can also be linked to the background or situation of a person. E.g. indigenous people versus western business people. (Wakeford, 2013, p. 18).

In both textbooks, extracts from individuals giving their view (often on environmental issues) and 'talking heads' cartoons emphasise the stakeholder view. Yet both texts also contain fragments which hint at disciplinary-consciousness. For example, Newton (2011) states that "sustainable interaction with the environment may be achieved by preventing, limiting, minimising or correcting environmental damage..." (p. 140). Such a list could be connected to behavioural, regulatory/managerial or technocentric perspectives. Yet without any further guidance, such a connection would need to be made by teachers who are very knowledgeable of theoretical perspectives, especially as sustainability can be informed by a number of different epistemological stances (Stevenson, 2007).

Wakeford's (2013) textbook hints more explicitly at the work of geographers and economists, although the connection to theoretical perspectives systematised by geographers also requires teasing out:

Geographers and economists have endeavoured to study and theorise about the characteristics of development, and out of these studies the discipline of development studies has emerged. The subject first appeared in university courses and as a career path in the 1960 s, when many economists realised that economic theory alone would not solve the problems of the developing nations.

(Wakeford, 2013, p. 17)

While this statement is brief, it introduces a historiography approach to learning about geography that is only hinted at in curriculum guidelines. As discussed in Chapter 3, precedence for such an approach can be found in the Nature of Science literature, in which 
it has been advocated that learning about science can be achieved when students are given opportunities for "appreciating the history and development of important [scientific] ideas and the social and intellectual circumstances surrounding their development" (Hodson, 2014, p. 2541). Such a commitment to geography is, however, unlikely to develop from textbook fragments.

Wakeford's text does outline some broad theories of development such as capitalism, socialism, sustainable development, environmentalism, participatory development and social justice which aligns to past NCEA Level 2 exam questions about worldviews of development (see, for example, Table 6.2). A further chapter on 'How is development measured?' is also very well aligned to the focus on indicators of development, although it is left to a teacher to make the connection between the empirical and positivist perspectives underpinning the use of objective indicators.

\subsubsection{A summary of perspectives in two textbooks}

As in much of the materials analysed for this first phase of analysis, stakeholder perspectives prevail in these two textbooks. In both books there are statements in which there are vestiges of disciplinary-consciousness, although these are implicit rather than clearly signposted. In the activities of both books, the stakeholder perspectives prevail. Because textbooks validate knowledge through the tasks they set students, these are exceptionally strong signals to teachers about the use of perspectives. All of the activities in the two textbooks focused on learning about individuals and organisations, rather than asking questions or setting tasks that would deepen understanding about the nature of geographical knowledge, or the disciplinary perspectives which inform such approaches.

\subsection{Chapter summary}

The baseline for this analysis of disciplinary-consciousness was the 1999 NZBoGT position paper, which stated that criteria for an 'ideal' geography programme at the turn of the $21^{\text {st }}$ Century was to "be consistent with current geographic thinking by incorporating developments in approaches and methodologies in geographic study consistent with those currently used by academic and professional geographers" (p. 19). In this chapter, my 
substantive task was to explore the extent to which this idea had been signalled by curriculum and assessment materials in the intervening 15 years.

I have presented evidence which suggests that the aspiration of the NZBoGT position paper to have school geography more attuned to disciplinary development has not been overtly or consistently communicated to secondary school teachers via channels of curriculum or assessment materials. Indeed, there seems to be what I call a framing settlement, such is the prevalence of the stakeholder orientation to perspectives. A summary of my findings is presented in Table 6.4. While the geography senior secondary curriculum guides give the most developed account of perspectives in a disciplinary sense, there is a lack of evidence of what this might look like in practice. Without clear, unambiguous, and supported examples, the chance of having the disciplinary-conscious framing of perspectives cognitively accommodated is greatly diminished (Spillane et al., 2002). Furthermore, the evidence from examiner reports presented in this chapter suggested that 'perspective' and 'perception/point of view', have been used interchangeably by some students, despite some curriculum guide attempts to make distinctions between the two terms.

The legitimisation of theoretical perspectives, irrespective of its (limited) appearance in the curriculum guides (MoE, 2013) and more recent position paper (Mutch et al., 2009) is likely to struggle given its virtual invisibility in assessment materials and text books. Fragments of disciplinary-consciousness are unlikely to be seriously engaged with by teachers unless some more direct messaging, from multiple curriculum and assessment materials is clearly signalled. The focus of NCEA and Scholarship assessment materials appears largely anchored to issues connected to the stakeholder framing rather than the disciplinary orientation, which gives powerful incentive for teachers to follow that framing, to such an extent that disciplinary-conscious possibilities are rendered unnecessary.

Even at the niche level of elite Scholarship academic achievement, the examiner reports sent a clear message that while disciplinary perspectives should be more nuanced than at NCEA assessment levels, stakeholder framings remain entrenched. While there are 
Table 6.4: Chapter 6 summary of findings

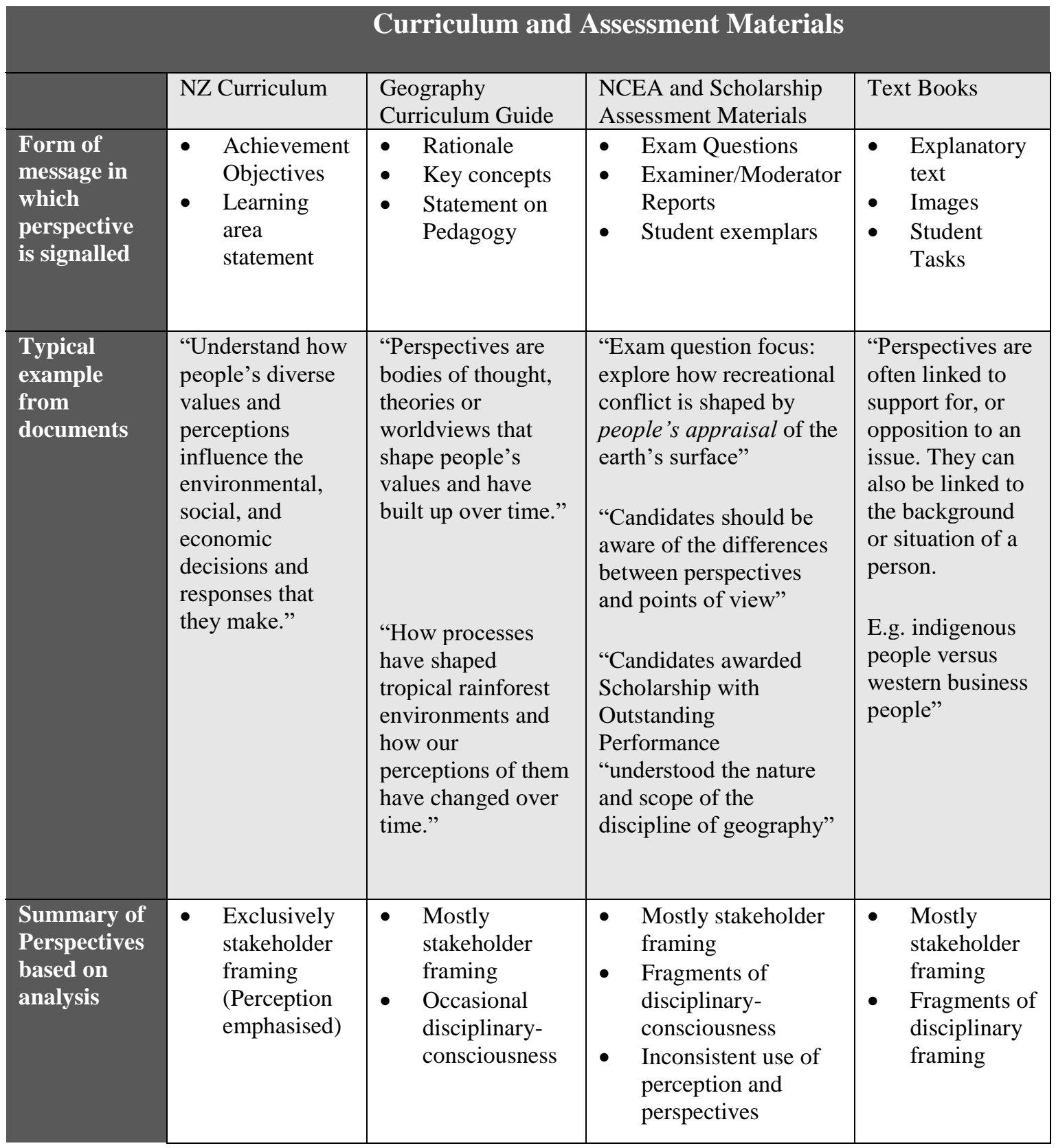

examples of 'Top Scholar' disciplinary-consciousness, these are exceptional, rather than the norm, even across a cohort of very capable students. The year-after-year signalling that students do not address perspectives well, is as much an indictment of the teaching than it is the learning. It is difficult to see a 'circuit-breaker' emerging from these reports, given the little exemplification of what disciplinary-conscious geography teaching and learning might amount to. 
The signalling of the key concept perspectives is somewhat muddled, and the great weight put on 'stakeholder framings' overwhelmingly occludes the fragments of a disciplinaryconscious orientation to geography. Further complicating matters is that there seems to be a fundamental confusion, in which 'perspective' is treated synonymously with 'point of view' or 'perception'. This confusion is a knot within the stakeholder framing, therefore preventing the likelihood of a disciplinary-conscious geography to develop.

While this chapter presents the current signalling of perspectives, an extra layer of investigation of the geography 'priesthood' (Bernstein, 1996; 2000) is required in order to give insights into the normative status of disciplinary-consciousness geography. In the following chapter, I sought the views of a group of geography subject specialists for their views on perspectives in school geography. This was to determine whether there was any appetite for engagement with theoretical perspectives by exploring what the perceived opportunities, challenges and barriers might be for explicitly revealing to students the theoretical foundations of geographical knowledge production. 


\section{Chapter 7: The Views of Subject Specialists}

\subsection{Introduction}

As noted in Chapter 5, Bernstein (2000) uses an ecumenical metaphor in which the actors responsible for the recontextualisation of knowledge from academia to schools are termed 'priests'. Crucially for my research, the priests of geographical education work in the field of recontextualisation. In this field, knowledge from the prophets of academia is selected and sequenced as part of the translation of ideas for the school subject, to be later interpreted by the teacher and student laity. In the English context, Puttick (2015a) found that such 'priests' (in his case examiners) held a great deal of sway in how curriculum was constructed, even to the extent that teachers complied with specific case studies advised by the examiner. I was interested to explore how this might play out in New Zealand geography.

In the New Zealand context, some subject specialists are contracted into temporary 'priesthood' roles of the official recontextualising field and pedagogic recontextualising field by a number of different institutions and government bodies. Those contracting this priesthood include:

- the MoE for curriculum guidance [ORF];

- the NZQA for examination setting or marking [PRF];

- publishing houses for text book production [PRF];

- the MoE for professional development provision [PRF].

- $\quad$ some ITE provision [PRF].

With such a range of actors, I was keen to explore how understanding of perspectives may have been recontextualised across this diverse group of geography education 'influencers'

In this chapter, I focused on the opinions of the 'priests' of the geography education community, by asking: how do curriculum and assessment specialists interpret the place and role of perspectives in New Zealand school geography? This second phase of research was stimulated by the original document analysis, as I was curious to discover how perspectives were understood by key subject specialists. By asking the 'priests' directly, I 
sought to get further insight to the findings of Phase 1. While the previous chapter focused on the current situation, the evidence presented in this chapter also sought to explore further the potential of a disciplinary-conscious approach to geography being taken. In order to do this, I initially identified a range of roles in the geography education community which shape curriculum and assessment.

Table 7.1 summarises the five distinct roles of these curriculum and assessment specialists/'priests', including how their work may influence teachers. It should be noted, also, that the exam writers, text book authors, curriculum advisers and professional development providers may also have been current or very recent teachers of geography.

Table 7.1: Subject specialist (Priest) roles

\begin{tabular}{|c|l|}
\hline \multicolumn{2}{|c|}{ Role } \\
$\begin{array}{c}\text { Exam Writer [EW] } \\
n=2\end{array}$ & $\begin{array}{l}\text { Responsible for crafting national, external assessments for NCEA Levels 2-3 or } \\
\text { Scholarship. Past examinations are one resource to guide teachers about expectations } \\
\text { of student learning requirements. }\end{array}$ \\
$\begin{array}{c}\text { [TBA] } \\
\boldsymbol{n}=\mathbf{2}\end{array}$ & $\begin{array}{l}\text { Producer of popular Year 12 or 13 geography texts on the market. Text books are } \\
\text { commonly used by geography teachers in senior secondary schools, and they are } \\
\text { typically marketed as being aligned to NCEA assessment. }\end{array}$ \\
$\begin{array}{c}\text { [CA] } \\
\boldsymbol{n}=\mathbf{4}\end{array}$ & $\begin{array}{l}\text { Have provided advice to Ministry of Education for matters related to the geography } \\
\text { curriculum. May have contributed directly or indirectly to online support material for } \\
\text { social science teachers. }\end{array}$ \\
\hline $\begin{array}{c}\text { Professional } \\
\text { Development } \\
\text { Provider [PDP] } \\
\boldsymbol{n}=\mathbf{2}\end{array}$ & $\begin{array}{l}\text { Presently or recently in a nationally recognised role as a provider of geography } \\
\text { specific professional development and learning. In a crowded market of professional } \\
\text { development opportunities, these roles are one of the few specific to geography } \\
\text { education. }\end{array}$ \\
\hline $\begin{array}{c}\text { Initial Teacher } \\
\text { Educator [ITE] } \\
\boldsymbol{n}=\mathbf{2}\end{array}$ & $\begin{array}{l}\text { Employed by one of six major tertiary providers of geography initial teacher } \\
\text { education. While predominantly focused on the education of beginning teachers, this } \\
\text { role extends to direct connections with teachers in schools. }\end{array}$ \\
\hline
\end{tabular}

As described in Chapter 5, I used an e-questionnaire, which was designed to initially explore the subject specialists' views of perspectives carte blanche, before focusing respondent attention on the 'geographic approaches'/disciplinary-conscious framing of perspectives advocated by the 1999 NZBoGT position paper. 


\subsection{How did the subject specialists view perspectives?}

In this section I present four key themes from my analysis of the views about perspectives by curriculum and assessment specialists. The four themes were:

i. The multiple purposes of perspectives;

ii. Framing of perspectives;

iii. Pedagogical approaches; and

iv. Challenges to teaching perspectives.

The full coding tables for all four themes are found in Appendix L. Table 7.2 in the following section shows an example of the coding analysis for the first of the four themes identified above (for an account of the data reduction process see Chapter 5, Section 5.5.2.3). Reading from the right towards the left of the table, this presentation format enables the reader to see how the open codes were grouped into increasing levels of abstraction, culminating in the single axial code which form the subheadings for the following four sections of this chapter.

\subsubsection{Multiple purposes of perspectives}

My analysis showed that the subject specialists revealed four major purposes of engaging with perspectives:

a) widening views - in which the purpose of perspectives was to build on and extend students understanding of how other people viewed the world;

b) critical thinking - in which perspectives were seen as an analytical tool to question assumptions and orthodox thinking;

c) personal positionality - in which the study of other perspectives allowed students to reflect on their own stance towards issues; and

d) active citizenship - in which understanding of diverse perspectives allowed students to be better informed as they considered people's responses to decisions or actively participated themselves.

Eight of the 12 specialists (see Table 7.2) explicitly focused on the need for students to understand a range of different perspectives. This was typically framed as the need to widen students' perceptual horizons, "because an understanding of perspectives enables students to grasp different ways of seeing the geographic world other than the scientific 
perspective they are most often exposed to" [CA1]. If students were equipped with a wider range of views, it would also, according to one specialist "make for better planning decisions" [TBA2], while for another it was also "very important for Geographers who are involved in decision making and planning processes to be aware of different perspectives and their own" [PDP1]. Foreshadowing Huckle's (2017) contention that school geography needs to explore deep societal mechanisms responsible for environmental malaise, one text book author suggested that "Social science needs to understand these 'forces' and their influence on human society." [TBA1].

Six of the specialists (see Table 7.2) indicated that engagement with perspectives encouraged aspects of critical thinking, either in terms of why the concept warranted a place in school geography or in terms of how they thought students should be able to utilise the concept. Three of the six specialists explicitly mentioned critical thinking skills. For example, one viewed introducing students to a range of perspectives being important otherwise "they may not be challenged to think differently, critically or beyond the cultural lens into which they were born/acculturated" [CA3]. While other specialists did not explicitly use the term 'critical thinking', others suggested terms such as 'weighting' or 'analysis' of different perspectives, thus implying dimensions of criticality (Elder \& Paul, 2010).

One of the ITE specialists extended critical thinking further towards a paradigm of social justice when s/he stated that:

perspectives...assist students with a means to develop their critical thinking skills. I see critical thinking not just as advantages and disadvantages, but as critical theory. What larger social, political, cultural, gender, environmental etc. forces are operating to impact on decision making about socio-geographic issues? [ITE2]

By name-checking critical theory (Habermas, 1972), this specialist appeared to be suggesting that geographic knowledge has the potential to be emancipatory if it allows students to critique oppressive forces - an indication of disciplinary-consciousness. What could not be determined, until a later point in the survey, was whether this respondent viewed her/his orientation as a background approach, or whether it was made explicit to students. 


\begin{tabular}{|c|c|c|c|}
\hline $\begin{array}{l}\text { Axial } \\
\text { Code }\end{array}$ & $\begin{array}{c}\text { Codes } \\
\text { (Participants) }\end{array}$ & $\begin{array}{l}\text { Open } \\
\text { coding }\end{array}$ & Exemplar Statements \\
\hline \multirow{10}{*}{$\begin{array}{l}\text { MULTIPLE } \\
\text { PURPOSES }\end{array}$} & $\begin{array}{l}\text { Widening } \\
\text { view } \\
\text { (EW2; TBA1; } \\
\text { TBA2; CA1; } \\
\text { CA2; CA3; } \\
\text { PDP1; ITE1) }\end{array}$ & $\begin{array}{l}\text { Understanding } \\
\text { different } \\
\text { perspectives }\end{array}$ & $\begin{array}{l}\text { - "Recent research shows that what some call "framing", and some } \\
\text { might think of as "spin" is much more important in understanding } \\
\text { how the thoughts and views of others can influence our thinking, } \\
\text { understanding and actions both individually and collectively" } \\
\text { "Because an understanding of perspectives enables students to } \\
\text { grasp different ways of seeing the geographic world"; } \\
\text { "Being able to understand that the world is not just seen } \\
\text { through one lens is vital to geographic study" }\end{array}$ \\
\hline & \multirow[t]{4}{*}{$\begin{array}{l}\text { Critical } \\
\text { Thinking } \\
\text { (CA1; CA3; } \\
\text { CA4; EW2; } \\
\text { PDP1; ITE2) }\end{array}$} & Critically & $\begin{array}{l}\text { - "Without students being introduced to a range of perspectives } \\
\text { during their studies they may not be challenged to think } \\
\text { differently, critically or beyond the cultural lens into which } \\
\text { they were born/acculturated" } \\
\text { "I would see the progression linked to increasing levels of } \\
\text { critical thinking, with students considering the impacts of wider } \\
\text { political, social, economic, cultural, technological, scientific, } \\
\text { environmental, feminist etc. forces..." } \\
\text { "A key part of critical thinking is the ability to look at multiple } \\
\text { viewpoints and why those views are held." } \\
\text { "If we do not awaken our students to these perspectives then it is } \\
\text { likely we will create young citizens less likely to challenge and } \\
\text { question what is happening within communities, our urban areas } \\
\text { and to our planet because of the decisions that have been made. } \\
\text { A good geographic education should develop the critical thinking } \\
\text { skills of our young people - to be the critical conscience of our } \\
\text { nation!" }\end{array}$ \\
\hline & & $\begin{array}{l}\text { Critical } \\
\text { theory }\end{array}$ & $\begin{array}{l}\text { - "I see critical thinking not just as advantages and disadvantages, } \\
\text { but as critical theory. What larger social, political, cultural, } \\
\text { gender, environmental etc. forces are operating to impact on } \\
\text { decision making about socio-geographic issues?" }\end{array}$ \\
\hline & & Weighting & $\begin{array}{l}\text { - "understanding weighting of different perspectives in different } \\
\text { societies and cultures" }\end{array}$ \\
\hline & & Analyse & $\begin{array}{l}\text { - "At Y13 they should be more ready to analyse the perspectives } \\
\text { seen within readings, documentaries or when speakers come in"; }\end{array}$ \\
\hline & \multirow{3}{*}{$\begin{array}{l}\text { Personal } \\
\text { positionality } \\
\text { (EW2; CA3; } \\
\text { CA4;) }\end{array}$} & Own position & $\begin{array}{l}\text { - "Being able to identify the position of others helps us to } \\
\text { understand and continually redefine our own position"; } \\
\text { "A capable Y13 student should be able to understand the } \\
\text { perspective through which they view the world..." }\end{array}$ \\
\hline & & $\begin{array}{l}\text { Conflict with } \\
\text { home }\end{array}$ & $\begin{array}{l}\text { - “...our students may find themselves in conflict with ethics or } \\
\text { perspectives of their homes, churches or peer groups. While } \\
\text { consciousness raising we also need to be teaching how to listen, } \\
\text { be open to the perspectives of others, to accept diversity..." }\end{array}$ \\
\hline & & $\begin{array}{l}\text { Live with } \\
\text { perspectives }\end{array}$ & $\begin{array}{l}\text { - "Students live with perspectives and studying them creates a } \\
\text { greater awareness of them, maybe even greater tolerance of } \\
\text { them." }\end{array}$ \\
\hline & \multirow[t]{2}{*}{$\begin{array}{l}\text { Active } \\
\text { Citizenship } \\
\text { (CA4; PDP1; } \\
\text { TBA1;) }\end{array}$} & $\begin{array}{l}\text { Decision } \\
\text { making and } \\
\text { solving }\end{array}$ & $\begin{array}{l}\text {-Very important for Geographers who are involved in decision } \\
\text { making and planning processes to be aware of different } \\
\text { perspectives and their own without negating either their own or } \\
\text { others understandings"; } \\
\text { "Understanding different perspectives will help students solve } \\
\text { some of the world's biggest issues" }\end{array}$ \\
\hline & & Debating skills & $\begin{array}{l}\text { - "work with a class on building their interactive discussion skills } \\
\text { so that they are ready to listen \& debate hard issues" }\end{array}$ \\
\hline
\end{tabular}


A further purpose of perspectives in geography suggested by three of the specialists was to develop students' personal positionality. Such a purpose was connected to the idea of looking outwards in order to look in. As one exam writer indicated, exploring a range of perspectives offered a platform to "continually define our own position" [EW2]. This specialist tied the outcome of personal positionality with the skill of thinking when stating that "reflexivity is an intellectual capacity and a core thinking skill that can be incorporated at almost any level of the curriculum" [EW2]. A note of caution was given by one specialist, however, when s/he suggested that self-awareness produced by “consciousness raising" could, at times mean, "our students may find themselves in conflict with ethics or perspectives of their homes, churches or peer groups" [CA3].

A fourth purpose of engaging with perspectives, according to four specialists, related to active citizenship, by emphasis of dispositional and action-oriented ideas. For example, one specialist noted the importance of critical thinking, that could enable students to "challenge and question what is happening in our communities, our urban areas, and our planet" and that this could be further enhanced by developing generic "interactive discussion skills so that they are ready to listen and debate hard issues without negating either their own or others understandings" [CA3]. The final part of this statement also echoed another specialist's hope of an outcome of "greater tolerance" [CA4] for fellow learners. A professional development provider suggested that the act of decision-making could be enhanced by engagement with perspectives, while a text book author went further, boldly suggesting that "understanding different perspectives will help students solve some of the world's biggest issues" [TBA2]. There was a clear sense, therefore, that perspectives were not simply to be learned about, but to be utilised in a participatory sense.

\subsubsection{Framing of perspectives}

In the previous chapter I used a tripartite analysis of perspectives (see figure 6.2). My analysis of e-questionnaire responses indicated that the subject specialists framed perspectives in some contrasting ways:

i. Stakeholder orientation - in which the framing focused on the views of individuals, groups and/or organisations associated with geographic issues; 
ii. Relationship to viewpoints and perceptions - in which the framing of perspectives focused on connections with, and differences between, viewpoints and values;

iii. As worldviews - in which framings focused on perspectives as the all-encompassing view that shaped individual and group perception;

iv. Disciplinary-conscious - in which framings of perspectives were linked to the views of geographers and the production of geographical knowledge.

Analysis of the e-questionnaire responses indicated that 11 of the 12 subject specialist specialists emphasised what can be described as what I have already established as a stakeholder framing of perspectives. The subject specialists had a clear vision of school geography providing learning opportunities to study the perceptions of individuals, groups and organisations, typically in relation to their interactions with environments: "Of course, how people have perceived and used the environments in which they live lends itself to perspectives learning" [CA3]. To one of the specialists, learning about perspectives was not simply an academic exercise, but was a necessary response to the changing demographic profile of contemporary New Zealand society:

As our country has a growing number of different nationalities/ethnicities coming to live in New Zealand and interacting with New Zealand in a number of different ways, students need to understand the different perspectives that these different groups might take towards a range of different issues. [ITE1]

The stakeholder orientation framing displayed in this statement is well aligned with the geography curriculum achievement objectives of the NZC (2007) and the social inquiry approach which encourages learning to "explore and analyse people's values and perspectives" and "consider the ways in which people make decisions and participate in social action" (MoE, 2007, p. 30).

A second framing of perspectives can be described as its relationship to viewpoints and values. Again, this is not altogether surprising, as the senior secondary geography guides present a diagram showing a 'nested' relationship between viewpoints, values and perspectives (see Figure 6.3). Nevertheless, the specialists presented the relationship between viewpoints and perspectives in ways that reveals slightly different conceptualisations. For example, a professional development provider stated that "After 
clearly stating a person's viewpoint, they need to ask: what is the lens this person is looking through?" and then later in the survey, that progression of learning about perspectives should follow the following pattern:

Year 11: describe the viewpoint and the reasons a person gives to justify their viewpoint. Year 12: as above plus what has influenced the person to hold this view Year 13: as above plus description of the lens and factors that might change the views. [PDP2]

There would be little controversy in the belief that learners need to progress from the simple to the more complex, from the concrete to the abstract; and certainly viewpoint might be considered a more straightforward concept than perspective because of its familiarity in everyday contexts (Taylor \& Keown, 2016). Yet it also seemed that PDP2 had interpreted the curriculum guidelines model (refer back to Figure 6.3) in a way which justified delaying deeper thinking about perspectives to Year 13, thus limiting students' capacity to be exposed to deeper notions of perspectives earlier.

Although the geography curriculum guides state that “...differentiation of concepts applies across the levels [and] a student's understanding of a concept assessed at NCEA Level 1 will be at a more basic level than an understanding at levels 2 or 3" (Ministry of Education, 2013c), an important distinction, emphasised in Chapter 6, was that viewpoint and perspective were not the same concept. As CA2 noted: "[The] ability to interpret a range of viewpoints - requires initial understanding of perspectives", which suggested a parallel development of perspectives and viewpoints. As TBA1 stated, “... teachers need to work hard to get beyond the viewpoint and values language they have been using from Year 1!", suggesting that s/he viewed perspectives as having a place in geography across all three levels of the senior school. This position would suggest engagement with perspectives at an earlier stage than indicated by PDP 2 on the previous page. The need to engage with perspectives at an earlier age was further underscored by the observation of one curriculum adviser that:

There is some evidence from NZ classrooms that Level $5^{18}$ learners are capable of understanding a range of perspectives as they apply to an issue. At Year 11

\footnotetext{
${ }^{18}$ A level of NZC learning typically the outcome of Year 9 and 10 learners.
} 
I would expect an understanding of umbrella terms such as 'feminist' perspectives... by Year 13 I would be looking for an understanding of subtleties under this umbrella. [CA1]

So, although relationships between perspectives and viewpoints and values were made by some of the specialists, there were some quite different views on what this meant for progression.

Five of the specialists framed perspectives as worldviews, consistent with the geography senior secondary curriculum guide (see MoE, 2013c). Three of the specialists used the term 'lens' to describe worldviews, a curriculum advisor noting that "not everyone sees the world through the same lens and that often the world-communities within which we live have been shaped both spatially and temporally by certain world views/perspectives i.e. Judeo-Christian, Capitalist" [CA3]. While this example was clearly a shift to the philosophical, it was unclear whether "everyone" was being applied to stakeholders, geographers, or both.

The final framing of perspectives was the most transparent disciplinary-conscious approach, albeit it was notably rare. It is important to note that subject specialist responses for this section were before the question 7 intervention, in which I asked the specialists to consider a more disciplinary-conscious orientation to perspectives. When asked to consider which aspects of geography teaching and learning they felt were more or less suitable for teaching the concept of 'perspectives' (see Question 5, Appendix B), only one specialist offered an explicit disciplinary-conscious interpretation of perspectives:

Human geography appears easier to apply an understanding of perspectives. However, I do wish that the perspective being used in physical geography was overtly named for students as a scientific perspective, and that students [developed] an understanding of the nature of scientific inquiry... as opposed to teaching physical geography as inert fact. [CA1]

This was one of the most transparent statements oriented to a disciplinary-conscious geography. This curriculum adviser's focus on the problem of 'inert fact' explicitly drew attention to the deliberate construction of knowledge by disciplinary communities of 
practice and aligns with Moje's (2015) contention that disciplinary literacy "makes clear to students that the disciplines are human constructions, with social and cultural norms, rather than merely bodies of knowledge to be digested" (p. 268).

The two textbook authors were the only two others who viewed perspectives as being appropriate for all aspects of geography, although the following comment from TBA1 suggests that their view was connected with a stakeholder framing of worldview, rather than a disciplinary orientation in an epistemological sense: "Most areas really as perspectives effect all aspects of life and society. The concepts are probably most accessible in relation to ecological, feminist/gender, cultural and globalization perspectives." [TBA1]. The fact that the other eight specialists identified issues and themes, which "seem to be [the] 'natural' area for perspectives based teaching and learning" [EW2], is further evidence that although CA1 had a disciplinary-conscious orientation to perspectives, s/he was very much in the minority.

Half-way through the survey an abridged extract of the disciplinary-conscious view of perspectives from the geography curriculum guideline was given to participants (see Appendix B, Question 8). After this, engagement with the nature of geographical knowledge permeated a wider number of specialist responses. For example, one curriculum adviser suggested that perspectives presented "permission to branch off into new and exciting areas of geography" [CA4] while another observed that the changing nature of geography had moved from an "accepted line or understanding" to a position where "we embrace uncertainty and difference" [CA3].

To get a sense of how much disciplinary-consciousness the specialists gave to their use of perspectives, I asked the subject specialists to give 'an approximation of what time was spent in their work on a stakeholder and an epistemic (how geographical knowledge is made)' orientation. There was no clear pattern of the focus given to perspectives by the subject specialists. For example, a text book author indicated that the nature of the material $\mathrm{s} /$ he wrote about, demanded quite a theoretical approach to perspectives, as s/he believed that a greater emphasis was "needed on more modern day perspectives to focus on real organisations" [TBA2]. An exam writer who reported 100\% epistemic focus supported 
his/her judgement with the statement that "Stakeholders are generally committed to their own positionality and are often un-reflexive although openly political" (EW2). While this statement is certainly supported by example of stakeholder actions worldwide, it was unclear why this meant EW2 believed s/he gave all of her/his thinking to epistemic dimensions of perspectives.

\subsubsection{Suitable pedagogy}

Every one of the 12 specialists focused at least some of their responses about the necessary approaches to pedagogy required to teach perspectives well (See Appendix M). I coded these as six themes:

i. Issues-based pedagogy - in which the specialists focused on the necessity of authentic geographical contexts, in which there tended to be some sort of debate or controversy about an event or use of some phenomena;

ii. Identification of perspectives - in which specialists indicated that teachers would be able to provide texts that would allow students to name or label perspectives or worldviews;

iii. Analysis of perspectives - in which students were given the opportunity to scrutinise different characteristics of perspectives;

iv. Application of perspectives - in which students should be given the chance to transfer their understanding of perspectives to new case studies or scenarios;

v. Future Focus - in which students are given the opportunity to consider the ramifications of groups having different perspectives and how this may contribute to decision making; and

vi. Balancing different framings of perspective - in which the stakeholder framing of perspective might be a stepping stone to disciplinary perspectives.

The questionnaire responses from the curriculum and assessment specialists firmly located perspectives in the longstanding issues-based pedagogical approach to teaching geography in New Zealand (Taylor, Richards, \& Morgan, 2015). This was commonly referred to in terms of 'issues', and typically supported by the naming of topics, case studies, and/or "socio-geographic issues such as overpopulation, dislocation caused by conflict, providing 
sufficient food for the world's population etc." [ITE2], in which perspectives of individuals, groups, or organisations could be studied.

There was considerable crossover between the issues-based pedagogy and the stakeholder conceptualisation of perspectives described in the previous section of this analysis. In keeping with this cross-over, TBA1 suggested that s/he would exhort a beginning teacher to bring stakeholders into the classroom, by introducing an issues-based approach through "REAL and SPECIFIC people to support or highlight the perspective - bring these to life with video or meet in person - making a connection to REAL people [is] important" [TBA1]. Similarly, for CA3, "bringing in speakers who may offer different perspectives on issues" was a key teaching approach.

Three more detailed pedagogical approaches commonly espoused were the identification, analysis, and application of perspectives. Typically, participants signalled the identification approach by using low-level thinking terms such as 'naming', 'matching' or 'identifying' (Bloom, 1956). A higher level of engagement was indicated by six of the specialists who indicated that teachers would need to encourage students to 'explain' or 'analyse' different perspectives. For example, one specialist suggested that analysis of political perspectives could be done by "the good old tried and true example of looking at an incident using three different news reports written through three different political lenses" [CA3]. Such an approach aligns well with one of Puttick's (2013) suggestion that looking at perspectives can be facilitated by comparing and contrasting perspectives. Another subject specialist indicated that an analysis of perspectives could be broken down into a series of related questions that asked "What reasons are they giving? What has influenced their ideas? Have their ideas changed? Are they likely to change? What might influence their view?" [PDP2]. An 'application' approach suggested higher order thinking in which, after introduction, students were able to 'transfer' and 'apply' perspectives in relation to new scenarios, case studies, or "increasingly unfamiliar and abstract situations" [CA2]. It is clear through these answers, however, that the meta-understanding was of perspectives as applied to 'all kinds of people' rather than knowledge as systematised by geographers (Wright, 1947). 
For seven of the specialists, the pedagogical interpretation of perspectives also had a view to the future. This was typically expressed through a focus on 'decision making and planning', the 'potential impacts' of events or, in one case, was framed as a question: "What are the societal consequences of different groups having perspectives?" [ITE 2]. This focus aligned well with the critical thinking purpose that was articulated by subject specialists, as such consequentialism requires students to speculate, forecast, and hypothesise based on a range of trajectories.

CA1 expressed a pedagogical relationship between the stakeholder and knowledge production framing of perspectives:

Understanding the nature of geographic knowledge is the end-game, however being able to explore the perspectives of particular groups is an important step towards that outcome. An understanding of how perspectives are 'received' and infuse thinking and actions is tied to an understanding of how knowledge is produced. [CA1]

So, although CA1 explicitly acknowledged disciplinary perspectives (see Section 7.2.2), s/he was not suggesting that disciplinary perspectives would usurp the orthodox stakeholder framing, but that the stakeholder framing could act as an important scaffold for the disciplinary-consciousness to be realised.

\subsubsection{A challenging concept to unpack}

Significant impediments to teaching perspectives were given by eight specialists, who indicated four broad challenges associated with perspectives: (i) the difficulty of interpretation; (ii) the scope of perspectives; (iii) challenges to the boundary of geography and; (iv) a lack of pedagogical guidance. In this section I present the evidence that supports the challenges of this concept for teachers.

Two of the four major challenges were the difficulty of interpretation and the scope of perspectives. That is, specialists felt that the intellectual terrain of some disciplinary perspectives were too challenging to be tackled at school geography level, and that there were also so many perspectives that teachers would need to carefully select those that they considered most appropriate for their teaching. Both of these challenges were especially articulated in relation to a list of perspectives that the specialists were asked to assign 
relative importance to. Figure 7.1 shows the specialists' perceived importance given to this list of different perspectives (see Section 5.5.2.2 where I outline the origins of this list).

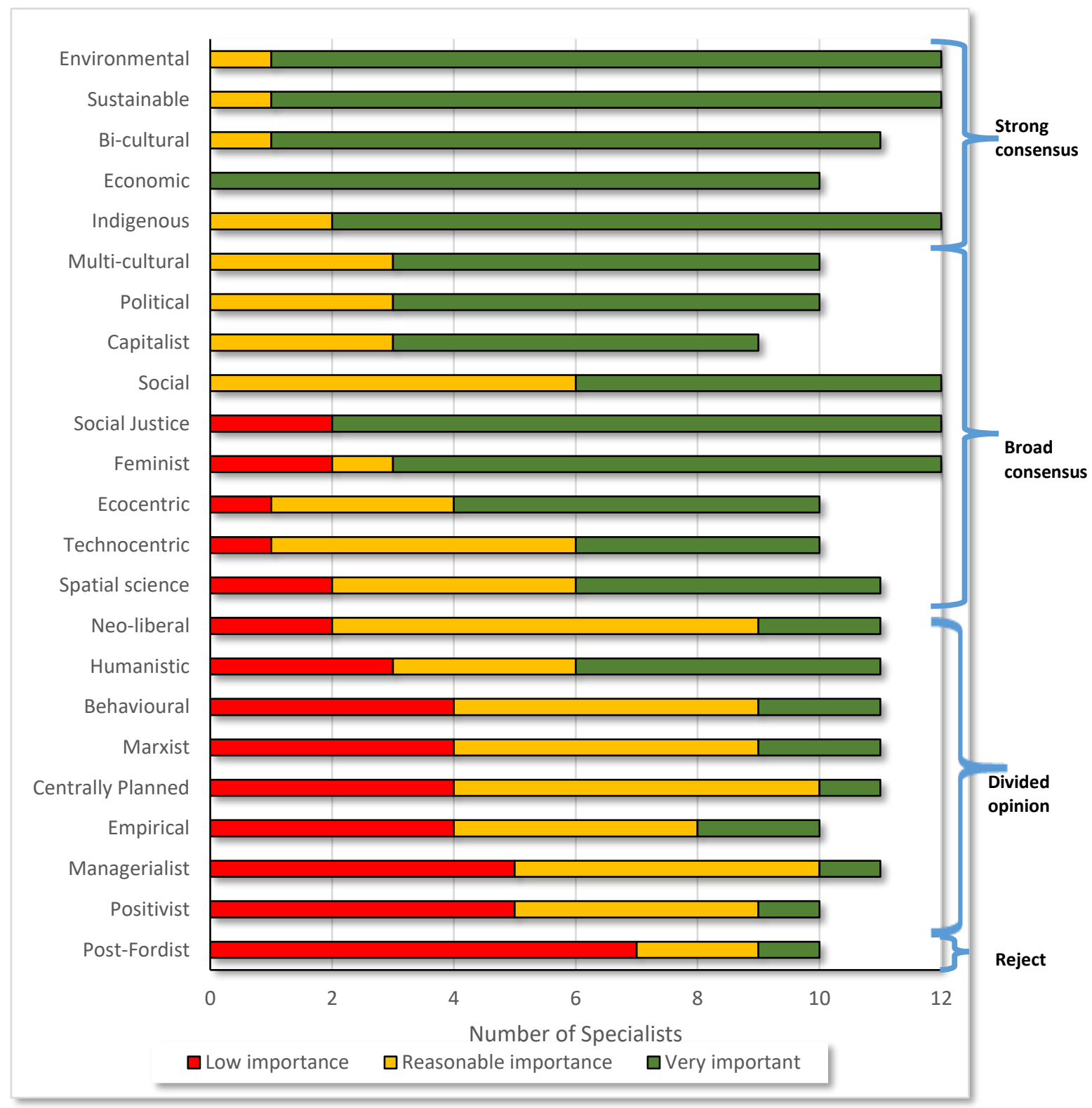

Figure 7.1: Subject specialists' perceived importance of different perspectives ${ }^{19}$

\footnotetext{
19 'Strong consensus': over $80 \%$ of responses rated as 'very important'; 'Broad consensus': at least $85 \%$ of responses rated as at least 'reasonably important'; 'Divided opinion': at least 35\% rated as 'low importance'; 'Reject': at least 70\% rated as 'low importance'. Differences in the total number of replies reflect that the e-questionnaire avoided forcing answers from participants.
} 
The majority of perspectives that have strong consensus are the broad thematic perspectives of 'environmental', 'sustainable', 'bicultural' and 'economic'. These framings are very typical of Year 11 geography, and indeed New Zealand's junior secondary school social studies programmes. I describe these as broad 'thematic' perspectives given that they are theoretically ambiguous. For example, technocentric and eco-centric approaches to the environment radically differ, the first based on rational-efficiency views of the world the later on normative, ethically infused frames.

Viewing the bottom of Figure 7.1, it was surprising that Post-Fordism was given 'low importance' status by over half of the subject specialists, especially as this perspective is considered to be the dominant mode of economic production in the western world in the latter decades of the $20^{\text {th }}$ Century. Post-Fordism is associated with flexible specialisation catering to fragmented consumer markets and has had significant geographical repercussions, such as the transnationalism of labour forces; outsourcing; service sector growth; specialism and diversification; feminisation of the labour force. Is the low ranking because Post-Fordism is a perspective best applied to themes that just are not taught much in New Zealand school geography? Some of the evidence suggests it may simply be that teachers are not familiar with the development of influential geographical perspectives: "[Post Fordist] not 100\% sure what it is"; "[Post Fordist] Unsure what it means!"; "PostFordist - what even is this? Marxist - Historical perspective?"; "Managerialist - I am unclear what exactly this means".

The extent of the list of disciplinary focused perspectives was also quite confronting to an initial teacher educator, who reflected that the stakeholder perspective orientation that $\mathrm{s} / \mathrm{he}$ typically focused on was less intellectually demanding than giving attention to the production of knowledge: "I realise I have taken the easy route and mainly addressed the multiple perspectives as per the social inquiry process and not as ways of knowledge making" [ITE 1]. This statement suggested that undertaking the survey created dissonance regarding his/her practice. As such the survey was a defacto structured learning opportunity that allowed him/her to construct an alternative interpretation of the concept perspective (Spillane et al., 2002). Furthermore, there seemed to be a hint of an emotional response through her choice of labelling the stakeholder approach as the "easy route". 
The challenge of understanding perspectives was clearly illustrated by a curriculum adviser who gave low importance to 'empirical perspectives' while earlier stating that "collection of primary data - geography in a nutshell!" [CA4]. The contradictory nature of the rank and statement suggests that CA4 seemed to have a tacit, rather than a codified, understanding of empiricism. Another example of a specialist not having a codified understanding of perspectives was TBA1 suggesting "humanistic more suited to psychology than geography". This raises the question of whether it is the inaccessibility of the language of perspectives that can be troublesome. One specialist wondered whether the centrality of spatial science in geography meant it subsumed perspectives because it took priority: "Geography is definitely a spatial science which underpins the whole subject, so is it a perspective as well?" [ITE2]. In his/her case, s/he was framing spatial science as the geographic perspective. As curriculum and assessment guidelines indicate that all concepts must have a spatial component (Ministry of Education, 2013c), this specialist's question was understandable. Yet unexpectedly, a spatial science perspective received two ratings of 'low importance', while three specialists also rated humanistic perspectives as 'low importance'. A spatial science approach is a very strong component of the current curriculum achievement objectives and associated Achievement Standards which emphasise patterns, processes and spatial variations. It would also be difficult to see NZ geography teachers ignoring 'values exploration' - a manifestation of the humanistic tradition in school geography.

Both professional development providers agreed that a focus on knowledge production was a high level abstraction with one suggesting that "theoretical perspectives are often beyond the understanding of many secondary students" and that such perspectives were "not strongly linked to the current curriculum and generally requires a more critical level of thinking" [PDP1]. PDP2 suggested that teachers, too, may be challenged by some of the perspectives suggested in the curriculum guides because their own formal geographic education pre-dated developments in the discipline: "Teachers will have limited understanding of what these mean. For those of us who completed geography degrees in the 1970s and 80s our study pre-dates many of these terms. The challenge is how to upskill teachers' knowledge" [PDP2]. 
As well as the 'depth' of perspectives being a barrier, a second challenge was the wide scope of perspectives available to teachers. Four of the subject specialists indicated that teachers would need to rationalise the number of perspectives, based on pragmatic (too many) and philosophical (i.e. determine their utility) decision making. After being asked to rank the long list of disciplinary perspectives, three of the subject specialists suggested that it was prudent to select some core perspectives to focus on and then possibly explore others as and when the confidence of students developed. Furthermore, ITE2 noted that views about the philosophical underpinnings of science in geography may differ across tertiary and school levels of learning: "Positivist: this perspective has been discredited as a paradigm, especially in tertiary studies of geography, but is still handy for explaining patterns (e.g., land use)" [ITE2]. This point of view is similar to Lambert's (2014) lament of teachers not including land-use models in their teaching on the basis of being 'out-ofdate', without giving serious consideration to whether these historical artefacts have considerable utility for exploring geographic 'ways-of-knowing'. Moreover, the divided opinion over positivism, suggests that some subject specialists do not seem to be disciplinary-conscious about the nature of New Zealand school geography, which has a long and continuing positivist outlook.

The third major challenge revealed by the interview data was the lack of pedagogical guidance for teachers - that is, the subject specialists were concerned that there was not enough guidance to help teachers operationalise how perspectives could be approached, and neither had there been quality resource materials that could be utilised by teachers. Five of the specialists suggested that interpretations of perspectives were encumbered by a lack of clear and specific pedagogical guidance. As Figure 7.2 shows, when asked to rate the helpfulness of resources about perspectives, the NZ curriculum guidelines (see MoE, 2013c) were considered more helpful than text books. EW2 suggested there was a resourcing issue that had resulted in a lack of guidance for teachers: "I haven't found a 'textbook' that goes close to meeting the needs of geographers in NZ - recommendations welcome! PD has been weak as well, in my view" [EW2]. TBA2 recognised that in his/her own work, the approach to offering robust pedagogical material for learning about perspectives, was limited to identification and rudimentary analysis: 
I did a very 'traditional' job of highlighting a perspective on [subject matter] wrote two paragraphs about it and how it formed, links to events that happened while this perspective was popular and then answer some 'basic recall' of the ideas in the paragraphs - very 2 dimensional. [TBA2]

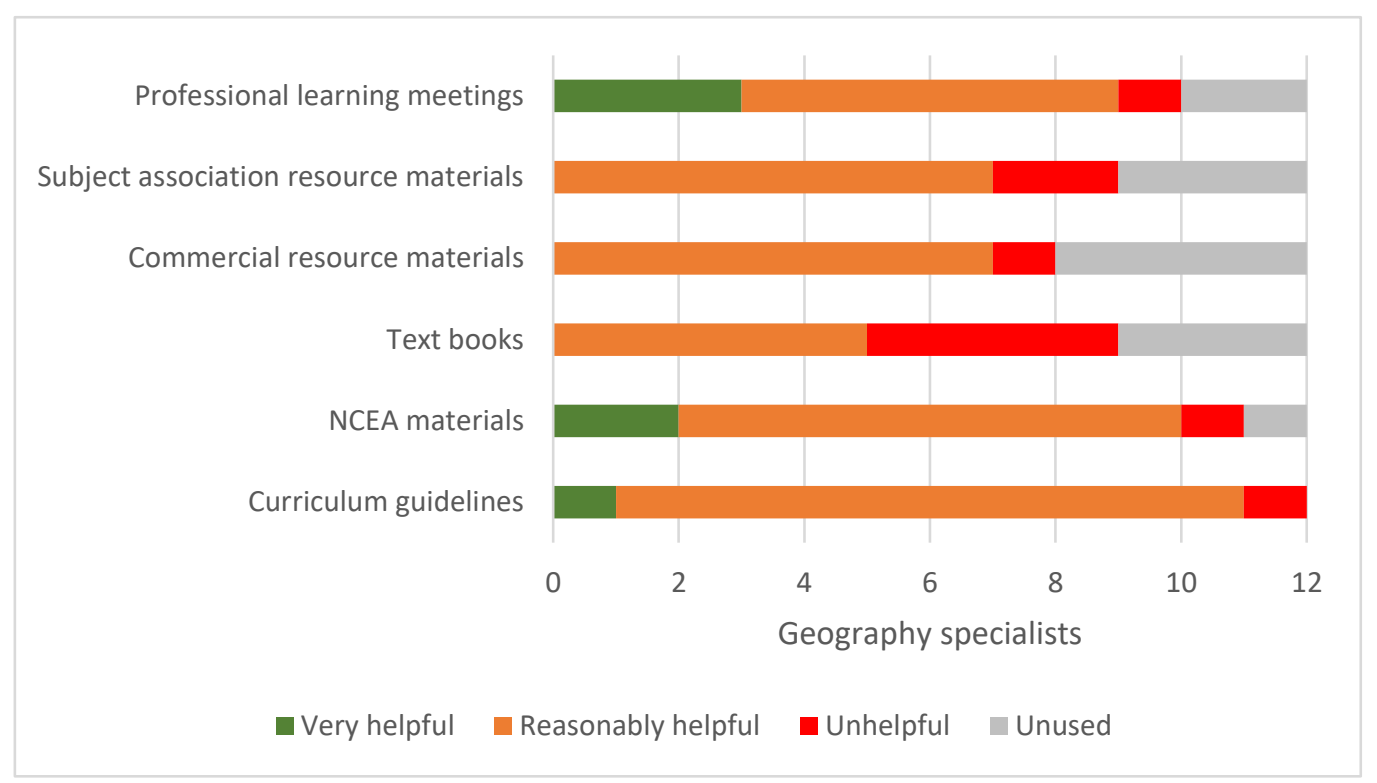

Figure 7.2: Subject specialist views on sources of guidance

Although 10 of the 12 specialists found the senior secondary curriculum guides 'reasonably helpful', CA1 noted that the online resource did not necessarily translate into the type of material that can help teachers support their students:

I think this statement indicates what is meant by a perspectivised approach to geography, but it is not content or pedagogical guidance. I wonder how many geography teachers would feel confident to teach a range of perspectives ...I can see how easily this could be relegated to the 'too hard' basket, largely because there is such minimal support for teachers beyond a definition for perspectives. [CA1]

The lack of pedagogical guidance was also indicated by TBA1 who suggested that geography teachers should look to some online social studies resources which s/he considered "down to earth, and provide example ideas and concepts. I think there is a real 
need to develop quality resources and material for students to work from as well as to show teachers how this area might be taught" [TBA1]. Another curriculum adviser recognised the presence of the perspective notes in the senior curriculum guides but indicated that these did not contribute a great deal to their overall impression of what a disciplinary-conscious orientation to perspectives might generate:

The Ministry of Education provides some guidance but the depth of thinking comes from the learning and building of knowledge one has gathered over time. I certainly experienced a 'disruption' to my thinking when at university due to being introduced to different perspectives and the notes from the MoE did nothing to enhance that, except to indicate we should introduce students to perspectives. I doubt the Ministry's aim was 'disruption'! [CA3].

Paralleling some concerns in the academy (see, for example, Golledge, 2002), a fourth broad challenge emerging from the analysis of subject specialist views was the challenge to the boundary of geography - that is, some specialists $(n=4)$ felt that a focus on disciplinary perspectives might challenge the identity of school geography. For TBA1 this was captured by the measured statement that "perspectives are also now very influential in all fields of knowledge", while CA4 was more emotive with the suggestion of the "possibility of Geography becoming 'hijacked' by non-geographers" [CA4]. Such a view echoed Bernstein's (2000) observation that disciplines with horizontal knowledge structures can be "particularly prone to appropriate the language of others" (p. 177), sometimes leading to a loss of disciplinary identity.

\subsection{Chapter summary}

My analysis in this chapter was designed to explore how subject specialists viewed the place and role of perspectives. The main purpose of this chapter's analysis, was to explore the thinking of the 'priests' of geography education who operate in the field of recontextualisation, an aspect of geography education research that has not had much attention (Puttick, 2015a).

It was evident that these subject specialists largely aligned with what I have called a 'framing settlement', in which the dominant framing of perspectives was a stakeholder 
orientation, 'naturally' aligned to an issues-based approach to teaching and learning geography. As noted by one specialist in a moment of self-awareness, this represented an easy approach. Furthermore, for most of the subject specialists, there was limited disciplinary-conscious interpretation of perspectives. Indeed, many considered theoretical perspectives related to knowledge production as very difficult for many students, and possibly for their teachers. This was partly explained by the lack of quality resources, and the feeling that such exploration was best reserved for the brightest and best Year 13 students or left for tertiary study. While concepts such as 'theoretical perspectives' are clearly multi-layered with dense semantic clustering, presumably this is no less so than for other key concepts such as place or environment. Yet there appears to be a significant uncertainty about how, or whether teachers should use the concept of perspectives as a portal to explore the varied specialised languages of the subject.

All the subject specialists believed that perspectives warranted a prominent position in school geography, although their reasoning was rarely connected to the production of knowledge. Rather, the purpose for studying perspectives drew upon other discourses that exist in the field of recontextualisation. Specifically, the four key purposes of perspectives, according to the subject specialists, was to widen views while developing critical thinking, positionality, and active citizenship. Broadly, I see these four purposes as being studentcentred rather than discipline-centred, which highlights the wider social realist argument that the 'spaces of ideological play' (Bernstein, 2000) have seen attention to these studentcentred discourses increase while conversations about the nature of knowledge have been dislodged (Wood \& Sheehan, 2012; Young, 2009; Young \& Muller, 2010). The implication here is that the educational benefits of the stakeholder framing of perspectives is perceived to be of great enough value, that the disciplinary-conscious framing of perspectives has been rendered unnecessary for secondary school aged students.

The lack of disciplinary-consciousness was well reflected in the subject specialists ranking of a long list of perspectives. While the importance of 'environmentalism', 'sustainability', 'economic' 'bicultural' and 'indigenous' perspectives received strong consensus, more theoretical perspectives received less broad support. What this seems to indicate is that the high degree of recontextualisation (Puttick, 2015) of perspectives from academia to senior 
secondary school level has developed curriculum perspectives which are a-theoretical in nature.

There were, of course, subject specialists with insights into theoretical perspectives and paradigms, yet these were relatively rare. For example, an exam writer suggested that positivism "was passé" as a perspective shaping knowledge production, and so was therefore of low importance compared to other perspectives. This view suggested a Kuhnian (1962) view of knowledge production, despite geography being typically marked by theoretical plurality (Hubbard, Kitchin, \& Valentine, 2008; Pacione, 2009). Positivism may have been discredited by those geographers working through humanist or critical paradigms, but it would be very difficult to imagine geographers working on slope instability, slow-slip earthquakes or Antarctic ice-core analysis not having some aspects of positivist underpinning. The teaching of patterns (with an emphasis of mapping an objective reality) and processes (emphasising explanation) is core to New Zealand school geography; fieldwork associated with primary data collection and analysis remains a 'signature pedagogy' (Shulman, 2005); and the advocacy of concept-led teaching and learning in order for students to write explanatory generalisations is a key characteristic of successful learning (Milligan, Plummer, \& Taylor, 2015). All of these aspects, and many more, have their roots in the positivist paradigm of geographic thought, yet it was ranged relatively lowly by the subject specialists. Lambert (2014) recently expressed his dismay at calls to reject 'outdated' geographic models, and argued that such representations, irrespective of their shelf life in academic circles, will provide a basis for school students exploring how geographers know what they know.

This analysis also focused on subject specialist's understanding of different ways in which perspectives could be approached. The analysis suggests that disciplinary-conscious progress can be approached within and across perspectives. The identify, analyse, and apply progression was an insight into the different levels of complexity through which perspectives may be approached by teachers. This approach offers increasing levels of thinking, with the first two components developed by looking at perspectives, while the application stage is more closely aligned to looking along a perspective (Puttick, 2013). The evidence from the specialists suggests that also viewing progress as an accumulation 
of different perspectives, in the way that Bernstein (1999) characterises horizontal knowledge structures as a collection of specialised languages, challenges teachers to make decisions on just how many paradigms or perspectives students should engage with. Perhaps that challenge becomes less significant once teachers recognise that all geographical knowledge is underpinned by paradigms and perspectives and that the problem of 'too many' was exacerbated by the commonly held belief that disciplinaryconsciousness should be delayed until Year 13.

In light of the framing settlement that has been signalled by the subject specialists in relationship to the key-concept perspectives, Chapter 8 explores a lesson study collaboration of three practitioners, who attempted to take a disciplinary-conscious approach to perspectives when teaching a group of Year 12 and 13 students about cities. As neither Phase 1 nor Phase 2 supported a widespread attention to disciplinary-conscious geography, I was keen to investigate if a lesson study approach could help advance disciplinary-conscious geography teaching and learning. 


\section{Chapter 8: A Disciplinary-Conscious Lesson Study Collaboration}

\subsection{Introduction}

In this chapter, I report on the outcomes of Phase 3 of the case study, in which I collaborated with two teachers and their students to enhance and deepen disciplinaryconscious geography through a lesson study sequence. In broad terms, this was an attempt to take a Futures-3 approach to knowledge (Young \& Muller, 2010), in which students would explore the socio-cultural origins of geographical knowledge while also consider the strengths and limitations of what that knowledge could say about geographical phenomena.

Our lesson study collaboration was, therefore, situated in the pedagogic recontextualising field, which typically involves the work of teachers who interpret and enact the curriculum and assessment materials that have been produced by the 'priests' in the official recontextualising field (Bernstein, 1996; 2000). Inevitably, this further recontextualises material from the ORF, as teachers are shaped by a range of other discourses that compete for their attention. Given the serious lack of guidance given to disciplinary-conscious teaching and learning in the ORF, however, it felt to me as though our collaboration was in spite of the Priests' work rather than because of it.

In Phase 3, Sacha (Te Awa High, hereafter TAH), Michelle (Ruamoko College, hereafter RC) and I planned to explicitly teach theoretical perspectives and/or paradigms to Year 12 and 13 students in a five-lesson sequence which we called: 'Studying Cities: Changing Perspectives'. Our goal of these lessons was primarily to teach about the development of geography, rather than substantive ideas about cities, although I accept that this distinction does not reflect the reality of overlapping learnings that cross substantive, procedural and syntactic knowledges (Lambert \& Morgan, 2010).

Where direct quotes are provided in this chapter, I have indicated the source of data through the use of the following codes: teacher baseline interviews [BI], collaborative 
planning meetings [PM], teacher exit interviews [EI] or student focus group discussions [FGD]. Sources of information also extend to the lesson study materials and evaluations, all of which can be found in Appendices $\mathrm{H}$ and $\mathrm{I}$.

\subsection{The 'Studying Cities: Changing Perspectives' programme}

Table 8.1 outlines the sequence of lesson-studies that were planned by Michelle, Sacha and myself. The table allows the reader to chart the sequence of lesson-studies, but also to see how each of these 90-minute lessons was divided up into their component learning activities. For example, the first lesson study was a broad overview of the development of $20^{\text {th }}$ century Anglo-American geography, with a focus on how this impacted on the study of cities (Pacione, 2009). Within this initial lesson study were three tasks: a note taking activity; posing questions in response to images of cities from the stance of a specific perspective; and allocating the abstracts of journal articles to specific theoretical perspectives. Lesson Studies 2-5 were each a more detailed examination of the key disciplinary perspectives outlined in the initial lesson: spatial science; humanist; structural (capitalist) and sustainable disciplinary stances.

Table 8.1 also highlights which of the three of us took a teacher or observer role during each lesson. The transparency with which we presented the lesson study process to students meant that they were also aware of the culture of learning that was taking place between the teachers. This was commented on by students long after the experience as "it seemed like you were observing us and then thinking about whether that worked and what you thought was best" [Simon, TAH FGD, 317-8] and "it seemed like the other teachers were learning as well, with you" [John, RC FGD, 599-600]. Finally, Table 8.1 also notes the names (all pseudonyms) of the three focus students for each lesson study. 


\begin{tabular}{|c|c|c|}
\hline Lesson Title & Key Student Activities & $\begin{array}{c}\text { Teacher / } \\
\text { Observers/ Three } \\
\text { Focus Students }\end{array}$ \\
\hline $\begin{array}{l}\text { \#1 Studying Cities: } \\
\text { Geographical } \\
\text { perspectives of } \\
\text { urbanisation }\end{array}$ & $\begin{array}{l}\text { - Note taking graphic organiser - } \\
\text { development of geographical thought } \\
\text { during the } 20^{\text {th }} \text { century } \\
\text { Question posing in response to images } \\
\text { from the view of a geographical } \\
\text { perspective } \\
\text { - Allocation of city study abstracts } \\
\text { according to perspective }\end{array}$ & $\begin{array}{l}\text { Mike } \\
\text { Sacha \& Michelle } \\
\text { Ahmed/Richard/Amelia }\end{array}$ \\
\hline $\begin{array}{l}\text { \#2 Studying Cities: } \\
\text { Spatial Science } \\
\text { Perspectives }\end{array}$ & $\begin{array}{l}\text { - Urban desirability mapping task- } \\
\text { computation, representation and } \\
\text { generalisations } \\
\text { - Application of spatial science thinking to } \\
\text { six images from Wellington City }\end{array}$ & $\begin{array}{l}\text { Mike } \\
\text { Sacha \& Michelle } \\
\text { Ahmed/Richard/Amelia }\end{array}$ \\
\hline $\begin{array}{l}\text { \#3 Studying Cities: } \\
\text { Humanist } \\
\text { Perspectives }\end{array}$ & $\begin{array}{l}\text { - Close reading of poems 'Upon West- } \\
\text { minster Bridge' and 'City Planners' } \\
\text { - Interviews of train station commuters } \\
\text { - Communication of interview findings } \\
\text { through rap / poem }\end{array}$ & $\begin{array}{l}\text { Mike } \\
\text { Sacha (Michelle ill) } \\
\text { Ardie/Darcy/Richard }\end{array}$ \\
\hline $\begin{array}{l}\text { \#4 Studying Cities: } \\
\text { Structural } \\
\text { Perspectives }\end{array}$ & 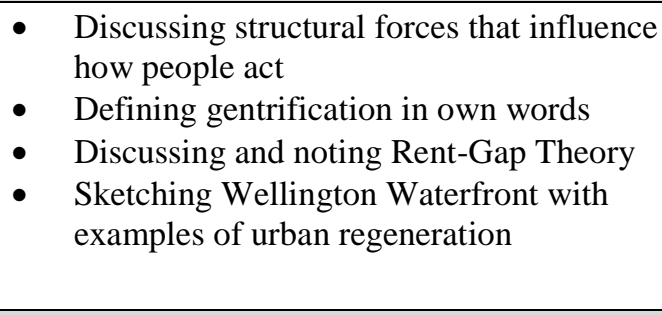 & $\begin{array}{l}\text { Sacha } \\
\text { Michelle \& Mike } \\
\text { Ardie/Chaz/Richard }\end{array}$ \\
\hline $\begin{array}{l}\text { \#5 Studying Cities: } \\
\text { Sustainable } \\
\text { Perspectives }\end{array}$ & 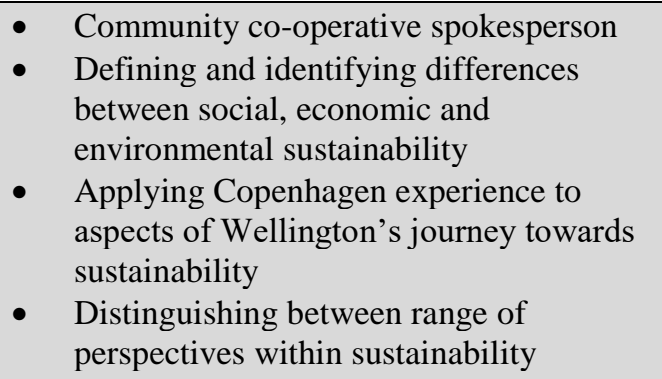 & $\begin{array}{l}\text { Michelle } \\
\text { Sacha \& Mike } \\
\text { Ardie/Chaz/Richard }\end{array}$ \\
\hline
\end{tabular}

\subsection{A guiding framework for the lesson study collaboration}

In response to the findings from Phase 2 (see Section 7.2.3) and the literature focused on disciplinary pedagogy (Section 3.4) I developed a framework to stimulate the planning and analysis of our lesson study collaboration, in which I allocated recommended ideas of disciplinary-conscious pedagogy from key literature (i.e. Hodson, 2014; Moje, 2015; 
Puttick, 2013) to each stage of the identify-analyse-apply approach derived from the Phase 2 findings.

It should be noted that the development of the framework was independent of our lesson study approach (Sacha and Michelle had more than enough to keep them occupied with the mechanics of lesson study) yet helped my thinking when contributing to the lesson study planning. For example, it was in the planning stages we agreed that Lesson Studies 2 - 5 would each focus on a different theoretical perspective or paradigm, yet all these would be designed around three central learning intentions that aligned with the identify-analyseapply approach identified in the analysis of the subject specialist e-questionnaire. Thus, the learning intentions were: 1) to show understanding that knowledge of cities can be shaped by a perspective; 2) to analyse the perspective; 3 ) to apply the perspective to an aspect of cities. Consequently, the progression that we sought from our programme design can best be thought of as horizontal and vertical. Horizontal, because each new perspective represented an explicit additional 'voice'. Vertical, because the identify-analyse-apply structure of each lesson aimed to increase levels of thinking (Bloom, 1956).

In the following sections I present the findings of the lesson study programme. The lesson study is itself a unit of analysis in the wider case study, and so each of the following four cases (each of the three adults and the group of students) are embedded within the unit of analysis. Figure 8.1 broadly identifies the sequence of learning we moved through within each lesson, from identifying, analysing, and then applying perspectives. 


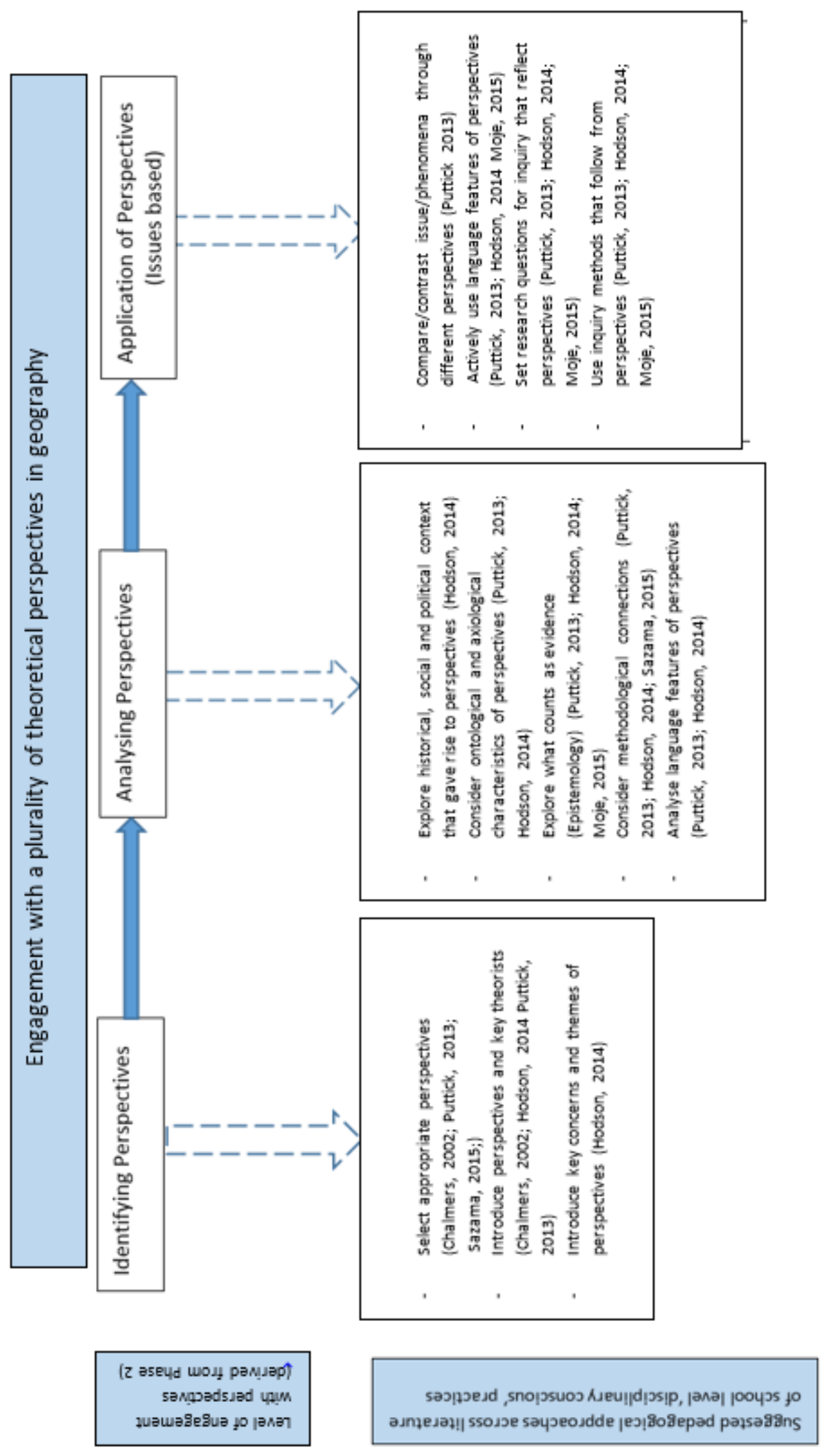

Figure 8.1: Framework to guide lesson study planning and analysis 


\subsection{Case Profile 1: Mike}

My position in the lesson-collaboration as an active participant intended to support the situated cognition of the teachers (Spillane et al., 2002). That is, I saw myself as offering the prompts, questions, and challenges to encourage the teachers to a deeper learning about theoretical perspectives - personally, and for their students. I did not presume to have 'answers' to the methods for teaching about geography, but I did have an understanding of theoretical perspectives and paradigms as the alternative view to the stakeholder orientation that I knew Sacha and Michelle were familiar with (see Sections 8.51. and 8.6.1). Both Sacha and Michelle acknowledged in their exit interviews that having my knowledge about the development of geographic thought was an important support for their own learning. Nevertheless, as the following section indicates, this facilitative role was by no means straightforward.

\subsubsection{Facilitating teacher disciplinary-consciousness}

My role as a 'knowledgeable other' in the lesson study collaboration provided a number of moments in which I offered prompts or questions to stimulate thinking. For example, Sacha and Michelle's initial choice to sequence perspectives (Sustainability; Spatial Science; Structuralist; Humanism) would have made it difficult for students to understand how geography had developed, in part, as a reaction to the orthodox research approaches of the times. I 'wondered out aloud' whether the significance of the order in which geography had developed should be taken into account as a chronological structuring system for the lessons we were to plan. Furthermore, I suggested that this timeline approach to our planning (see Appendix $\mathrm{H}$ ) presented space at the beginning of each lesson to include a critique of the perspective from the previous week as a segue into the 'newly arriving' geographical perspective of the current lesson (Puttick, 2013). This was my first significant prompt, and it did generate a chronological structure of spatial science, humanism, structural and sustainability perspectives. Note that our selection included paradigms as well as theoretical perspectives.

There were moments in the early planning stages, where it was clear that my disciplinaryconscious focus helped generate thinking that may not have occurred at that point. For example, during the design of the first lesson study I asked whether 'spatial science' would 
be preferred as an alternative to 'positivism'. Sacha and Michelle accepted my reasoning that spatial science might have more resonance than positivism simply because spatial patterns are a common focus in school geography, and these are explored through a scientific focus on observation, measurement and prediction. I suggested that 'positivism' might also confuse some students because of prior association with an inherent 'good' that such a term might invoke. As Appleman (2009) and Puttick (2013) have suggested, tweaking the nomenclature can be a small but useful way to remove barriers to imposing language, while not over-simplifying the general characteristics of theoretical perspectives. Furthermore, I felt that it was unlikely that a hagiographic approach to the life and times of August Comte (to whom positivist thought is traced) would be necessary for these students, and so we came to agreement that 'spatial science' was a proxy for the tenets of positivism.

Selecting 'sustainability' as a theoretical perspective was vexing for me from the outset. This was largely because I found it difficult to entertain the idea that sustainability possessed a distinct epistemology. Yet, similar to many others (see Figure 7.1), sustainability was clearly a curriculum perspective that Sacha and Michelle often presented to their students. Indeed, the concept of sustainability in an increasingly urbanised world is perhaps one of humanity's most confronting challenges (United Nations, 2013). My difficulty was understanding that sustainability can be researched from a range of different epistemological positions (e.g., technological fixes underpinned by positivism; exploring the subjectivities of those at the forefront of social injustice). Unsustainable practices are a wicked problem that generate a multiplicity of geographies, which require research from different perspectives to inform our responses. I was also conscious of Sacha's desire for her students to have more insight into the nuance of perspectives than the 3-legged stool conception of environment, society and economy (see Section 8.4). At this early point of our collaboration, I decided to keep my own counsel, as perhaps sustainability could be shorthand for the social re-constructionist paradigm of geographical research in a similar way that spatial science had become our proxy for positivism.

I found that analysing perspectives in comparative terms required emphasising on a number of occasions. In the following example, I borrowed heavily from Cresswell (2013), 
to reinforce how humanist geography was a reaction to spatial science. It produced an affective response from Michelle, both in relation to her lived experience, and motivation for learning, that I could not have foretold:

Mike: ...the humanist perspective, which really brings out the idea that people are not rational thinkers. That they have hopes, dreams, experiences, that make them make geographical decisions. So the classic example is: 'Which fish ' $n$ ' chip shop are you going to on Friday night?' A spatial scientist would say, "Well that's easy. You go to the...?

Sacha: Closest one.

Mike: Because you use less fuel to get there. You get there quicker, and you get your fish ' $n$ ' chips. But we know that the best fish ' $n$ ' chips are actually 2 kilometres further away. We also know that the person who serves our fish 'n' chips is a bit cute and we actually imagined that they were flirting with us the last time we spoke to them...

[Raucous laughter]

Michelle: Used to dictate what coffee shop I went to in Lyall Bay!

Sacha: I have to say I've never flirted with someone in a fish ' $n$ ' chip shop! [Laughs]

Mike: The coffee may be $\$ 1$ more expensive but...

Michelle: I wouldn't care!

Mike: Because you're human - exactly.

Sacha: I'm trying to think if I make any decisions based on...

Michelle: But do you make decisions on where not to go if people have annoyed you? I do that in shops.

Mike: Yup, even though it might be the closest shop. Essentially the humanist perspective was that for human beings our decision making is much more complex than what the spatial scientists assumed. The spatial scientists assumed we are all rational human beings that make the most logical choice. But the human condition...

Michelle: I like that. I really like this. I'd love the kids to be able to do more into that in itself. It's really interesting, you know? [PM \#2, 415-455]

I judged at the time, that this very accessible way in which the humanist perspective was presented contra spatial science, helped galvanise Michelle's commitment to thinking 
more deeply about the nature of geographic knowledge. Whether such commitment was short or long-term reveals itself more fully in Michelle's case profile (see Section 8.5).

There were other moments of tension in my facilitative role, that caused me to question whether to intervene or not. For example, in the week before our lesson on the role of capitalism on Wellington's waterfront, I read a Masters of Planning thesis that questioned whether the process of gentrification was applicable to Wellington Waterfront (Crack, 2005). In our planning for Lesson 4, Sacha had already shown Michelle and me that she intended to emphasise Ruth Glass' classic definition of gentrification, which highlighted the social injustice of working class families being driven out of traditional areas because of rent increases. The thesis, however, highlighted that Wellington's harbour side redevelopment had converted empty warehouses and been supplemented by newly built high rise apartments, and so the process of gentrification was not really as applicable to Wellington, as it is to other inner-city urban regeneration developments such as London or New York. I passed on the thesis to Sacha, pointing out the problem of assigning the 'gentrification' label to Wellington Waterfront. My intervention received a cool reception, and as Appendix H demonstrates, Ruth Glass, Gentrification and Wellington Waterfront remained central to Lesson Study 4. I initially considered Sacha's reaction to the new material as being an example of what can happen in the recontextualising process when sources are brought together that conflict each other (Puttick, 2015b). On further reflection, I interpreted another factor in play that justified her cool response. Sacha was focused on teaching about geography, analysing the structural (capitalist) explanation of gentrification. My 'intervention' was a new loading of substantive knowledge about the distinction between waterfront inner-city development and gentrification. Her decision to bypass this new evidence was an active commitment to remaining focused on learning about geography as the knowledge I supplied her with was extraneous to the requirements of the key learning of Lesson Study 4. This was important self-learning about the delicacy of facilitating disciplinary-consciousness, and the need to recognise the constraint that a single lesson on one idea brought to the recontextualising process. 


\subsubsection{Developing disciplinary-conscious pedagogy}

Puttick (2013) contends that exploring the language of theoretical perspectives is one way of analysing or looking at a geographic perspective. For our planning of Lesson 1 (see Appendix H) I had selected a range of abstracts from an academic journal focused on cities. Abstracts were a suitable pedagogical resource because they required significantly less reading than a full article, yet summarised the aims, methods, results and conclusions of geographical research. Exposing students to authentic geographical research further aligned to our focus on the disciplinary community, which was not something that any of the three of us had done before in our teaching of senior secondary students. Furthermore, our own discussion about the abstracts during the planning was a good example of the situated cognition that emerged from the lesson study process (Dudley, 2015; Spillane et al., 2002).

My sense-making in relation to the big idea of our programme was sometimes shaped by the classroom interaction with students. This was exemplified during the second lesson study in which it was our intent that an examination of some classic land-use models would help students see more of the characteristics of the spatial science perspective (see Appendix H). During the classroom interaction with students I could sense their desire to know more about the substantive content of the zones in the models, which increased my consciousness of the need for a learning about geography approach. Therefore, my exposition did not spend as much time on the characteristics of areas of 'urban blight' or 'dormitory suburbs' as I might normally, because I spent more time emphasising observation, measurement, simplification, generalisation and prediction as key tenets of the spatial science perspective. So although the lesson was planned to do this, I had to consciously put my hand on the rudder to make sure the exposition and discussion were not blown off course. This was an example of a short teaching spell in which the action of teaching helped consolidate my own disciplinary-consciousness (Spillane et al., 2002).

While Hodson (2014) has argued that learning about science is quite different than doing science, Puttick's (2013) description of looking along a perspective and Moje's (2015) inquiry based 'engagement' focus in disciplinary literacy, impressed on me the importance of developing disciplinary-consciousness through the practice of geographical inquiry. The 
two dominant activities in Lessons 2 and 3 (i.e., the urban desirability mapping task and the commuter viewpoints research) were the manifestations of the application of perspectives. By designing a structured inquiry, in which students analysed data collected through a designated procedure to answer a question posed (Hodson, 2014), we hoped that students would be able to explicitly show how doing geography related to words such as ontology, epistemology and methodology within the perspective of spatial science and humanism. Section 8.6 details, through the outcomes of student work, the extent to which this was successful.

Lesson Study 4 took a looking at, rather than looking along (Puttick, 2013), approach to learning about capitalism, as an example of structuralist thinking. Our 'doing' geography approach in this lesson was a field sketch of Waterfront development. On reflection I found it difficult to reconcile this task with structuralism per se, as field-sketching is a skill that tends to emphasise observation, measurement (approximate scale) and recording, in keeping with a positivist/spatial science outlook. To some extent it felt like the task was high on engagement, but more strongly linked to the substantive particulars of urban regeneration, rather than the focus of structuralist perspectives. As our reflection notes also indicated (see Appendix I), I wondered whether a greater emphasis on the values-led intention to question unequal power structures to 'make the world a better place' would have helped students better understand the social reconstructionist critique of the role of capital in re-making cities.

\subsection{Case Profile 2: Sacha}

\subsubsection{Baseline Interview}

Sacha's view of geographical knowledge heading into our collaboration was well aligned with the distinction between factual, substantive, and procedural knowledge:

I guess there's your basic geographic knowledge. Like I'll say to them where the places are, where the capital cities are, those types of things. I think that's geographical knowledge. I think there's geographical knowledge where you understand why things are the way they are. So in the physical environment, you know, the way that works. I think there is geographical knowledge where you explore people and the decisions people make. 
And why you make those decisions. And I think there is geographical knowledge that helps you investigate something as well. [BI, 187-194]

Sacha indicated that the concept of perspective was confusing to teachers, and "I wouldn't have said that it is explicit in the curriculum, no. It's buried underneath" [BI, 313-4]. When I asked her to comment on the theoretical perspectives indicated in the Geography Curriculum Guides, she was hesitant, although there was some evidence that a tacit, rather than codified knowledge was present. For example, she hinted at the realist ontology of physical geography with her words and actions: "I often think about physical geography as being 'it's the way it is [hits desk firmly with hand]; and that's the way it is'" [BI 221-2]. Sacha contrasted this with the subjectivity of human geography, although she did not appear consciously aware of the behavioural perspective she attributed to human geography: "I mean, the perspectives of a human geographer is very much about people and their thought processes and why they do the things they do" [BI 241-2].

Sacha's prior understanding of perspective aligned with the orthodox New Zealand Curriculum Guide messaging, in that she described them as "a worldview, and that your worldview has been shaped by your experiences and your exposure to different parts of society" [BI 43-5]. Her view of perspectives also aligned with the active citizenship purpose described by subject specialists in the previous chapter: "I don't want them to stand there thinking 'I don't really know, I don't understand why that is being talked about" "[BI, 172-3]. Her motivation for engaging with the research was fuelled by a desire for greater intellectual engagement from her students:

I think I want to come away with the students having more than 'Oh miss, that's because they're an economist perspective' or 'I think that's a green perspective'. I would like them to be slightly more insightful about their understanding about perspectives. [BI, 565-8]

While much of Sacha's initial thoughts connected perspectives to issues-based geography and stakeholders, she did extend its application to herself. The mediating influence of the teacher was likely to implicitly shape prevailing perspectives in the classroom:

So I guess what your knowledge is of geography will shape your perspective. Is that too simple? I don't know. I'm trying to think of what my perspective, when I look at 
things, what is my perspective about them? I tend to look at things from quite a global perspective, maybe? Thinking about 'how, why that is different here to somewhere else?' When I think about, when I am a geographer I suppose I always err on the side of environment possibly as well. I often go to places and I think 'why was the decision made to do that?' [BI, 474-480]

\subsubsection{During the lesson study: Reconnecting with the academic discipline}

During the planning stages Sacha showed particular interest in structuralist perspectives, to the extent that this motivated her to take the teaching role of Lesson Study 4. While she committed to structuralism, she was also open to critiquing it by holding it up to scrutiny against subsequent (feminist) perspectives:

From my understanding, like feminism almost came out after structuralism because it didn't give rise to how different groups in society could change. And that's where kind of ideas of feminism came from...Because I found that what happened with capitalism, with that theory, was the fact that it didn't account for things like ethnic groups and sexuality groups to change things. In the explanations that I read [feminism] came after. Like this one [reading from book extract], it says: 'Criticism of structuralism was that it was neglected along lines such as ethnicity, gender, and sexuality.' And that kind of got my idea: it didn't think about feminism.

[PM\#3, 1716-1721]

Although Sacha articulated the limits of structuralist thought, this did not diminish its value to her. Indeed, she showed Michelle and me that she had been reading David Harvey's seminal text Social Justice and the City, despite her protestation that "This makes me look really geeky, I'm not really" [PM\#3, 482]. This was an example of Sacha maintaining her teacher self-identity: engaging with literature from the parent discipline seemed so unusual to Sacha, that she distanced herself from 'geeky' academia. She conceded later on, however, that her engagement with structuralism was also a motivator to her commitment to understanding perspectives more: "I must admit, it has been so nice actually having to think, making me work at this level of thinking a little bit. Sitting reading something and thinking 'okay, what does this mean?'... I feel quite good” [PM\#3, 2139-2143]. This was clearly a sign of Sacha re-connecting with the parent discipline. In her exit interview Sacha also reflected on the connection between substantive knowledge 
and perspectives when she stated that "It made me realise all these times I've taught gentrification, or I've taught urban re-generation, I've not ever really referred to this idea of having a capitalist perspective of looking at it" [EI, 41-3]. This confirmed that Sacha was connecting thinking about perspective not simply as another key concept, but a lens through which other substantive concepts could be filtered.

\subsubsection{During the lesson study: Navigating disciplinary-conscious pedagogy}

Initially, when deciding on which perspectives to focus on in our programme, Sacha agreed with Michelle's use of student-centred criteria to choose which perspectives to select:

Michelle: Looking at [perspectives] from where we come from, from where we teach, I think they would be in line with some of the things we teach already. I think some of them are quite complex, and maybe too complex, for our students at the moment. So I think I read them with the eyes of them I guess.

Sacha: Yeah, I'm the same. I think Environmentalism because that might be the easiest one, for them to grasp to begin with. And then Humanism because I think that will challenge them perhaps in terms of some of their pre-conceived ideas maybe. And then structuralism I think from a boy's point of view, they might like some of the economics side of it. [PM\#1, 382-391]

These selection criteria suggested that both teachers were keen to protect their students from cognitive overload, echoing one of the key messages from the subject specialists in Phase 2 of this research. The social situation of this conversation was an important factor as well: I had given a 20-minute introductory didactic talk about the historiography of geography. Sacha and Michelle were still processing the ideas I had introduced which generated an attitude of 'tread lightly to begin' for Sacha.

For the second lesson study planning we decided to support student understanding of spatial science by introducing them to urban land-use models (see Lesson 2 Appendix H). At the time, Sacha had reflected that these models were outdated, and for that reason she did not teach them in her regular schemes of work. Nevertheless, although the applicability of Burgess, Hoyt or Ullman \& Harris models of land-use are severely limited in their transferability to contemporary cities, Sacha accepted their value as exemplars of spatial 
science/positivist thought. This was an early occasion in which the distinction between learning geography and learning about geography was important, in order that lesson study material was focused on the latter.

For Sacha, Lesson-studies 2 and 3 were particularly effective because they allowed the students to engage in forms of geographic inquiry. She identified the qualitative data collection during the humanistic lesson as a particular highlight of the programme: "I thought it was really good when they had to go and ask people in the train station...I think it kind of put them right in the thick of society if you like" [EI, 297-9]. She was, however, also alert to the constraints around the development of the task, suggesting that the pool of data the students gathered from commuters was not as detailed as they required to develop a subsequent song. According to Sacha, this ultimately "opened up too much for hilarity...there wasn't a huge amount for them to work with. Which then meant they could start putting their own spin on it" [EI, 379-380]. Nevertheless, despite her critique of the 'communicating claims' (Moje, 2015) aspect of this lesson, Sacha was welcoming of an approach which encouraged students to undertake geographic research looking along a humanist perspective.

One of the challenges for Sacha as the lead teacher of the fourth lesson study, was to operationalise the idea of market force influence as a structure responsible for the (re)shaping of cities. As the lesson materials in Appendix H show, Sacha did this by exploring the idea of Smith's (1979) Rent Gap, as an explanatory theory for when large scale capital flows are likely to look for investment opportunities. Although as a collective we hoped that the students would be able to interpret the rent-gap theory graph, Sacha stepped in to do much of the analysis of the graph for the students, who at that stage of the lesson were unusually reticent.

\subsubsection{After the lesson study: Applying multiple disciplinary-perspectives}

Almost ten weeks after our lesson study collaboration in the exit interview, I sought to establish whether there were signs of disciplinary-consciousness in Sacha's thinking by selecting migration (on the spot) as a specific problem that geographers might investigate. When prompted to consider a range of perspectives, this was her response: 
I think the spatial scientist would be asking questions about where they're going, the impact on place, how those places differ to where they are. I think the humanists' perspective would be very much interested in the people - their stories, how they are feeling: How do the people feel of where they're going? How do people outside of the whole situation feel about what's going on, or what they can interpret is happening? I think someone from a sustainable perspective would think about the longevity of what's happening. You know, 'Is it going to continue?', 'What do we do to mitigate what's happening?', 'What can we, what is happening in those countries for this to happen?' And then the structuralist, I would be looking at systems that we could put in place to actually cope with it, the problem. [EI, 79-89]

This extract indicates some significant differentiation in the types of questions and characteristics of different perspectives (Puttick, 2013), and corroborated Sacha's perception that "for me, [it] definitely upskilled my knowledge and understanding of perspectives. It was really good as well to look back over time at the progression that geography has made, and where we've come from, and where we are now” [EI, 29-32].

An unprompted exit interview reflection from Sacha also suggested a literal reconnection between our lesson study collaboration and the parent discipline as she reflected on the connection with perspectives and paradigms as a "school" or "branch" of geography, which was not something she had previously thought. Furthermore, Sacha did not view the production of geography as simply the outcome of academic endeavour of these 'schools of geography', but recognised the socio-cultural context shaped the discipline, in which "those different [perspectives] have been very much influenced by what is going on in society at the time" [EI, 16-17].

\subsubsection{After the lesson study: Split-screen framing of perspectives}

There was certainly much in Sacha's thinking to suggest that a disciplinary-conscious approach to geography had taken hold. Nevertheless, and echoing the 1999 NZBOGT position paper, Sacha had not supplanted the orthodox stakeholder framing of perspective with her new understanding, but could see perspectives taking two distinct pathways: "if we were going to look at an issue, what are the multiple perspectives that that issue will have, but what will the students in front of you as the geographer [Sacha's emphasis], 
be thinking about those issues?" [EI, 103-5]. Sacha was articulating a 'split-screen' approach in which she was accommodating both stakeholder and disciplinaryconsciousness framings of perspectives, in much the way the 1999 BOGT position paper had recommended.

\subsection{Case Profile 3: Michelle}

\subsubsection{Baseline interview}

Michelle's understanding of geographical knowledge leading into the collaboration was tentative: "it's scientific, but it's human. It's trying to link together lots of different types of knowledge". After searching for the words to explain further what she meant she conceded that, "it's quite hard to think about 'what is geographical knowledge?"” [BI, 265270]. Nevertheless, Michelle revealed some of her views on the nature of geographical knowledge indirectly. For example, she declared that "Even though $\mathrm{SLT}^{20}$ will tell us that a student can be put in your class at any time, it's actually really important that students have had all the layers to build upon that knowledge, you know?" [BI, 210-2]. Michelle implied that geographical knowledge was vertically structured, in which progression was premised on the integration and incorporation of increasingly complex ideas. Students in 'advanced' Year 13 geography classes, with no previous study at Year 11 or 12, were in Michelle's view, less likely to achieve than their peers who had previously developed some foundational building blocks.

Michelle also aligned geography with the natural sciences. This view was implicitly given when she described using land-use models with her students to 'test against the reality' of land-use patterns in Wellington City. When prompted to explicitly draw comparisons between scientific and geographical knowledge Michelle stated:

I guess in terms of the investigation element, testing, and using your data, data analysis and conclusion. You know, what you are taught in science from year dot in terms of 'this is how you carry out an investigation' is pretty much what we do. We follow those steps and we go back if 'you can't make your conclusions if you don't have your analysis done.' So I do think it is quite scientific in terms of that way. [BI, 333-7]

\footnotetext{
${ }^{20}$ Senior Leadership Team (of Ruamoko College)
} 
The procedural emphasis Michelle gave in her explanation, did little to reveal, however, the underpinning ontologies or epistemologies of constructing geographical knowledge.

Michelle, like Sacha, had a sound working definition of perspectives, focusing on the subjectivity of geographical knowledge through the stakeholder framing:

I always saw [perspectives] as a way of viewing. We call it here at Ruamoko, and I don't know if it's right or wrong, but we call it glasses. We say "pretend you are putting on this person's glasses" and that's how we try and come at it for our students. For example, the big topic where it is massive is the $\mathrm{TVC}^{21}$. At Year 12 where they come at the development of the TVC from an economic perspective, a European perspective, a Māori perspective, and an Ecologist perspective. [BI, 26-32]

Michelle believed that engaging with the views of others would support learners as citizens, developing their critical thinking skills to see beyond information at face-value, as "if we want students to come out of school and make valuable contributions, then they need to have understandings of where people come from and how they look at a problem. Whatever job they do it's going to be important." [BI, 108-111]. Furthermore, Michelle connected the study of perspectives to personal growth:

So if you get into an argument with someone who you disagree with, so you have a gist of 'oh that's where that person comes from, and that's why they are arguing like that'...that's what I'd like. For them to be able to walk away and be a reasonable human being! (Laughs) [BI, 406-9]

Michelle clearly had a vision of how investigations into the perspectives of stakeholders had a broad educational purpose. The following sections explore the extent to which she shifted to a disciplinary-conscious framing of perspectives during the programme.

\subsubsection{During the lesson study: Reconnecting with the academic discipline}

In our first planning meeting I suggested that our group of students might benefit from an introduction to key authors and the paradigms of geographical knowledge production in

${ }^{21}$ TVC is an abbreviation for the Tongariro Volcanic Centre in New Zealand's North Island 
which their work was located. Our need to identify some prominent geographical thinkers, sparked a revealing exchange between Michelle and Sacha, which demonstrated that their knowledge of key geographers at the forefront of knowledge production was limited:

Mike: Kids come out of science knowing who some of the great scientists are, yeah?

Such as Ernest Rutherford for splitting the atom. Why don't they know who the geographers are? As well as doing this through how geography has changed over time, do we also do it through some of the people...

Michelle: Who have made it happen. I like the idea of some sort of timeline...

Sacha: Of the development of geography.

Michelle: ...to help them see. But yeah, you could start introducing some of these names.

Sacha: Who would you say are great geographers?

Michelle: I don't know.

Sacha: No, that's the thing!

Michelle: Even when Mike asked the questions about models and stuff, it's like, who do you know? Who do you remember?

Sacha: Can you name any great geographers?

Michelle: [Long pause] No. Mercator?

[PM\#1, 629-645]

Michelle's preference for taking a timeline approach to explore the development of geographic thought suggested nascent understanding of the need to consider theoretical development. It was also clear, however, that her recourse to only a Flemish $16^{\text {th }}$ Century cartographer, would do little to help her populate the timeline of contemporary geographic thought. $^{22}$

At the conclusion of the first lesson study planning session Michelle triumphantly exclaimed "we've used our brains!" [PM\#1]. I highlight this small, but telling proclamation to illustrate that punctuated throughout the planning process Michelle was developing understandings about theoretical perspectives that she later acknowledged as new territory: "I have certainly never talked to this depth about perspectives" [PM\#2, 1094]. An apparent moment of Michelle's recognition of disciplinary perspectives was

\footnotetext{
${ }^{22}$ Later in the same planning meeting Sacha, without knowledge of Warren Thompson (a U.S. based demographer in the $20^{\text {th }}$ Century inter-war period), half-heartedly joked "Who came up with the demographic transition model? Was it an examination board?!"
} 
exemplified when she sought to clarify the purpose of our first lesson study planning, in which nascent disciplinary-consciousness emerged:

Michelle: Okay, so if I was going to approach this as a lesson, what is it that I want them to get out at the end of this lesson? That there isn't just this one overall way of looking at things in geography, that actually when you break it down, there have been these stages and this development of different perspectives.

Sacha: Yeah.

Michelle: And the interest that would, you know? Like, hopefully they would see that geography is quite an eye opener. And it's got this actually...I don't say 'academic' to them...but they can see it and it's their subject that actually is going to do quite a few changes and is actually quite acclaimed as a subject. [PM\#2, 927-938]

Michelle's reporting of her reluctance to use the word 'academic' with her students draws some parallels with Sacha wishing to distance herself from a 'geeky' image. Such observations make me wonder what it is about geography teaching that would influence teachers to resist bookish or intellectual labels.

\subsubsection{During the lesson study: Identifying her own disciplinary stance}

During planning Michelle realised that much of what she had experienced and taught in geography was underpinned by the spatial science perspective. For example, shortly after I gave an overview of the history of the development of geography, Michelle reflected on her personal stance towards geographic knowledge: "You see, I feel very positivist....and I wonder why that is? Is it the geography diet I have been brought up on? That's very much how I feel, that I am in that camp." [PM\#1, 239-242]. This was reinforced in a later exchange between the three of us, in which a need for certainty was contrasted with the fallibility of knowledge:

Sacha: [To Michelle] What you said about your positivism, do you think it is because there is a certain comfort or confidence that 'that's how it is'?

Michelle: Yeah, I do quite like rules [laughs].

Sacha: Certainty.

Mike: As human beings we might quite like certainty. 
Michelle: This might be it. I like rules. I don’t like airy fairy. (Laughs) [PM\#1, 267-272]

Evidently this was an example of Michelle indicating her own stance towards knowledge. The influence of the social situation is also evident in this extract, with Sacha's dialogue offering prompts to support Michelle's thinking. This was further understood by Michelle during our joint analysis of diagnostic student data (see Appendix N). In her view, the prevalence of implicit spatial science and sustainability stances underpinning student responses was because "that would be highlighted in what we teach! That's what we bang on about" $[\mathrm{PM} \# 3,1018]$. This was a lightbulb moment for Michelle in which the presence of perspectives was revealed by their implicit reproduction in student work.

\subsubsection{During the lesson study: Wedded to a stakeholder framing}

Despite the momentary examples of Michelle's disciplinary-consciousness during our planning, our fifth lesson study preparation suggested that Michelle remained quite wedded to the stakeholder framing of perspective. This was evident in her by her organisation of a talk about social and environmental sustainability by an employee of a social-co-operative, rather than how a geographer might approach studying the work of that cooperative. ${ }^{23}$ Michelle was receptive to my discussion about sustainability in our planning, in which I suggested to her that sustainability does not have a unified epistemology, and that geographers from all sorts of perspectives might address issues associated with sustainability. This focus on knowledge production was reflected in the penultimate slide of Lesson 5 (refer to Appendix H), although the overall planned content of this lesson (in which Copenhagen and Wellington issues were compared) suggested a greater focus on substantive knowledge rather than how geographers go about producing that knowledge. In short, despite the planning of Lesson Studies 1-4, when Michelle took the lead she presented sustainability through the eyes of actors in society, rather than exploring how geographers might utilise a sustainability lens.

\footnotetext{
${ }^{23}$ For example, a demographic count of families helped by the community co-operative or a review of the relationship between non-government organisations and the state's commitment to welfare provision come from two different theoretical perspectives.
} 


\subsubsection{After the lesson study: Valued insights but overwhelmed}

Michelle's reflection of the lesson study collaboration suggested that a focus on disciplinary perspectives brought benefits to both her students and herself, by providing a bigger picture. This big picture outcome was a connection between the school subject and its parent discipline:

...kind of getting the bigger picture is that what they're learning in class has been kind of shaped I guess through years and years. And those geographers, everyone, they've gone on this journey, you know? And they're only 17 and it's cool to know 'oh, this is what people thought back then' and then somebody else got involved and said 'no, this is what they think.' So I think that kind of change in geography was really interesting, I found it really interesting. [EI, 176-182]

A challenge Michelle said that she faced during the programme was the need to 'unpick' the terminology of disciplinary perspectives. Michelle had a strong professional interest in the functional literacy of secondary aged students, as she had presented at PLD workshops inside and outside her school on the subject. The switch to a disciplinary literacy outlook was a struggle, reflected in her comments 12 weeks after the programme:

I'm a bit, what's, you know 'new cultural geography'? You know some of these, I mean yes 'socially critical' but I don't know if, teaching students to be critical thinkers I wouldn't think 'oh well that's a perspective.' I guess it is, I guess it's a way of them unpacking the information they're being given but I do wonder about some of the language used there. [EI, 503-7].

In this case Michelle was conflating 'socially critical' disciplinary perspectives with critical thinking. It appeared the word 'critical' was being assimilated into a pre-existing understanding Michelle had, rather than being developed in a significantly new direction. Later, Michelle indicated a need to "sit down sometimes and think not about NCEA, not about exams or anything like that, but just to actually the pure geography side of it which we really don't, there's no time for that." [EI, 228-231]. In this respect, Michelle's engagement had given her cause to reflect on the need for knowledge to be balanced with the external accountability pressures of high stakes assessment, supporting the observations by Firth $(2011 ; 2013)$ and Lambert and Morgan (2010), that geographical 
knowledge was being increasingly marginalised as a source to inform teachers' curriculum-making.

For Michelle, some of the content that had specific theoretical value to a study of urban patterns made an impression: "When we looked at 'Bid-Rent': we never do that. Why on earth don't we do that when we do urbanisation?" [EI, 841-2]. In her view this was symptomatic of the need "to actually think a bit deeper about what we're trying to get across. I think I sometimes feel I am probably a bit too thin you know, in digging deeper." [EI 845-7]. There was a sense, therefore, that Michelle's barrier to analysing perspectives was not solely a result of linguistic barriers, but a more fundamental tension with the differentiation between stakeholder and theoretical perspectives.

Michelle suggested there were some barriers that would mean that she would struggle to incorporate theoretical perspectives into their lessons. For example, while she acknowledged that urbanisation appeared to be an appropriate context through which to teach about disciplinary perspectives, Michelle was not readily able to transfer theoretical perspectives to another context. Indeed, she acknowledged how she "slowly unpicked" the ideas that were introduced to her about perspectives, but candidly suggested that despite the advice from the Curriculum Guidelines (MoE, 2013) to explore a range of theoretical perspectives: "You know, is that what we should be doing? I'm not. I don't know how we would do that. I...Honestly, that would overwhelm me in terms of if that's where I needed to go" [EI 395-7]. In this respect, Michelle was addressing her own dissonance, with the 'policy' message. She doubted whether she had the individual cognition to explore such disciplinary-conscious avenues, and it also appeared that the situated cognition required during the lesson study programme, was not deep enough to encourage a shift from a stakeholder framing of perspectives to a stance of disciplinary-consciousness.

In the following section, I turn to the students to examine what the outcomes of the lesson studies were for them. 


\subsection{Case Profile 4: Student Outcomes}

The previous three case profiles have revealed some contrasting stances towards disciplinary-consciousness. In this section the focus is on the student learning, through an analysis of their identification, analysis and application of theoretical perspectives.

\subsubsection{During the lesson study: Quick gains when looking at perspectives}

The note taking task, of which Table 8.2 is a representative example, indicated that most students were able to identify key information as they listened to the introductory presentation on the history of the development of geography. Ultimately this task demonstrated student capabilities in receptive and productive language acquisition. The learning was supported further by the structure of the graphic organiser, which was aligned with the content of the exposition. As a precursor to this part of the lesson, only one student offered the name of a geographer ${ }^{24}$, and so to be able to add a further six to ten names of influential geographers of the $20^{\text {th }}$ century. in this graphic organiser, which all students did, was a promising early sign.

Table 8.2: Transcribed extract of student note-writing framework (Lesson Study 1)

\begin{tabular}{|c|c|c|c|c|c|}
\hline Perspective & Decade & Typical City Themes & $\begin{array}{l}\text { Key } \\
\text { Geographers }\end{array}$ & $\begin{array}{l}\text { View of reality } \\
\text { (philosophy) }\end{array}$ & Key methods used \\
\hline Regional & $\begin{array}{l}1900 \text { S }^{-} \\
30 \mathrm{~s}\end{array}$ & $\begin{array}{l}\text { Aerial } \\
\text { differentiation }\end{array}$ & $\begin{array}{l}\text { Paul Vidal } \\
\text { de Blanche } \\
\text { Kenneth } \\
\text { Cumberland }\end{array}$ & $\begin{array}{l}\text { There are a series of } \\
\text { possibilities, shaped } \\
\text { by the influence of } \\
\text { culture and } \\
\text { environments that } \\
\text { develop a science of } \\
\text { the particular }\end{array}$ & \\
\hline $\begin{array}{l}\text { Spatial } \\
\text { Science } \\
\text { (positivism) }\end{array}$ & $1950 s$ & $\begin{array}{l}\text { - } \quad \text { Concentric rings } \\
\text { - Generalizations } \\
\text { - Sphere of } \\
\text { Influence } \\
\text { Economics, } \\
\text { growth }\end{array}$ & $\begin{array}{l}\text { Ernest } \\
\text { Burgess } \\
\text { Walter } \\
\text { Christaller }\end{array}$ & $\begin{array}{l}\text { Reality is external to } \\
\text { people (i.e. } \\
\text { objective) } \\
\text { Reality is observable } \\
\text { and measurable } \\
\text { People's decision } \\
\text { making is rational }\end{array}$ & $\begin{array}{ll}- & \text { Models } \\
\text { - } & \text { Statistical } \\
\text { observations } \\
\text { - } & \text { Geographic } \\
& \text { Information } \\
\text { systems(mod } & \text { ern spatial } \\
\text { science) }\end{array}$ \\
\hline Humanistic & $\begin{array}{l}\text { Late } \\
1960 \text { s }\end{array}$ & $\begin{array}{l}\text { Irrational decision } \\
\text { making } \\
\text { Identity linked to } \\
\text { place } \\
\text { Cities lose identity } \\
\text { due to development }\end{array}$ & $\begin{array}{l}\text { Ted Relph, } \\
\text { yi Fu Tuan, } \\
\text { Anne } \\
\text { Buttimer }\end{array}$ & $\begin{array}{l}\text { Reality is subjective } \\
\text { (i.e. constructed by } \\
\text { the meanings that we } \\
\text { give it) } \\
\text { Human beings have } \\
\text { free will (agency) }\end{array}$ & $\begin{array}{l}\text { - } \quad \text { Qualitative } \\
\text { analysing } \\
\text { Interviews, } \\
\text { surveys etc } \\
\text { - Focus on } \\
\text { Arts } \\
\end{array}$ \\
\hline
\end{tabular}

\footnotetext{
${ }^{24}$ Richard's suggestion was the late Hans Rosling - the Swedish developer of the Gap Minder website, a very popular geography teaching resource. Nevertheless, Rosling was a public health academic, albeit his work employed many important geographic concepts.
} 
The end of the first lesson study was an opportunity to see how much learning, after only an hour of classroom activity, had taken place. As described in Section 8.3.2, the final task in the first lesson asked students to allocate a range of abstracts from a contemporary academic journal, according to the theoretical perspective or paradigm that underpinned each study. This allocation activity was completed in pairs, in which the students discussed the merits of each study before coming to an agreement on which perspective or paradigm the abstract revealed. As Table 8.3 shows, the group did reasonably well (10 correct, three incorrect, three not categorised) at allocating the 16 abstracts. This task was less about the placement of abstract in piles, however, and more about the dialogue between students as they first read, and then identified the perspectives underpinning the abstracts. Given that this was the first lesson, in strange surroundings with some unknown teachers, this elicitation strategy was designed to minimise the feelings of anxiety that are counterproductive to in-depth talk about abstract ideas (Barton, 2015). For example, Richard and Ahmed justified the spatial science perspective they believed an abstract to be influenced by notably using the words "pattern" and "distribution", as well as focusing on the scientific approach to the methodology. In contrast, Amelia and Niamh's allocation of an abstract about the pattern of trees in a city to the sustainable perspective, suggested they were swayed by the environmental focus rather than the spatial science approach to mapping the distribution of trees.

Table 8.3: Student allocation of abstracts according to perspective

\begin{tabular}{ll}
\hline Disciplinary perspective & City Study Abstract \\
\hline Spatial science & $\# 12 \checkmark, \# 13 \checkmark$ \\
Humanist & $\# 1 \checkmark, \# 11 \checkmark$ \\
Structural & $\# 2 \times, \# 3 \checkmark, \# 8 \checkmark, \# 14 \checkmark$ \\
Sustainable & $\# 6 \times$ $67 \checkmark, \# 10 \times, \# 15 \checkmark, \# 16 \checkmark$ \\
Not allocated & $\# 4 \&$ \&9 (both Humanist); \\
& $\# 5$ (Spatial science);
\end{tabular}

\subsubsection{During the lesson study: Looking along perspectives}

This section reports on some key student outcomes in relation to application of perspectives. The learning was based on activities that align to Puttick's (2013) 
conceptualisation of looking along a perspective and Moje's (2015) 'engagement' core of her 4Es heuristic for disciplinary literacy.

In the first lesson study students were asked to pose questions in response to a range of city photographs, self-selecting from spatial science, humanistic, structural and/or sustainable perspectives. This activity was looking along a perspective, as the questions posed by students were shaped by the perspective of the individual asking the question. Now equipped with an explicit understanding of some of perspectives, we were curious to know whether students would reveal themselves thinking like a geographer from a particular stance (Aitken \& Valentine, 2014). As Figure 8.2 shows, there were varying levels of posing questions from distinct theoretical/paradigmatic standpoints. For example, Candice and Sarpreet captured the flavour of the humanist focus on lived experience, while Ardie and John's second of three questions, focusing on happiness, also suggested understanding of a humanist perspective. Although Ardie and John's first and third questions were not quite as clearly influenced by a humanistic perspective, they also generated two sustainability influenced questions, framed with a future focus. The spatial science questions posed by Chaz and Simon were also indicators of students having caught the essence of some perspectives early on. It was, however, notable that only Ahmed, Richard and Dante attempted to pose questions from a structuralist perspective, suggesting that this perspective was proving more difficult to grasp than the others at this early stage of the program. Nevertheless, the opportunity to respond to visual resources encouraged productive dialogue among all the students.

Our second deliberate approach to applying, or looking along, a perspective took place in Lesson Study 2 in which a spatial science perspective was the focus. We intended to invoke a mathematical/quantitative dimension and how that could be translated to map making, which is supported by Moje's (2015) observation that the translation of data from one representation to another can feel invisible to students. In a very short structured inquiry (Hodson, 2014), we asked students to rank their individual preference of NZ cities, derive a class rank, and then map the results onto an outline map of New Zealand. The majority of students displayed strong mental arithmetic, although Darcy became frustrated at the speed of calculations that his peers were computing, as he perceived his own pace to 


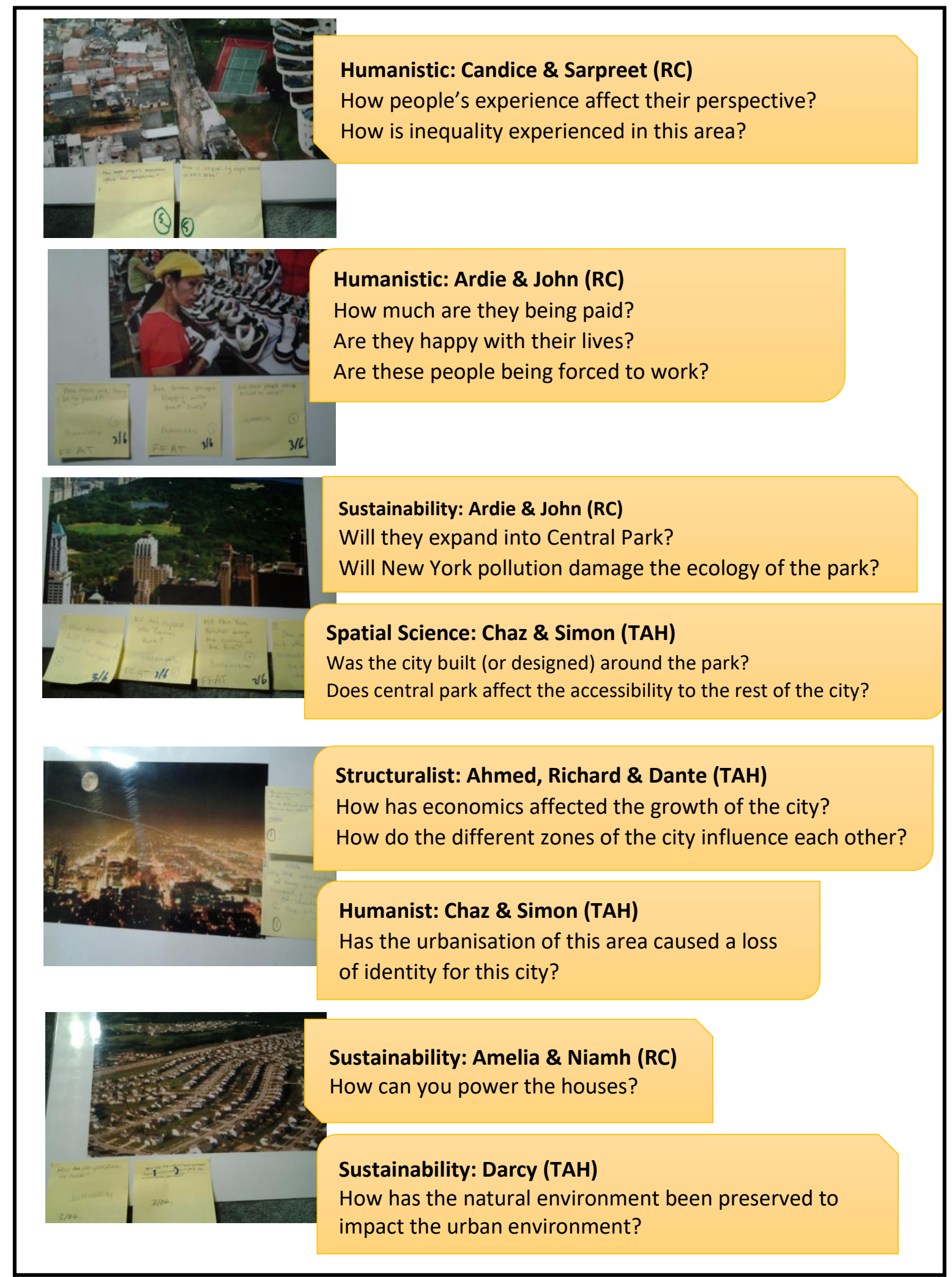

Figure 8.2: Posing questions from disciplinary perspectives (Lesson Study 1) 
be 'holding up' the class calculations (see Lesson Study 2 Evaluation, Appendix I). Darcy's affective response (red in the face, throwing his hands in the air) presented a 'teachable moment' opportunity about the development of geography in the 1950s being supported by the availability of increased computational power to enable increasingly large data sets to be mapped. This was an example of linking the development of geographical knowledge production with wider societal influences, while at the same time legitimising Darcy's reaction rather than viewing his reaction as a problem.

The mapping element, which required students to construct isopleths of NZ desirability proved far more challenging for the students than the mathematical work. Three of the students gave up at the complexity of trying to generate isopleths based on the numerical data, while the remainder attempted the task with rather limited success (see Figure 8.3 for an example). Although the mapping was not pleasing to the eye it did provide the students with the experience of authentic knowledge production (i.e. this groups' collective geographical imagination of New Zealand's urban areas) and despite the difficulty that ensued, students plotted urban locations and then attempted to construct isopleths showing

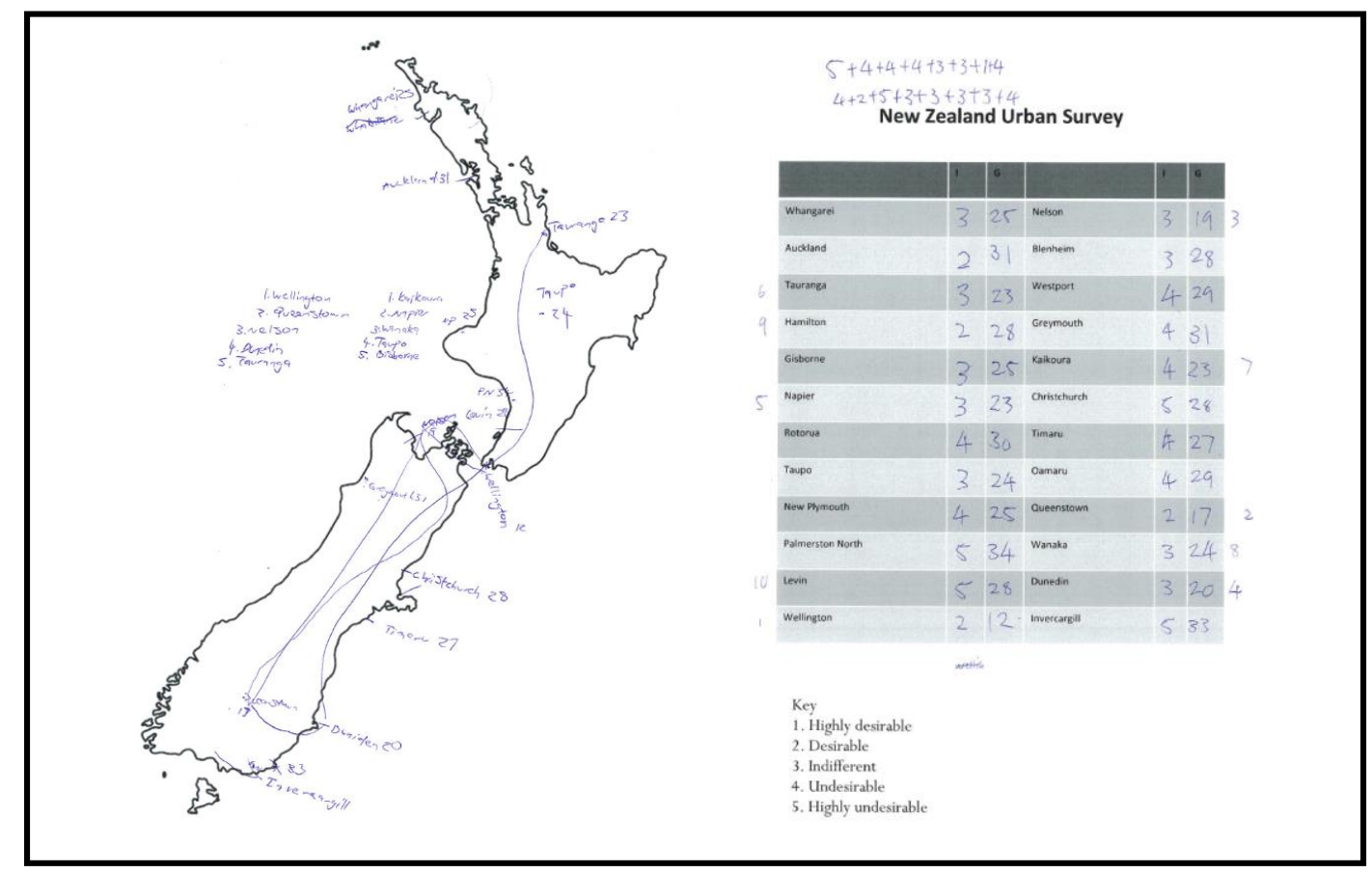

Figure 8.3: Mapping of urban desirability (Lesson Study 2) 
the pattern of desirability. This activity, did, however, remind us that the role of geographical 'basic facts' is sometimes very important. For example, Ahmed and Richard competitively sped through this part of the exercise to demonstrate their confidence in locational knowledge, while Amelia's progress was hampered by far less confidence in locating places (see Lesson Study 2 analysis record in Appendix I).

We noted John's (RC) critical observation of the problem with communicating the data as a map constructed by isopleths. In his view, translating the results of the 24 urban areas to an entire map of New Zealand created some of the difficulty, "because large areas of New Zealand are mountainous or rural". This was an example of insightful commentary about the representation of findings that Maude (2015) would recognise as "knowledge that gives students some power over their own learning" (p. 22). Although at this stage it was a critique of selected methodologies within the perspective of spatial science, rather than of the paradigm itself, it was nevertheless a powerful statement that made explicit geographical practices rather than accepting them as merely a body of knowledge to be digested (Moje, 2015).

Figure 8.4 shows examples of three different student's responses to a selection of Wellington city maps in Lesson Study 3, which encouraged a spatial science perspective. In these examples, note the productive student language such as 'concentrated', 'zoning / rezoned', 'C.B.D.' 'pattern', 'areas' and 'accessibility' which showed that students were employing spatial science language through their interpretations. It was affirming to see such language in student work, although we could not isolate this activity from their previous work in geography, which presents the (unifying) geographical perspective as being fundamentally spatial.

In Lesson Study 3 a further structured inquiry to help students experience looking along a perspective - this time a humanistic perspective - was planned. Specifically, we planned that students would interview railway users about their experience of their commute. Figure 8.5 shows an example of data collected by students, their experiences supporting fruitful classroom discussion. For example, the class listened to a pair of students' experience of being asked to move away by a platform guard which prevented their ability 


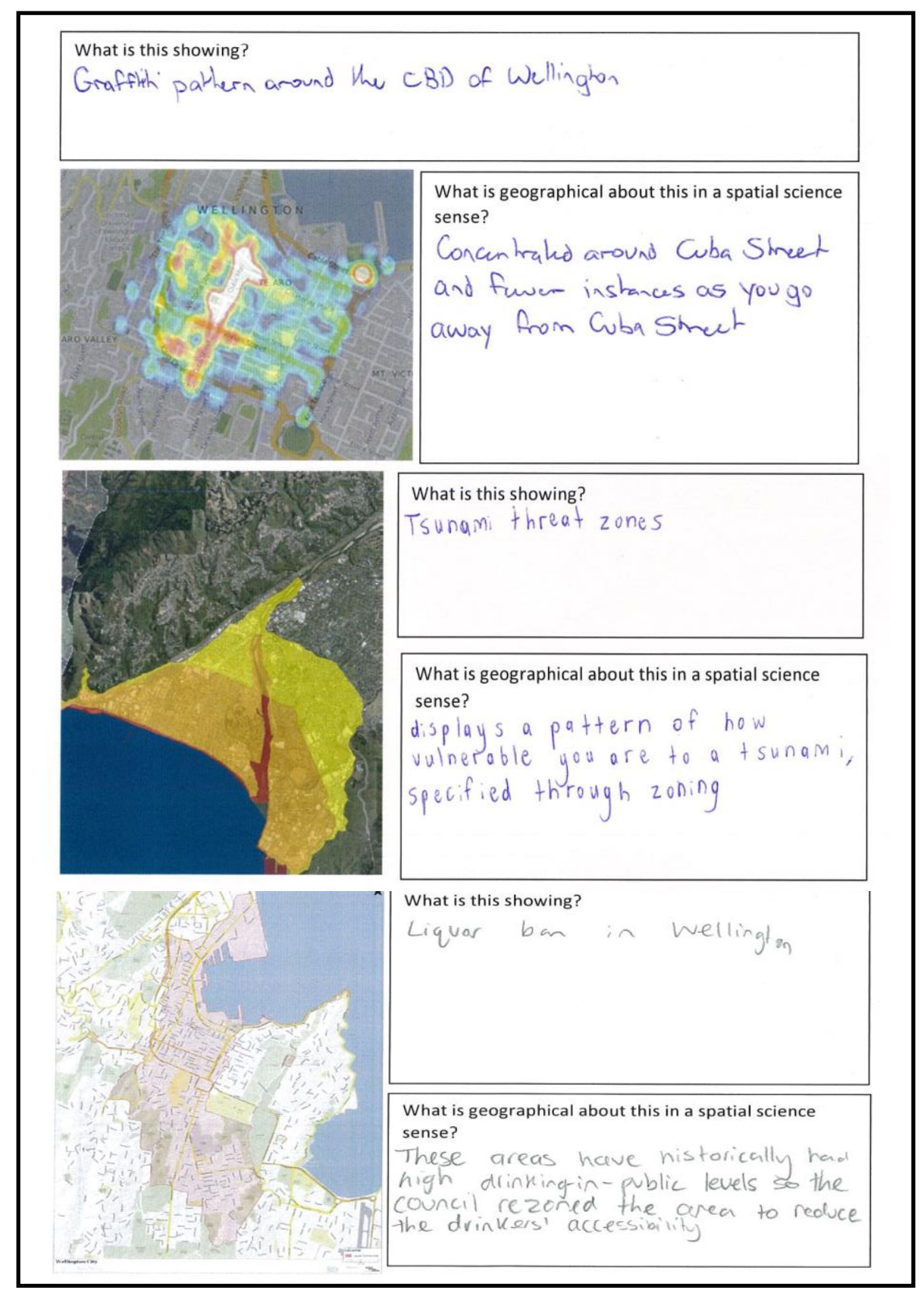

Figure 8.4: Student applications of a spatial science perspective (Lesson Study 2)

to collect data. This presented another teachable moment to explain the need to scope public areas as sites for research, and what steps may need to be taken in the future to prevent awkward encounters with people in authority. For some other students the opportunity to approach and engage with strangers was a challenge, which meant that some returned with data from a single respondent rather than the requested two. This 
allowed me to take another 'teachable moment' in which I briefly touched upon the 'interviewer as research instrument'. Nevertheless, the discussion after the interviewing suggested that the students were invigorated by having the autonomy to conduct some geographically focused research, in which stakeholder points of view were central to the humanist perspective. Nevertheless, the lack of distinction between viewpoints and perspectives may, for some, have remained, as illustrated by Ardie's statement that, "I enjoyed the experience and how you can interact with people and find out perspectives" (See Lesson 3 Evaluation, Appendix Iiii).

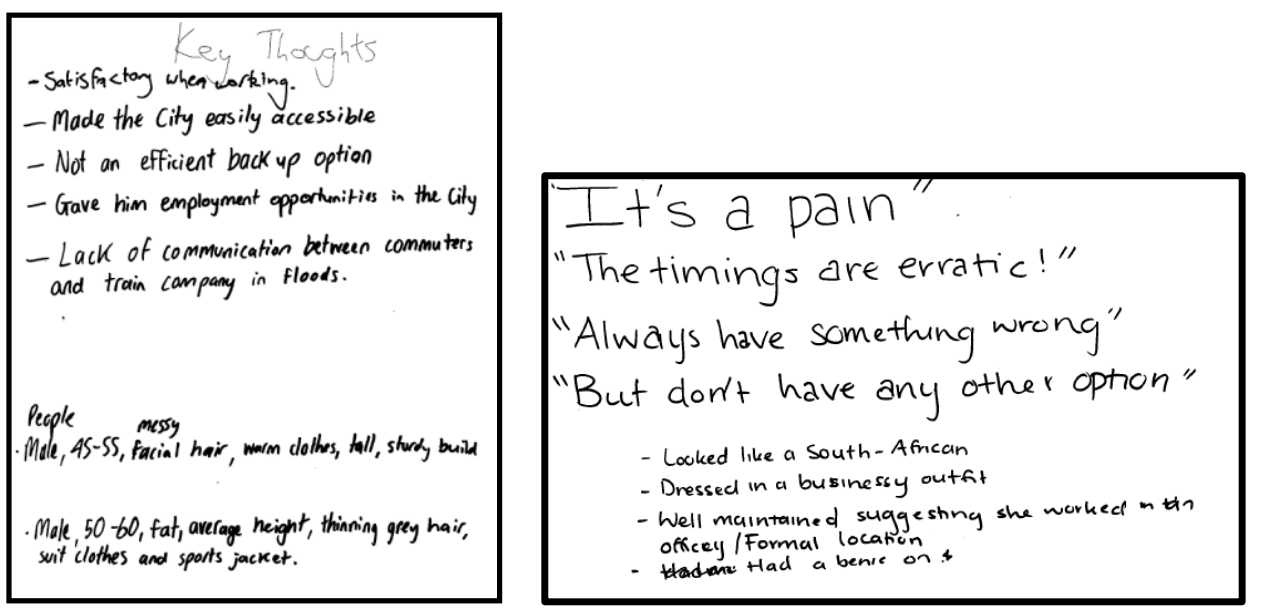

Figure 8.5: Students' recorded interview notes of commuters (Lesson Study 3)

The follow up task was a return to creative forms of expression, in which students were asked to present their findings in a poetic or rap form. We planned this as a way of applying a humanist perspective to communication, as it distanced itself from the overtly quantitative and scientific style of spatial science research we had focused on in the previous lesson. As the evaluation notes show (see Appendix liii), however, this aspect produced rather disappointing results. The idea of a rap was flatly rejected by students who appeared self-conscious in front of their peers. One student was still rather smarting from his interview experience so withdrew from this component of the lesson. We reflected that this was an opportunity missed on our part to make his encounter with the station guard the subject of this task, although that may not have developed geographical learning. As noted by Sacha (see Section 8.4.3), rather a lot of student 'off-task talk' and hilarity ensued. 


\subsubsection{After the lesson study: Seeing the big picture}

The focus group discussions at $\mathrm{RC}$ and $\mathrm{TAH}$ 10-12 weeks after the programme, indicated that some students were able to successfully analyse perspectives. The two dominant expressions of analysis were that it took a broad view of the development of geography, or a micro-view in which a specific perspective was unpacked. For example, Richard revealed his understanding of the discipline and its theoretical perspectives as "human constructions, with social and cultural norms" (Moje, 2015, p.268) when he reflected on the evolution of geography in terms of the democratisation of the discipline:

I guess it opened up the subject to a more broad [sic] range of people. Cos it's like back in the day or something just like old white men and stuff. And now, you know, tonnes of different people like to do geography. [TAH FGD, 94-6]

For John the big picture of disciplinary perspectives was unshackling the subject from an essentialist view, as “Geography isn’t just spatial...There's different ways of solving problems. Yeah, a humanist would possibly solve a problem differently to a structuralist or spatial science person" [RC FGD, 365-7]. John was also reflective on his experience of school geography, expressing that it was "a bit dumb that we mainly do spatial science in school". Prompted by John's sense of the variegated approach of geographers, Ardie articulated the incommensurability of languages in geography in a combative way, when he stated that some geographers "might not work together at all. They could get into a fight" [RC FGD, 373]. While English was Ardie's second language, the intent of his statement was not that far removed from Golledge's (2002) bemoaning of internecine conflict within the academy (see Chapter 1, Section 1.1). Moreover, the general tenor of these thoughts suggest a meta-conceptual application of perspectives (Maude, 2015) in which some students were equipped with a new way of thinking about the world of geographic knowledge production.

Ahmed brought yet another insight to the role of perspectives, recognising that he found learning about geography "was quite interesting cos we saw that based on perspectives rather than what we did during school which is we sort of study a topic. So it is quite interesting just to sort of categorise things a bit differently" [TAH FGD, 102-4]. 
Unbeknown to him, Ahmed was differentiating between Bernstein's (2000) General Approach and Specific Problem Plane (see Chapter 4).

\subsubsection{After the lesson study: Analysing specific paradigms and perspectives}

Ahmed was one of four students during the exit interviews who articulated an analytical understanding of specific perspectives. During his reflection on the connection between capitalism and gentrification he cogently spoke of property speculation premised on profitseeking motives:

Well the primary goal in capitalisation is to make money, right? So they're sort of looking at opportunities where they can buy cheaply and sell it at a high price, so I guess that's what gentrification is - people coming in to sort of white collar neighbourhoods, buying things up and then hopefully selling them for a higher price.

[TAH FDG 152-154]

I wanted to see whether students could analyse perspectives to aspects of city life that we had not used as a context in the five lessons. To see how well students could transfer their understandng of disciplinary perspectives after the programme, I asked them to annotate the characteristics of perspectives that underpinned writing about the Christchurch postearthquake rebuild from particular perspectives (Bennett, Dann, Johnson, \& Reynolds, 2014). Richard (TAH) was confidently able to identify the language characteristics of all four disciplinary perspectives that we had attended to in the lesson study collaboration. In Figure 8.6 (see next page), his annotation showed the clarity with which he was able to highlight key language features of the text underpinned by a humanistic perspective. Note too, the annotation at the bottom of the text, which suggested that Richard not only focused on the communication style of the text, but also epistemological methods that align with the humanistic perspective.

John (RC) was another student who was able to confidently distinguish between the four different perspectives 12 weeks after the programme. For the Christchurch rebuild text with a sustainability focus, he commented that "It's all about like making it better and like keeping it good for future generations", and for the structuralist oriented text "it's all about that class kind of thing. Gentrification it's becoming too, like there are a lot of poor people 
in Christchurch and that's becoming too upmarket I guess for this (RC FDG 545-7).

\section{Post-Quake Christchurch text 3}

Those who live in Christchurch, and want to keep loving it, can easily feel
defeated. Feelings of powerlessness, depression and a lack of hope are
not just the preserve of property owners but of all who call Christchurch
home. Those who worked in the red-zone were displaced and had to find
temporary accommodation.
The Christchurch City Mission, with lots of help and hard work, only closed
for four days and kept in contact with as many or their clients in order to
feed, counsel, and instil a sense of hope. Many of their clients tried to
cope through toxic and unhealthy choices: alcohol and drug use appeared
to increase. The City Mission now not only counsel for addiction but deal
with depression and more complex social problems.
There has been no plans to rebuild bedsits, many of which were lost in the
quake. In the immediate aftermath of the quakes family and friends helped
each other find shelter, but now, three years later, goodwill and
relationships are being strained, as many long to have safe, affordable
and healthy homes of their own. Insurance companies could stop playing
games with lives by giving correct information and not looking for clauses
in contracts to avoid payments and acting in ways that may be legal but
are of questionable morality.
People in the east of the city need to know their needs are being heard
and that they are important also. However, it will be an empty city if we do
not take care of each other on a more personal level. If we feel
marginalised becaue of poverty, if some landlords exploit us, if those in
power don't look at our basic needs for safe, healthy homes, then we may person ing (indusive
have a city that has glossy buildings but we will not have a city that loves. emotiona/ stake.

$$
\begin{aligned}
& \text { Little escalio Quantitative Evidence, mostly qualitative, anectotal which } \\
& \text { equates to a numanist persective. }
\end{aligned}
$$

Figure 8.6: Richard's annotation of a geography text

As the reader might infer from Figure 8.6, Richard had grasped the nature of the humanistic paradigm. Such power of analysis was also evident in a moment of curious reflection on a short discussion that had happened in Lesson Study 5:

Richard: ...the whole deal with sustainability. Is that really a perspective?

Mike: Right. What's your concern about why it may or may not be a perspective?

Richard: We discussed this. Cos it's not, it's more of a viewpoint than a 
perspective... or is it more of a concept than a sort of like a perspective, maybe?

[TAH FGD, 245-251]

While this was a partially formed expression, it nevertheless pointed towards his critical stance to thinking about the characteristics of a perspective, and confirmed some of my own reluctance to name sustainability as a perspective, without at least addressing different epistemological positions within such a broad idea.

\subsection{Conclusions from the lesson-study collaboration}

The relatively small number of lessons $(n=5)$ demonstrated that with careful planning and teaching there is every possibility of senior students developing a disciplinary-conscious awareness of geographic thought. While science education researchers have reported many teachers suggesting that disciplinary-consciousness needs to be delayed for secondary students (Akerson et al., 2011; Leden et al., 2015), the lesson study findings somewhat disrupt the received wisdom from the official recontextualising field that senior secondary geography students are not ready to engage with theoretical foundations of the subject.

The conclusions from our lesson study indicate that the intellectual idea of paradigms and theoretical perspectives, when engaged with in a seriously, can be understood by teachers as opportunities for individual and socially situated cognition are presented (Spillane et al., 2002). That is just the starting point, however, as lesson study is deeply focused on making the abstract come alive in teaching and learning, and therefore degrees of recontextualisation (Puttick, 2015) are rarely far removed from participant focus. The following two sections offer some conclusions about the process and the products of our lesson study collaboration.

\subsubsection{The lesson-study approach}

Lesson study as mechanism for teacher professional development brings with it a longstanding history of Japanese utilisation, yet for the three of us it was a new experience to collaboratively plan, teach and evaluate the outcomes of lessons. It is worth reemphasising that we agreed to conduct the lesson study with a small group of self-selected 
students from two different schools $(n=13)$ in an 'after-hours' environment, which had some impact on the ebb and flow of students throughout the series of five lessons.

For Sacha, Michelle and myself, the lesson study approach was an opportunity to construct lesson plans, followed by monitoring and evaluation of the subsequent learning and teaching in a collaborative environment. As the detailed observation of student outcomes in Appendix I demonstrate, the characterisation of lesson study as a 'forensic examination' of teaching and learning (Dudley, 2015) resonated with our approach to thinking about, planning, enacting and evaluating disciplinary-conscious geography teaching and learning. Neveretheless, we also recognised that, while lesson study is focused, it is necessarily time consuming and intensive. Our weekly after-school programme meant that the post lesson evaluations were conducted in the 30minutes following each lesson in order that we could make some decisions about planning for the subsequent lesson. In retrospect, the lesson study approach may seek greater depth if spaced out less intensively across a school year, giving us the opportunity for more thinking time in the evaluative component of the Lesson Study.

Lesson study allowed for discussion of ideas, experimentation in our teaching, and drew upon resources from academic geography, leading to learning for all three of us. We found it fortunate that lesson study has been operationalised by some very helpful teacher guides that have high congruence with classroom activities, and therefore we could incorporate these into our approach (e.g., planning and observation sheets) effieciently (see, for example, Stepanek et al., 2007). Such supports helped us mainatin attention on evidence of learning in the classroom, which was further supported by questions, and evaluation sheets that helped us track back from the classroom evidence of learning to our teaching and planning decisions about perspectives.

While the level of teacher and student learning was distributed unevenly, the open interaction of the lesson study approach was acknowledged by students who saw the three teachers learning from each other. Being so open about the teacher learning with the students was a new experience for all three of us that helped develop a 'research stance' (Stepanek et al., 2007). 
It was likely that the after-school 'elective' nature of the group meant that the pedagogic norms embedded in the regulative discourse, and also being shaped by the evaluative discourse (Bernstein, 2000), were not in play in quite the same way that a 'regular' classroom environment might have been. For example, our experiemental approach was unencumbered by the presence of NCEA imperatives which would have made our concentrated focus on theoretical perspectives very difficult indeed. Michelle and Sacha wer partially attracted by the fact that our lesson study programme would be outside 'regular classes' and despite her engagement with the process, fell back on her perception that disicplinary-consciousness was not necessary for student academic success.

The collaborative focus of lesson study meant much of the planing, teaching and evaluation helped generate socially situate cognition as we got to grips with new ideas about the development of geographical knowledge over time. While Sacha and Michelle declared that without the external input I provided on paradigms and perspectives they would have struggled to make headway, I too benefitted from socially situated cognition. This was particularly the case as input from both teachers and students helped me consider the 'pitch' at which higher level thinking and abstraction about the nature of geographical knowledge could be targeted.

\subsubsection{Pedagogical actions}

In this section I identify five pedagogical factors that supported the learning of the students across the duration of the lesson study collaboration.

\subsubsection{Selecting and sequencing paradigms and perspectives}

Faced with a paradigm proliferation (Lather, 2006), a key starting point was to limit our selection of key paradigms and perspectives. As Slater's (1981) list of questions suggested, deciding on what perspectives to choose was not only influenced by each one's relation to the history of geographical knowledge, but by their significance to student interest and societal importance. In our experience there was some tension between my 'knowledgecentred' and Sacha and Michelle's 'student centred' bias to the selection of perspectives. In the context of this research, the sequencing of perspectives helped facilitate a 'compare and contrast' approach, given that the introduction of a new perspective demanded 
consideration of the perceived limitations of the previous perspective (Puttick, 2013). Such sequencing may not be quite so important if a single perspective is being approached over a longer period of time.

\subsubsection{Knowing when we are teaching disciplinary-consciousness}

As described in this chapter, there were tensions at moments when teaching geography took precedence over teaching about geography. For example, my misguided advice to Sacha about the need to include Wellington specific detail in relation to gentrification. As Hodson (2014) makes clear in the context of science education, having a very explicit focus on teaching about the nature of the subject is likely to be much more successful than leaving it to chance. By being clear in our minds about the key thinkers, socio-political milieu in which the perspective emerged, the philosophical underpinnings and typical methodologies associated with a perspective, gave us a framework for getting to grips with new knowledge about our chosen perspectives.

\subsubsection{Pitching language at student-appropriate levels}

It is a fine line between oversimplification and making ideas accessible. Typically, the Goldilocks Principle of getting it 'just right' for language was attempted. For example, 'rebranding' positivism as spatial science and modifying journal abstracts helped lower the barriers of impenetrable language. Although we described epistemologies and ontologies, we rarely used that specific vocabulary. It was also important, however, that we gave student opportunities to examine the language of different theoretical perspectives (Moje, 2015), such as using modified abstracts from authentic journal articles. In this respect, our modification of perspectives and paradigms would be recognised as Puttick's (2015b) fourth degree of recontextualisation in the source material had become "summarised in teacher's own words" (p. 29). We were heartened to hear and see examples of productive language aligned to different paradigms and perspectives from a small number of students, despite the short period of time that the lesson study collaboration lasted.

\subsubsection{Planning structured inquiry looking along perspectives}

Developing authentic, albeit condensed, structured inquiry research activities (Hodson, 2014) in Lesson Study 2 and 3 were the most memorable for teachers and students. Both the urban desirability ranking/mapping activity, and the interviewing of evening 
commuters exemplified the practice of doing geography at the same time as developing an understanding of how such methodologies aligned with the perspective being studied. These designed activities were consistent with Puttick (2013)'s looking along conception of teaching perspectives; Moje's (2015) disciplinary practices in the engagement component of her 4-Es heuristic; and Vernon's (2016) "geography shaped by its epistemology" (p. 103). The major outcome of such approaches is that students can make the connection between theoretical perspective and methodological approaches as they engage in dialogue about their experiences. In keeping with Moje (2015), this "engineering of deliberate acts of teaching" (p. 268) means that teachers are crucial elements in the pedagogical relationship, as the structured inquiry requires reinforcement and elicitation of key ideas.

\subsubsection{Seizing 'teachable moments'}

Although our two structured inquiry activities in Lesson Study 2 and 3 were clearly planned, the students' negotiation of these bitesize chunks of research activity produced unanticipated outcomes that presented teachable moments to help develop understanding about knowledge production. As described in Section 8.7.2, these teachable moments both arose from moments in which students expressed a 'problem' with the methodology being employed (the frustration of mental arithmetic not being quick enough; being barred from accessing potential commuter interviewees). Grasping these teachable moments was supported by our clarity of purpose towards disciplinary-consciousness and also having explicit knowledge about the development of geography that lay well beyond any geography curriculum guideline.

\subsection{Chapter summary}

In this chapter I have presented the findings of a collaborative lesson study approach to disicplinary-conscious geography. The purpose of these lessons was to explore how the adult participants and their students could recontextualise the concept of 'perspectives' in order to explicitly reveal the differences in the nature of knowledge production. 
The three case profiles of Sacha, Michelle and myself also demonstrate that disicplinaryconsciousness is a challenging, yet ultimately rewarding, direction for school geography teachers to follow. Although Michelle experienced disciplinary-conscious moments in relation to her own understandings and teaching practice, she ultimately found it difficult to differentiate between teaching geography and teaching about geography. Consequently, she remained strongly wedded to the stakeholder framing of perspectives, and candidly indicated that taking disciplinary-conscious approach to geography itself was personally overwhelming. Despite Michelle's wish to "dig a bit deeper" in her geography teaching the depth and scope of enagaging with the parent discipline was rather intimidating.

In contrast, it was clear that the new intellectual challenge of engaging with the development of geographic thought was motivating to Sacha. Her engagement with academic texts demonstrated that she was willing to bridge the school subject and academia, while she also made explicit the connection perspectives to the 'schools of geography' that she recalled from her undergraduate learning. Sacha engaged with theoretical perspectives in ways that indicted that she had differentiated between the orthodox stakeholder and disciplinary-conscious framing of perspective.

This chapter has also presented evidence from student work and focus group interviews that teaching and learning about the nature of geographical thought, while not straightforward, is achievable for senior students. John (Year 13), Richard (Year 12) and Ahmed (Year 12) were the shining beacons of this group of students who demonstrated some quite impressive understanding of different geographic approaches over this short period of time. Other students found some of the material rather a struggle at times, although there was consensus that the act of doing geography immersed in a particualr paradigm was the most engaging aspect of the lesson study programme. This looking along a perspective approach was, for the teachers, a concrete way of introducing different methodological approaches

In my final chapter I bring together the findings from all three empirical phases of my research to offer some some ways forward so that disicplinary-conscious geography might become a more visible feature of New Zealand's secondary school classrooms. 


\section{Chapter 9: Discussion}

\subsection{Introduction}

The 1999 NZBoGT position paper was a call for New Zealand school geography to pay greater attention to theoretical developments in the academy. It suggested that a 'geographical approaches' pathway should be followed in order that the school subject and academic discipline become closer connected. On the back of this call, my study defines disciplinary-conscious geography as teaching and learning about paradigms and/or theoretical perspectives as frames of reference from which to sense, interpret, measure or codify geographical phenomena. Such a definition ties the theoretical focus of my study to Bernstein's (2000) 'general approach plane' of geographical knowledge as it considers the proliferation of 'ways of seeing' that have shaped the discipline in the last 60 years. I also contend that disciplinary-consciousness can usefully build on Maude's (2015) operationalisation of powerful knowledge; one element of which requires that "students need to know something about the ways knowledge is developed and tested in geography... an underdeveloped area of geographical education” (pp. 22-23). At a more grounded level still, my study also provides insights into the recontextualisation required to make the concept of perspectives both challenging yet accessible to senior secondary school teachers and students.

In this chapter I summarise findings of research questions 1-3 and then discuss implications for New Zealand school geography. I then offer some recommendations to some of the key actors who may be able to influence a shift towards disciplinary-conscious teaching in New Zealand school geography education. Recognising that my research is only a springboard towards disciplinary-conscious teaching and learning, I note some of the limitations of this study before offering some future research directions.

\subsection{Research summary}

This sequential case study was designed to explore the current signalling, and future potential, of using the concept perspective as a portal for teachers and students to develop 
greater disciplinary-consciousness. In the following sub-sections, I summarise my findings from the three research questions that have driven this project, while also commenting on how these have provided a contribution to the geography education literature.

\subsubsection{Answering research question 1}

Following the disciplinary-conscious advocacy of the 1999 NZBoGT position paper, my initial research question asked, "To what extent have curriculum and assessment materials signalled a disciplinary-conscious orientation to geography, since the publication of the 1999 NZBOGT position paper?" I concluded that although the 2001 NCEA teacher guidance notes included a range of theoretical perspectives that could be explored in geography, subsequent curriculum and assessment materials revealed minimal signalling of explicit disciplinary-consciousness.

What my analysis of the curriculum and assessment materials did strongly signal was a stakeholder framing of perspectives. The stakeholder framing gives attention to the subjective views of individuals, groups and organisations such as government, conservationists, commercial interests, and Māori groups as typical stakeholders, so that the issue or phenomena is the visible object of study (rather than geography). Learning about the perspectives of different individuals, groups, and organisations may be an opportunity to look along the humanist perspective (Puttick, 2013), but there was no clear guidance to promote explicit awareness of humanistic geography's contribution to the theoretical development of academic geography. Furthermore, my analysis of documents in the recontextualising field suggested that there was a lack of clarity in the differentiation between terms such as 'viewpoint, 'perception' and 'perspective' and that, according to examiner reports, there was concomitant difficulty for student understanding. This inconsistency is likely to divert attention from the disciplinary-consciousness framing taking hold.

In short, the contribution of this phase was empirical support of Firth's (2011) and Maude's agreement (2015) that while geography education should develop school students' understanding of the nature of geographic knowledge, this has rarely been the case. Findings from this research question also bolstered the local observation that 
engaging with theoretical perspectives was "not every body's cup of tea" (Miller, 2001, p. $8)$. Furthermore, my study found that the signalling of the term perspectives was muddled and inconsistent. To find out more why this might be the case, and whether there was potential for more disciplinary-conscious geography I sought the opinions of subject specialists who strongly shape the field of recontextualisation.

\subsubsection{Answering research question 2}

My findings in Phase 1 were further supported by an e-questionnaire of subject specialists, who had roles including curriculum advisors, examiners, PLD providers, ITE educators and text book authors. Specifically, my question was: How do geography curriculum and assessment specialists view the value, place and role of perspectives in New Zealand secondary school geography? The voices of these different 'priests' of geography education have rarely been a focus of published research in New Zealand since the NGCC debates of the 1980s (see Chapter 3, Section 3.3.2). Therefore, these findings contributed a thread of empirical research that might shed light on the relationship between the official and pedagogical recontextualising fields.

The subject specialists considered disciplinary-conscious geography to be best reserved for Scholarship geography, and overall, they saw more value in broad curriculum perspectives than those with theoretical or philosophical characteristics. As one subject specialist stated, theoretical perspectives appeared to have been consigned to the 'too hard basket' by teachers, while the stakeholder framing of perspectives was considered by another to be the path of least resistance. The difficulty of teaching and learning theoretical perspectives was considered to be a student maturation issue by some subject specialists (i.e., too hard, too young), while others indicated that teachers' understanding of some theoretical perspectives was limited. This latter point, for example, was confirmed by subject specialists themselves who gave less importance to empiricism and positivism (see Figure 7.1 in Section 7.2.4), despite both being central to New Zealand school geography for decades (Chalmers, 2005). This surprising outcome of the e-questionnaire, suggested that the recontextualisation of these theoretical ideas into teacher language and practice is so ingrained ("collection of primary data - geography in a nutshell!"), that it has become an “indistinguishable part of teachers' embodied subject knowledge” (Puttick, 2015b). The 
flip side of this high degree of recontextualisation is that the language of this intellectual source material has been stripped away. To use the well-known fish bowl analogy, the orthodox, stakeholder framing of perspectives has become so prevalent that some school geography specialists may be oblivious to the theoretical waters in which they are, or could be, immersed.

Overall, the challenge of disciplinary-consciousness was, according to the subject specialists, attributed to: 1) the difficulty of interpreting theoretical perspectives - for both teachers and students; 2) a lack of pedagogical guidance for teachers; 3 ) a suspicion that geography could become detoured by ideas not central to geography; and 4) concern about too many theoretical perspectives for the school subject. By this stage of my research, it was evident that the path to disciplinary-consciousness was largely un-travelled.

In a broad sense then, my combined findings from Phase 1 and Phase 2 suggest that conflict and contestation over the concept of 'perspectives' were not a strong feature of the pedagogic recontextualising field. Rather, the orthodox framing of perspectives seemed settled and there was no clear signalling for disciplinary-consciousness. This provoked me on to consider whether work in the PRF by teachers could trouble some of the subject specialists' assumptions (Bernstein, 2000).

\subsubsection{Answering research question 3}

By attempting to enact a disciplinary grounded approach to geography teaching in Phase 3 of my research, I sought to help to reframe two teachers' - and their students' understanding of theoretical perspectives and paradigms (Puttick, 2013). Specifically, I asked What are the outcomes of a lesson study collaboration focused on disciplinaryconscious geography? The lesson study collaboration was a necessary 'intervention', given that Phase 1 and 2 of my research highlighted that disciplinary-consciousness has been rendered invisible in the wider recontextualising field. Bernstein (2000) suggested that the ORF and PRF need to be insulated from each other, in order that agents in the PRF had some autonomy on the construction of pedagogic discourse and practice. In this final phase of my case study, I wanted to explore whether, under certain conditions, there was 
the possibility of shifting teacher attention away from the orthodox framing of perspectives to a more disciplinary-conscious orientation and approach.

Therefore, the contribution of Phase 3 was to offer an example of collective pedagogical experimentation within the PRF, in which an alternative pathway to teaching perspectives might be taken, while also giving teacher and student voice to strategies suggested in models by Puttick (2013), Hodson (2014) and Moje (2015). A particular outcome of this phase of research was the development of a framework in which I connected key strategies from the literature to progressively higher level of thinking when engaging with perspectives and paradigms (see Figure 8.1 in Section 8.3).

Engaging with the development of geographic thought was new territory for all of us in the lesson study collaboration. At moments during the collaboration, both Sacha and Michelle distanced themsleves from a 'geeky' self image, reinforcing Miller's (2001) contention that engaging with the philosophical foundations of geographical knowledge is not to everybody's taste. Yet during times of dialogue and collaborative planning, each had moments of disciplinary-consciousness to a greater or lesser degree, with Sacha admitting that she had enjoyed engaging with intellectual knowledge direct from the field of reproduction. By Michelle's own admission, disciplinary-conscious geography teaching was an overwhelming prospect. Furthermore, in her distinctly pragmatic view, Michelle felt that her students could achieve in geography, without the need to develop disciplinaryconsciouness. Therefore, at the end of the collaboration, Michelle remained wedded to a stakeholder framing of perspective while, in contrast, Sacha connected paradigms and theoretical perspectives to what she considered to be different 'schools of geography'. Furthermore, after the lesson study collaboration Sacha demonstrated an ability to apply her new found disciplinary-consciousness to thinking about other geographic phenomena (see Section 8.5.4).

Over two months after the conclusion of the programme, three of the students were able to deconstruct in detail previously unseen texts though the lens of different paradigms and perspectives. This demonstrated that geographical knowledge production had become visible to the students, some of whom were able to confidently analyse language features 
of written texts, identify methodologies associated with perspectives, and give nuanced accounts of city phenomena through the lens of theory (see Section 8.7.4). While a larger number of students certainly found engaging with the development of geographical thought challenging, the short time period over which the programme was conducted suggested that with careful teacher planning, instruction, and iterative exposure, senior secondary students can be supported to develop their disciplinary-consciousness. In short, the re-imagination of the concept perspectives was challenging for all involved, but by no means unachievable.

In light of this summary, I discuss some of the broader implications of this study that draw attention to theoretical, empirical and methodological contributions of this research.

\subsection{Theoretical reflections}

In this section I reflect on the implications of my study and what it contributes to the literature. I begin with reflections of a theoretical nature, which focus on two distinct aspects. First, is the nature of relations within the recontextualising field (Bernstein, 2000) and the impact this has on curriculum and pedagogical development. Second, is the connection between Maude's (2015) articulation of powerful knowledge and Bernstein's (1999) theorisation of the segmented structure of knowledge in the social sciences, which has allowed me to provide an explanatory bridge between the abstraction of the social realist debate and implications for teacher practice.

\subsubsection{Relations in the recontextualising field}

This study confirms the general utility of Bernstein's (2000) work to explain how knowledge is translated due to the influence of the priesthood in the recontextualising field. Bernstein stated that curriculum and pedagogical development in a school subject is the outcome of a contestation of ideas between the Priests in the ORF (e.g., NZC or Curriculum Guide writers) and the PRF (e.g., examiners, PLD providers, text book authors) as they interpret the work of the 'Prophets' in academia, while also mediating discourses that originate from sites beyond the field of knowledge production. Bernstein's theorisation can therefore, help explain both the prevalence and marginalisation of the stakeholder and disciplinary-conscious framings of perspective. In respect to the 
stakeholder framing, subject specialist priests of the NGCC were responding to developments in the discipline as systemised by key prophets (Buttimer, 1976; Ley, 1977; Relph, 1976; Tuan, 1974) whilst the promulgation of wider educational discourses, such as values education (see, for example, Chandler, 1979) also legitimised the stakeholder framing of perspective. Subsequent discourses of the current national curriculum, such as active citizenship, multiculturalism and global connectedness are examples of further 'ideological space' (Bernstein, 2000) for the stakeholder framing of perspectives to inhabit.

The paucity of disciplinary-consciousness signalled or enacted in New Zealand senior secondary school geography, suggests that the current ideological space being activated by the priests of the recontextualising field is not conducive to its growth. I suggest there are two reasons for this. First, the priests of geography education appear disengaged from the knowledge production work of the disciplinary prophets. Second, and influenced by the weakened relationship between prophets and priests, narratives associated with a Futures-2 curriculum (Young \& Muller, 2010) have shaped developments in the recontextualising field.

According to Bernstein (2000), the structuring of the recontextualising field requires a clear classification between the ORF and the PRF. Puttick (2015b) concluded that Bernstein's ideal may not hold for school geography in England, where Chief Examiner power over distributive, regulative and evaluative rules represented "something of a collapsing of a distinction between the ORF and PRF" (p. 481). I suggest that in the New Zealand geography education setting, there has also been somewhat of a collapse of distinction between the two sub-fields of recontextualisation, but for a different reason than in the English context. In New Zealand school geography, the Priests have a stronger relationship with the teaching and student laity than they do with the Prophets of academia. This may reflect that the New Zealand geography recontextualising field is inhabited by many actors who are a contracted lay priesthood: examiners and exam moderators are contracted teachers, text book writers are teachers (and possibly examiners), professional development providers are teachers, teachers are asked to provide curriculum advice to the MoE. The prospect of disciplinary-conscious geography seems a remote prospect if the 
'lay priests' (as I feel is more appropriate to call them in New Zealand) called upon are not acquainted with the historiography of geographical knowledge and/or more broad educational discussions about the structure of knowledge. To this end, we might say that, in New Zealand geography education context, the Priesthood as imagined by Bernstein (2000) has been subject to a flattening of the ecumenical hierarchy.

A second reason for disciplinary-consciousness not taking hold is because the intensification of teacher work (NZPPTA, 2016) prevents deep engagement with conversations about geographical knowledge. Part of the intensification of work that the lay-priests experience is the constant negotiation with discourses that are characteristic of the broader Futures-2 $21^{\text {st }}$ Century progressive curriculum (Young \& Muller, 2010). The stakeholder framing of perspective can be accommodated by many of these discourses, as indicated by the subject specialists who emphasised the need for students to widen their view for cross-cultural understanding, develop critical thinking, cultivate their own positionality and demonstrate active citizenship (see Section 7.2.1). As Futures-2 discourses predominate, knowledge focused conversations appear unlikely to prosper.

\subsubsection{Connecting geography teachers to a Futures-3 Scenario}

As a result of this research I propose a heuristic designed to bridge the social realist inspired Futures-3 'curriculum of engagement' (Firth, 2013; Young \& Muller, 2010) and how this relates to making geography visible in the classroom (see Figure 9.1). There is considerable overlap between Bernstein's (1999) sociological account of the segmented structure of (geographical) knowledge and the geography literature that charts the historiography of disciplinary development (i.e. Boxes 1 and 2, Figure 9.1). For classroom practitioners this is the source material required to get to grips with disciplinary-conscious teaching. As revealed in my study, there is a general feeling that this material is difficult, although it should be noted that, at this stage of the heuristic, the material is to be engaged with by teachers rather than students. While there may not be a strong tradition of geography teachers engaging with the development of the discipline or its key actors, Sacha's preparatory engagement with Harvey (1973) in our collaboration showed that geography teachers can benefit from, and enjoy, engaging with academic source material. 
Such engagement with theoretical underpinnings of geographical topics could also have the extra impact of supporting teachers "to higher levels of thinking and conceptualisation" (Maude, 2015, p. 28) about the nature of geographical knowledge.

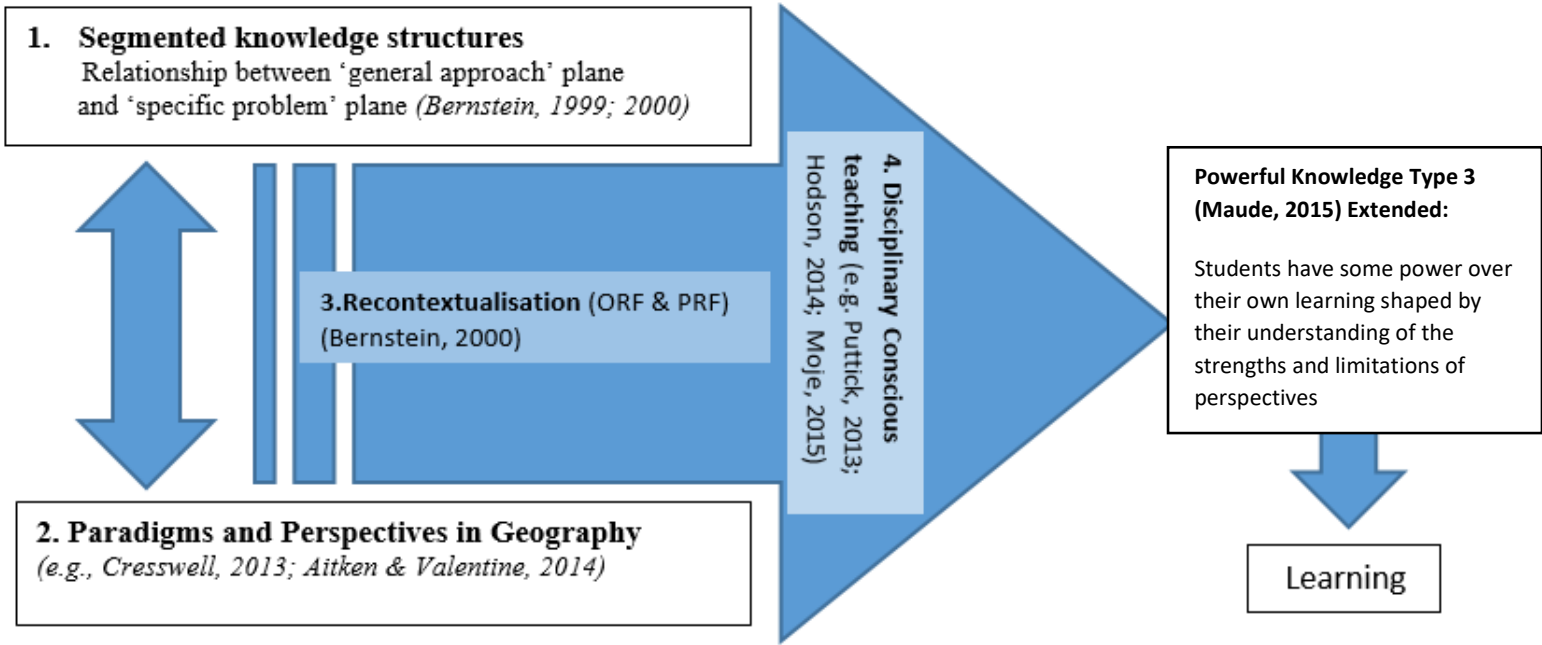

Figure 9.1: Connecting the knowledge debate to classroom practice: A heuristic

My heuristic signposts that although the energy of disciplinary-consciousness draws upon source material from the field of knowledge production, that such energy is attenuated as it is recontextualised (Box 3) through the ORF and PRF. As noted in the previous section, the relations within and between the ORF and PRF can significantly re-imagine the source material, so in a context of curriculum-making autonomy (see Section 2.3.1), teacher recontextualisation practices in the classroom assume significance. Therefore, it is at this point in my heuristic that professional literature which conceptualises pedagogical approaches (Box 4), at this gives some 'how to' advice that participants in this research considered deeply lacking (see Section 7.2.4). Finally, my heuristic connects to Maude's (2015) recent articulation of powerful knowledge. His framework articulates what powerful knowledge can do for learners, thus providing my heuristic with a 'so what?'. A theoretical contribution of this research is that disciplinary-consciousness builds upon Maude's (2015) metacognitive element of powerful knowledge, as it gives students control over, inter-alia, the posing of questions, selection and application of appropriate methodologies, and analysis of texts. As meta-cognition is a generic term that usefully 
frames student's ability to monitor their own learning, then disciplinary-consciousness is a subject-specific variation of meta-cognition that supports the 'curriculum of engagement' concept of the wider social realist project.

\subsection{Empirical reflections}

My focus on the key concept of perspective led me to identify a range of intentional strategies that could support disciplinary-conscious teacher planning and student learning (see Chapter 8, Figure 8.1). While these had some successes for some of the students, previously established recontextualisation of the concept meant that a combination of ambiguous curriculum signalling and pre-configured cognitive scripts (Spillane et al., 2002) gave only limited space for disciplinary-conscious approaches to develop at the macro or micro scale of New Zealand school geography.

The lesson study phase of this case study research showed that, learning about the paradigms and perspectives which have shaped geographic knowledge production is not completely out of reach. This was an important challenge to the view of several subject specialists, who professed an inclination to delay theoretical perspectives for the most capable Year 13 students. Remember both these schools were not elite schools. The evidence from our lesson study collaboration was that there were regular negotiations with the fidelity of paradigms and theoretical perspectives while recontextualising resources or our pedagogical approaches. Our experience of the recontextualisation of paradigms and theoretical perspectives supports Puttick's (2013) observation that teachers will need to seek to modify the language that is associated with theoretical perspectives while balancing this with an accurate representation of the perspective being explored. The many layers attached to perspective at the highest levels of abstraction were dropped and/or recast as the concept was shaped to our context.

The experiences of our lesson study supported the value of Puttick's (2013) distinction between looking at and looking along perspectives. While Puttick's framework was targeted at learners, I reflect that the it also has utility for teachers who have had little disciplinary-consciousness. For example, engaging with source material, such as journal abstracts, and discussing the differences between individual paradigms and perspectives 
were done so from a looking at approach in which the "detached account" (Puttick, 2013, p.358) helped Sacha and Michelle orientate themselves to specific paradigms and perspectives reasonably quickly. The students also benefitted from looking at perspectives, as it helped them get quick gains, especially in the first lesson study of our series, when they were asked to examine how geographers write in different ways (Moje, 2015). Nevertheless, the feedback from teachers and students was that the two structured inquiries (Hodson, 2014) were the most engaging aspects of the programme, as it was clearly a way of exploring aspects of cities by looking along a perspective (Puttick, 2013).

Despite the successes, there was also confirming evidence from all three phases of this case study to show that geography teachers are not encouraged to be closely connected to the roots and routes (Keighren et al., 2012) of the parent discipline. For example, PostFordism was rejected by subject specialists in this study, several acknowledging their own ignorance about this perspective (see Section 7.2.4). Similarly, Michelle and Sacha's difficulty naming some $20^{\text {th }}$ century geographers also suggested disciplinary disconnection, while Sacha's engagement with Harvey (1973) was a step that she admitted was extremely unusual. This disciplinary disconnectedness was a theme further supported by Sacha and Michelle's self-reluctance to be viewed as 'geeky' or 'academic', suggesting that teacher self-identity is a component that may either promote or stall disciplinary-consciousness in the school geography.

\subsubsection{Repositioning the concept perspective}

A crucial implication of developing disciplinary-consciousness that came about as a result of my study is that theoretical perspectives do not operate at the level of other concepts, but act as a filter through which those concepts may be viewed. For example, the concept of 'environment' when viewed through:

- a positivist lens is an objective reality to be manipulated and controlled, perhaps for exploitative or conservational purposes;

- a critical theory lens can be understood as a virtual reality shaped by the contingencies of social and political values;

- a constructivist/humanist lens an environment is a locally mediated reality to be made sense of by its myriad inhabitants. 
Currently, yet confusingly, the concept perspective is one of seven 'key concepts' in the NZC which have a dual function as organisational concepts to assist with teacher planning, yet also appear regularly as substantive concepts in student exams (see Appendix L). When used as a disciplinary filter, the function of perspective requires repositioning to a far more analytical role. This repositioning was captured by Sacha's distinction between the socio-cultural and disciplinary approach: "if we were going to look at an issue, what are the multiple perspectives that that issue will have, but what will the students in front of you as the geographer be thinking about those issues?" (see Section 8.5.5). Given this repositioning, perspective shifts from a substantive to analytical status (Maude, 2015).

In short, disciplinary-consciousness not only requires a greater collection of theories and epistemologies, but also demands a cognitive repositioning of its relationship with other concepts. By re-imagining perspective as a meta-concept it acknowledges all geographical knowledge as inherently theoretical.

\subsection{Reflections on Lesson Study as professional learning}

Spillane et al. (2002) emphasise that situated cognition supports professionals to make sense of policy signals. In this case study, because the policy signal of disciplinaryconsciousness was so weak, choosing a methodological approach that emphasised collaboration appeared to have high face validity. Indeed, as our experience of lesson study unfolded, it was evident that situated cognition was promoted throughout the process: in planning; teaching; observation; and evaluation of outcomes (Perry \& Lewis, 2009; Stepanek et al., 2007).

In the last decade there has been a movement to Teaching-as-Inquiry in secondary schools, largely as a result of its inclusion in the New Zealand Curriculum (MoE, 2007). A key aspect of teaching-as-inquiry is to develop a stance towards evidence in the classroom (ref). Our experience of Lesson Study suggests that is an appropriate methodological approach to develop Teaching-as-Inquiry attitudes and dispositions across the profession. As noted by advocates of Lesson Study, the approach is multi-scalar, as it simultaneously demands attention to a micro-level inspection of evidence while developing dispositional 
qualities or 'habits of mind' for its participants (Dudley, 2015; Stepanek et al., 2007). In this respect Lesson Study generated professional learning about approaches to teaching disciplinary-consciousness, while also serving a developing our own professionalism as we grew increasingly accustomed to collaboration and de-privatisation of practice (Timperley, Wilson, Barrar, \& Fung, 2007).

An implication that arises from this study is the future provision of deep level subject specific professional development for geography teachers. I suggest that the extremely limited pool of research-led, geography specific support available teachers makes this type of professional experience a very rare occurrence, unless geography teachers connect with (rarely) funded classroom-based projects. The teaching-as-inquiry approach advocated in the NZC may have generated personal classroom inquiries for the sake of staff appraisal, but this has not encouraged systematic study of teaching and learning open to public scrutiny (Benade, 2015), nor encouraged rigorous notions of evidence.

Our experience suggests that the relational and collaborative focus of Lesson Study requires effective knowledge brokerage. For example, my input into the collaborative lesson study programme, while no means a paragon of perfection, was acknowledged by both Sacha and Michelle as having the necessary impetus to introduce them to the development of geographical thought. Essentially, Sacha and Michelle were acknowledging that I was conversant with the development of geographical thought, which they would need to grapple with at the outset of the collaboration (see Figure 9.1). My substantive knowledge was also complemented by procedural knowledge and adaptive action-competence, specifically evolving around lesson study practices (see Chapter 5, Section 5.5.3.2). The power of social-cognition is that is generated by collaborators who have different view, so that the professional development is not just supportive but at some times critical (Fernandez, 2002; Lewis et al., 2012). There were times throughout lesson study in which we were not in agreement (see, for example, Section 8.4.1), but norms of trust and openness helped us work towards common goals.

As noted in Chapter 3, in the New Zealand setting, school advisory services, were a key mechanism for the widespread dissemination of curriculum and pedagogical support, yet 
their demise in a 'death by a thousand cuts' over the last decade has seen geography specialists removed from this important research-led space. This means that there are just not enough geography education specialists with curriculum, pedagogical and assessment expertise to support geography teachers across the breadth of the country. Very recently, the Tomorrow's Schools Independent Taskforce's (2018) recommended that approximately 20 'Education Hubs' be established to address the "limited curriculum expertise" within the MoE, and to support teachers who "want access to curriculum and assessment expertise to provide them with advice, access to resources and curriculum leadership" (p. 118). Should such a recommendation be adopted, capacity building will be required so that a new wave of 'Priests' can be relied on to support teachers in sustained, relational PLD opportunities. Lesson study clusters could be a feature of such Hubs. Nevertheless, a further, related implication, is that professional development approaches such as Lesson Study are time consuming and intensive, therefore requiring significant expertise and resource allocation. This research has demonstrated that disciplinaryconscious geography teaching can be achieved, but along with more appropriate resourcing and guidelines, the professional development to turn things around at this point is significant if the desire for implementation is to be taken seriously.

\subsection{Recommendations}

In this section I suggest some recommendations, with a view to stimulating greater disciplinary-consciousness in New Zealand school geography. These are targeted at a range of actors in the ORF and PRF, as there is little prospect of getting traction if these recommendations are done in a piecemeal fashion. In addition, drawing upon my personal experience in ITE, I propose a number of models and strategies that may serve as starters for these actors to reflect on.

\subsubsection{New Zealand Board of Geography Teachers}

\section{- Instigate a national conversation about the nature of geographical knowledge}

Notwithstanding the fact that the NZBoGT is largely comprised of classroom teachers for whom disciplinary-consciousness may not be well developed, the national subject association does have the leverage to draw upon academics, professional geographers, 
teacher educators and educationalist who can form an advisory committee to the MoE. A restructuring of the field of recontextualisation could be instigated if a committee of 'prophets' and 'priests' were to be established, much like the highly influential NGCC in the 1970s and 80s. This will help develop a stronger relationship between the personnel of academic and school geography at which 'high level discussions' about the nature of knowledge in the school subject take place and potentially inform the ORF. The field of recontextualisation will always continue to integrate wider educational discourses, but stronger attention to knowledge might develop if geography education Priests and Prophets engage in creative dialogue.

\subsubsection{MoE Curriculum Guidelines Writers}

\section{- Develop resources with pedagogic value.}

Figure 9.2 is a suggestion for two resource that might help teachers organise their thinking around a range of theoretical perspectives / paradigms. The first resource is a structured overview template, which helps identify the key components of a paradigm or perspective. For teachers this encourages looking at perspectives (Puttick, 2013), as it is an analysis of a perpective, breaking it down into component parts. The second resource is a template that teachers might use as a support to work directly with senior secondary students. It gives opportunities for students to identify, analyse and apply perspectives, allowing for increased levels of thinking. Appendix $\mathrm{P}$ is a working example of how such a template might be used, in which the perspectives of agency, structuralism, and functionalism are applied to migration policy. Note also, the pedagogical value of posing questions both from stakeholder and disciplinary-conscious framings. By doing this, it signals a difference between the two framings. 


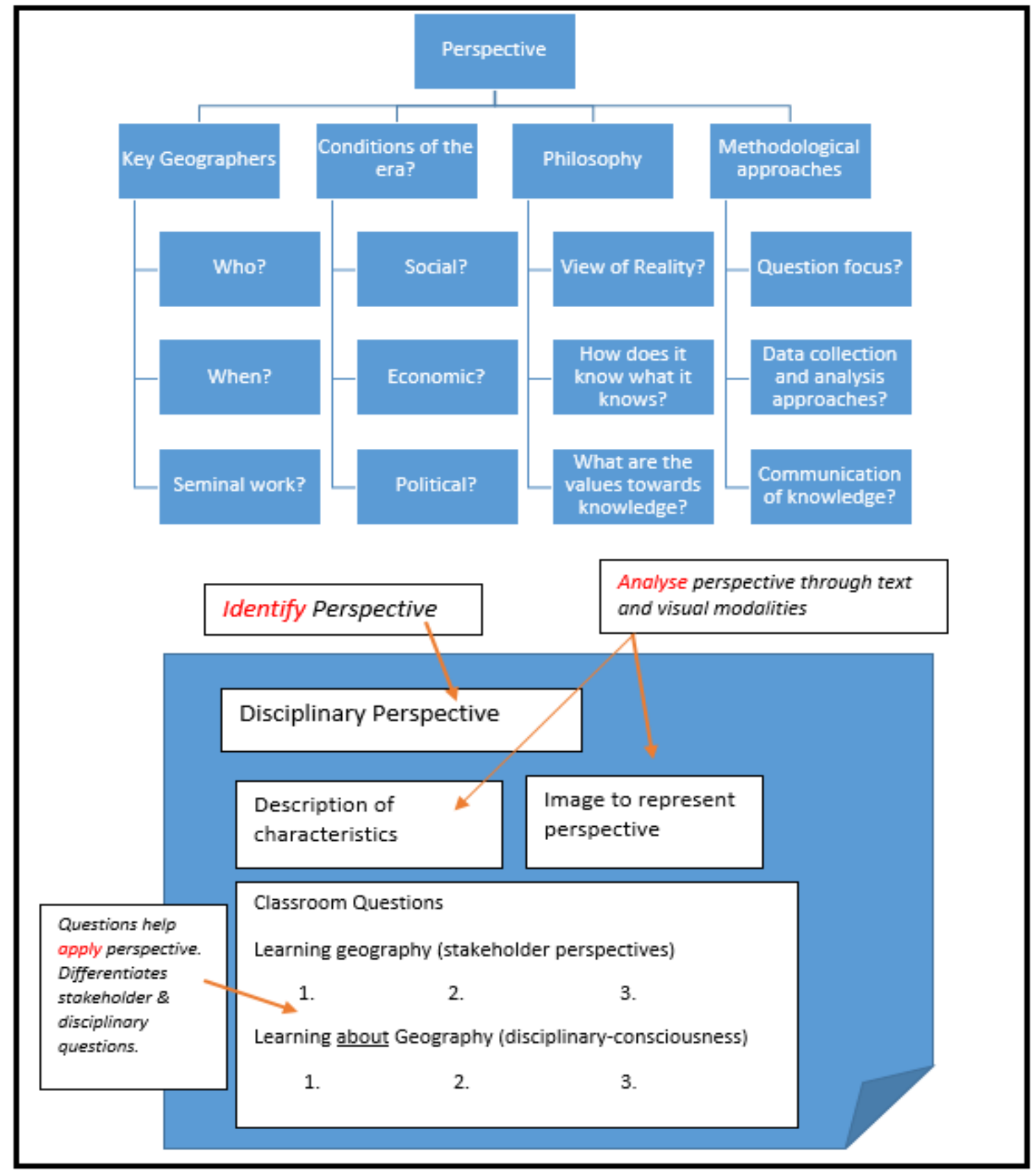

Figure 9.2: Resources for teaching perspectives

\section{- Develop a framework for disciplinary-consciousness progression}

Drawing on Brooks (2013) framework for conceptual progression, Figure 9.3, might be a useful planning prompt to help teachers plan for disciplinary-consciousness over the course of three years of senior school geography. The framework identifies four dimensions across which disciplinary-consciousness may develop: depth of analysis of a given paradigm or perspective; application of a wider number of perspectives; increased 
confidence in the use of language associated with a paradigm/perspective; and increasing knowledge of significant actors and the wider socio-cultural conditions in which perspectives emerged. By using this framework, disciplinary-conscious progression is linked both to Bernstein's (2000) 'voices' on the general approach plane, while developing vertically and iteratively over multiple contexts on the specific problem plane. Moreover, it is an important signal to teachers of how students can broaden and deepen their disciplinary-consciousness, that draws upon the identify-analyse-apply strategy of our lesson study collaboration.

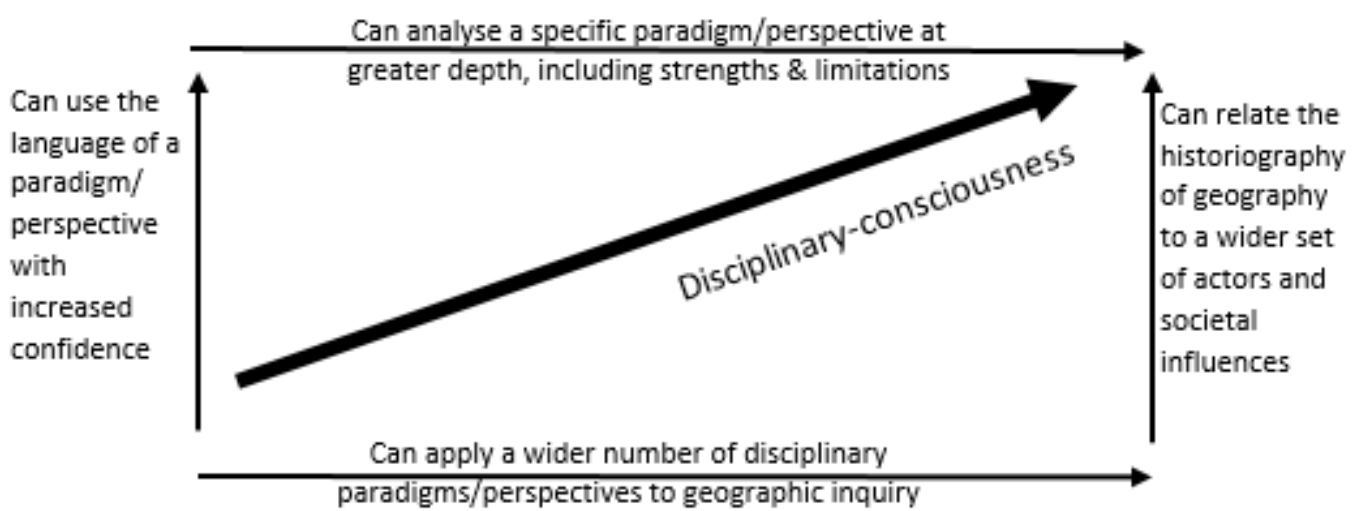

Figure 9.3: A suggested framework for progression in disciplinary-consciousness

\section{- Consider an alternative term than 'perspectives' for disciplinary-consciousness}

Given that my findings have showed subject specialists have a strong leaning towards atheoretical perspectives such as economic, social, cultural, and environmental, then maybe the disciplinary-conscious approach should use different terminology. Sacha's suggestion of the 'schools of geography' may point the disciplinary-conscious in a direction that avoids the problem of perspectives having both the stakeholder and disciplinary meaning. Alternatively, the term 'paradigm' could be utilised more regularly, as that terminolgy is less easily vernacularised than perspective has been. 


\subsubsection{NZQA Assessment developers and examiners}

\section{- Give scope for disciplinary-consciousness in NCEA standards}

Elsewhere I have shown how the re-imagined prescription for the 'Extreme Natural Events' Achievement Standard (in Year 11) now has much greater scope for a politicaleconomy perspective than in previous decades (Taylor, 2013). An unrealised opportunity might be to take the NCEA Level 3 Achievement Standard "Analyse a significant contemporary event from a geographic perspective" and frame it in such a way that students really do have a choice of perspective. Currently this Achievement Standard notes that "Geographic perspective refers to a spatial dimension and the interaction between people and the environment" (NZQA, 2017) and the analysis has to involve planning and decision making. So, the expansive title appears quite limited by the circumscribed notion of perspective. Developing an achievement standard "Analyse a significant contemporary geographical event from two or more theoretical perspectives" might be suitably challenging and immediately signals much deeper engagement with theory and perspectives.

\section{- Examine disciplinary-consciousness more regularly}

When a 2007 NCEA Level 3 exam did present a question explicitly based on a theoretical perspective, the examiner's report made it very clear that students had not been supported enough (see Section, 6.3.1). The fact that no such similar type of question has been asked since 2007 suggests that examiners have passed up on the opportunity to test students' disciplinary-consciousness. Perhaps a harder, yet more rewarding road in terms of connecting school geography with academic geography, would be to continue incorporating such questions in examinations. After all, New Zealand teachers have been working in a heightened 'what gets assessed is what gets taught' environment since the introduction of the NCEA (Hipkins et al., 2016).

\subsubsection{Initial Teacher Educators}

\section{- Model disciplinary-conscious pedagogy}

In my own ITE work, it is only over the course of writing this thesis that I have made space in my programme to consider how geographical knowledge production is represented in the school subject. This may support student-teachers to reach higher levels 
of thinking and conceptualisation beyond curriculum and assessment prescription (Maude, 2015), as well as articulate a personal rationale for geography education. Despite my own tentative steps in this regard, I have to agree with Lambert's (2013) observation that "little time is now devoted to such matters in the preparation of teachers, as training programmes have become intensely and heavily focused on the technical aspects of teaching and learning and skills acquisition" (p. 91) . This is an ongoing challenge in a performance focused education era (Codd, 2005).

\subsubsection{Teachers}

\section{- Engage with disciplinary-conscious texts}

In this research I found that the most efficient way to read about the historiography of geography was to select texts that spanned the development of mid to late $20^{\text {th }}$ century geography. This is another looking at approach (Puttick, 2013), which may help teachers develop a swift orientation to the historiography of the subject. A geography department investment in one core text a year would be a good start. Cresswell (2013) is an excellent and up-to-date text aimed at undergraduate audiences and thus not too intimidating for teachers who have lost touch with reading texts straight from the field of knowledge production. Aitken and Valentine (2014) offer a similarly concise overview, while those really interested in the politics and contestation in the field of knowledge production could bravely take on Johnston \& Sidaway (2004).

If progression in geography is, in part, engagement with a wider range of theoretical voices, then building up taxonomies that bring together Bernstein's specific problem plane and general approach plane (of theories) is a sensible approach for teachers. For example, Table 9.2 shows four theories to explain migration. This is by no means an exhaustive list of theories relating to migration, but it would be interesting to know how many teaching the topic of migration go beyond the text book staple of the neo-classical push-pull model. 


\begin{tabular}{|l|l|l|}
\hline Theory & Explanation for Migration & Typical Scale \\
\hline Neo Classical & $\begin{array}{l}\text { Labour surplus in low wage economy moves to labour } \\
\text { shortage in higher wage economy. (Push Pull rationality) }\end{array}$ & Individual \\
\hline Institutional & $\begin{array}{l}\text { Visa limits and quotas generate demand for organisations } \\
\text { such as recruitment agencies, immigration lawyers, and even } \\
\text { smugglers to facilitate international migrant flows }\end{array}$ & Continental/Global \\
\hline $\begin{array}{l}\text { Mobility } \\
\text { transition }\end{array}$ & $\begin{array}{l}\text { Demographic transition generates different flows (e.g. early } \\
\text { stages rural to urban; later stages net importer of cheap } \\
\text { overseas labour) }\end{array}$ & $\begin{array}{l}\text { National/ } \\
\text { Continental }\end{array}$ \\
\hline $\begin{array}{l}\text { Segmented labour } \\
\text { market }\end{array}$ & $\begin{array}{l}\text { Locals have secure, safe jobs while migrants are channelled } \\
\text { to precarious, low paid, unsafe jobs (e.g., Filipino } \\
\text { construction workers in Dubai) }\end{array}$ & Global \\
\hline
\end{tabular}

\section{- Adopt an iterative, long term view of disciplinary-consciousness teaching}

Students should be in regular negotiation with the concept of perspective, particularly as they learn about, and practise, geography. As a meta-concept, a disciplinary-conscious stance towards knowledge requires navigation throughout the duration of geography programmes of study (see Figure 9.3). Drip-feeding disciplinary-conscious questions, methodologies, analysis and communication in small, targeted moments will help build methodological understanding over time. While geographic research projects may require teachers to focus on disciplinary-consciousness more than at other times of the year, if teachers have developed an understanding of the roots and routes of geography, then they can also draw upon this knowledge in unanticipated moments of their teaching.

\subsection{Limitations and future research directions}

The limitations of my research were shaped by the interpretive paradigm in which I located this research, the research design and its attendant methodologies, as well as contextual factors. Furthermore, within the research matrix itself, there were some aspects of my study that also constrained what could and could not be said about diciplinaryconscious approaches to school geography in New Zealand. Therefore, in this section I identify some of these limitations, while suggesting future directions for researchers exploring disciplinary-conscious teaching and learning in school geography. 
Although the Phase 1 component of my case study used a wide number of documents from the recontextualising field as a proxy for the 'state of play' of disciplinary-conscious school geography, the Phase 2 and 3 components were narrow in terms of the number of subject specialists, teachers, and students who contributed to this study. This limits the generalisability of my study. While this is not an inherent problem for my case study design per se, it does present an opportunity for researchers going forward. For example, a future research direction could involve interviewing a wider number of geography teachers about their knowledge of the development of geography and how this connects to their own identity as geography teaching specialists and represents itself in the school subject they teach. To test some of the findings I have, a second research direction that seeks a wider view than my study, could be directed to students. It would, for example, be interesting to evaluate the responses of a large sample of Year 10-13 students about statements that relate to the nature of geographic knowledge (e.g. 'Geographers take the view of dispassionate scientists'), particularly to see if there is any shift in theoretical or epistemological state as students experience more senior school geography. In addition, my survey of subject specialists had small numbers, largely due to the limited number of people who actually hold these positions in New Zealand. It would therefore be intersting to take this further and examine if my finding of low disciplinary-consciousness applied to other curriculum area and other jurisdictions.

Although I found that the very little codification of the langauge of paradigms and perspectives was distributed across subject specialists and teachers, this may be because some aspects of disciplinary-consciousness have been recontextualised to such a degree that 'teacher talk' has rendered 'academic language' invisible. Empiricism and positivism are the litmus test for this claim, and so one of my clear limitations of this study was not having access to observation of Sacha and Michelle's teaching of geographic research, where discussion about observation, measurement, analysis and generalisations may have been a feature of greater recontextualisation (Puttick, 2015b). To test this implication, a future direction for research could be to explore the recontextualisation of empiricism and positivism teachers apply in research components of geography teaching and learning. While such an approach may not provide insight on a plurality of theoretical perspectives, 
it would at least begin to open up New Zealand geography to explicit enagagment with geographical knowledge production.

New Zealand school geography lacks a research programme focused on a detailed analysis of teacher practices and student outcomes. Although the Phase 3 component of this research sought to add to the absence of classroom focused research, it was limited to a small number of lessons $(n=5)$. More immersive, expansive classrrom focused research might give finer grained analysis to:

- The impact of a wider range of teaching strategies to build and extend disicplinaryconsciousness.

- Developing students productive lanaguge in relation to a selection of theoretical perspectives. The outcome of this research might develop glossaries and other literacy focused strategies to make disciplinary-consciousness more accessible to younger social science students.

- Evaluating the impact (on teachers and students) of a unit of work that has been designed and taught with explicit attention to a specific perspective or pardigm. A collection of research studies each focused on disciplinary-consciousness within a specific perspective might generate gerater detail and opoprtunity for cross-case comparisions. Do, for eaxmple, certain strategies work better for looking at or looking along different perspectives?

\subsection{Final comment}

Firth (2011) has observed that "Geography teachers need to engage with questions about the production and nature of knowledge if they are to enable their students to make sense of how geography helps them to make sense of the world." (p. 154). As this small-scale case-study has shown, disciplinary-consciousness deepens the thinking of teachers and students, and through carefully planned recontextualisation in the classroom, can strengthen the relationship between the school subject and academic discipline. Our geography students are entitled to an understanding of how we know what we know, to understand that geographical knowledge is not a given, but the product of collective minds and iterative development. By re-orientating New Zealand secondary school geography to 
knowledge, students will, over time, develop a deeper appreciation of the many different lenses through which our understanding of the world is filtered, thus enhancing their ability to contribute as knowledge-rich citizens. 


\section{References}

Abd-El-Khalick, F., \& Lederman, N. G. (2000). Improving science teachers' conceptions of nature of science: a critical review of the literature. International Journal of Science Education, 22(7), 665-701. doi:10.1080/09500690050044044

Aerts, D., Apostel, L., Moor, B. D., Hellemans, S., Maex, E., Belle, H. V., \& Veken, J. V. d. (2007). Worldviews: From fragmentation to integration Retrieved from http://www.vub.ac.be/CLEA/pub/books/worldviews.pdf

Aitken, G. (2006). Signalling shifts in meaning: The experience of social studies curriculum design. Curriculum Matters, 2(1), 6-25.

Aitken, S., \& Valentine, G. (2014). Ways of knowing and ways of doing geographic research. In S. Aitken \& G. Valentine (Eds.), Approaches to human geography philosophies, theories, people and practices (pp. 1-15). Los Angeles, CA: Sage.

Akerson, V. L., Buck, G. A., Donelly, L. A., Nargund-Joshi, V., \& Weiland, I. S. (2011). The importance of teaching and learning nature of science in the early childhood years. Journal of Science, Education and Technology, 20(5), 537-549. doi:10.1007/s10956-0119312-5

Appleman, D. (2009). Critical encounters in high school English: Teaching literary theory to adolescents (2nd ed.). New York, NY: Teachers College Press and NCTE.

Astle, A. (1987). Commentary. New Zealand Journal of Geography, 84, 6-8.

Atherton, M. (Ed.) (1999). The empiricists: critical essays on Locke, Berkeley and Hume Lanham, MD: Rowan and Littlefield.

Baldwin, S. (2012). Placing geography in the New Zealand curriculum. New Zealand Geographer, 68(3), 211-218.

Bartlett, L. (1983). Questions and viewpoints: The art of interpretation in teaching geography. New Zealand Journal of Geography, 74, 7-13.

Barton, K. C. (2015). Elicitation techniques: Getting people to talk about ideas they don't usually talk about. Theory and Research in Social Education, 43(2), 179-205. Retrieved from doi:10.1080/00933104.2015.1034392

Bassett, K., \& Short, J. (1989). Development and diversity in urban geography. In D. Gregory \& R. Walford (Eds.), Horizons in Human Geography (pp. 175-193). Basingstoke: Macmillan Education Ltd.

Bassey, M. (1999). Case study research in educational settings. Buckingham: Open University Press.

Benade, L. (2015). Teaching as inquiry: Well intentioned, but fundamentally flawed. New Zealand Journal of Education Studies, 50(1), 107-120.

Bennett, B., Dann, J., Johnson, E., \& Reynolds, R. (Eds.). (2014). Once in a lifetime: City-building after disaster in Christchurch. Christchurch, NZ: Freerange Press.

Bergeron, L., \& Rogers, L. (2015). Teaching the theory of knowledge course in IB World Schools. Retrieved from https://www.ibo.org/contentassets/d1c0accb5b804676ae9e782b78c8bc1c/teaching-tokin-ib-schools-en.pdf

Bernstein, B. (1996). Pedagogy, symbolic control and identity: Theory, research and critique. London: Taylor \& Francis.

Bernstein, B. (1999). Vertical and horizontal discourse: An essay. British Journal of Sociology of Education, 20(2), 157-173. Retrieved from doi:10.1080/01425699995380

Bernstein, B. (2000). Pedagogy, symbolic control and identity: Theory, research, critique (2nd ed.). Oxford: Roman and Littlefield. 
Bliss, S. (2005). Perspectives in Australian global education and geography/mätauranga matawhenua. New Zealand Geographer, 61(3), 225-241. doi:10.1111/j.17457939.2005.00038.x

Bloom, B. S. (1956). Taxonomy of educational objectives, handbook I: The cognitive domain. New York: David McKay Co Inc.

Blue, B., \& Brierley, G. (2016). 'But what do you measure?' Prospects for a constructive critical physical geography. Area, 48(2), 190-197. doi:10.1111/area.12249

Bos, W., \& Tarnai, C. (1999). Content analysis in empirical social research. International Journal of Educational Research, 31(8), 659-671. Retrieved from doi:10.1016/SO8830355(99)00032-4

Bridge, G., \& Watson, S. (Eds.). (2013). The new Blackwell companion to the city. Chichester, UK: Wiley-Blackwell.

Brooker, J. (2007, 6 December). Students asked to give 'feminist perspective' on geography. New Zealand Herald. Retrieved from: http://www.nzherald.co.nz/nz/news/article.cfm?c id=1\&objectid=10480663

Brooks, C. (2006). Geographical knowledge and teaching geography. International Research in Geographical and Environmental Education, 15(4), 353-369. doi:10.2167/irg200.0

Brooks, C. (2013). How do we understand conceptual development in school geography? In D. Lambert \& M. Jones (Eds.), Debates in geography education (pp. 75-88). Abingdon, Oxon: Routledge.

Brown, B. J., \& LeVasseur, M. L. (2006). Geographic perspective: Content guide for educators. Retrieved from http://education.nationalgeographic.com/education/media/geographicperspective/?ar $a=1$

Bruner, J. (1960). The process of education. Cambridge, Mass.: Harvard University Press.

Butt, G., \& Collins, G. (2013). Can geography cross 'the divide'? In D. Lambert \& M. Jones (Eds.), Debates in geography education (pp. 291-301). Abingdon, UK: Routledge.

Buttimer, A. (1976). Grasping the dynamism of lifeworld. Annals of the Association of American Geographers, 66(2), 277-292. doi:10.1111/j.1467-8306.1976.tb01090.x

Cant, G. (1982). Ground rules for school based geography programmes. A response to $\mathrm{Mr}$ O'Malley's comment on the NGCC Draft National Guidelines. New Zealand Journal of Geography(72), 10-11.

Chalmers, L. (2003). The place of perspectives in geographical education in New Zealand secondary schools. Paper presented at the New Zealand Geographical society 22nd Conference Proceedings., New Zealand.

Chalmers, L. (2005). Traces of the secondary Geography curriculum. New Zealand Geographer, 61(2), 148-157. doi:10.1111/j.1745-7939.2005.00018.x

Chalmers, L., Keown, P., \& Kent, A. (2002). Exploring different 'perspectives' in secondary geography: professional development options. International Research in Geographical and Environmental Education, 11(4), 313-324. doi:10.1080/10382040208667499

Chalmers, L. (2015). Advancing Scholarship/scholarship in geography classrooms. In M.Taylor, L. Richards, \& J. Morgan. Geography in focus: Teaching and learning in issues based classrooms (pp. 107-122). Wellington, NZ: NZCER Press.

Chandler, G. (1979). Some valuing strategies. In N. Zepke \& R. Sommerville (Eds.), Approaches to Social Studies (pp. 97-103). Wellington: Methuen.

Charmaz, K. (2006). Constructing grounded theory: A practical guide through qualitative analysis. thousand Oaks, CA: Sage Publications.

Codd, J. (2005). Education policy and the challenges of globalisation: Commercialisation or citizenship? In J. Codd \& K. Sullivan (Eds.), Education policy directions in Aotearoa New Zealand. Southbank, VI: Dunmore Press. 
Cohen, L., Manion, L., \& Morrison, K. (2003). Research methods in education (5 ed.). London: RoutledgeFalmer.

Cohen, L., Manion, L., \& Morrison, K. (2011). Research methods in education (7 ed.). London: Routledge.

Cole, J. P. (1973). Perception in geography. In J. Bale, N. Graves, \& R. Walford (Eds.), Perspectives in geographical education (pp. 239-248). Edinburgh, UK: Oliver \& Boyd.

Crack, C. E. (2005). The dilemmas of displacement: Revitalisation and gentrification in inner city Wellington, New Zealand Retrieved from http://hdl.handle.net/10523/3354

Creswell, J. W. (1994). Research design: Qualitative and quantitative approaches. Thousand Oaks, CA; Sage Publications.

Creswell, J. W. \& Plano Clark, V. (2011). Designing and conducting mixed methods research (2 ${ }^{\text {nd }}$ ed.). Los Angeles, CA: Sage Publications.

Cresswell, T. (2008). Place: encountering geography as philosophy. Geography, 93(3), 132-139.

Cresswell, T. (2013). Geographic thought: A critical introduction. Chichester, UK: Wiley-Blackwell.

Creswell, J. (2009). Research design: Qualitative, quantitative and mixed methods approaches Thousand Oaks, CA: Sage Publications.

Crotty, M. (1998). The foundations of social research: Meaning and perspective in the research process London, UK: Sage Publications.

De Putter-Smits, L. G. A. (2012). Science teachers designing context-based curriculum materials: Developing context-based teaching competence (Doctoral dissertation. Eindhoven University of Technology, Netherlands). Retrieved from https://www.researchgate.net/publication/254759584 Science teachers designing cont ext-based curriculum materialsdeveloping context-based teaching competence

Deng, Z., \& Luke, A. (2008). Subject matter: Defining and theorizing school subjects. In F. M. Connelly, M. F. He, \& J. Phillion (Eds.), The Sage Handbook of Curriculum and Instruction (pp. 66-89). Thousand Oaks, CA: Sage Publications.

Denscombe, M. (2007). The good research guide (3rd ed.). Maidenhead: McGraw Hill / Open University Press.

Denzin, N. K., \& Lincoln, Y. S. (2018). Paradigms and perspectives in contention. In N. K. Denzin \& Y. S. Lincoln (Eds.), The Sage handbook of qualitative research (5th ed., pp. 97-107). Thousand Oaks, CA: Sage Publications.

Denzin, N. K., \& Lincoln, Y. S. (Eds.). (1998). The landscape of qualitative research, theories and issues. Thousand Oaks, CA: Sage Publications.

Department of Education. (1987). Report on the Social Studies Subjects Survey 1981-1983 Wellington, NZ: Author.

Dobbins, M. (2010). Education policy in New Zealand - Successfully navigating the international market for education. In K. Martens, A.-K. Nagel, M. Windzio, \& A. Weymann (Eds.), Transformation of Education Policy (pp. 153-178). Basingstoke, UK: Palgrave Macmillan.

Dudley, P. (2015). How lesson study works and why it creates excellent learning and teaching. In P. Dudley (Ed.), Lesson study: Professional learning for our time (pp. 1-28). Abingdon, UK: Routledge.

Durkin, E. (2018, September 12). North Carolina didn't like science on sea levels...so passed a law against it. The Guardian. Retrieved from https://www.theguardian.com/usnews/2018/sep/12/north-carolina-didnt-like-science-on-sea-levels-so-passed-a-lawagainst-it

Eddy, S. A., \& Olsen, A. F. (2011). New Zealand: Pioneer teachers and the implementation of GIS in schools. In A. J. Milson, A. Demirci, \& J. J. Kerski (Eds.), International perspectives on teaching and learning with GIS in secondary schools (pp. 179-189). Dordrecht: Springer. 
Edens, J. (2016, November 14). Earthquake: There's no evidence the moon causes quakes. The Dominion Post. Retrieved from https://i.stuff.co.nz/national/86433394/earthquaketheres-no-evidence-the-moon-causes-quakes

Eflin, J. T., Glennan, S., \& Reisch, G. (1999). The nature of science: A perspective from the philosophy of science. Journal of Research in Science Teaching, 36(1), 107-116. doi:10.1002/(SICI)1098-2736(199901)36:1<107::AID-TEA7>3.0.CO;2-3

Elder, L., \& Paul, R. (2010). The thinker's guide to analytical thinking: how to take thinking apart and what to look for when you do. Retrieved from http://www.criticalthinking.org/files/SAM Analytic Think2007b.pdf

Evans, S. (2017). Applying literary theory in the secondary Literature classroom Idiom, 53(2), 2426. Retrieved from https://search-informit-comau.helicon.vuw.ac.nz/documentSummary; dn=171229763898320;res=IELHSS

Faggella-Luby, M. N., Graner, P. S., Deshler, D. D., \& Drew, S. V. (2012). Building a house on sand: Why disciplinary literacy is not sufficient to replace general strategies for adolescent learners who struggle. Topics in Language Disorders, 32(1), 69-84. Retrieved from https://dpi.wi.gov/sites/default/files/imce/cal/pdf/building-house-on-sand.pdf

Fastier, M. (2016). Curriculum change, challenges and teacher responsibility. New Zealand Geographer, 72(1), 51-56. doi:10.1111/nzg.12108

Fernandez, C. (2002). Learning from Japanese approaches to professional development: the case of lesson study. Journal of Teacher Education, 53(5), 393-405.

Flick, U. (1998). An introduction to qualitative research. Thousand Oaks, CA: Sage Publications.

Fien, J., \& Gerber, R. (Eds.). (1988). Teaching geography for a better world (2nd ed.). Edinburgh: Oliver \& Boyd.

Firth, R. (2011a). Debates about knowledge in the curriculum: Some implications for geography education. In G. Butt (Ed.), Geography education and the future (pp. 141-163). London: Continuum.

Firth, R. (2011b). Making geography visible as an object of study in the secondary school curriculum. Curriculum Journal, 22(3), 289-316. doi:10.1080/09585176.2011.601209

Firth, R. (2013). What constitutes knowledge in geography? In D. Lambert \& M. Jones (Eds.), Debates in Geography Education (pp. 59-74). Abingdon, Oxon: Routledge.

Fiske, E. B., \& Ladd, H. F. (2000). When schools compete: A cautionary tale. Washington, DC: Brookings Institution Press.

Forer, P. C., \& Owens, I. F. (1979). The Frontiers of Geography in the 1980s. New Zealand Journal of Geography, 67, 2-5.

Gabriel, R., \& Wenz, C. (2017). Three directions for disciplinary literacy. Educational Leadership, 74(5). Retrieved from http://www.ascd.org/publications/educationalleadership/feb17/vol74/num05/Three-Directions-for-Disciplinary-Literacy.aspx

Gale, L. E. F. (1996). Maori and Pakeha geographies: Towards a culturally plural geography in Aotearoa-New Zealand. . (MSc), A thesis submitted in part fulfillment of Master of Social Science, University of Waikato, Hamilton.

Gerring, J. (2007). Case study research: Principles and practices. New York, NY: Cambridge University Press.

Gilbert, J. (2005). Catching the knowledge wave? The knowledge society and the future of education. Wellington: NZCER Press.

Glaser, B., \& Strauss, A. (1967). The discovery of grounded theory. Chicago: Aldine.

Godwin-Jones, R. (2008). Emerging technologies: mobile-computing trends: lighter, faster, smarter. Language learning and technology, 12(3), 3-9.

Goldman, S. R. (2012). Adolescent literacy: Learning and understanding content. The Future of Children, 22(2), 89-116. 
Golledge, R. G. (2002). The Nature of Geographic Knowledge. Annals of the Association of American Geographers, 92(1), 1-14. doi:10.1111/1467-8306.00276

Goodson, I. F. (1988) Becoming a school subject. In I. F. Goodson (Ed.) The Making of Curriculum: Collected Essays. Brighton, UK: Falmer

Goudie, A. (1993). Guest editorial: Schools and universities - the great divide. Geography, 78(4), 338-339. doi:10.2307/40572548

Graves, N. J. (1979). Curriculum planning in geography. London: Heinemann Educational Books.

Gregory, D., \& Walford, R. (Eds.). (1989). Horizons in human geography. London: MacMillan.

Gritzner, C. F. (2002). What is where, why there, and why care? Journal of Geography, 101(1), 3840.

Grünbaum, N. N. (2007). Identification of ambiguity in the case study research typology: what is a unit of analysis? Qualitative Market Research: An International Journal, 10(1), 78-97. doi:10.1108/13522750710720413

Habermas, J. (1972). Knowledge and human interests. London: Heinemann.

Hartshorne, R. (1939). The nature of Geography: A critical survey of current thought in the light of the past. Annals of the Association of American Geographers, 29(3), 173-412.

Harvey, D. (1973). Social justice and the city. Oxford: Blackwell.

Hattie, J. (2008). Visible Learning: A Synthesis of over 800 Meta-Analyses Relating to Achievement. London: Routledge.

Hay, I. (1987). Optical analysis: (Pr)isms in geographic thought. New Zealand Journal of Geography. 83, 2-8.

Heller, R. (2010). In praise of amateurism: A friendly critique of Moje's "Call for Change" in secondary literacy. Journal of Adolescent \& Adult Literacy, 54(4), 267-273. Retrieved from doi:10.1598/JAAL.54.4.4

Hicks, D. (2013). A post-carbon geography. Teaching Geography, 38(3), 94-97.

Hipkins, R., Johnson, M., \& Sheehan, M. (2016). NCEA in context. Wellington: NZCER Press.

Hirst, P. H. (1974). Knowledge and the curriclum. London: Routledge \& Kegan Paul.

Hodson, D. (2014). Learning science, learning about science, doing science: Different goals demand different learning methods. International Journal of Science Education, 36(15), 2534-2553. doi:10.1080/09500693.2014.899722

Hubbard, P., Kitchin, R., \& Valentine, S. (Eds.). (2008). Key texts in human geography. Thousand Oaks, CA.: SAGE.

Huckle, J. (2002). Towards a critical school geography. In M. Smith (Ed.), Teaching Geography in Secondary Schools (pp. 255-265). London: RoutledgeFalmer.

Huff, A. S. (2009). Designing research for publication Thousand Oaks, CA: Sage.

Insch, G. S., Moore, J. E., \& Murphy, L. D. (1997). Content analysis in leadership research: Examples, procedures, and suggestions for future use. Leadership Quarterly, 8(1), 1-25. Retrieved from doi:10.1016/S1048-9843997)90028-X

International Encyclopedia of the Social Sciences. (2008a). Paradigm. Retrieved from http://www.encyclopedia.com/doc/1G2-3045301866.html

International Encyclopedia of the Social Sciences. (2008b). Theory. Retrieved from http://www.encyclopedia.com/doc/1G2-3045302740.html

International Encyclopedia of the Social Sciences. (2008c). Weltanschauung. Retrieved from http://www.encyclopedia.com/doc/1G2-3045302961.html

Isaac, J. (2017). Experiment with literary perspectives using a visual approach at NGV. Idiom, 53(2), 35-36. Retrieved from https://search-informit-comau.helicon.vuw.ac.nz/documentSummary; dn=171639689266001;res=IELHSS

Johnston, K. (2016, 26 September). Revealed: What's beneath rising NCEA pass rates. New Zealand Herald. Retrieved from https://www.nzherald.co.nz/nz/news/article.cfm?c id=1\&objectid=11713953 
Johnston, R. J. (1996). Paradigms and revolution or evolution? In J. Agnew, D. N. Livingstone, \& A. Rogers (Eds.), Human geography: An essential anthology (pp. 37-53). Oxford: Blackwell.

Johnston, R. J., \& Sidaway, J. D. (2004). Geography and geographers: Anglo-American human geography since 1945 (6th ed.). London: Arnold.

Kant, I. (2000). The critique of pure reason. South Bend, IN: Infomotions, Inc.

Keighren, I. M. (2005). Geosophy, imagination, and terrae incognitae: Exploring the intellectual history of John Kirkland Wright. Journal of Historical Geography, 31(3), 546-562. Retrieved from http://www.sciencedirect.com/science/article/pii/S0305748804000362 doi:10.1016/j.jhg.2004.04.004

Keighren, I. M., Abrahamsson, C., \& della Dora, V. (2012). On canonical geographies. Dialogues in Human Geography, 2(3), 296-312.

Koelsch, W. A. (2003). William H. Tillinghast, John K. Wright, and some antecedents of American humanistic geography. Journal of Historical Geography, 29(4), 618-630. Retrieved from http://www.sciencedirect.com/science/article/pii/S0305748802904834 doi:http://dx.doi.org/10.1006/jhge.2002.0483

Krippendorff, K. (2004). Content analysis: An introduction to its methodology (2nd ed.). Thousand Oaks, CA: Sage Publications

Kuhn, T. S. (1962). The structure of scientific revolutions. Chicago: Chicago University Press.

Kwan, M.-P. (2002). Feminist visualisation: Re-envisioning GIS as a method in feminist geographic research. Annals of the Association of American Geographers, 92(4), 645-661.

Lambert, D. (2011). Reviewing the case for geography and the "knowledge turn" in the English National Curriculum. The Curriculum Journal, 22(2), 243-264.

Lambert, D. (2013). Geography in school and a curriculum of survival. Theory and Research in Education, 11(1), 85-98. doi:10.1177/1477878512468385

Lambert, D. (2014). Subject teachers in knowledge-led schools. In M. Young, D. Lambert, C. Roberts, \& M. Roberts (Eds.), Knowledge and the future school. London, UK: Bloomsbury Academic.

Lambert, D., \& Morgan, J. (2009). Corrupting the curriculum? The case of geography. London Review of Eductaion, 7(2), 147-157.

Lambert, D., \& Morgan, J. (2010). Teaching Geography 11-18: A conceptual approach. Maidenhead, UK: Open University Press.

Lambert, S. (2014). Indigenous peoples and urban disaster: Maori responses to the 2010-12 Christchurch earthquakes. Australasian Journal of Disaster and Trauma Studies, 18(1), 3948.

Lather, P. (2006). Paradigm proliferation as a good thing to think with: teaching research in education as a wild profusion. International Journal of Qualitative Studies in Education, 19(1), 35-57. doi:10.1080/09518390500450144

Leden, L., Hansson, L., Redfors, A., \& Ideland, M. (2015). Teachers' ways of talking about nature of science and its teaching. Science \& Education, 24(9), 1141-1172. doi:10.1007/s11191-0159782-6

Lee, J., \& Catling, S. (2015). Some perceptions of English geography textbook authors on writing textbooks International Research in Geographical and Environmental Education, 24(1), 118. doi:10.1080/10382046.2015.1106204

Lewis, C. (2015). What Is improvement science? Do we need It in Education? Educational Researcher, 44(1), 54-61. doi:10.3102/0013189x15570388

Lewis, C., Perry, R., \& Friedkin, S. (2009). Lesson study as action research. In S. E. Noffke \& B. Somekh (Eds.), The SAGE handbook of educational action research (pp. 142-155). London: Sage publications Itd.

Lewis, C., R., P., \& Murata, A. (2006). How should research contribute to instructional improvement? The case of lesson study. Educational Researcher, 35(3), 3-14. 
Lewis, C. C., Perry, R., \& Hurd, J. (2009). Improving mathematics instruction through lesson study: a theoretical model and North American case. Journal of Mathematics Teacher Education, 12(4), 285-304. doi:10.1007/s10857-009-9102-7

Lewis, C. C., Perry, R. R., Friedkin, S., \& Roth, J. R. (2012). Improving teaching does improve teachers: Evidence from lesson study. Journal of Teacher Education, 63, 368+.

Lewis, C. C., \& Tsuchida, I. (1998). A lesson is like a swiftly flowing river. American Educator, 22(4), 12-17, 50-52. Retrieved from doi:10.1177/136548029900200117

Ley, D. (1977). The personality of a geographical fact*. Professional Geographer (29), 8-13.

Lichtman, M. (2010). Qualitative research in education: A user's guide (2nd ed.). Los Angeles, CA: Sage.

Lincoln, Y. S., \& Guba, E. G. (1985). Naturalistic inquiry. Beverley Hills, Calif.: Sage.

Longhurst, R. \& Peace, R. (1993). Lecture theatre to classroom: feminist geography. New Zealand Journal of Geography, 96(1), 16-19. doi:10.1111/j.0028-8292.1993.tb00331.x

Lowenthal, D. (1961). Geography, experience, and imagination: Towards a geographical epistemology. Annals of the Association of American Geographers, 51(3), 241-260.

Lumsden, J. (2007). Online-questionnaire design guidelines. In R. Reynolds, R. Woods, \& J. Baker (Eds.), Handbook of research on electronic surveys and measurements. Hershey: IGI Global.

MacLeod, D. G. (2014). A teacher's perspective of Geography: A school subject for today, tomorrow, and for all time. Geography Teacher, 11(1), 3-6. doi:10.1080/19338341.2013.854262

Massey, D. (1995). Spatial divisions of labor: social structures and the geography of production (2nd ed.). New York: Routledge.

Maton, K. (2014). Knowledge and knowers: towards a realist sociology of education. Abingdon, Oxon.: Routledge.

Maude, A. (2015). What is powerful knowledge and can it be found in the Australian geography curriculum? Geographical Education, 28, 18-26.

Maude, A. (2016). What might powerful geographical knowledge look like? Geography, 101(2), 70-76.

Maude, A. (2018). Geography and powerful knowledge: A contribution to the debate. International Research in Geographical and Environmental Education, 27(2), 179-190. Retrieved from doi:10.1080/10382046.2017.1320899

Maykut, P., \& Morehouse, R. (1994). Beginning qualitative research: A philosophic and practical guide London, UK: Falmer Press

McPhail, G. (2016). The fault lines of recontextualisation: The limits of constructivism in education. British Educational Research Journal, 42(2), 294-313. Retrieved from doi:10.1002/berj.3199

McPhail, G., \& Rata, E. (2016). Comparing curriculum types: 'powerful knowledge' and '21st century learning'. New Zealand Journal of Education Studies, 51, 53-68.

Mead, H. (1975). Types and problems of philosophy (3rd ed.). Fort Worth, TX: Harcourt College Publications

Merriam, S. B. (1998). Qualitative research and case study applications in education. San Fransisco, CA.: Jossey-Bass.

Merriam, S. B. (2001). Qualitative research and case study applications in education. San Francisco, CA: Jossey-Bass.

Miller, L. (2001). NCEA implementation support material: Geography. Wellington: New Zealand Qualifications Authority.

Milligan, A., Plummer, J., \& Taylor, M. (2015). Concepts and conceptual understanding in issues based geography. In M. Taylor, L. Richards, \& J. Morgan (Eds.), Geography in focus: 
teaching and learning in issues based classrooms (pp. 39-55). Wellington, NZ: New Zealand Council of Educational Research.

Milligan, A., \& Wood, B. (2010). Conceptual understandings as transition points: making sense of a complex social world. Journal of Curriculum Studies, 42(4), 487-501. doi:10.1080/00220270903494287

Ministry of Civil Defence \& Emergency Management. (2016, 20 November). Drop, cover and hold is still the right action to take. Retrieved from $\mathrm{http}$ ://www.civildefence.govt.nz/getready/at-home-get-ready-get-thru/drop-cover-and-hold-is-still-the-right-action-to-take/

Ministry of Education. (1990). Syllabus for schools: Geography Forms 5-7. Wellington: Learning Media.

Ministry of Education. (1993). New Zealand Curriculum Framework. Wellington: Learning Media. Ministry of Education. (2007). New Zealand curriculum. Wellington: Learning Media.

Ministry of Education. (2008). Approaches to social inquiry. Wellington: Crown.

Ministry of Education. (2012a). New Zealand scholarship: Geography performance standard. Retrieved from http://www.nzqa.govt.nz/ngfdocs/ncearesource/achievements/2013/as91428.pdf

Ministry of Education. (2012b). Statement of Intent 2012-2017. Retrieved from Wellington:

Ministry of Education. (2013a). Glossary of Maori concepts. Retrieved from http://seniorsecondary.tki.org.nz/Social-sciences/Geography/Pedagogy/Socialinquiry/Glossary

Ministry of Education. (2013b). New Zealand curriculum guide: Geography. Retrieved from http://seniorsecondary.tki.org.nz/Social-sciences/Geography

Ministry of Education. (2013c, 21 February 2013). New Zealand Curriculum Guides senior secondary: Key concepts. Retrieved from http://seniorsecondary.tki.org.nz/Socialsciences/Geography/Key-concepts

Ministry of Education. (2015). New Zealand curriculum guide: Key concepts. Retrieved from http://seniorsecondary.tki.org.nz/Social-sciences/Geography/Key-concepts

Ministry of Education. (2018a). NCEA review discussion document: Big opportunities Retrieved from http://img.scoop.co.nz/media/pdfs/1805/NCEA Review Big Opps.pdf

Ministry of Education. (2018b). Why have we changed PLD? Retrieved from http://services.education.govt.nz/pld/background/why-are-we-changing-pld/

Moje, E. B. (2007). Developing socially just subject-matter instruction: A review of the literature on disciplinary literacy teaching. Review of Research in Education, 31(1), 1-44. Retrieved from doi:10.3102/0091732X07300046001

Moje, E. B. (2008). Foregrounding the disciplines in secondary literacy teaching and learning: A call for change. Journal of Adolescent \& Adult Literacy, 52(2), 96-107. doi:10.1598/JAAL.52.2.1

Moje, E. B. (2015). Doing and teaching disciplinary literacy with adolescent learners: A social and cultural enterprise. Harvard Educational Review, 85(2), 254-301. Retrieved from doi:10.17763/0017-8055.85.2.254

Morgan, J. (2002). Constructing school geographies. In M. Smith (Ed.), Teaching geography in secondary schools. London: Routledge/Falmer.

Morgan, J. (2012). Teaching secondary geography as if the planet matters. Oxford: Routledge.

Morgan, J., \& Lambert, D. (2005). Geography: teaching school subjects 11-19. London: Routledge.

Muller, J. (2009). On splitting hairs: hierarchy, knowledge and the school curriculum. In C. Frances \& J. R. Martin (Eds.), Language, knowledge and pedagogy: functional lingusitic and sociological perspectives. London: Continuum.

Mutch, C., Hunter, P., Milligan, A., Openshaw, R., \& Siteine, A. (2009). Understanding the social sciences as a learning area. Retrieved from http://ssol.tki.org.nz/Social-studies-years-110/Curriculum 
Nairn, K. (1997). Hearing from quiet students: the politics of silence and voice in geography classrooms In J. P. J. III, H. J. Nast, \& S. M. Roberts (Eds.), Thresholds in Feminist Geography. Lanham, MD: Rowman and Littlefield.

Newton, M. (2011). Our world: Geography concepts and case studies for New Zealand students. North Shore, NZ: Nelson/Cengage

New Zealand Board of Geography Teachers. (1999). Position Paper: future directions of Geography education and assessment for 2001 and beyond. Retrieved from Hamilton:

New Zealand Geographical Society (Inc). (1999). Position Paper: Future directions of Geography education and assessment for 2001 and beyond. Retrieved from Hamilton:

New Zealand Post Primary Teachers' Association. (2016). PPTA workload taskforce report: Report of the 2015 investigation into issues of workload intensification for secondary school teachers in New Zealand. Retrieved from Wellington: https://www.ppta.org.nz/dmsdocument/133

New Zealand Qualifications Authority. (2006a). Assessment report scholarship 2005: Geography. Retrieved from http://www.nzqa.govt.nz/qualifications-standards/awards/new-zealandscholarship/scholarship-subjects/scholarship-geography/\#resources

New Zealand Qualifications Authority. (2006b). Level 2 Geography, 2005: 90331 Explain a natural landscape. Retrieved from http://www.nzqa.govt.nz/nqfdocs/ncearesource/exams/2005/90331-exm-05.pdf

New Zealand Qualifications Authority. (2006c). Level 2 Geography, 2005: 90333 Explain disparities of development within or between countries. Retrieved from http://www.nzqa.govt.nz/nqfdocs/ncea-resource/exams/2005/90333-exm-05.pdf

New Zealand Qualifications Authority. (2006d). Level 2 Geography, 2006: 90331 Explain a natural landscape. Retrieved from http://www.nzqa.govt.nz/ngfdocs/ncearesource/exams/2006/90331-exm-06.pdf

New Zealand Qualifications Authority. (2006e). Level 3 Geography, 2006: 90704 Select and apply skills and ideas in a geographic context. Retrieved from http://www.nzqa.govt.nz/nqfdocs/ncea-resource/exams/2006/90704-exm-06.pdf

New Zealand Qualifications Authority. (2007a). Assessment report scholarship 2006: Geography. Retrieved from http://www.nzqa.govt.nz/qualifications-standards/awards/new-zealandscholarship/scholarship-subjects/scholarship-geography/\#resources

New Zealand Qualifications Authority. (2007b). Level 2 Geography, 2007: 90331 Explain a natural landscape. Retrieved from http://www.nzqa.govt.nz/nqfdocs/ncearesource/exams/2007/90331-exm-07.pdf

New Zealand Qualifications Authority. (2007c). Level 3 Geography, 2007: 90704 Select and apply skills and ideas in a geographic context. Retrieved from http://www.nzqa.govt.nz/nqfdocs/ncea-resource/exams/2007/90704-exm-07.pdf

New Zealand Qualifications Authority. (2008a). Assessment report: Level 3, 2007 Geography. Retrieved from http://www.nzqa.govt.nz/nqfdocs/ncearesource/reports/2007/level3/geography.pdf

New Zealand Qualifications Authority. (2008b). Level 2 Geography, 2008: 90333 Explain disparities of development within or between countries. Retrieved from http://www.nzqa.govt.nz/nqfdocs/ncea-resource/exams/2008/90333-exm-08.pdf

New Zealand Qualifications Authority. (2008c). Level 3 Geography, 2008: 90704 Select and apply skills and ideas in a geographic context. Retrieved from http://www.nzqa.govt.nz/nqfdocs/ncea-resource/exams/2008/90704-exm-08.pdf

New Zealand Qualifications Authority. (2009a). Assessment report scholarship, 2008: Geography. Retrieved from http://www.nzqa.govt.nz/qualifications-standards/awards/new-zealandscholarship/scholarship-subjects/scholarship-geography/\#resources 
New Zealand Qualifications Authority. (2009b). Level 2 Geography, 2009: 90331 Explain a natural landscape. Retrieved from http://www.nzqa.govt.nz/ngfdocs/ncearesource/exams/2009/90331-exm-09.pdf

New Zealand Qualifications Authority. (2009c). Level 2 Geography, 2009: 90333 Explain disparities of development within or between countries. Retrieved from http://www.nzqa.govt.nz/nqfdocs/ncea-resource/exams/2009/90333-exm-09.pdf

New Zealand Qualifications Authority. (2009d). Level 3 Geography, 2009: 90704 Select and apply skills and ideas in a geographic context. Retrieved from http://www.nzqa.govt.nz/nqfdocs/ncea-resource/exams/2009/90704-exm-09.pdf

New Zealand Qualifications Authority. (2010a). Level 2 Geography, 2010: 90331 Explain a natural landscape. Retrieved from http://www.nzqa.govt.nz/nqfdocs/ncearesource/exams/2010/90331-exm-2010.pdf

New Zealand Qualifications Authority. (2010b). Level 2 Geography, 2010: 90333 Explain disparities of development within or between countries. Retrieved from http://www.nzqa.govt.nz/nqfdocs/ncea-resource/exams/2010/90333-exm-2010.pdf

New Zealand Qualifications Authority. (2011a). Level 2 Geography, 2011: 90331 Explain a natural landscape. Retrieved from http://www.nzqa.govt.nz/nqfdocs/ncearesource/exams/2011/90331-exm-2011.pdf

New Zealand Qualifications Authority. (2011b). Level 2 Geography, 2011: 90333 Explain dispartities of development within or between countries. Retrieved from http://www.nzqa.govt.nz/nqfdocs/ncea-resource/exams/2011/90333-exm-2011.pdf

New Zealand Qualifications Authority. (2012a). Level 2 Geography, 2012: 91240 Demonstrate geographical understanding of a large natural environment. Retrieved from http://www.nzqa.govt.nz/nqfdocs/ncea-resource/exams/2012/91240-exm-2012.pdf

New Zealand Qualifications Authority. (2012b). Level 2 Geography, 2012: 91242 Demonstrate geographic understanding of differences in development. Retrieved from http://www.nzqa.govt.nz/nqfdocs/ncea-resource/exams/2012/91242-exm-2012.pdf

New Zealand Qualifications Authority. (2013). Level 2 Geography, 2013: 91242 Demonstrate geographic understanding of differences in development. Retrieved from http://www.nzqa.govt.nz/nqfdocs/ncea-resource/exams/2013/91242-exm-2013.pdf

New Zealand Qualifications Authority. (2014a). Geography matrix. Retrieved from http://ncea.tki.org.nz/Resources-for-Internally-Assessed-Achievement-Standards/Socialsciences/Geography

New Zealand Qualifications Authority. (2014b). Level 2 Geography, 2014: 91240 Demonstrate geographical understanding of a large natural environment. Retrieved from http://www.nzqa.govt.nz/nqfdocs/ncea-resource/exams/2014/91240-exm-2014.pdf

New Zealand Qualifications Authority. (2014c). Level 3 Geography, 2014: 91429 Demonstrate understanding of a given environment(s) through selection and application of geographic concepts and skills. Retrieved from http://www.nzqa.govt.nz/nqfdocs/ncearesource/exams/2014/91429-exm-2014.pdf

New Zealand Qualifications Authority. (2014d). Scholarship 2014: Geography.

New Zealand Qualifications Authority. (2015a). Exemplar for internal achievement standard geography level 3. Retrieved from https://www.nzqa.govt.nz/assets/qualifications-andstandards/qualifications/ncea/NCEA-subject-resources/Geography/91428/91428-EXP.pdf

New Zealand Qualifications Authority. (2015b). Exemplar for internal assessment resource Geography for Achievement Standard 91430. Retrieved from http://www.nzqa.govt.nz/qualificationsstandards/qualifications/ncea/subjects/geography/annotated-exemplars/level-3as91430/ 
New Zealand Qualifications Authority. (2015c). Geography skills and concepts. Retrieved from http://seniorsecondary.tki.org.nz/Social-sciences/Geography/Skills-and-concepts

New Zealand Qualifications Authority. (2015d). Level 2 Geography, 2015: 91242 Demonstrate geographic understanding of differences in development. Retrieved from http://www.nzqa.govt.nz/nqfdocs/ncea-resource/exams/2015/91242-exm-2015.pdf

New Zealand Qualifications Authority. (2015e). Level 3 Geography, 2015: 91429 Demonstrate understanding of a given environment(s) through selection and application of geographic concepts and skills. Retrieved from http://www.nzqa.govt.nz/nqfdocs/ncearesource/exams/2015/91429-exm-2015.pdf

New Zealand Qualifications Authority. (2015f). Scholarship 2014 assessment report: Geography. Retrieved from http://www.nzqa.govt.nz/qualifications-standards/awards/new-zealandscholarship/scholarship-subjects/scholarship-geography/\#resources

New Zealand Qualifications Authority. (2015b). Level 2 Geography, 2015: 91243 Apply geography concepts and skills to demonstrate understanding of a given environment. Retrieved from http://www.nzqa.govt.nz/nqfdocs/ncea-resource/exams/2015/91243-exm2015.pdf

New Zealand Qualifications Authority. (2016a). 2015 NZ scholarship assessment report: Geography. Retrieved from http://www.nzqa.govt.nz/qualificationsstandards/awards/new-zealand-scholarship/scholarship-subjects/scholarshipgeography/\#resources

New Zealand Qualifications Authority. (2016b). Exemplar answer script - excellence 2015. Retrieved from http://www.nzqa.govt.nz/nqfdocs/ncearesource/exemplars/2015/91242-exp-2015-excellence.pdf

New Zealand Qualifications Authority. (2016c). Secondary statistics consolidated data files for 2015. Retrieved from https://www.nzqa.govt.nz/studying-in-new-zealand/secondaryschool-and-ncea/find-information-about-a-school/secondary-school-statistics/

New Zealand Qualifications Authority. (2017). Analyse a significant contemporary event from a geographic perspective. Retrieved from https://www.nzqa.govt.nz/nqfdocs/ncearesource/achievements/2017/as91428.pdf

New Zealand Qualifications Authority. (2018). Secondary statistics consolidated data files for 2017. Retrieved from https://www.nzqa.govt.nz/studying-in-new-zealand/secondaryschool-and-ncea/find-information-about-a-school/secondary-school-statistics/

Nietzsche, F. (1887/1998). On the genealogy of morality: A polemic (M. Clarke \& A. J. Swenswen, Trans.). Indianapolis, IN: Hackett Publishing.

O'Malley, M. P. (1977). Viewpoints on geographical education: A decade of change. New Zealand Journal of Geography, 63, 1-8.

O'Neil, J., Duffy, C., \& Fernando, S. (2016). Charities, philanthropists, policy entrepreneurs, international companies and state schooling in Aotearoa new zealand. Retrieved from https://www.ppta.org.nz/dmsdocument/569

Openshaw, R. (2009). Reforming New Zealand secondary education: The Picot Report and the road to radical reform. New York, NY: Palgrave Macmillan.

Organisation of Economic Co-operation and Development. (1997). Definition and Selection of Competencies: Theoretical and Conceptual Foundations. Paris: OECD Publishing.

Organisation of Economic Co-operation and Development. (2009). 21st century skills and competencies for new millenium learners in the OECD countries. Paris: OECD Publishing.

Pacione, M. (2009). Urban geography: a global perspective (3rd ed.). New York: Routledge.

Papotti, D. (2014). Re-reading Terrae incognitae. The place of imagination in geography by J.K. Wright. Journal of research and didactics in geography, 1(3), 89-100. Retrieved from http://i-reading.org/index.php/geography/issue/view/6 
Patton, M. Q. (2002). Qualitative research \& evaluation methods. Thousand Oaks, CA: Sage Publications.

Pauw, I. (2015). Educating for the future: the position of school geography. International Research in Geographical and Environmental Education, 24(4), 307-324. Retrieved from doi:10.1080/10382046.2015.1086103

Pedder, D. (2015). Prospects for further development of lesson study. In P. Dudley (Ed.), Lesson study: Professional learning for our time (pp. 145-151). Abingdon, UK: Routledge.

Peet, R. (1998). Modern geographical thought Oxford: Blackwell Publishers.

Perry, R., \& Lewis, C. C. (2009). What is successful adaptation of lesson study in the US? Journal of Educational Change, 10(4), 365-391. doi:10.1007/s10833-008-9069-7

Peters, R. S. (1967). What is an educational process? In R. S. Peters (Ed.), The concept of education (pp. 1-23). London: Routledge \& Kegan Paul.

Postman, N., \& Weingartner, C. (1971). Teaching as a subversive activity. Harmondsworth, England: Penguin Books.

Priestley, M., \& Sinnema, C. (2014). Downgraded curriculum? An analysis of knowledge in new curricula in Scotland and New Zealand. The Curriculum Journal, 25(1), 50-75.

Pring, R. (2015). Philosophy of educational research (3rd ed.). London: Bloomsbury.

Puttick, S. (2013). Looking at and looking along: A conceptual framework for teaching different perspectives in geography. International Research in Geographical and Environmental Education, 22(4), 353-366. doi:10.1080/10382046.2013.826546

Puttick, S. (2015a). Chief examiners as Prophet and Priest: relations between examination boards and school subjects, and possible implications for knowledge. The Curriculum Journal, 26(3), 468-487. doi:10.1080/09585176.2014.1000936

Puttick, S. (2015b). Recontextualising knowledge for lessons. Teaching Geography, 40(1), 29-31.

Rabin-Havt, A. (2016). Lies incorporated: The world of post truth politics. New York, NY: Anchor Books.

Rapley, T. (2007). Doing conversation, discourse and document analysis. London: Sage Publications.

Rawding, C. (2013). How does geography adapt to changing times? In D. Lambert \& M. Jones (Eds.), Debates in geography education (pp. 282-290). London: Routledge.

Rawling, E. M. (2001). Changing the subject: The impact of policy on school geography 1980-2000. Sheffield: Geographical Association.

Reginster, B. (2001). The paradox of perspectivism. Philosophy and Phenomenological Research, 62(1), 217-233. doi:10.2307/2653601

Relph, E. (1976). Place and placelessness. London, UK: Pion.

Roberts, M. (2003). Learning through enquiry. Sheffield: Geographical Association.

Roberts, M. (2013). Geography through enquiry: Approaches to teaching and learning in the secondary school. Sheffield: Geographical Association.

Robertson, M., Morgan, J., \& Kriewaldt, J. (2017). Australia and New Zealand: Do we need to understand 'progress' before we can develop learning progressions? . In O. M. Solari, M. Solem, \& R. Boehm (Eds.), Learning progressions in geography education (pp. 1-17). London, UK: Springer.

Rychen, D. S., \& Salganik, L. H. (Eds.). (2003). Key competencies for a successful life and wellfunctioning society. Cambridge, MA: Hogrefe \& Huber.

Sadegh-Zadeh, K. (2012). Handbook of Analytic Philosophy of Medicine. Dordrecht: Springer Netherlands.

Sazama, T. (2015). Theory in practice in the high school classroom: Using The Kite Runner to teach literary theory. Minnesota English Journal Online, (40), n.p. Retrieved from https://minnesotaenglishjournalonline.org/2015/04/30/theory-in-practice-in-the-highschool-classroom-using-the-kite-runner-to-teach-literary-theory/ 
Schroor, B. (2017). The deep end: Teaching theoretical perspectives in literature. Idiom, 53(2), 3739. Retrieved from https://search-informit-comau.helicon.vuw.ac.nz/documentSummary; dn=171658322237259;res=IELHSS

Schwab, J. J. (1978). Education and the structure of the disciplines. In I. Westbury \& N. J. Wilkof (Eds.), Science Curriculum and Liberal Education (pp. 229-272). Chicago: University of Chicago Press.

Shanahan, T., \& Shanahan, C. (2008). Teaching disciplinary literacy to adolescents: Rethinking content-area literacy. Harvard Educational Review, 78(1), 40-59. doi:doi:10.17763/haer.78.1.v62444321p602101

Shulman, L. S. (2005). Signature pedagogies in the professions. Daedalus(134), 52-59.

Simons, H. (2014). Case study research: In-depth understanding in context. In P. Leavy (Ed.), The Oxford Handbook of Qualitative Research. Oxford, UK: Oxford University Press.

Singh, P. (2002). Pedagogising knowledge: Bernstein's theory of the pedagogic device. British Journal of Sociology of Education, 23(4), 571-582. doi:10.1080/014256902200003842 2

Sinnema, C. (2016). The ebb and flow of curricular autonomy: Balance between local freedom and national prescription in curricula In D. Wyse, L. Hayward, \& J. Pandya (Eds.), The Sage handbook of curriculum, pedagogy and assessment (pp. 965-983). Thousand Oaks, CA.: Sage.

Slater, F. (1981). What is your view of people? Some comments on recently changing viewpoints in geographical research. New Zealand Journal of Geography(71), 6-9.

Slater, F. (1983). The mishmash curriculum. New Zealand Journal of Geography(75), 7-9.

Slater, F. (1987a). Guest editorial. New Zealand Journal of Geography(84), 2-4.

Slater, F. (1987b). Optical analysis: prisms in geographic thought and the geography teacher. New Zealand Journal of Geography(83), 8-11.

Slater, F., Graves, N., \& Lambert, D. (2016). Editorial. International Research in Geographical and Environmental Education, 25(3), 189-194. Retrieved from https://doi.org/10.1080/10382046.2016.1155321 doi:10.1080/10382046.2016.1155321

Smith, L. T. (2006). Researching in the margins: Issues for Māori researchers - A discussion paper. Alternative: An International Journal of Indigenous Peoples, 2(1), 4-27.

Smith, N. (1979). Toward a theory of gentrification: A back to the city movement by capital, not people. Journal of the American Planning Association, 45(4), 538-548.

Spillane, J. P. (2004). Standards deviation: How schools misunderstand education policy. Cambridge, MA: Harvard University Press.

Spillane, J. P., Reiser, B. J., \& Reimer, T. (2002). Policy implementation and cognition: Reframing and refocusing implementation research. Review of Educational Research, 72(3), 387-431.

Stake, R. E. (1995). The art of case study research. London: Sage.

Stannard, K. (2003). Earth to academia: On the need to reconnect university and school geography Area, 35(3), 316-322. Retrieved from http://www.jstor.org/stable/20004326 doi:doi:10.1111/1475-4762.00181

Stengel, B. (1997). 'Academic discipline' and 'school subject': Contestable curricular concepts. Curriculum Studies. 29(5), 585-602.

Stepanek, J., Appel, G., Leong, M., Mangan, M. T., \& Mitchell, M. (2007). Leading lesson study: A practical guide for teachers and facilitators. Thousand Oaks, CA: Learning Point Associates, NWREL and Corwin Press.

Stevenson, R. B. (2007). Schooling and environmental education: Contradictions in purpose and practice. Environmental Education Research, 13(2), 139-153. doi:10.1080/13504620701295726

Strauss, A. L., \& Corbin, J. (1998). Basics of qualitative research: Techniques and procedures for developing grounded theory. Thousand Oaks, CA: Sage. 
Strongman, S. (2016, November 16). Bishop Brian Tamaki blames gays, murderers and sinners for earthquakes. New Zealand Herald. Retrieved from http://www.nzherald.co.nz/nz/news/article.cfm?c id=1\&objectid $=11749215$

Taylor, L. (2008). Key concepts and medium term planning. Teaching Geography, 33(2), 50-54.

Taylor, M. (2013). (Re)presenting disaster vulnerability in New Zealand school geography. New Zealand Geographer, 69(2), 158-166. doi:10.1111/nzg.12018

Taylor, M., \& Keown, P. (2016). Deepening thinking through viewpoints, values and perspectives. In M. Harcourt, A. Milligan, \& B. Wood (Eds.), Social Studies for critical, active, citizenship (pp. 64-81). Wellington: NZCER Press.

Taylor, M., Richards, L. \& Morgan, J. (Eds.) (2015) Geography in focus: Teaching and learning in issues-based classrooms. Wellington, NZ: NZCER Press.

Taylor, M., Yates, A., Meyer, L. H., \& Kinsella, P. (2011). Teacher professional leadership in support of teacher professional development. Teaching and Teacher Education, 27(1), 8594. doi:http://dx.doi.org/10.1016/j.tate.2010.07.005

Thomas, P. R. (1973). Education and the New Geography. In J. Bale, N. Graves, \& R. Walford (Eds.), Perspectives in Geographical Education. Edinburgh, UK: Oliver \& Boyd.

Thrift, N. (2008). Spatial formations. New York: Sage.

Timperley, H., Wilson, A., Barrar, H., \& Fung, I. (2007). Teacher professional learning and development best evidence synthesis iteration (BES). Wellington: Ministry of Education

Tomorrow's Schools Independent Taskforce. (2018). Our schooling futures: stronger together. Retrieved from Wellington: https://conversation.education.govt.nz/assets/TSR/Tomorrows-Schools-Review-Report13Dec2018.PDF

Tuan, Y. F. (1974). Topophilia: a study of environmnetal percpetion, attitudes and values. Englewood Cliffs, NJ: Prentice-Hall.

United Nations. (2013). World economic and social survey 2013: Sustainable development challenges. New York, NY.

Vernon, E. (2016). The structure of knowledge: Does theory matter? Geography, 101(2), 100-104.

Vidal, C. (2008). Wat is een wereldbeeld? (what is a worldview?). In H. V. Belle \& J. V. d. Venken (Eds.), Nieuwheid denken. De wetenschappen en bet creative aspect van de werkelijkheid. Leuven: Acco.

Wakeford, S. (2013). Differences in development. Auckland, NZ: Pearson

Walford, R. (1996). 'What is geography?' an analysis of definitions provided by prospective teachers of the subject. International Research in Geographical and Environmental Education, 5(1), 69-76. doi:10.1080/10382046.1996.9964991

Winter, C. (2006). Doing justice to geography in the secondary school: deconstruction, invention and the national curriculum. British Journal of Educational Studies, 54(2), 212-229.

Winter, C. (2011). Curriculum knowledge and justice: content, competency and concept. Curriculum Journal, 22(3), 337-364. doi:10.1080/09585176.2011.601627

Wood, B. E., \& Sheehan, M. (2012). Dislodging knowledge? The New Zealand curriculum in the 21st century. Pacific-Asian Education, 24(1), 17-30.

Wright, J. K. (1947). Terrae incognitae: The place of the imagination in geography Annals of the Association of American Geographers, 37(1), 1-15. Retrieved from doi:10.1080/00045604709351940

Wright, T. (2016). Seismologist says supermoon could have triggered the north Canterbury earthquakes. Retrieved from http://www.newshub.co.nz/home/newzealand/2016/11/seismologist-says-supermoon-could-have-triggered-the-northcanterbury-earthquakes.html

Wylie, C. (2013). Vital connections: why we need more than self managing schools. Wellington: NZCER. 
Wylie, C., \& Bonne, L. (2016). Secondary schools in 2015: Findings from the NZCER national survey. Retrieved from Wellington:

http://www.nzcer.org.nz/system/files/NZCER\%20Secondary\%20Survey\%202015\%20Full \%20report 0.pdf

Wylie, C., Hipkins, R., \& Hodgen, E. (2008). On the edge of adulthood: Young people's school and out-of-school experiences at 16. Retrieved from Wellington: https://www.educationcounts.govt.nz/publications/ECE/2567/35121/35122

Xu, H., \& Pedder, D. (2015). Lesson study: An international review of the research. In P. Dudley (Ed.), Lesson study: Professional learning for our time (pp. 29-58). Abingdon, UK.: Routledge.

Yates, L., \& Millar, V. (2016). 'Powerful knowledge' curriculum theories and the case of physics. Curriculum Journal, 27(3), 298-312. Retrieved from doi:10.1080/09585176.2016.1174141

Yin, R. K. (2003). Case study research (3rd ed.). Thousand Oaks: Sage.

Yin, R. K. (2014). Case study research: Design and methods (5th ed.). Thousand Oaks, CA.: Sage.

Young, M. (1971). Knowledge and control: New directions for the sociology of education. London: Collier Macmillan.

Young, M. (2008). Bringing knowledge back in: From social constructivism to social realism. London: Routledge.

Young, M. (2009). What are schools for? In H. Daniels, H. Lauder, \& J. Porter (Eds.), Knowledge, values, and education policy (pp. 10-18). London: Routledge.

Young, M., \& Muller, J. (2007). Truth and truthfulness in the sociology of educational knowledge. Theory and Research in Education, 5(2), 173-201. doi:10.1177/1477878507077732

Young, M., \& Muller, J. (2010). Three educational scenarios for the future: lessons from the sociology of knowledge. European Journal of Education, 45(1), 11-27. doi:10.1111/j.14653435.2009.01413.x

Zeichner, K. G., \& Gore, Y. J. (1990). Teacher socialization. In M. Cochrane-Smith, S. FeimanNemser, D. J. McIntyre, \& K. E. Demers (Eds.), Handbook of Research on Teacher Education (pp. 329-348). New York, NY: MacMillan. 


\section{Appendices}

Appendix A: VUW Ethics Approval

\begin{tabular}{l|l}
\hline SUBJECT & $\begin{array}{l}\text { Ethics Approval: 20841 } \\
\text { Knowing a discipline? Exploring 'perspectives' as a tool for } \\
\text { geographical enquiry in New Zealand secondary schools }\end{array}$ \\
\hline
\end{tabular}

Thank you for your application for ethical approval, which has now been considered by the Standing Committee of the Human Ethics Committee.

Your application has been approved from the above date and this approval continues until 12 December 2017. If your data collection is not completed by this date you should apply to the Human Ethics Committee for an extension to this approval.

Best wishes with the research.

Kind regards

Convener, Victoria University Human Ethics Committee 


\section{Appendix B: Phase 2 E-Questionnaire}

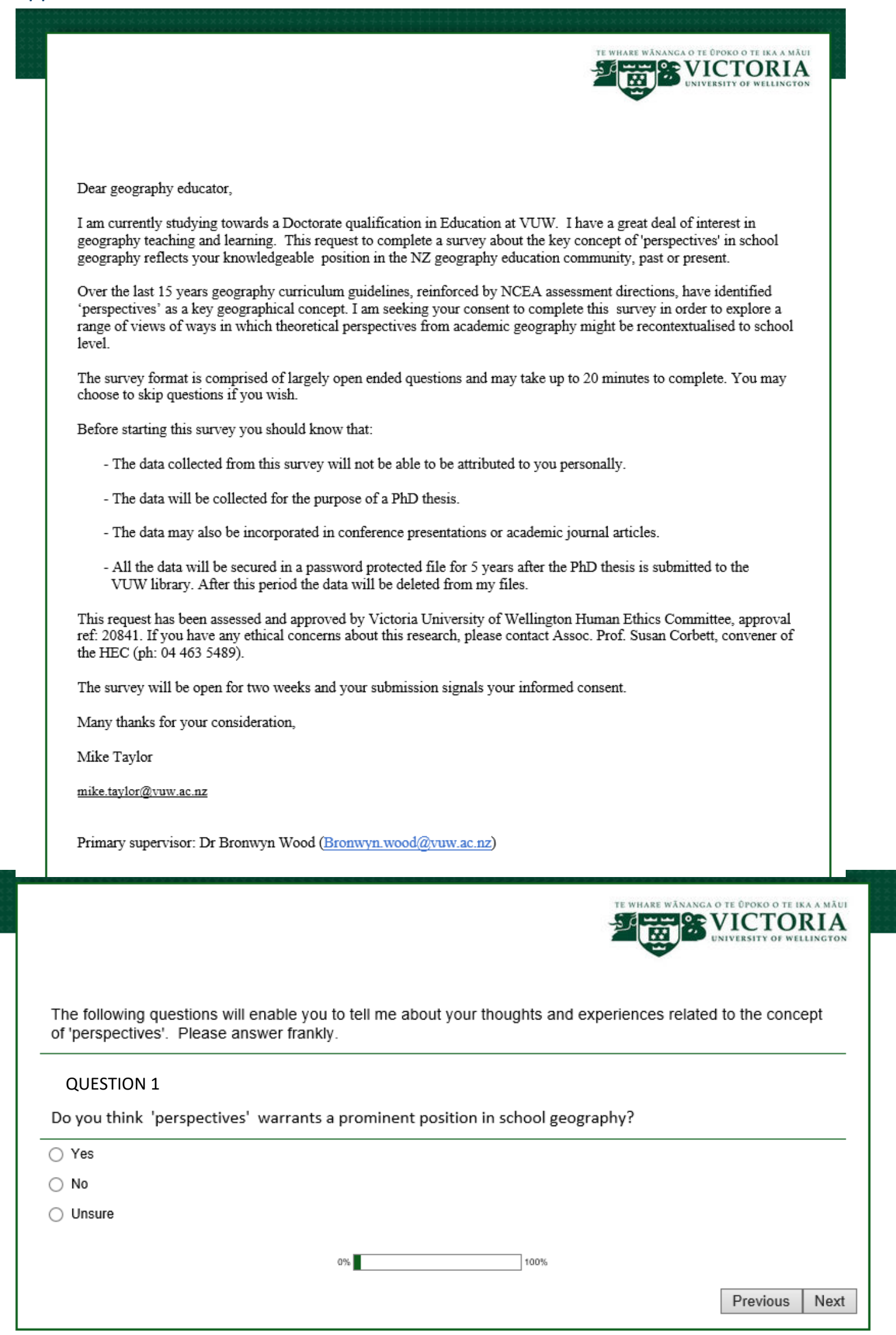

Survey Powered By Qualtrics 
Q2a

Why do you think perspectives warrants a prominent position in school geography?

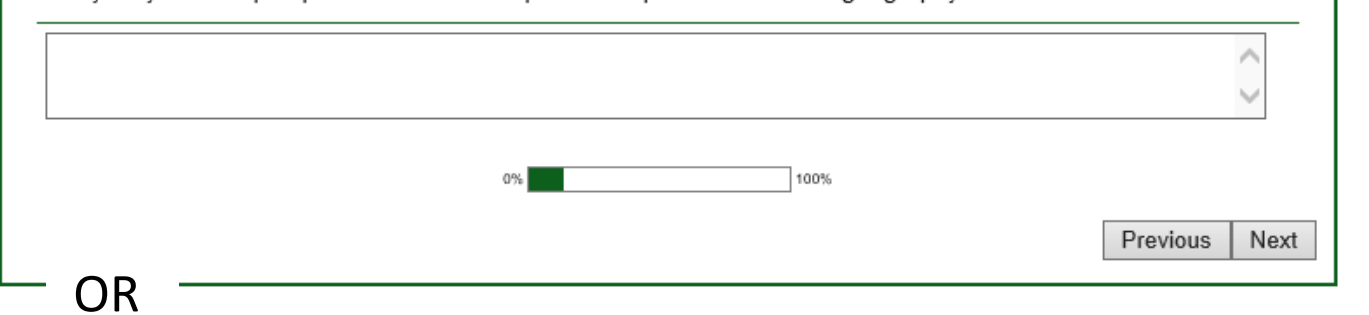

Survey Powered By Qualtrics

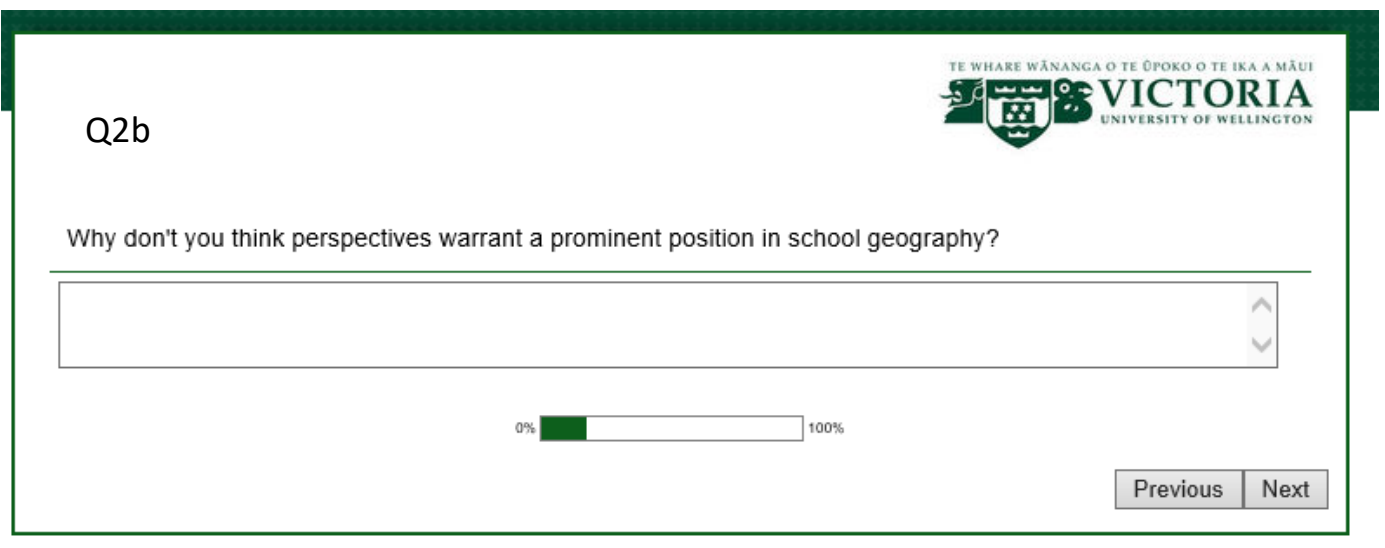

OR

Q2c

Why are you unsure whether perspectives warrants a prominent position in school geography?

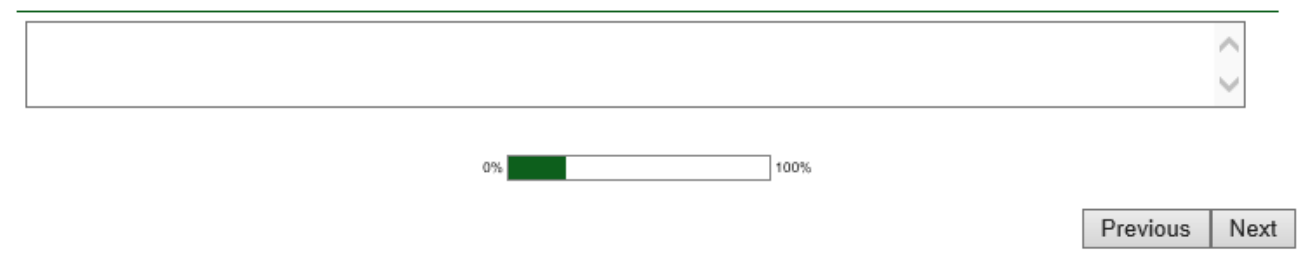

Survey Powered By Qualtrics 
QUESTION 3

\begin{tabular}{|c|c|c|c|c|}
\hline \multicolumn{5}{|l|}{ QUESTION 3} \\
\hline \multicolumn{5}{|c|}{ How helpful have you found guidance on the concept of 'perspectives' in....? } \\
\hline & Very helpful & Reasonably helpful & Unhelpful & Not used \\
\hline Curriculum guidelines & $\mathrm{O}$ & $\bigcirc$ & O & O \\
\hline $\begin{array}{l}\text { NCEA materials (e.g., } \\
\text { Standards or Exemplars) }\end{array}$ & 0 & $\mathrm{O}$ & $\mathrm{O}$ & $\mathrm{O}$ \\
\hline Text books & O & 0 & $\mathrm{O}$ & O \\
\hline $\begin{array}{l}\text { Resource materials } \\
\text { (professionally produced) }\end{array}$ & 0 & 0 & $\mathrm{O}$ & 0 \\
\hline $\begin{array}{l}\text { Subject association resource } \\
\text { materials (e.g NZBOGT etc) }\end{array}$ & $\bigcirc$ & $\bigcirc$ & $\bigcirc$ & O \\
\hline Professional learning meetings & 0 & 0 & 0 & $\mathrm{O}$ \\
\hline \multicolumn{5}{|l|}{ Q3b } \\
\hline \multicolumn{5}{|c|}{ Do you have any comments to add to any of these ratings? } \\
\hline
\end{tabular}
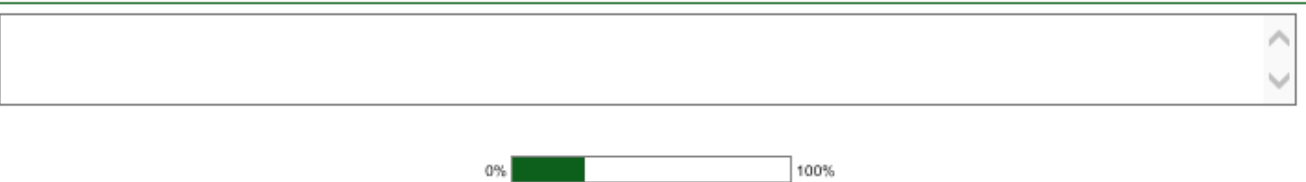

\section{QUESTION 4}

How should a capable Year 13 student be able to apply the concept of 'perspective' in their geography learning? Use hypothetical examples if it helps.

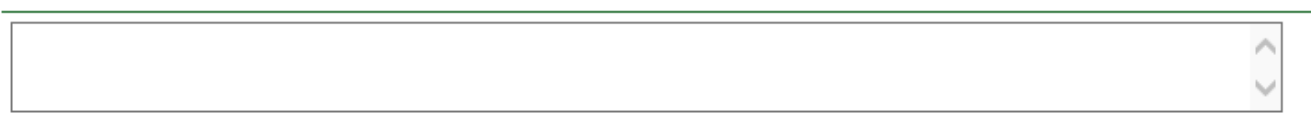

\section{QUESTION 5}

What aspects of school geography teaching and learning do you think are more or less suitable for exploring the concept of 'perspective(s)'? Why?

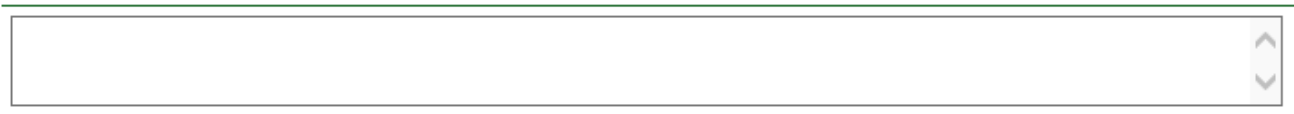

\section{QUESTION6}

Please describe how you would expect to see learning about perspectives develop/progress from Year 11 to Year 13 geography.

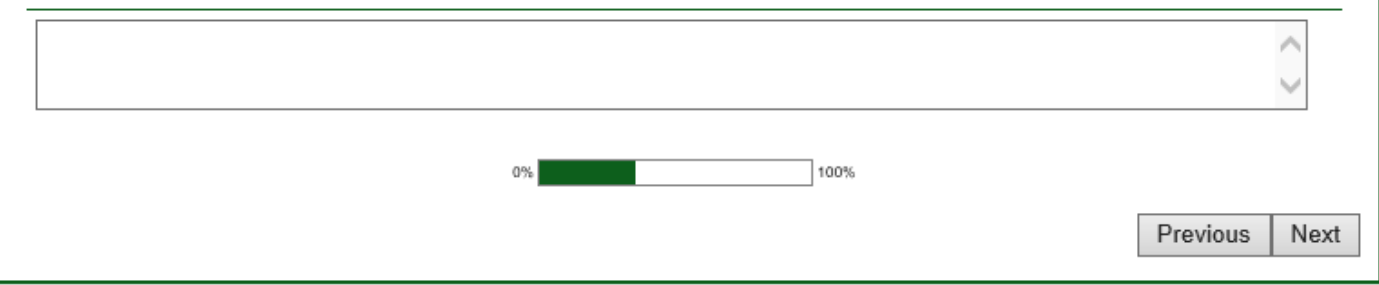

Survey Pomered By Qualtrics 


\section{QUESTION 7}

Rate the following perspectives according to how important you think they are for senior secondary school geography students

\begin{tabular}{|c|c|c|c|}
\hline & Low importance & Reasonable importance & Very important \\
\hline Behavioural & $\mathrm{O}$ & $\mathrm{O}$ & $\bigcirc$ \\
\hline Social & 0 & $\mathrm{O}$ & 0 \\
\hline Environmental & 0 & $\mathrm{O}$ & $\mathrm{O}$ \\
\hline Bi-cultural & 0 & $\mathrm{O}$ & 0 \\
\hline Positivist & $\mathrm{O}$ & $\bigcirc$ & 0 \\
\hline Economic & 0 & 0 & 0 \\
\hline Ecocentric & $\mathrm{O}$ & 0 & $\mathrm{O}$ \\
\hline Sustainable & 0 & 0 & $\mathrm{O}$ \\
\hline Indigenous & 0 & $\bigcirc$ & 0 \\
\hline Marxist & 0 & $\mathrm{O}$ & $\mathrm{O}$ \\
\hline Technocentric & 0 & 0 & 0 \\
\hline Social Justice & 0 & 0 & 0 \\
\hline Post-Fordist & $\mathrm{O}$ & $\bigcirc$ & 0 \\
\hline Multi-cultural & 0 & 0 & 0 \\
\hline Managerialist & 0 & 0 & $\mathrm{O}$ \\
\hline Empirical & 0 & 0 & 0 \\
\hline Neo-liberal & $\bigcirc$ & 0 & $\bigcirc$ \\
\hline Capitalist & $\mathrm{O}$ & 0 & $\mathrm{O}$ \\
\hline Spatial science & $\mathrm{O}$ & $\bigcirc$ & $\mathrm{O}$ \\
\hline Political & 0 & 0 & 0 \\
\hline Humanistic & 0 & 0 & 0 \\
\hline Centrally Planned & 0 & $\mathrm{O}$ & 0 \\
\hline Feminist & $\mathrm{O}$ & $\mathrm{O}$ & $\mathrm{O}$ \\
\hline
\end{tabular}

Q7b

Please give reasons for one or two of the listed perspectives you have rated as low importance.

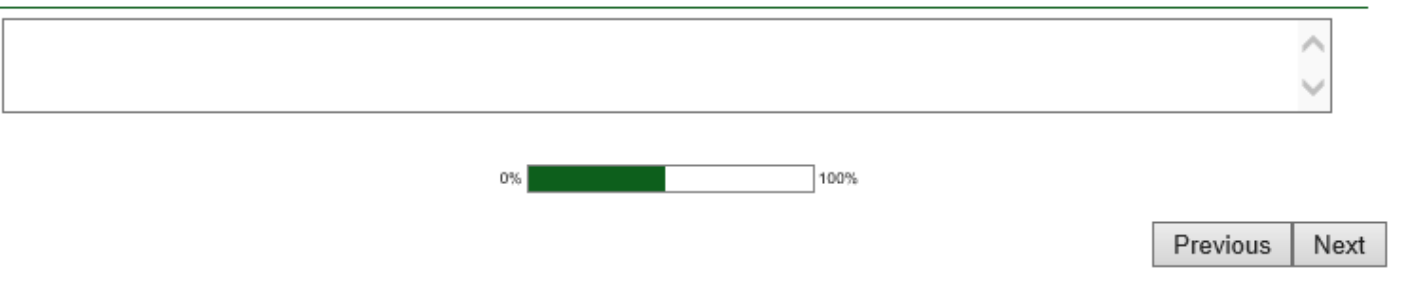




\section{QUESTION 8}

Please read the following guidance on perspectives from the current geography curriculum guide material on the TKI website. The question after this extract will focus on how this advice is framed:

"Geographic perspectives' also refers to how knowledge is organised and understood differently in the discipline, and the varying lenses that may be used when undertaking geographic research. These theoretical perspectives have labels such as 'gender geography' 'feminist geography', 'new cultural geography', 'postmodern geography', 'socially critical approaches', and 'Kaupapa Māori Geography' - but these are not the only ones."

Source: http//seniorsecondary.tki.org.nz/Social-sciences/Geography/Pedaqogy/Social-inquiry\#exploring

What do you consider to be the opportunities and/or challenges that the extract above presents to taking a 'perspectivised' approach to geography?

\section{QUESTION 9}

Select one role that you have had which required you to give thought to the concept 'perspectives':

NCEA or Scholarship exam writer

NCEA Level 2 or 3 internal assessment moderator

NCEA Level 2 or 3 exam marker

Scholarship exam marker

Text book or curriculum resource writer

Curriculum adviser/writer

Professional development provider

Initial Teacher Education provider 
Briefly describe features of a quality example of student work that you have moderated/marked that shows understanding about theoretical perspectives in geography.
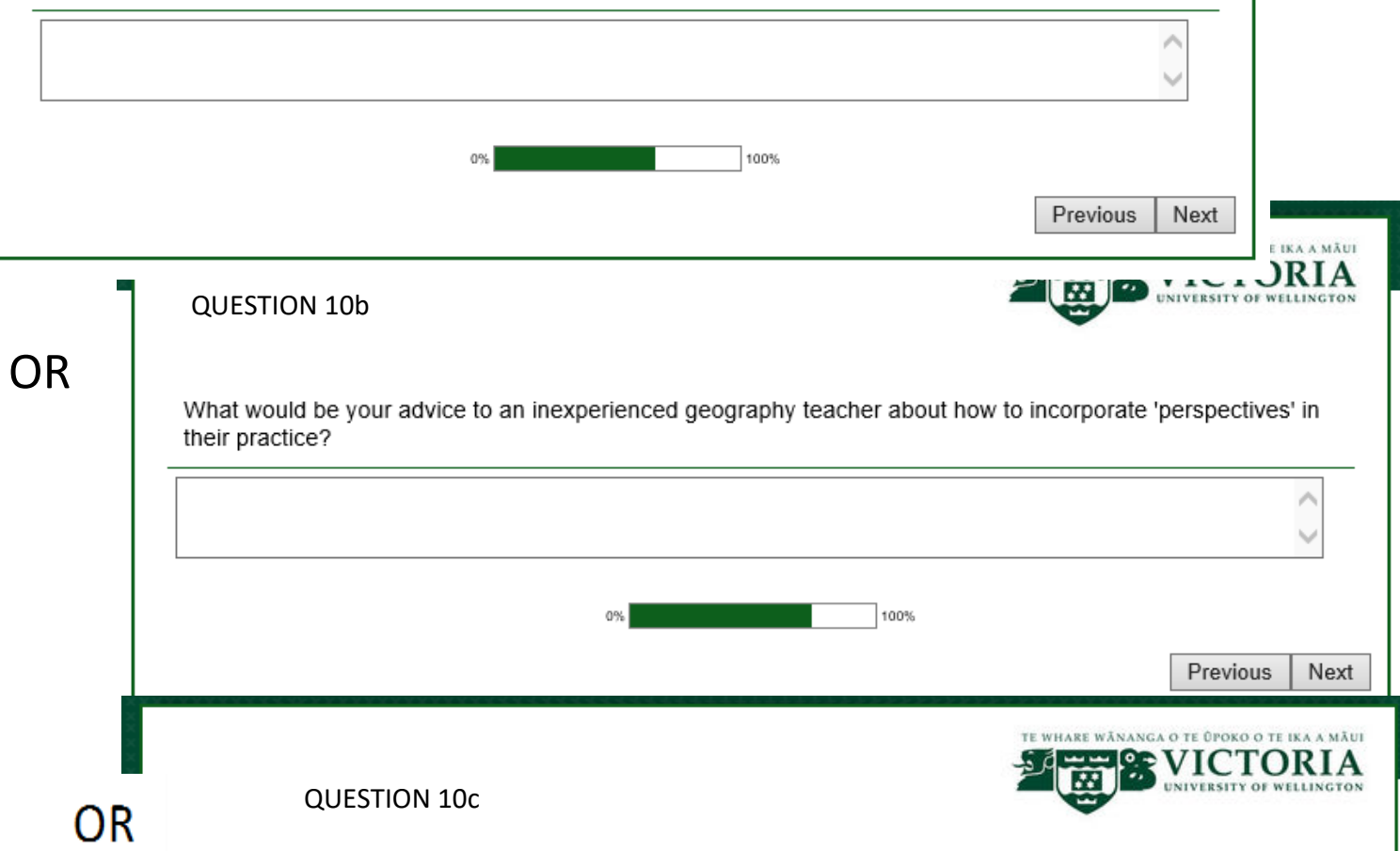

Describe how you have gone about designing text book material, resources, or examination questions that have focused on 'perspectives'.

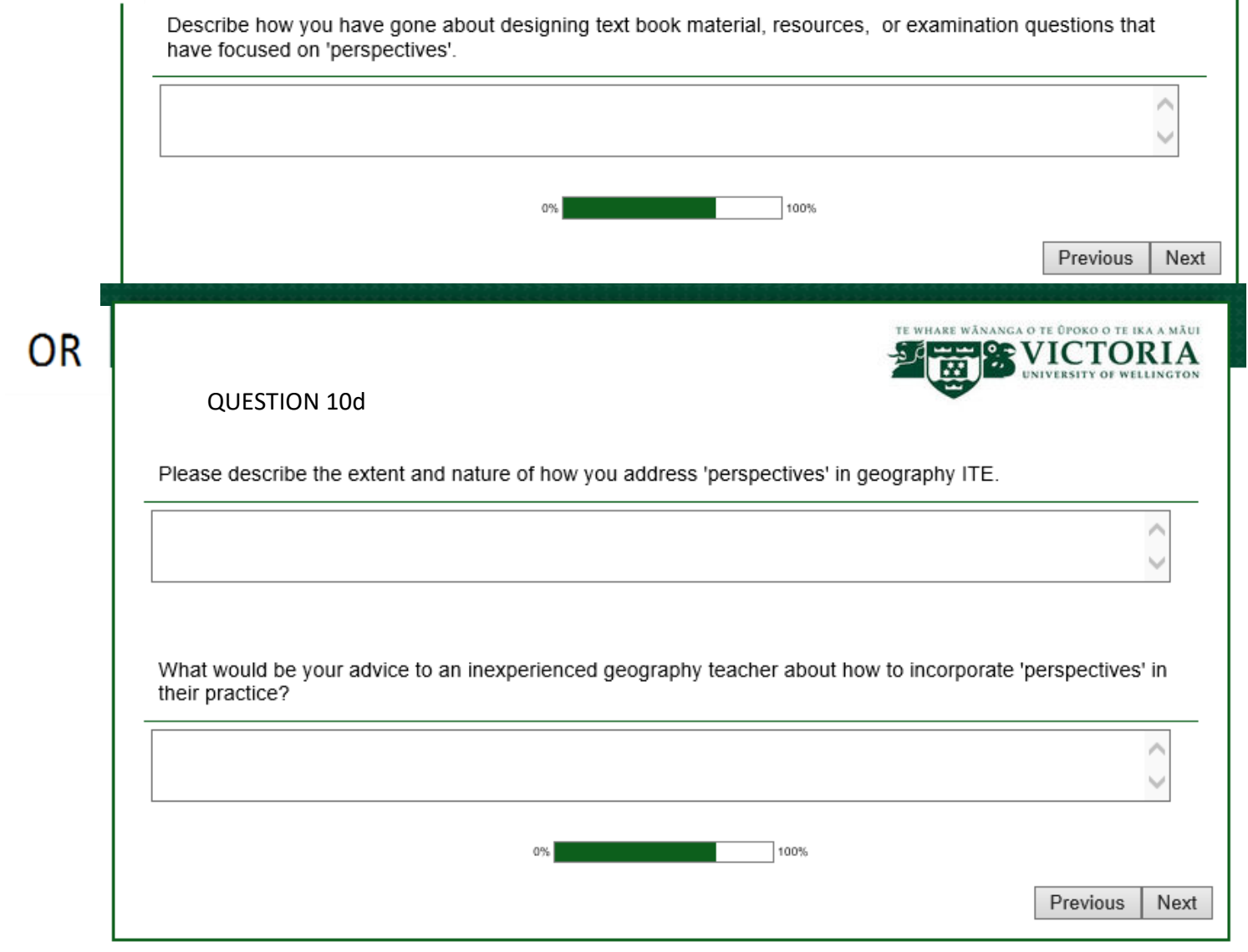

Survey Powered By Qualtrics 
How do you think the concept 'perspectives' could be used with school students to explore the idea that geography encompasses very different ways of knowing, from the natural and social sciences and

the humanities?

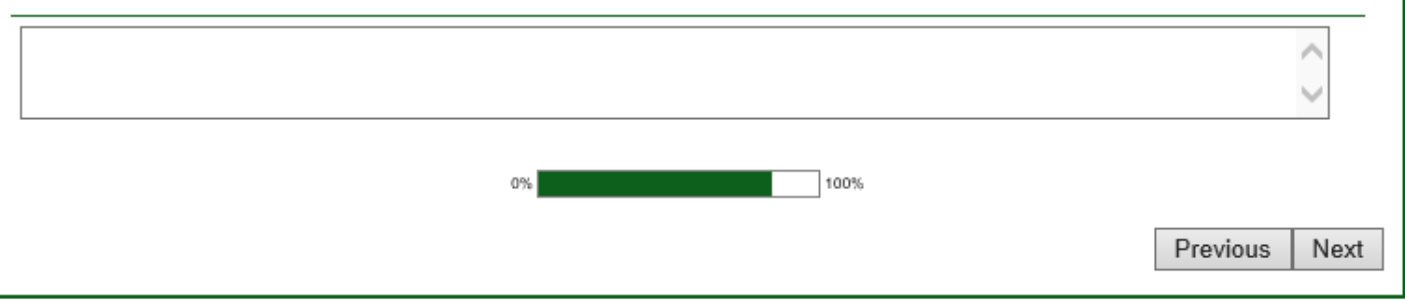

Survey Powered By Qualtrics

QUESTION 12

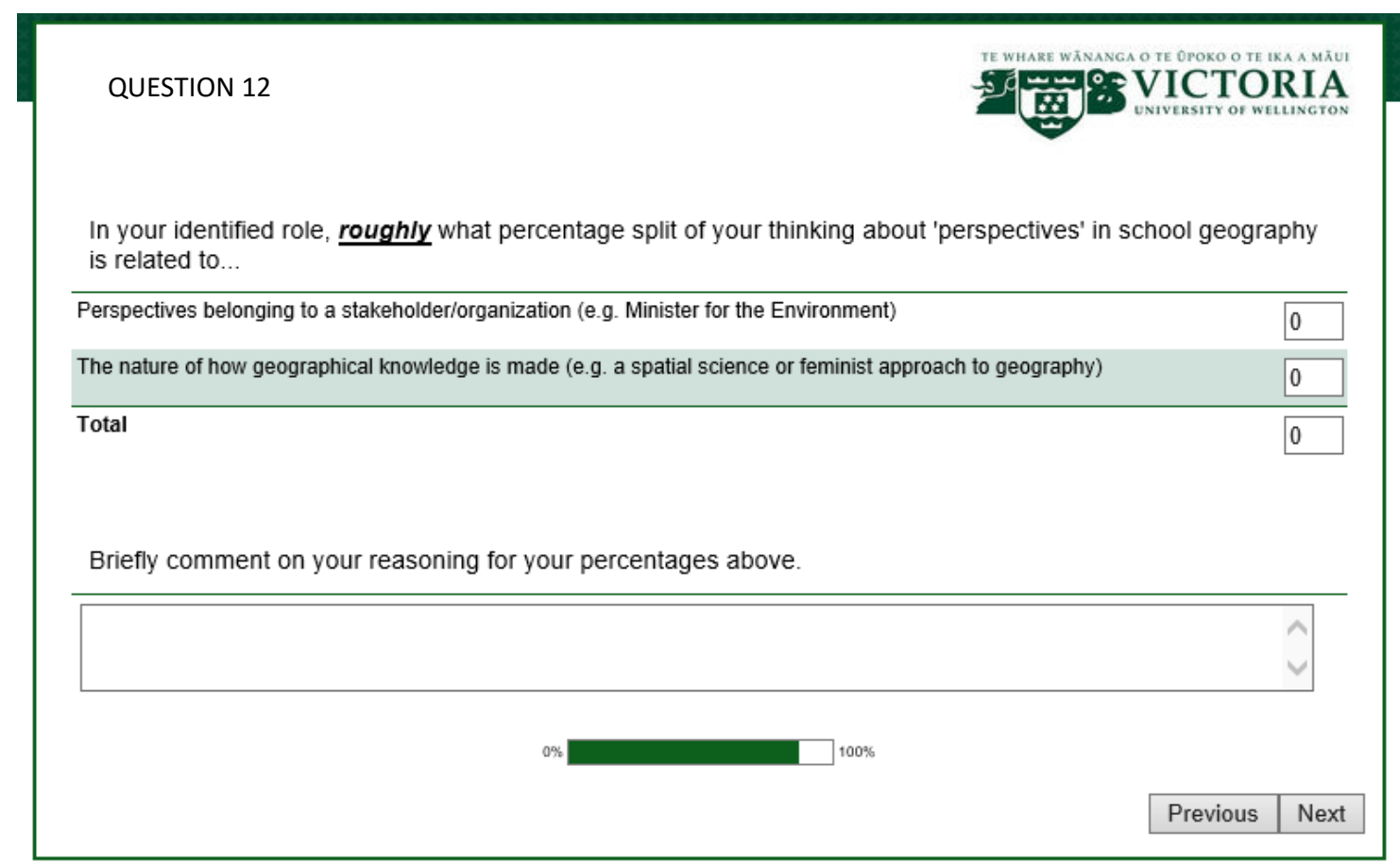

QUESTION 13

Do you have any final comments about the curriculum presence and/or teaching of 'perspectives' you would like to add? 


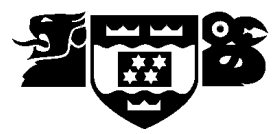

\section{Investigating 'perspectives' to support geographic enquiry in New Zealand Secondary Schools}

Dear [Principal name],

My name is Mike Taylor, and I am currently a lecturer at VUW Faculty of Education with full NZ teacher registration. I am studying towards a doctorate focused on my interest in senior high school geography teaching and learning. In recent years, geography curriculum guidelines and assessment practices in the senior school have identified 'perspectives' as one of seven key geographical concepts. The advice regarding perspectives has, however, been limited and potentially confusing. Furthermore, the role of disciplinary perspectives has not been fully investigated and so I am undertaking research into how teachers support students to think about the nature of geographic knowledge via the concept of 'perspectives'. As such, this project seeks to foreground the foundations of geographical knowledge. The Nature of Science strand is an equivalent focus in the NZ Curriculum science learning area, while the International Baccalaureate (IB) programme also has a mandatory 'Theories of Knowledge' component for senior high school students.

The research will involve a collaborative approach to professional learning, in which myself and a group of teachers plan, observe, and evaluate the outcomes of a Year 12/13 extension programme: 'Studying Cities: Changing Perspectives'. I am requesting whether you will consent to me approaching XXXX and some Year 12 students to be involved during Term 1 and 2, 2015. They would need to give their consent to this invitation also. Specifically, this project involves me:

a. electronically recording an interview with Hayley about her current thinking and practice behind the concept 'perspective'

b. electronically recording a series of collaborative planning meetings to design and develop a six week after-school Year 12/13 geography extension programme. Michelle will be one of a small group of geography teachers involved in this collaborative exercise

c. teaching Year 12 students from your school during the extension programme. The extension programme will be taught at the schools of the contributing teachers. Michelle and the other geography teachers will observe and evaluate the teaching and learning during the extension lessons 
d. electronically recording teacher reflective discussions after each lesson in the extension programme

e. electronically recording a student group discussion about the extension programme, after its conclusion

I intend to use this data for a $\mathrm{PhD}$ thesis, which may also be reported at future conferences or in journal articles. If you agree to this request I propose that a letter first be given to Michelle and eventually the Year 12/13 students to ask permission for their participation. A sample copy of those letters is attached.

The data collected from this project will only be available to myself and my two $\mathrm{PhD}$ supervisors. All the collected data will be securely stored and archived on a password protected computer or in a locked filing cabinet. They will be destroyed/shredded five years after the $\mathrm{PhD}$ thesis is lodged in the university library.

Because of the collaborative nature of this project, your school will be identifiable by the teachers and students participating in this project, but remain confidential at all times in the reporting of this project. To reduce the risk that students and/or your school are identifiable, I will use pseudonyms for the schools and individuals in any external reporting or publication.

This request has been assessed and approved by Victoria University of Wellington Human Ethics Committee, approval ref: 20841. If you have any ethical concerns about this research, contact Dr Allison Kirkman (Allison.Kirkman@ vuw.ac.nz ), ph: 463 5676, Chair of the Human Ethics Committee, Victoria University of Wellington.

Please complete the attached informed consent form and return to me if you agree to Michelle and Year 12/13 geography students being approached to participate in this research. If you have any questions, please do not hesitate to contact me or either of my supervisors, details of which are below.

Yours sincerely, 


\section{Investigating 'perspectives' to support geographic enquiry in New Zealand Secondary Schools}

\section{PRINCIPAL INFORMED CONSENT}

I have read the information sheet, had the opportunity to ask questions and am happy with the answers.

I understand that:

- Mike Taylor may invite [XXXX] from my school and interested Year 12 students to participate in a geography extension programme running for 6 to 7 weeks after school at participating Wellington schools (including my own)

- $\quad[X X X X]$ will be collaboratively working with Mike Taylor and other geography teachers from Wellington schools to design the geography extension programme

- Mike Taylor, a fully NZ registered teacher [223920], will be teaching Year 12 students, while other geography teachers observe and evaluate learning

- Year 12 students participating in the extension programme will have the freedom to decline or give consent to their participation in the $\mathrm{PhD}$ research component. This will ensure that those year 12 students who wish to attend the extension programme but do not wish to be included in the research are not disadvantaged in any way

- Students who give consent will also participate in a focus group discussion about their learning 2-3 weeks after the conclusion of the extension programme.

By signing this consent I also understand that:

- The data collected will be used for a PhD thesis, and possible conference presentations and journal articles.

- All the collected data will be destroyed/shredded five years after the thesis is marked and submitted to the Victoria University of Wellington library.

- My school, the geography teacher, and participating Year 12 students will have their confidentiality protected by use of pseudonyms and non-attributed data in the PhD thesis and any other written reporting of the research.

By ticking the following boxes,

I give my consent for the geography teacher and students to be approached for participation in this project.

I would like to receive a summary of the findings.

Name:

School: .

Signature:

Date: 


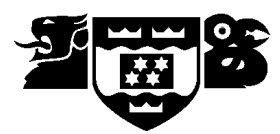

\section{Investigating 'perspectives' to support geographic enquiry in New Zealand Secondary Schools TEACHER INFORMATION SHEET}

\section{Dear XXXX}

As a lecturer at VUW with full NZ teacher registration and currently studying towards a doctorate, I have a great deal of interest in senior high school geography teaching and learning. In recent years, geography curriculum guidelines and assessment practices in the senior school have identified 'perspectives' as one of seven key geographical concepts. The advice regarding perspectives has, however, been limited and potentially confusing. Furthermore, the role of disciplinary perspectives has not been fully investigated and so I am undertaking research into how teachers support students to think about the nature of geographic knowledge, via the concept of 'perspectives'. As such, this project seeks to foreground the knowledge foundations of geography. The Nature of Science strand is an equivalent focus in the NZ curriculum science learning area, while the International Baccalaureate (IB) programme has a mandatory Theories of Knowledge component for senior high students.

This research will involve a lesson study approach to professional learning, in which myself and a group of teachers collaboratively plan, observe, and evaluate the outcomes of a Year 12 'Studying Cities: Changing Perspectives extension programme. Attached to this letter is a summary of the lesson study approach.

I am inviting you to be involved in a small, collaborative team of teachers with some of your Year 12 geography students to investigate how 'perspectives thinking' might enhance outcomes for students. Specifically, this would involve you:

- Participating in an individual electronically recorded interview about 'perspectives' in your geography teaching

- Facilitating a 20-minute diagnostic activity for participating Year 12 students at your school in order to inform our initial planning of the extension programme

- Participating in a series of electronically recorded lesson study meetings to develop a six-week geography extension programme with the researcher and a group of Wellington geography teachers [Term $1 \& 2,2015]$

- Allowing me to teach during our extension programme, while you and the other collaborating teachers observe and record the learning [Term 2, 2015]

- Participating in reflective post-lesson discussions with the other geography teachers about the learning in the extension programme

- Participating in an individual interview 2-3 weeks after the conclusion of the extension programme. 
I envisage that your time commitment to this project, should you agree to be involved, would be 3 to 4 planning meetings in mid-late Term 1 as well as full participation in the 6-week extension programme in Term 2, in your role of lesson study observer. Confidentiality ground rules would be discussed and established across the group for the duration of the project.

If you agree to this request, I propose that you will advertise the extension programme to your Year 12 students. Using your normal school policy, we will provide an information sheet so that students and their parents can give informed consent to i) participate in the extension programme; and ii) make their own transport arrangements to the extension programme lessons that are off your school site.

During the first lesson of the extension programme, I will outline to students the nature of the research before giving them informed consent forms to be signed by them and a parent/guardian. The students and parents should have 72 hours to consider the request before they return the letter to you. A sample copy of the informed consent forms is attached. This approach will ensure that all Year 12 students who want to attend the extension programme are able to do so without necessarily committing to the research component of the project.

I intend to use this data for a $\mathrm{PhD}$ thesis, which may also be reported at future conferences or in journal articles. The collected data will only be available to myself and my two supervisors. All the collected data will be securely stored and archived on a password protected computer or in a locked filing cabinet. This will be destroyed/shredded five years after the thesis is lodged in the university library.

Because of the collaborative nature of this project your school will able to be identified by the teachers and students participating in this projects, but remain confidential at all times in the reporting. To reduce the risk that students may consequently be identifiable, I will use pseudonyms for your school and all individuals in any external reporting or publication.

It is your right to withdraw from this research at any point, giving no reason for doing so, up until the final recorded group reflection interview. Your Year 12 students, however, may continue in the research component of the programme if they wish.

This request has been assessed and approved by Victoria University of Wellington Human Ethics Committee, approval ref: 20841. If you have any ethical concerns about this research, contact Dr Allison Kirkman (Allison.Kirkman@ vuw.ac.nz ), ph: 04463 5676, Chair of the Human Ethics Committee, Victoria University of Wellington.

Please complete the attached informed consent form and return it to me if you agree to my invitation to participate. If you have any questions, please do not hesitate to contact me or either of my two supervisors, for whom details are given below.

Yours sincerely, 


\section{Investigating 'Perspectives' to support geographic enquiry in New Zealand Secondary Schools TEACHER INFORMED CONSENT}

I have read the information sheet, had the opportunity to ask questions and am happy with the answers.

I understand that:

- I have been asked to participate in a doctoral study with Mike Taylor and up to four other geography teachers from Wellington schools exploring student learning about geographical perspectives on urbanisation.

- I will facilitate a 20-minute diagnostic activity for participating Year 12 students at my school in order to inform our initial planning of the extension programme

- I will actively participate in the collaborative planning, observation and evaluation of our lesson study inspired extension programme during Term 1 and 2, 2015.

- I give permission to Mike Taylor (a fully registered teacher) to teach my Year 12 students as part of the extension programme.

- Year 12 students from my school will be invited to participate in the extension programme, running from 6 to 7 weeks after school at host Wellington schools (including my own).

- Students participating in the extension programme will have the freedom to decline or give consent to their participation in the $\mathrm{PhD}$ research.

By signing this consent, I also understand that:

- I have the right to withdraw from this research up to the end of the final interview, without giving a reason. My Year 12 students may, however, continue their participation in the research.

- The data collected will be used for a $\mathrm{PhD}$ thesis, and possible conference presentations and journal articles.

- All the collected data will be destroyed/shredded five years after the $\mathrm{PhD}$ thesis is submitted to the VUW library

- I will have my confidentiality protected by use of pseudonyms and non-attributed data in the $\mathrm{PhD}$ thesis and any other written reporting of the research. 
By ticking the boxes below,

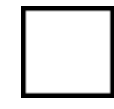

I consent to take part in this Lesson Study inspired research

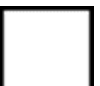

I commit to collaboratively plan, observe and evaluate the learning in the Year 12 'Geographic perspectives on urbanisation' extension programme.

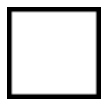

I wish to receive a summary of the findings of this research

Name:

Date:

Signature:

PLEASE RETURN BY EMAIL OR IN THE RETURN ENVELOPE 
Welcome and acknowledgement etc.

I will inform the teachers that the length of the semi-structured interview will be no more than an hour, and that the questions are designed to encourage them to think about what they know and feel about the nature of geographic knowledge as well as the role of 'perspectives' in the classroom.

1. Describe a potted history of your time as a geography teacher

2. What are your thoughts and feelings about geographical 'perspectives'?

3. The Geography teaching guidelines name a bunch of perspectives (show the extract):

'Geographic perspectives' also refers to how knowledge is organised and understood differently in the discipline, and the varying lenses that may be used when undertaking geographic research. These theoretical perspectives have labels such as 'gender geography' 'feminist geography', 'new cultural geography', 'post-modern geography', 'socially critical approaches', and 'Kaupapa Māori Geography' - but these are not the only ones.

Are there any that you emphasise more than others when you teach? (Why?) Are there any you emphasise that are not on this list? (Why?)

4. We are going to be collaboratively looking at how students utilise 'perspectives' in their geographical enquiry? What are you looking forward to about this?

In the next part of this interview the questions focus on geographic knowledge:

5. Tell me what you enjoy about geographical knowledge. Why is it important?

6. How simple or complex do you think geographical knowledge is? (Why?)

7. How certain or uncertain do you think geographic knowledge is? (Why?)

8. To what extent do you think geographical knowledge is 'scientific'? (Why?)

How would you explain the perspective of a physical and a cultural geographer to differ?

9. In the curriculum or assessment are there any signals to teachers about what it means to be a geographer?

In the last part of this interview the questions focus on geographical knowledge, and especially 'perspectives', and 'urbanisation' in schools 
10. Do you ever teach about how geographical knowledge is made/constructed? Can you give an example? Should you? Is this important? Why? Why not? Urban Models?

11. What do you think about the concept of geographical 'perspectives' as a link to geographical knowledge?

12. How do you think a student should be able to utilise 'perspectives' in geography?

13. We're going to be focusing on perspectives on urbanisation. What would you say is key learning about urbanisation? Why?

Thank teacher and reinforce how much I am looking forward to working with them over the coming weeks. 


\author{
VICTORIA UNIVERSITY OF WELLINGTON \\ Te Whare Wananga o te Upoko o te Ika a Maui

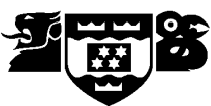 \\ Investigating 'Perspectives' to support geographic enquiry in New Zealand \\ Secondary Schools \\ STUDENT INFORMATION SHEET
}

Dear geography student,

As a participant in the 'Studying Cities: Changing Perspectives' extension programme you will be thinking about how geographical knowledge about cities has been constructed and what this might mean for how geographers pose and answer questions about urbanisation. The extension programme, which has been designed by a group of geography teachers and myself, is an opportunity for you to explore different types of geographical knowledge about urbanisation. During the extension programme, the geography teachers will be documenting your learning.

I am requesting your consent to participate in a study that examines the outcomes of this extension programme. You are most welcome to continue to participate in the extension programme yet not participate in the research component.

As I am interested in documenting this extension programme for other geography teachers and educators, I am inviting you to give permission for:

- The analysis of the short tasks you did at school in preparation for the extension programme to be included in this study

- Collection of copies of your work that you complete during the extension programme

- Collection of verbal interactions you have with myself, another teacher, or a fellow student during the extension classes

- Your participation in a student group discussion interview at your school, of up to 45 minutes, about your learning during the extension programme

You will not be treated any differently in the programme if you decide not to give consent. If you do give consent, it will just mean that any interaction you have with me or a peer is likely to be observed and recorded. If you do not give consent I will not include anything you say or do in the research.

I would like to publish what I find out as a $\mathrm{PhD}$ thesis and possibly at future conferences and journal articles. Should you give consent, you and your work will not be identifiable in any way if it is used in any written report. To make sure that you are not identified, I will use a pseudonym for you in any presentations or publications. 
If any of your work is copied it will be securely stored in a locked filing cabinet. The material will be destroyed five years after the $\mathrm{PhD}$ is completed. Only I, the teachers, and my two $\mathrm{PhD}$ supervisors will have access to the photocopied work and the notes recorded during the extension programme.

Attached to this letter are separate consent forms for you and your parent/guardian to fill out should you agree to participate in this extension programme research. If you choose not to give permission your learning will not be affected in any way. If you do agree to participate, you have the right to withdraw from the research up until the end of the final group-discussion interview, without giving any reason for your decision.

This request has been assessed and approved by Victoria University of Wellington Human Ethics Committee, approval ID 20841. If you have any ethical concerns about this research, contact Dr Allison Kirkman (Allison.Kirkman@ vuw.ac.nz ),ph: 04463 5676, Chair of the Human Ethics Committee, Victoria University of Wellington or my primary supervisor Dr Bronwyn Wood (Bronwyn.Wood@vuw.ac.nz)ph: 044639611.

Please complete the attached informed consent form, along with the consent form from your parent/guardian and return it to your geography teacher by Monday $8^{\text {th }}$ June if you agree to this request. If you have any further questions, please do not hesitate to contact me, details below.

Many thanks 


\section{Investigating 'Perspectives' to support geographic enquiry in New Zealand Secondary Schools STUDENT INFORMED CONSENT}

I have read the information sheet, had the opportunity to ask questions and am happy with the answers.

I understand that:

- The information is inviting me to participate in a $\mathrm{PhD}$ research project about my extension programme 'Studying Cities: Changing Perspectives'

- Geography teachers may observe the extension programme lessons, take notes about discussions I have, and copy samples of my work while I am taught by Mike Taylor

- After the completion of the extension programme, I agree to participate in a 45 minute student group discussion at my school.

By giving consent I also understand that:

- I have the right to withdraw from this research up to the end of the student group discussion, without giving a reason

- Although I may withdraw from the research at any time, this will not impact on my continued participation in the extension programme

- The data collected will be used for a PhD thesis and possibly conferences and in journal articles

- All the collected data will be destroyed/shredded five years after the $\mathrm{PhD}$ thesis is marked

- I will not be named, or be able to be identified, in any publication.

By ticking the boxes below,

I consent to participate in this research.

I am happy to have the analysis of the tasks I did before the extension programme included in the research

I would like to receive a summary of the research.

Name:

Date:

Signature :

School: 
Appendix G: Timeline of Phase 3 research

\begin{tabular}{|l|l|l|l|l|l|l|l|l|l|l|}
\hline \multicolumn{7}{|c|}{ Term 1 Academic School Year 2015 } \\
\hline & Week 1 & Week 2 & Week 3 & Week 4 & Week 5 & Week 6 & Week 7 & Week 8 & Week 9 & Week 10 \\
\hline $\begin{array}{l}\text { Michelle base- } \\
\text { line interview }\end{array}$ & & & & & & $2 / 4 / 15$ & & & & \\
\hline $\begin{array}{l}\text { Sacha base- line } \\
\text { interview }\end{array}$ & & & & & & & & & $20 / 4 / 15$ & \\
\hline $\begin{array}{l}\text { Collaborative } \\
\text { Meeting A }\end{array}$ & & & & & & & & & & \\
\hline $\begin{array}{l}\text { Collaborative } \\
\text { Meeting B }\end{array}$ & & & & & & & & & \\
\hline
\end{tabular}

\section{Term 2 Academic School Year 2015}

\begin{tabular}{|c|c|c|c|c|c|c|c|c|c|c|}
\hline & Week 1 & Week 2 & Week 3 & Week 4 & Week 5 & Week 6 & Week 7 & Week 8 & Week 9 & Week 10 \\
\hline $\begin{array}{l}\text { Collaborative } \\
\text { Meeting C }\end{array}$ & & $21 / 5 / 15$ & & & & & & & & \\
\hline $\begin{array}{l}\text { Student baseline } \\
\text { tasks }\end{array}$ & & & & & & & & & & \\
\hline $\begin{array}{l}\text { Lesson Study \#1 } \\
\& \text { modifications }\end{array}$ & & & & $3 / 6 / 15$ & & & & & & \\
\hline $\begin{array}{l}\text { Lesson Study \# } 2 \\
\& \text { modifications }\end{array}$ & & & & & $10 / 6 / 15$ & & & & & \\
\hline $\begin{array}{l}\text { Lesson Study \# } 3 \\
\& \text { modifications }\end{array}$ & & & & & & $17 / 6 / 15$ & & & & \\
\hline $\begin{array}{l}\text { Lesson Study \# } 4 \\
\& \text { modifications }\end{array}$ & & & & & & & $25 / 6 / 15$ & & & \\
\hline Lesson Study \# 5 & & & & & & & & $2 / 7 / 15$ & & \\
\hline
\end{tabular}

\section{Term 3 Academic School Year 2015}

\begin{tabular}{|l|l|l|l|l|l|l|l|l|l|l|}
\hline & Week 1 & Week 2 & Week 3 & Week 4 & Week 5 & Week 6 & Week 7 & Week 8 & Week 9 & Week 10 \\
\hline TAH focus group & & & & & & & & & \\
\hline RC focus group & & & & & & & & $10 / 9 / 15$ & & \\
\hline $\begin{array}{l}\text { Michelle exit } \\
\text { interview }\end{array}$ \\
\hline $\begin{array}{l}\text { Sacha exit } \\
\text { interview }\end{array}$
\end{tabular}


Appendix H: Lesson Study Plans 1 - 5

Lesson Study \#1, 3/6/15

\begin{tabular}{|c|c|c|}
\hline $\begin{array}{l}\text { Learning } \\
\text { Intentions }\end{array}$ & Teaching \& learning sequence & $\begin{array}{l}\text { Evidence for } \\
\text { learning }\end{array}$ \\
\hline $\begin{array}{l}\text { To begin to } \\
\text { describe different } \\
\text { characteristics of } \\
\text { geographical } \\
\text { perspectives }\end{array}$ & $\begin{array}{l}\text { Introductions etc. (5mins) } \\
\text { - Students \& Staff to share some insights on the } \\
\text { image they have supplied as representative of city- } \\
\text { life. (10mins) } \\
\text { - Slide presentation on different geographical } \\
\text { perspectives (20mins) } \\
\text { - Students active note-taking using graphic } \\
\text { organiser to note: } \\
\text { a) Typical city theme of perspective } \\
\text { b) Period in which perspective emerged } \\
\text { c) Key Geographers } \\
\text { d) Methodologies typically used by } \\
\quad \text { geographers associated with that } \\
\text { perspective } \\
\text { - In pairs, students to pose questions, from a range } \\
\text { of perspectives, on post-it notes in 'Bus Stop } \\
\text { activity', based on } 4 \text { of } 6 \text { photos depicting cities. } \\
\text { (10mins) } \\
\text { - Mike to describe his PhD research, need for } \\
\text { informed consent. Letters to be signed by students } \\
\text { and returned to teachers at school. (10mins) } \\
\text { In groups of } 4 \text {, students to read abstracts of recent } \\
\text { geographical studies and categorise according to } \\
\text { dominant perspective (10 mins) } \\
\text { Plenary Q \& A (5mins) }\end{array}$ & $\begin{array}{l}\text { Collect Post-it notes for } \\
\text { post lesson analysis. } \\
\text {-Do questions reflect } \\
\text { different perspectives? } \\
\text { Why? } \\
\text { Record student } \\
\text { conversations about } \\
\text { their categorisation of } \\
\text { abstracts. } \\
\text {-Are abstracts correctly } \\
\text { categorised? } \\
\text {-Can students describe } \\
\text { language used to link to } \\
\text { a perspective? }\end{array}$ \\
\hline
\end{tabular}

Necessary Resources: Powerpoint slides; Graphic Organiser for student note taking; A3 Laminated Photos of City Life; Post-it Notes ; A4 Laminated Abstracts \& Perspective Headings 

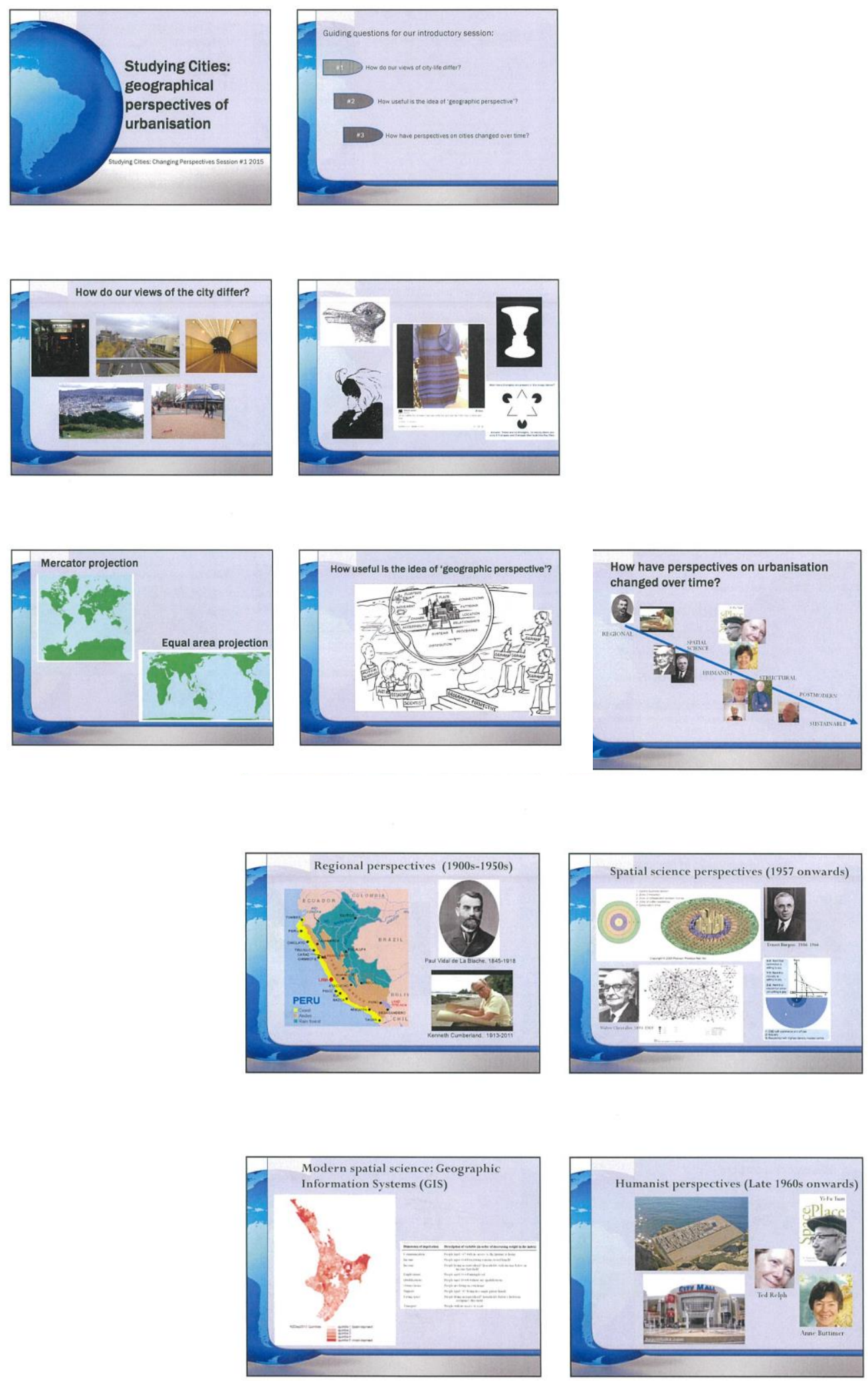

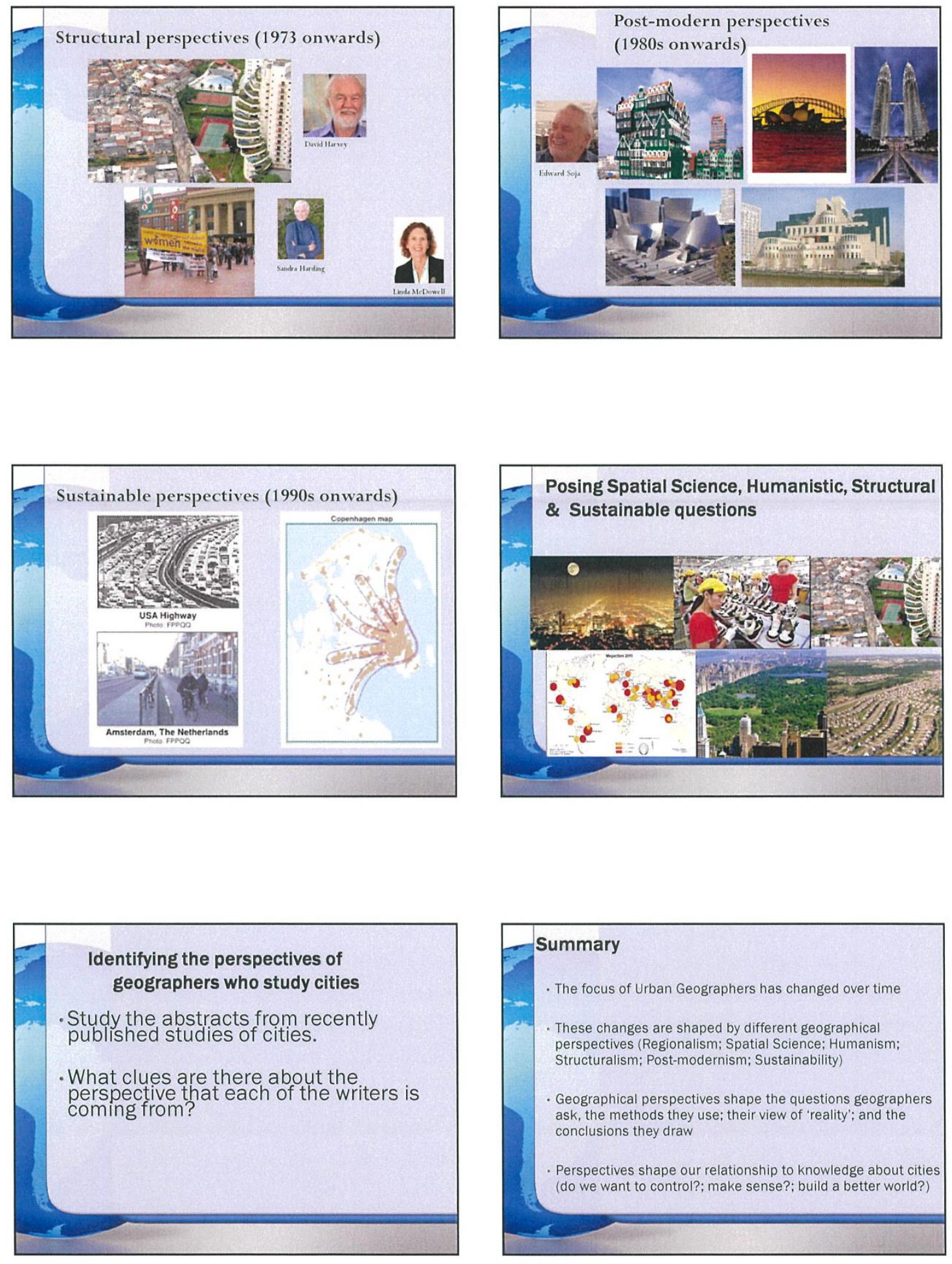


\section{Appendix Hii}

Studying cities: Spatial science perspectives. Lesson Study \#2, 10/6/15

\begin{tabular}{|c|c|c|}
\hline $\begin{array}{l}\text { Learning } \\
\text { Intentions }\end{array}$ & Teaching \& learning sequence & $\begin{array}{l}\text { Evidence for } \\
\text { learning }\end{array}$ \\
\hline $\begin{array}{l}\text { To understand } \\
\text { that knowledge } \\
\text { of cities can be } \\
\text { shaped by a } \\
\text { spatial science } \\
\text { perspective }\end{array}$ & $\begin{array}{l}\text { Introductions etc. (5mins) } \\
\text { - Icebreaker - new face illusion } \\
\text { "Do these illusions help you understand about } \\
\text { perspectives?" (5mins) } \\
\text { - Students to complete NZ city survey by } \\
\text { individually ranking perception of city before } \\
\text { aggregating class score. } \\
\text { Plot on Map \& create divide line of 'desirable } \\
\text { and non-desirable'. } \\
\text { Create some law-like statements based on map } \\
\text { - } 25 \text { mins) } \\
\text { Teacher Slide presentation: (15mins) } \\
\text { Role of Models (using Burgess, Hoyt \& Harris } \\
\text { and Ullman as exemplars) in spatial science and } \\
\text { assumptions of Spatial Science perspective } \\
\text { NB: allow for student questions to clarify } \\
\text { Class discussion: How can six photos of } \\
\text { Wellington represent/be informed by the spatial } \\
\text { science perspective? (15mins) }\end{array}$ & $\begin{array}{l}\text { Record student } \\
\text { questions, } \\
\text { clarifications, } \\
\text { observations etc. } \\
\text { Record student } \\
\text { written work about } \\
\text { selected images, with } \\
\text { particular focus on } \\
\text { linkages to spatial } \\
\text { science perspective. }\end{array}$ \\
\hline
\end{tabular}

\section{Necessary Resources:}

\section{Powerpoint slides}

Urban survey worksheets \& outline map of NZ

\section{A3 Laminated Photos of City Life}

\section{Wellington City image worksheets}



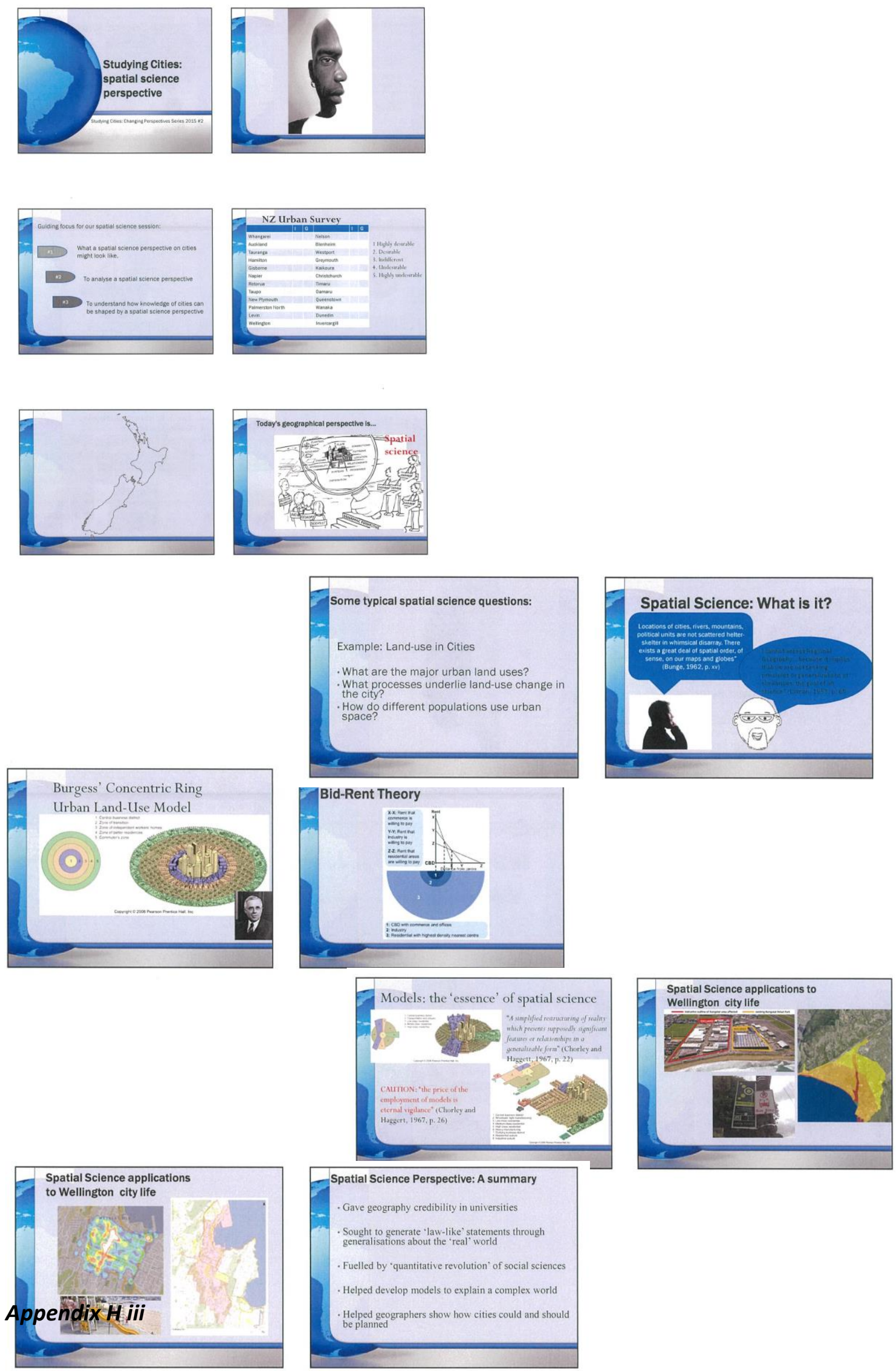


\begin{tabular}{|c|c|c|}
\hline $\begin{array}{l}\text { Learning } \\
\text { Intentions }\end{array}$ & Teaching \& learning sequence & $\begin{array}{l}\text { Evidence for } \\
\text { learning }\end{array}$ \\
\hline $\begin{array}{l}\text { To understand } \\
\text { that knowledge } \\
\text { of cities can be } \\
\text { shaped by a } \\
\text { Humanistic } \\
\text { perspective }\end{array}$ & $\begin{array}{l}\text { - Introductory exposition: } \\
\text { Re-cap of key ideas about spatial science from } \\
\text { previous session: } \\
\text { 1. Knowledge based on observable reality } \\
\text { 2. Spatial science sought generalisations (law like), which } \\
\text { could become testable theories and construct models } \\
\text { 3. Knowledge used to control society } \\
\text { - Introduce humanistic geography as an attempt by } \\
\text { geographers to 'personalise' lived experience [e.g. in } \\
\text { cities] by recognising that: } \\
\text { 1. Knowledge based on subjective realities } \\
\text { 2. Humanistic geographers interested in recording varied } \\
\text { realities } \\
\text { 3. Emphasis of human agency and consciousness } \\
\text { 4. Knowledge based on 'making meaning' and so drew } \\
\text { upon varied accounts of city life } \\
\text { - Students to read Wordsworth 's 'Composed upon } \\
\text { Westminster Bridge' and Margaret Atwood's 'The City } \\
\text { Planners'. Teacher-Student dialogue focusing on the } \\
\text { meanings about cities that these poets } \\
\text { can help inform. } \\
\text { - Humanistic research: Commuter survey } \\
\text { Students to take a humanistic approach by briefly } \\
\text { interviewing commuters for their experiences of Wellington } \\
\text { railway station. } \\
\text { Students to present their findings in the form of a poem or } \\
\text { rap. }\end{array}$ & $\begin{array}{l}\text { Accurate collection } \\
\text { of: } \\
\text { 1. Demographic } \\
\quad \text { data } \\
\text { 2. Interviewee } \\
\quad \text { responses } \\
\text { Creative } \\
\text { representation of } \\
\text { findings. }\end{array}$ \\
\hline
\end{tabular}

\section{Necessary Resources:}

Powerpoint slides

Poem handouts 

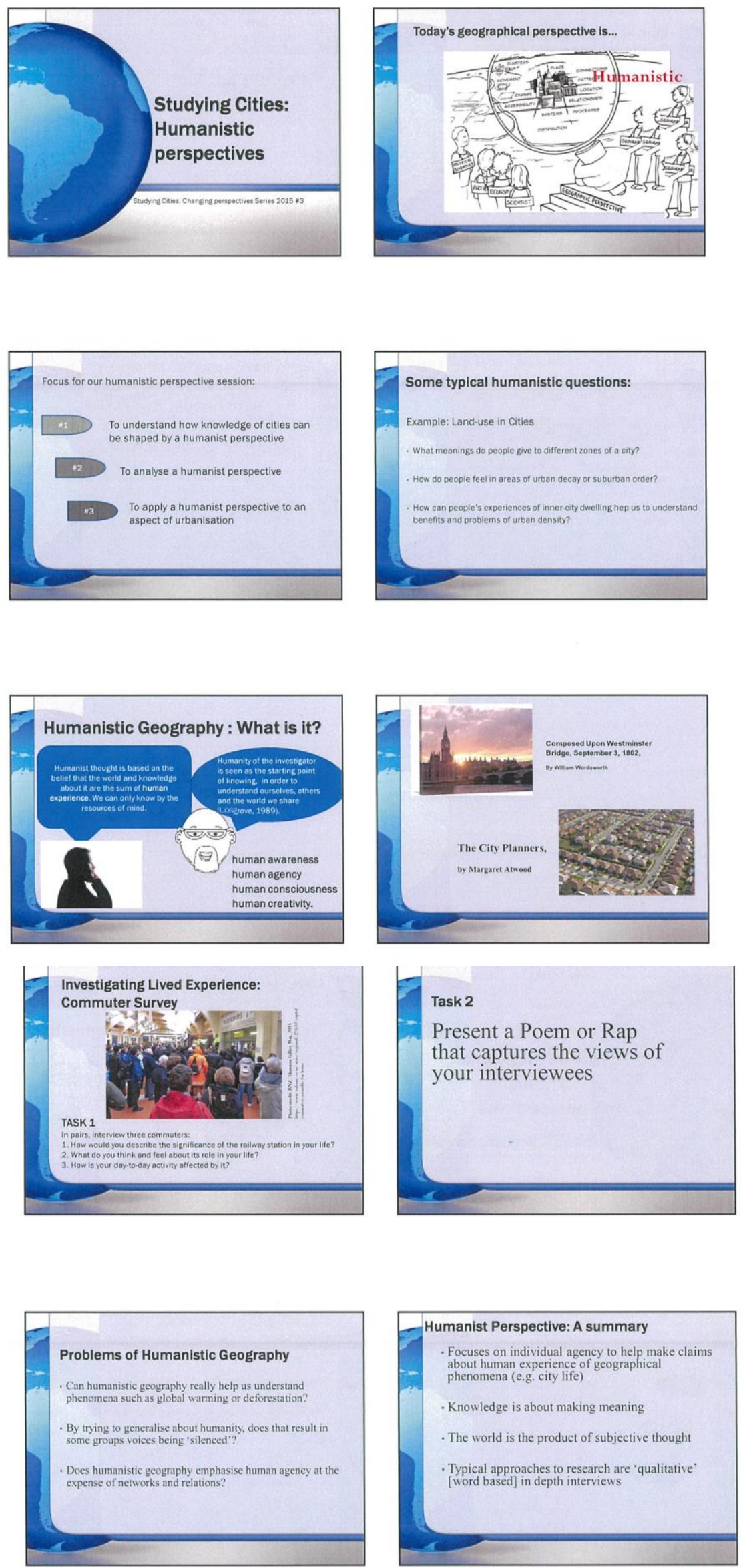


\section{Appendix H iv continued}

Studying cities: Structuralist perspective. Lesson Study \#4 25/6/15

\begin{tabular}{|c|c|c|}
\hline $\begin{array}{l}\text { Learning } \\
\text { Intentions }\end{array}$ & Teaching \& learning sequence & $\begin{array}{l}\text { Evidence for } \\
\text { learning }\end{array}$ \\
\hline $\begin{array}{l}\text { To understand } \\
\text { that knowledge } \\
\text { of cities can be } \\
\text { shaped by a } \\
\text { structural } \\
\text { perspective }\end{array}$ & $\begin{array}{l}\text { Starter Activity: around the stick figure annotate with labels } \\
\text { describing the concept of capitalism. What might someone } \\
\text { who represents capitalism look like? (Not physically!) } \\
\text { Teacher B to give some framework to help with labels. (5m) } \\
\text { Introduction to the perspective of structuralism - } \\
\text { Teacher led (10m) } \\
\text { - Theory: Key ideas - society is shaped or governed } \\
\quad \text { by mechanisms and structures e.g. capitalism. Make } \\
\quad \text { connections with starter activity. } \\
\text { Brief exposition of how capitalism evolved. } \\
\text { Student activity: think pair and share connection with starter } \\
\text { through key questions. (5m) } \\
\text { Make link between structuralism and the urban } \\
\text { environment. - Teacher led (20m) } \\
\text { they have been gentrified and/or revitalised. } \\
\text { - Key ideas - different institutions and groups that control } \\
\text { certain aspects of the built environment- give examples } \\
\text { Introduce gentrification - and revitalisation } \\
\text { Student activity: Read the definition of Gentrification and } \\
\text { describe in own words and the scene she is portraying. } \\
\text { - Continue with the explanation of Gentrification and } \\
\text { Gentrification / Revitalisation. } \\
\text { Walk out the WW and take a short walk and observe changes } \\
\text { introduce Rent Gap Theory } \\
\text { Student activity: look at the model and see if they can } \\
\text { the key features of gentrification. } \\
\text { - }\end{array}$ & $\begin{array}{l}\text { Making connections } \\
\text { with starter activity } \\
\text { Able to describe } \\
\text { Gentrification in own } \\
\text { words after } \\
\text { interpreting the } \\
\text { description by Ruth } \\
\text { Glass. }\end{array}$ \\
\hline
\end{tabular}

Necessary Resources: Powerpoint slides, Worksheet handouts, Blank A4 for field sketch 

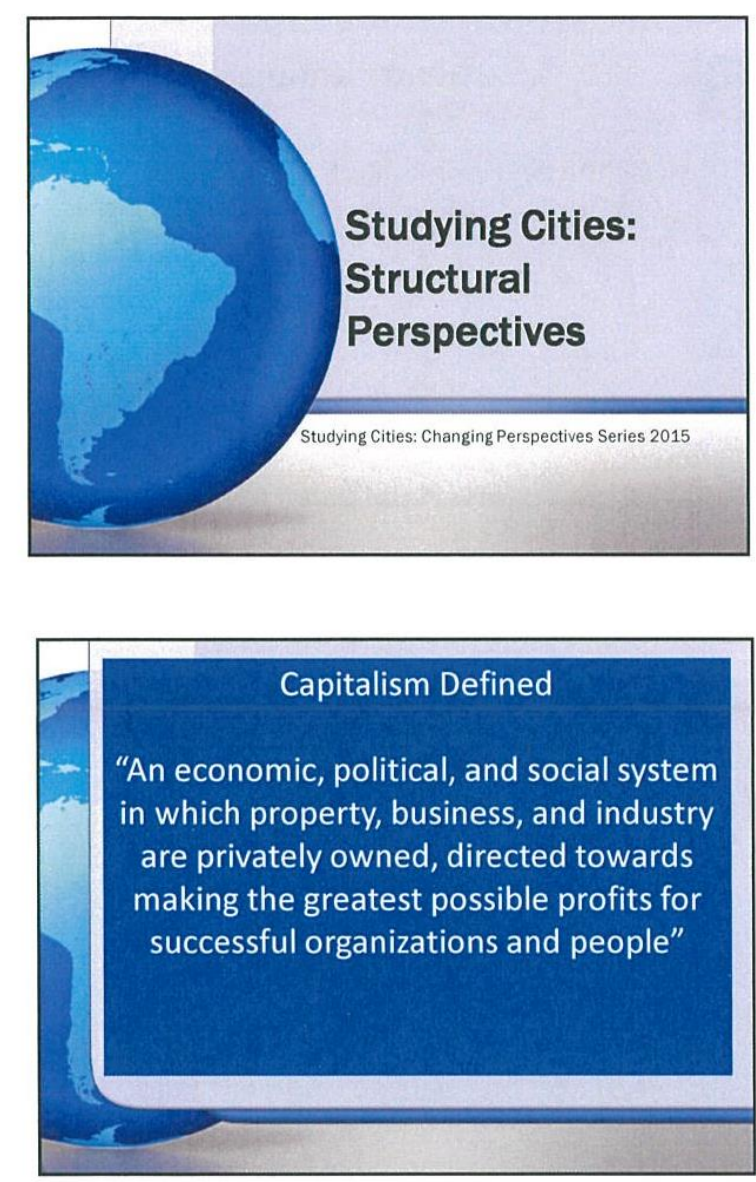

\section{Structualist perspective}

- "To understand people and society you needed to look beneath the surface and identify the

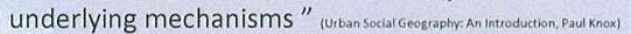
-What does this mean?!

-What we do as individuals is governed or determined by structures, rules, conventions or restraints.

- The mechanisms or structures cannot be observed directly...

rax
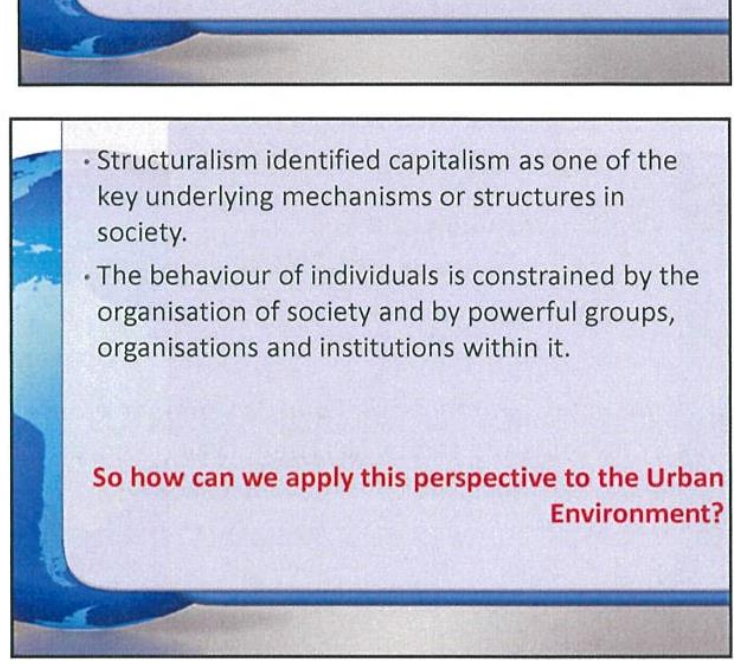

\section{Starter Activity: Capitalism}

Quick assessment of K \& U ... .

What do we mean by capitalism?

TASK: Imagine this stick figure is someone who represents the capitalist system. Label and/or annotate with what this may look like.

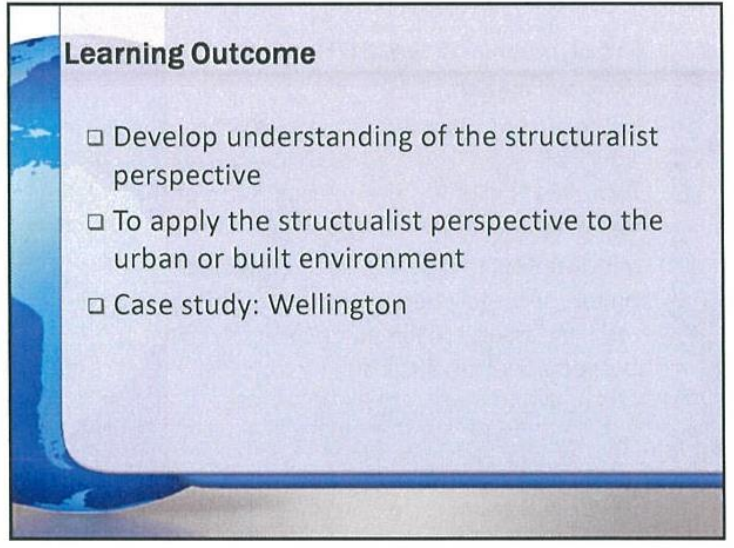

TASK: Over to you .... In a pair ... Consider the following questions...
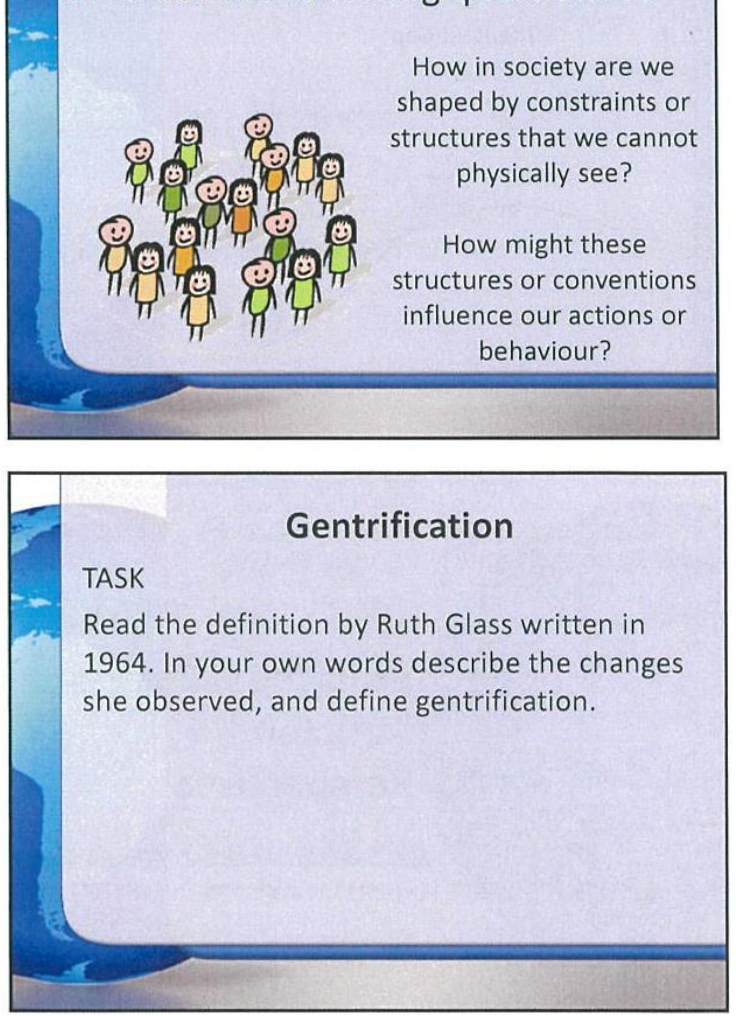


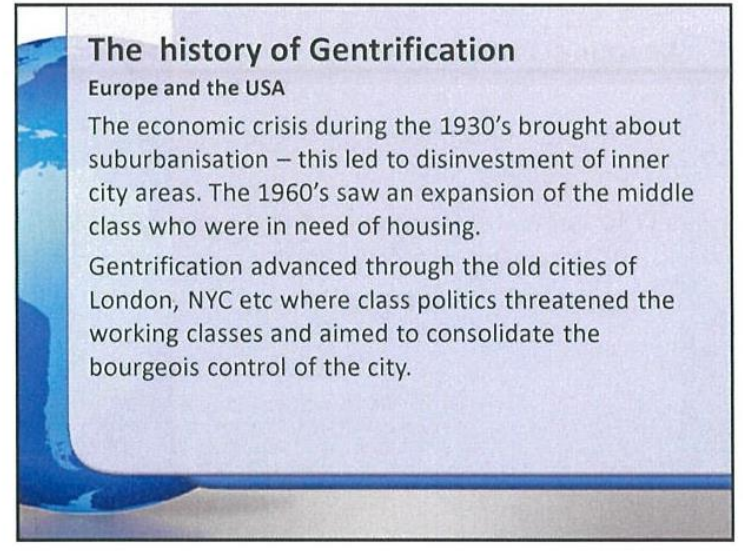

The Rent Gap Theory - TASK: what do think is being shown on this graph / model?
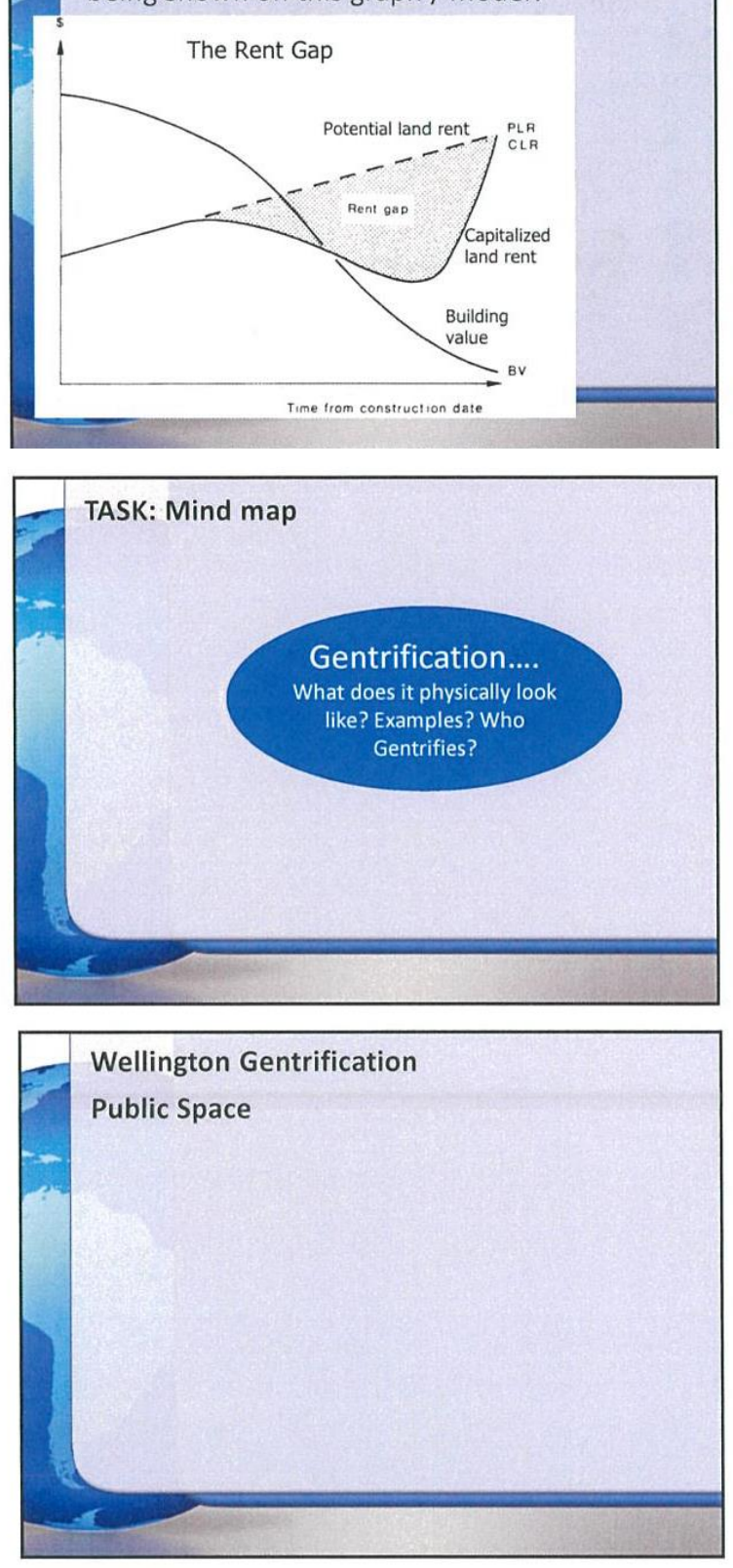
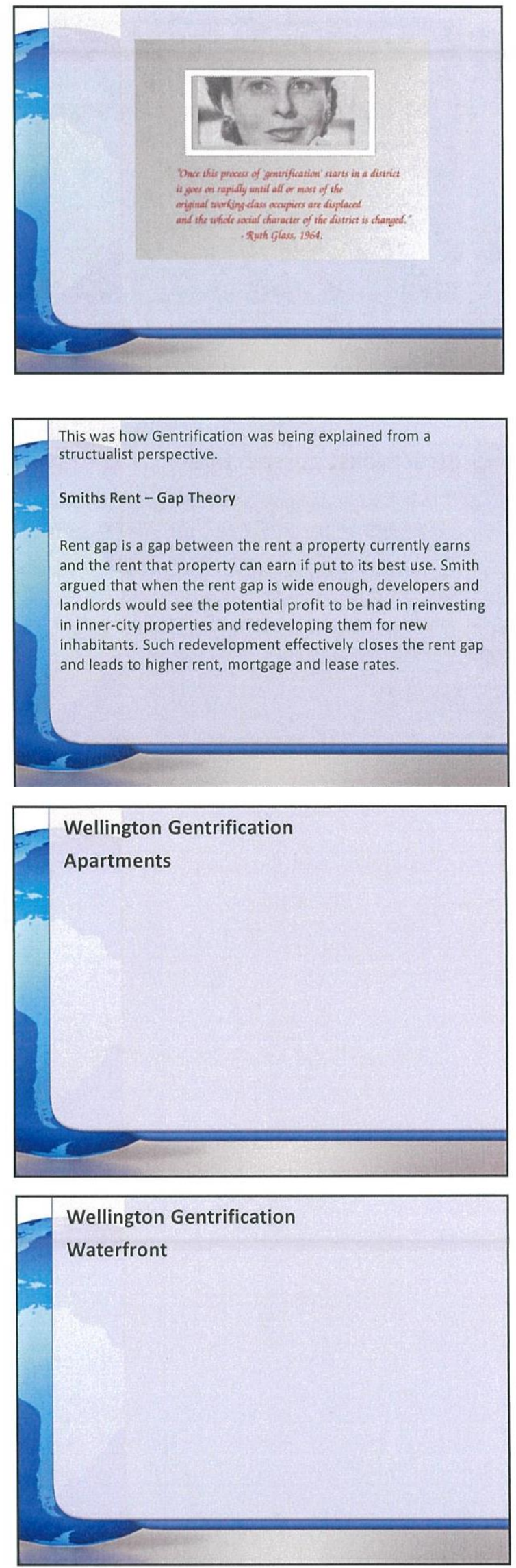


\section{Appendix $\mathrm{H} v$ continued}

Studying cities: Sustainable perspectives Lesson Study \# 5 2/7/2015

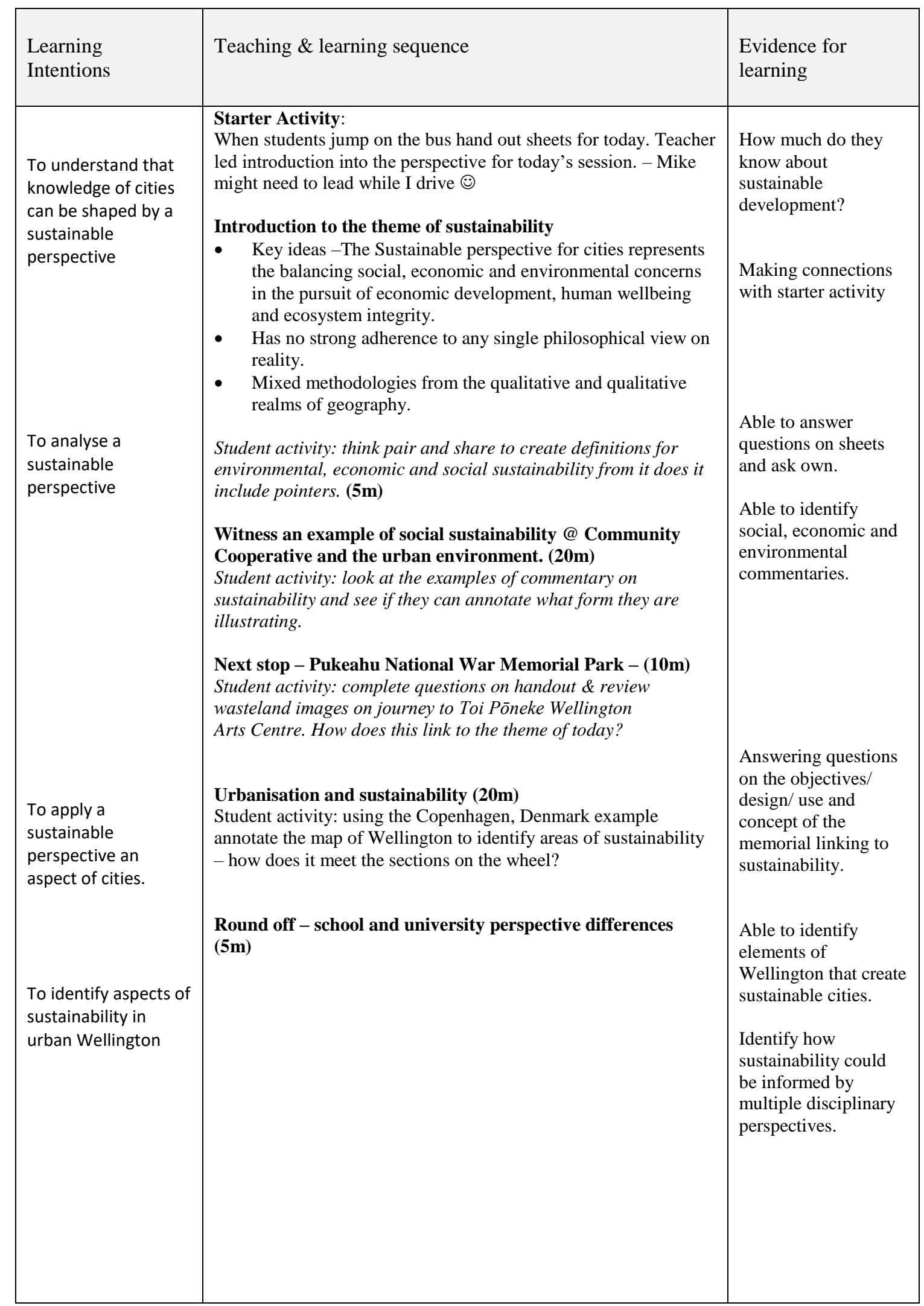



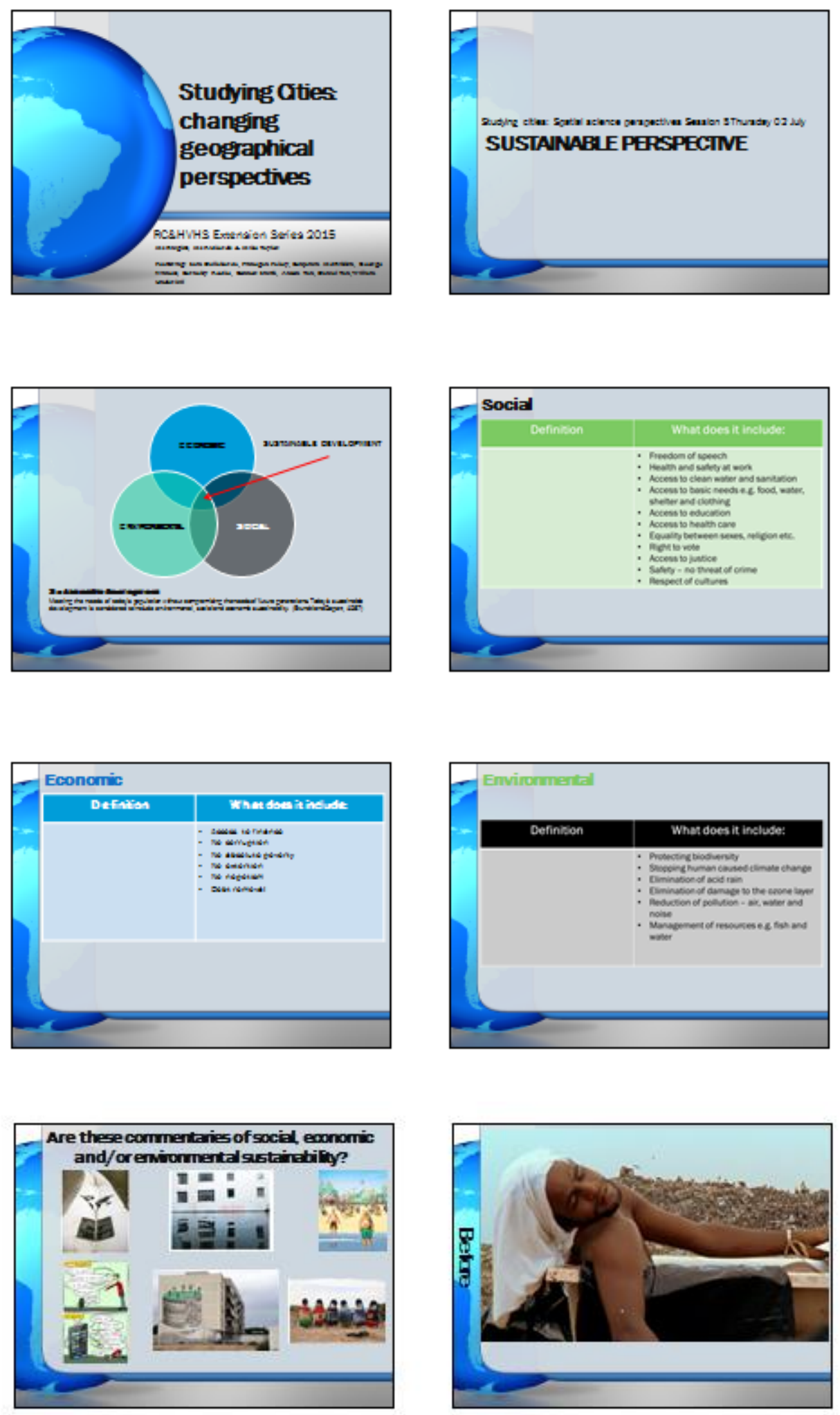

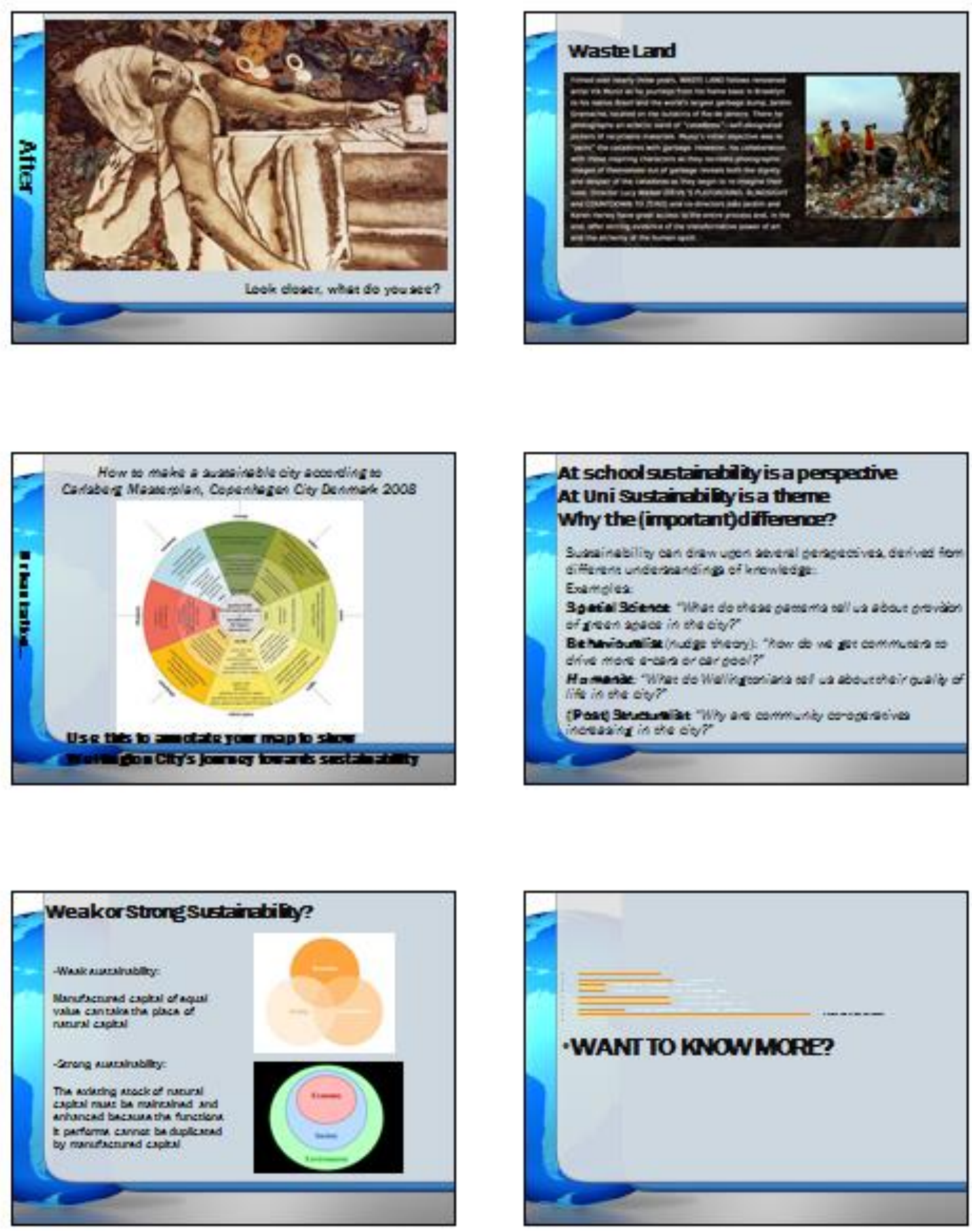
Appendix li: Lesson Observation, Annotation and Analysis Reflections

Lesson Study \#1 [Observation Key: Red = Michelle; Black = Sasha; Green = Mike]

\begin{tabular}{|c|c|c|}
\hline 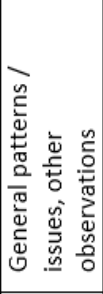 & 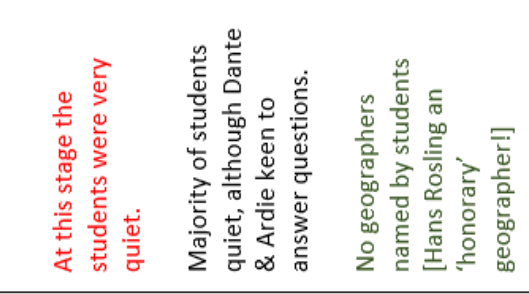 & 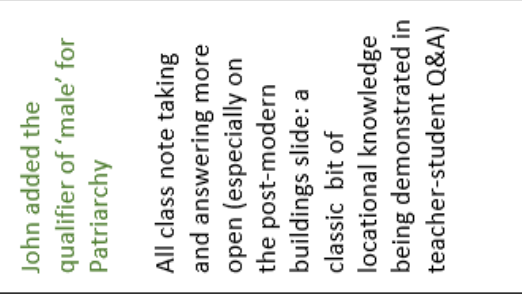 \\
\hline 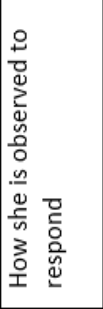 & 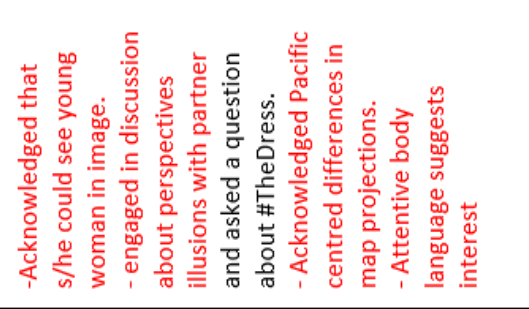 & 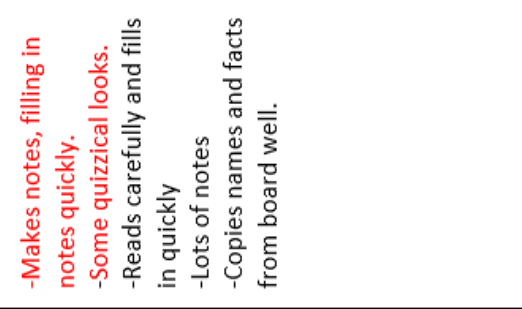 \\
\hline 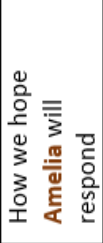 & 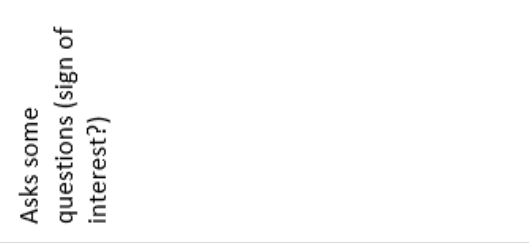 & 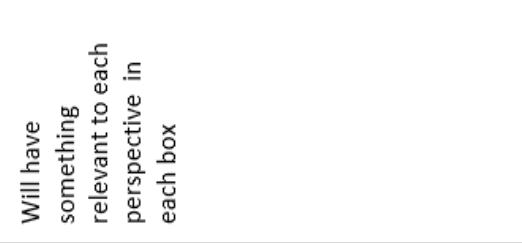 \\
\hline 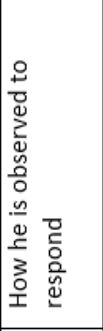 & 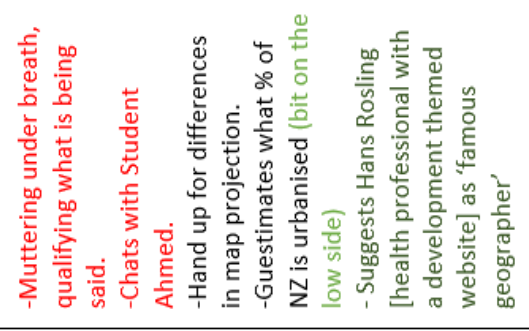 & 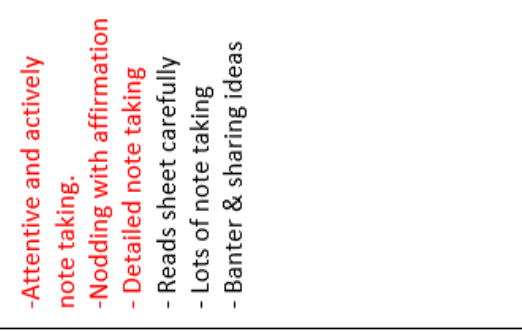 \\
\hline 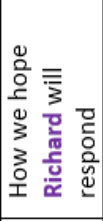 & 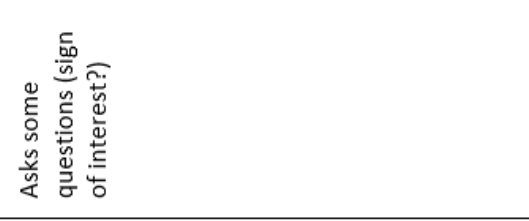 & 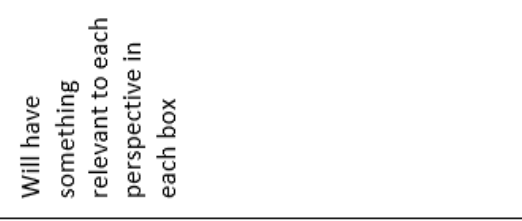 \\
\hline 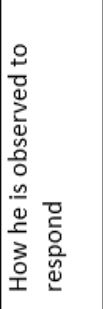 & 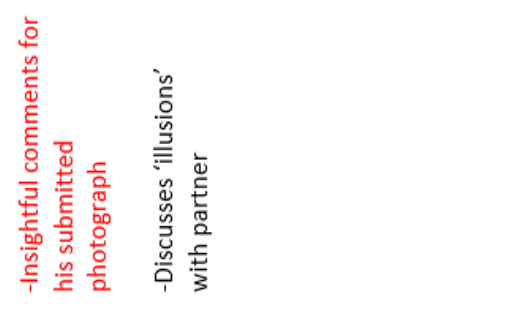 & 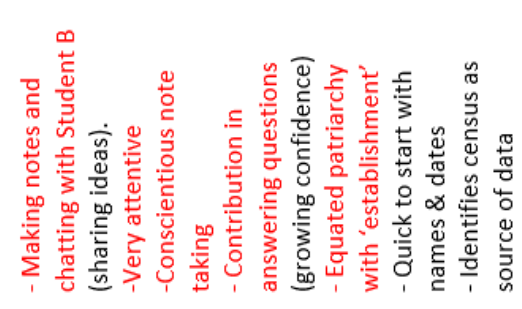 \\
\hline 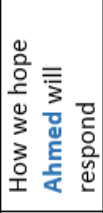 & 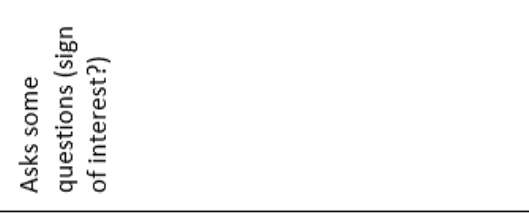 & 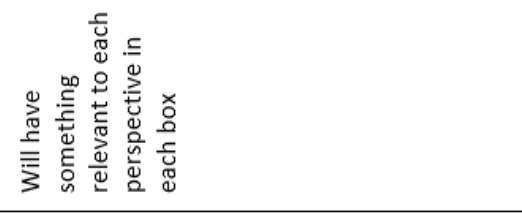 \\
\hline 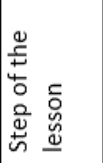 & 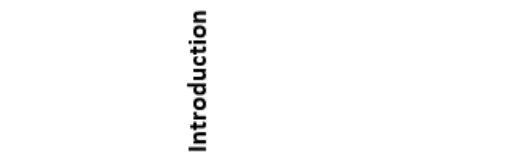 & 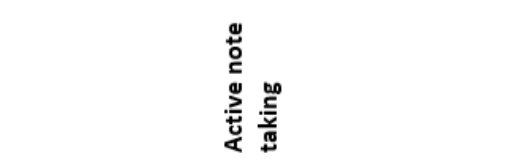 \\
\hline
\end{tabular}


Lesson Study \#1 Observation and Annotation Sheet continued...

\begin{tabular}{|c|c|c|c|}
\hline 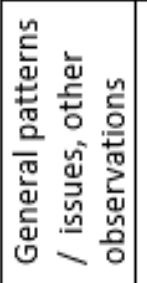 & & & 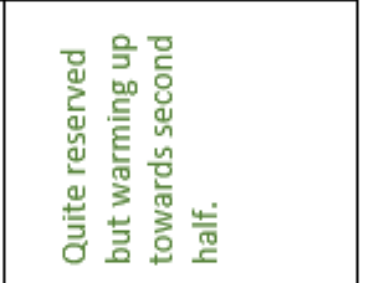 \\
\hline 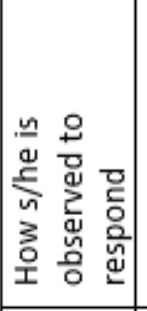 & 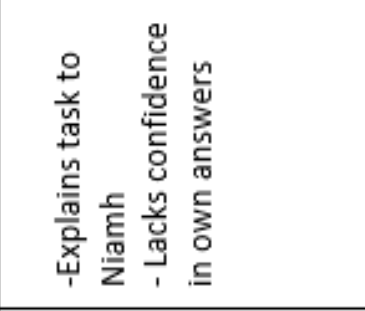 & 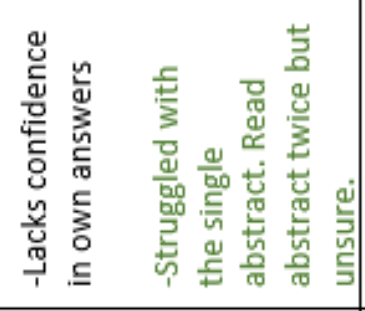 & 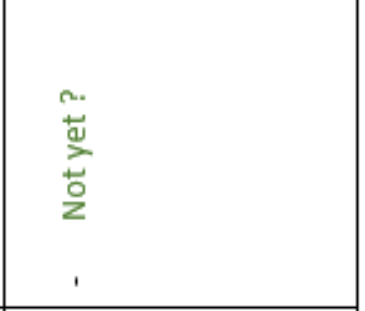 \\
\hline 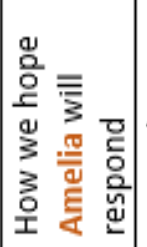 & 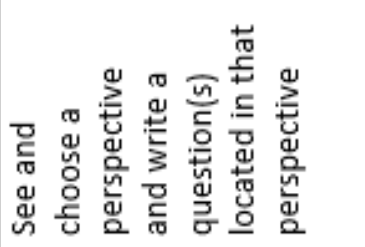 & 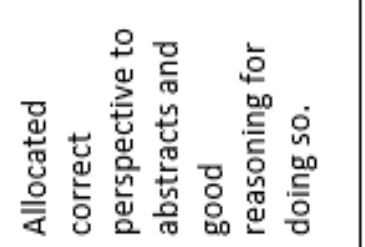 & 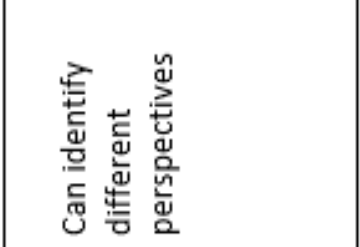 \\
\hline 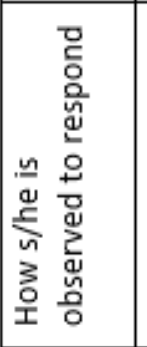 & 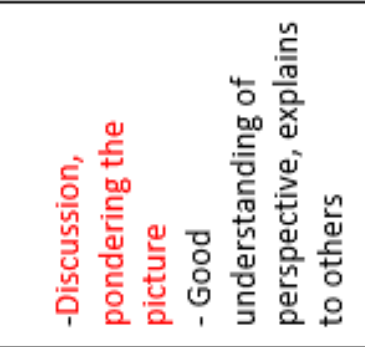 & 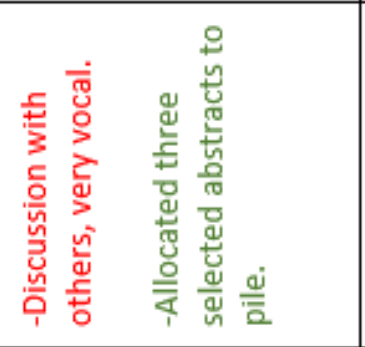 & 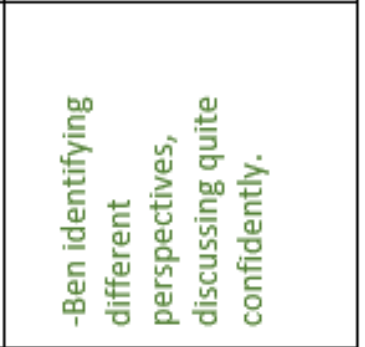 \\
\hline 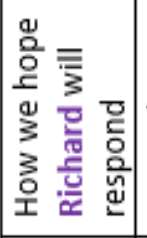 & 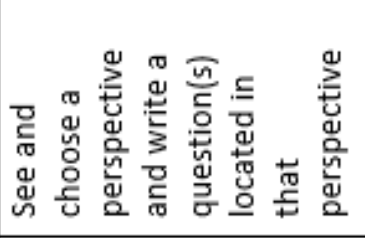 & 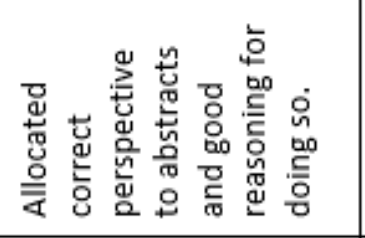 & 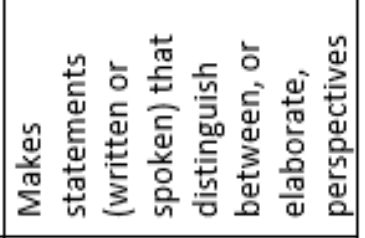 \\
\hline 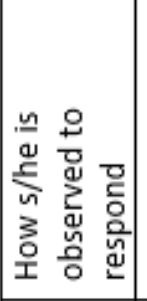 & 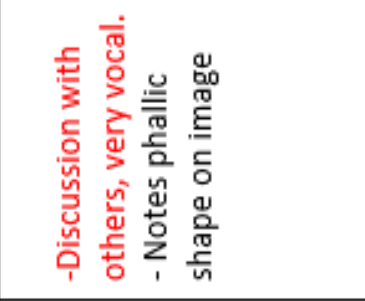 & 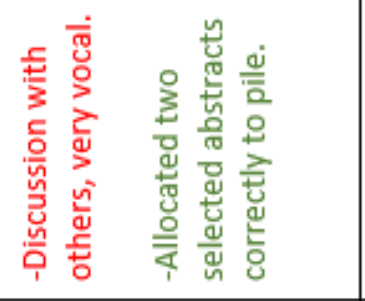 & 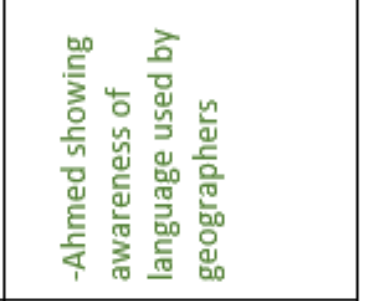 \\
\hline 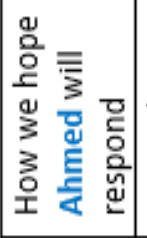 & 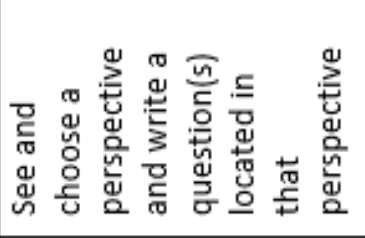 & 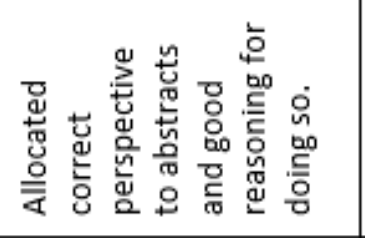 & 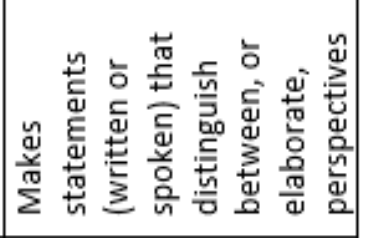 \\
\hline 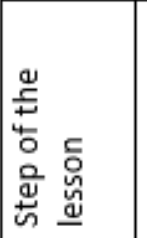 & 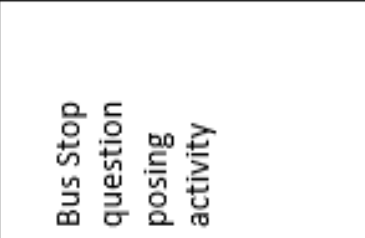 & 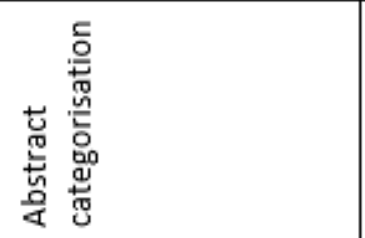 & 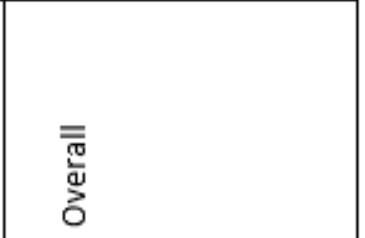 \\
\hline
\end{tabular}


Lesson \# 1 Analysis Record

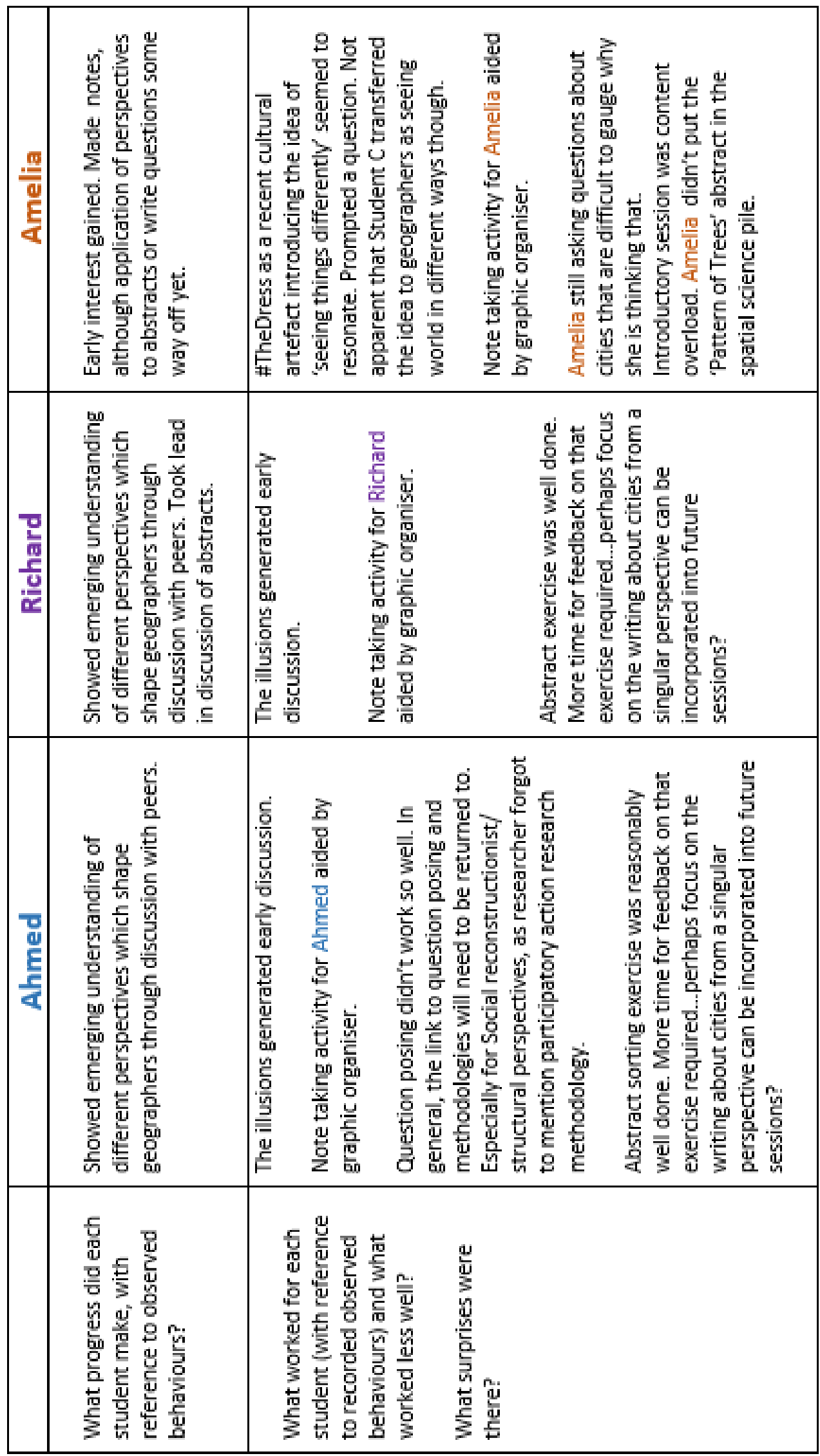


Lesson \#1: Analysis Record continued...

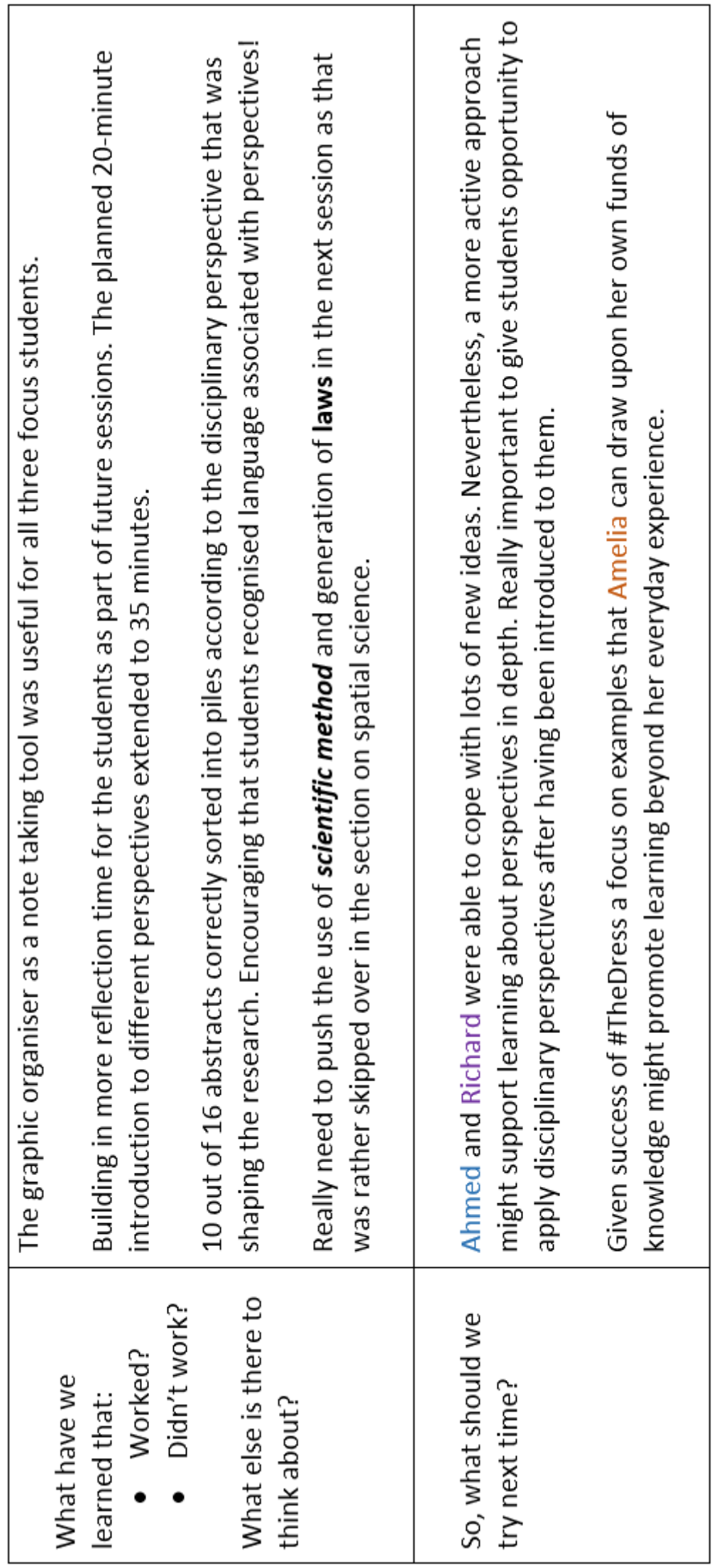




\section{Appendix lii}

Lesson Study \#2 [Observation Key: Red = Michelle; Black = Sasha; Green - Mike]

\begin{tabular}{|c|c|c|c|c|c|}
\hline 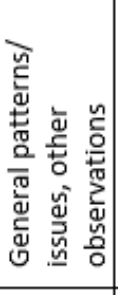 & 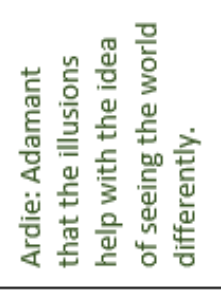 & \multicolumn{2}{|c|}{ 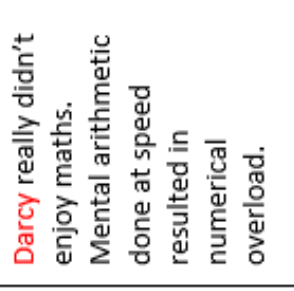 } & \multicolumn{2}{|c|}{ 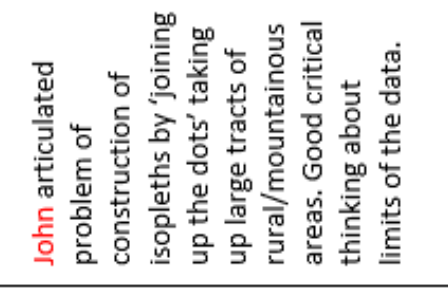 } \\
\hline 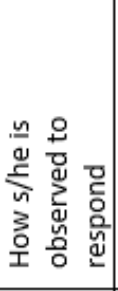 & 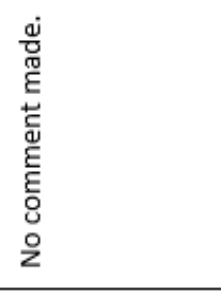 & \multicolumn{4}{|c|}{ 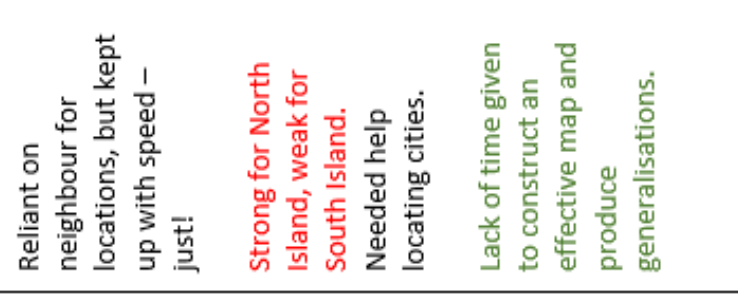 } \\
\hline 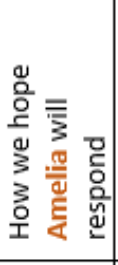 & 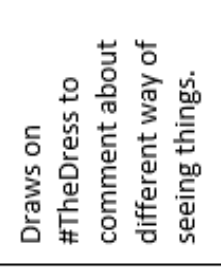 & \multicolumn{4}{|c|}{ 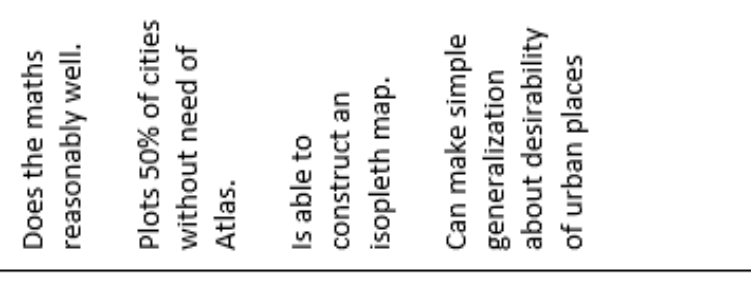 } \\
\hline 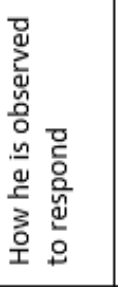 & 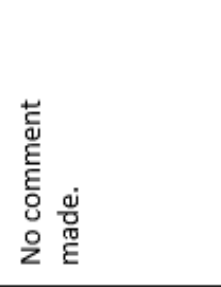 & \multicolumn{4}{|c|}{ 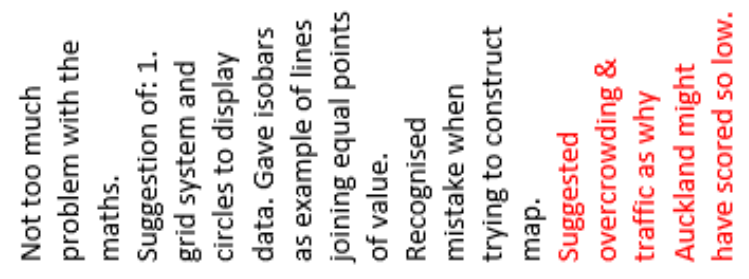 } \\
\hline 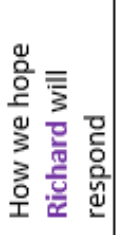 & 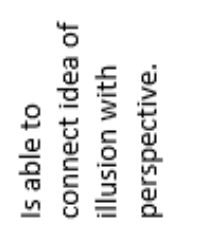 & 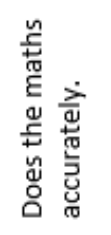 & 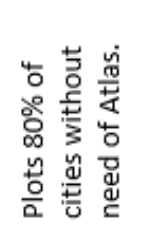 & 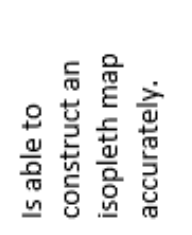 & 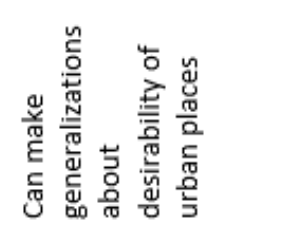 \\
\hline 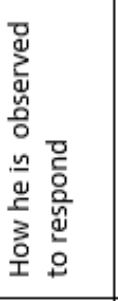 & 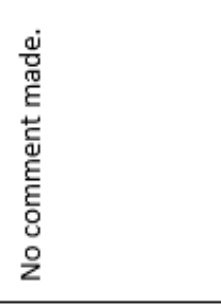 & \multicolumn{3}{|c|}{ 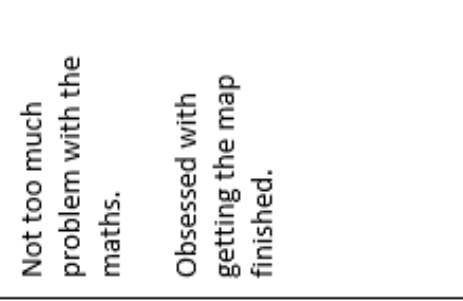 } & 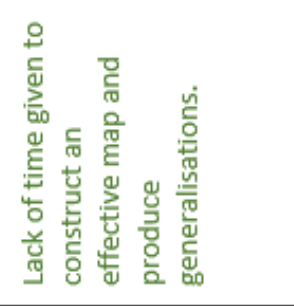 \\
\hline 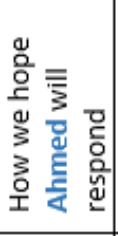 & 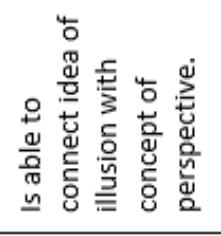 & 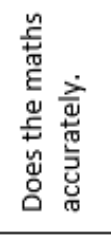 & 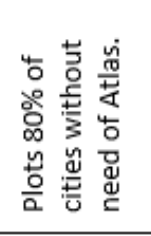 & 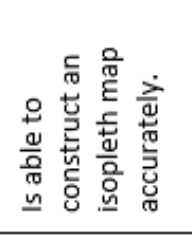 & 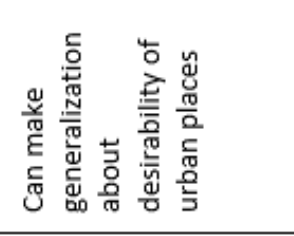 \\
\hline 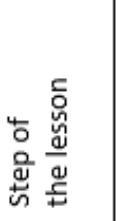 & 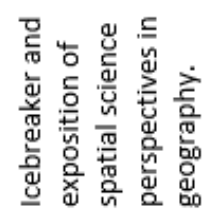 & \multicolumn{4}{|c|}{ 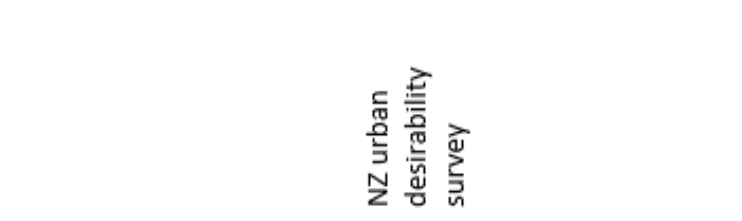 } \\
\hline
\end{tabular}


Lesson Study \#2 Observation and Annotation Sheet continued...

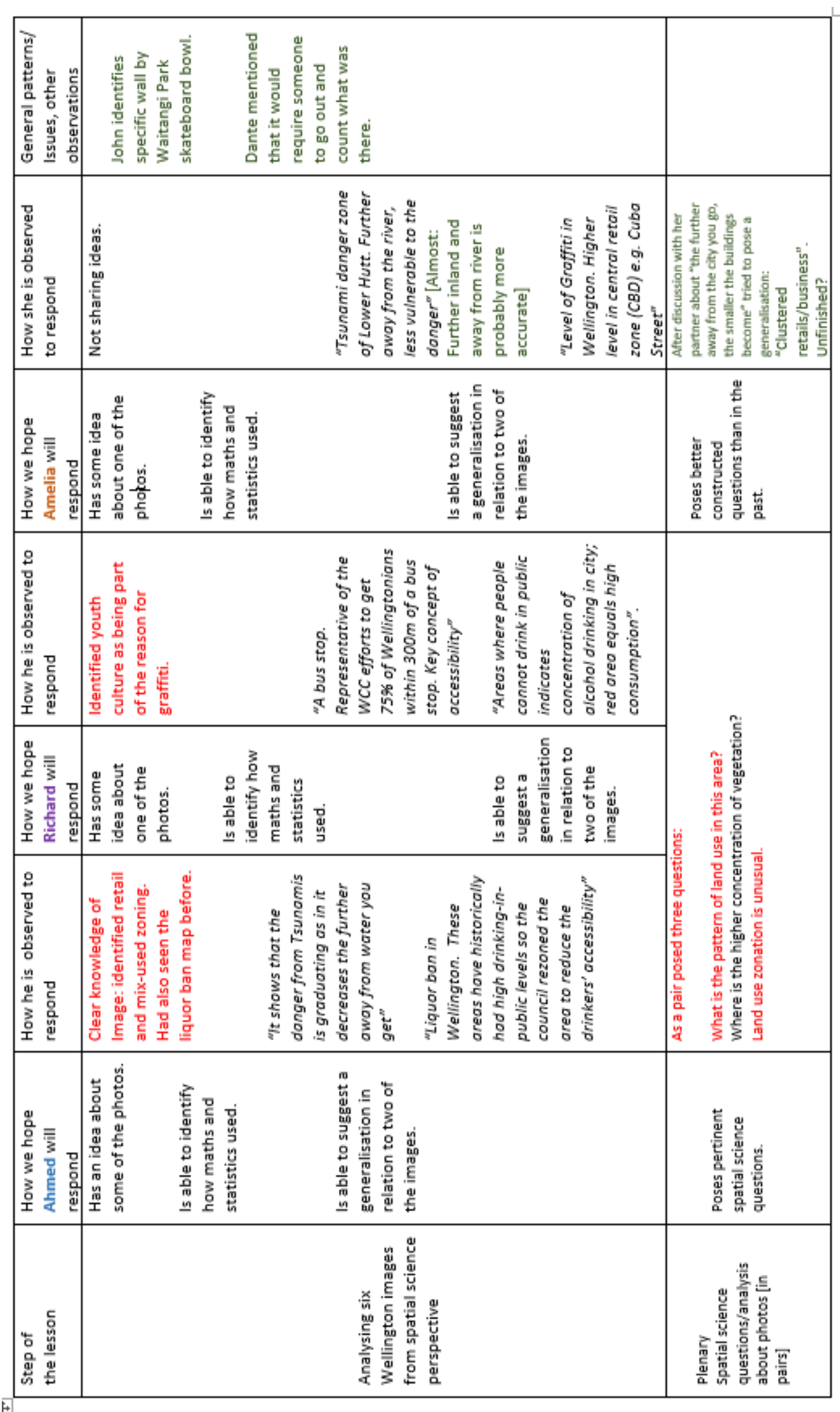


Lesson \# 2 Analysis Record

\begin{tabular}{|c|c|c|c|c|c|}
\hline 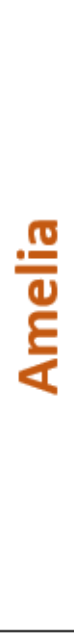 & 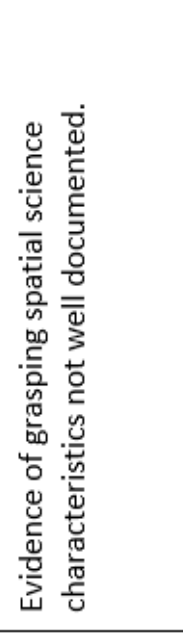 & \multicolumn{2}{|c|}{ 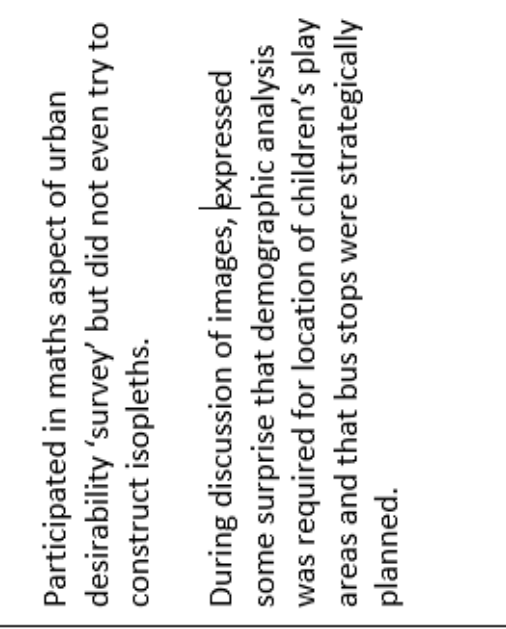 } & \multirow{3}{*}{ 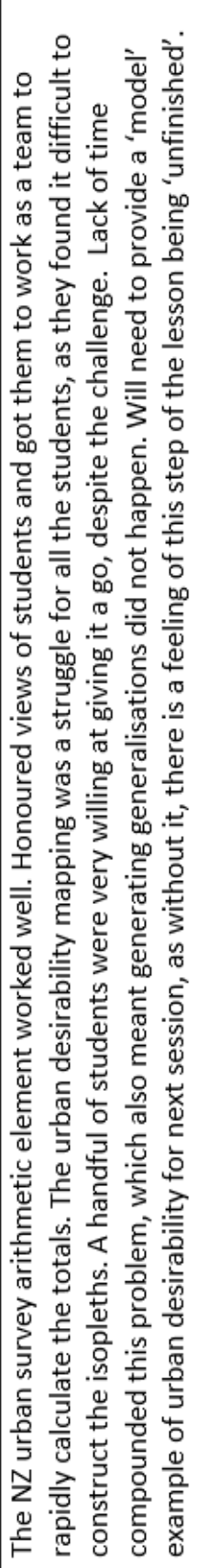 } & \multirow{3}{*}{ 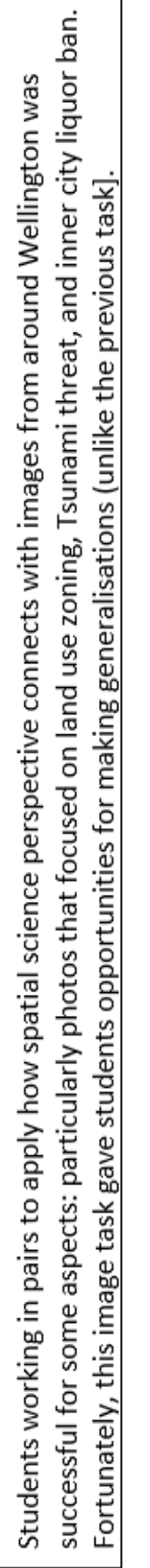 } \\
\hline 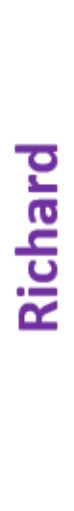 & 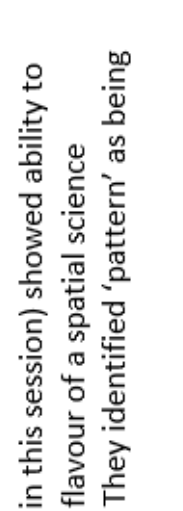 & 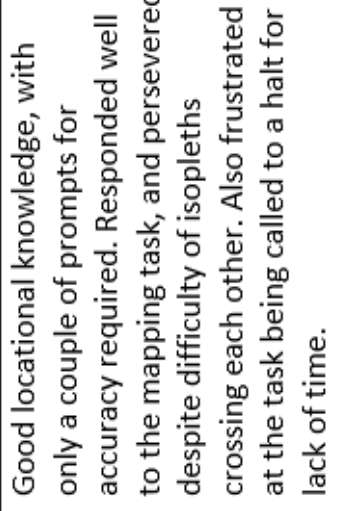 & 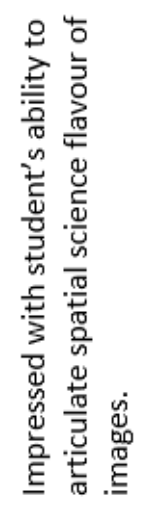 & & \\
\hline & 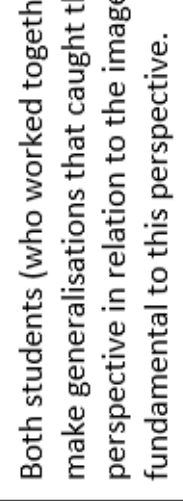 & 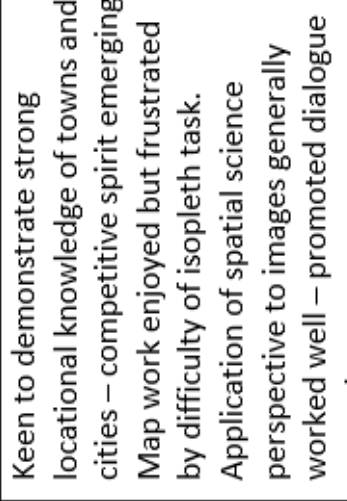 & & & \\
\hline & 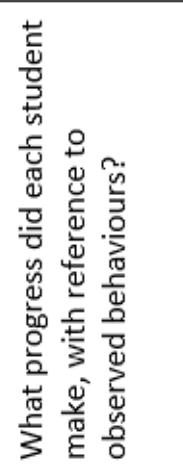 & 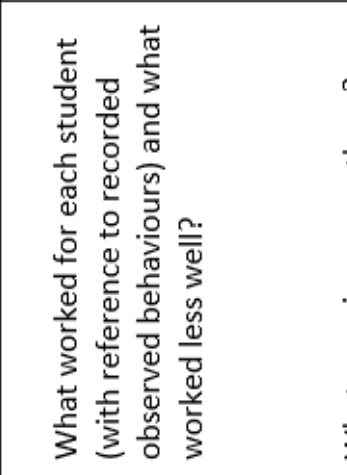 & & 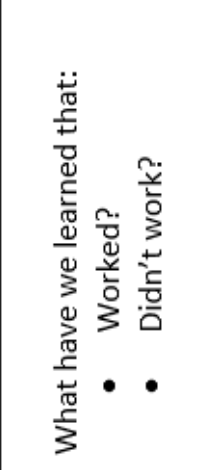 & 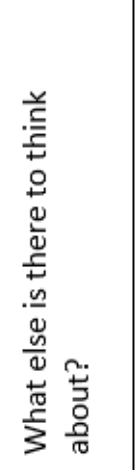 \\
\hline
\end{tabular}




\section{Appendix liii continued}

Lesson Study \#3 [Observation Key: Black = Sasha; Green = Mike]

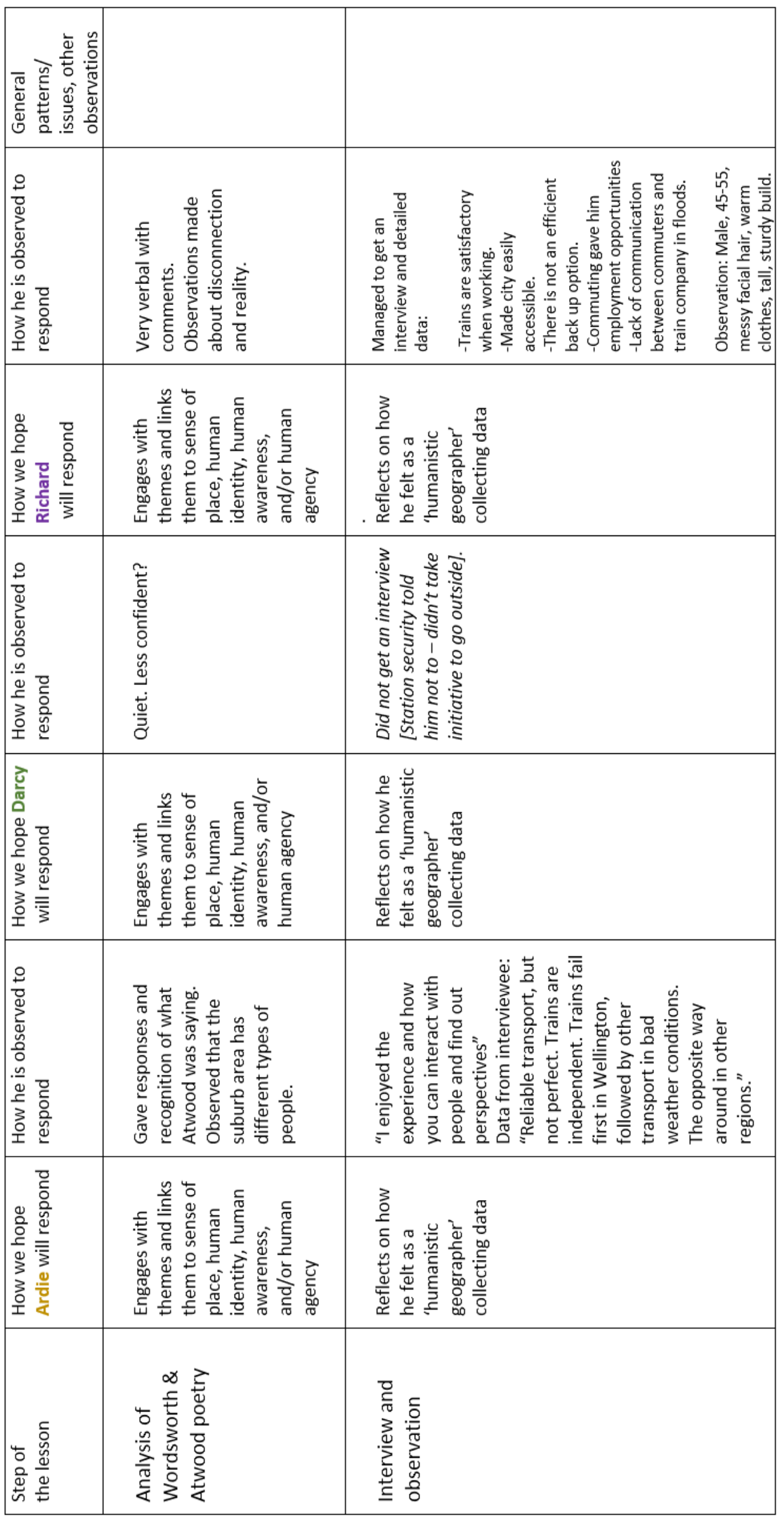


Lesson Study \#3 Observation and Annotation Sheet continued...

\begin{tabular}{|c|c|c|}
\hline 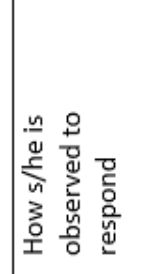 & 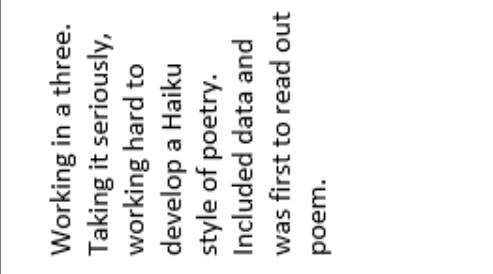 & 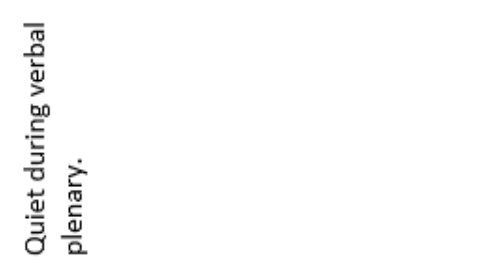 \\
\hline 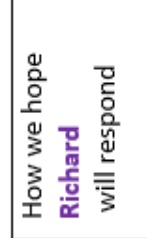 & 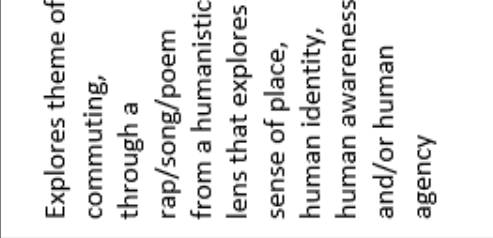 & 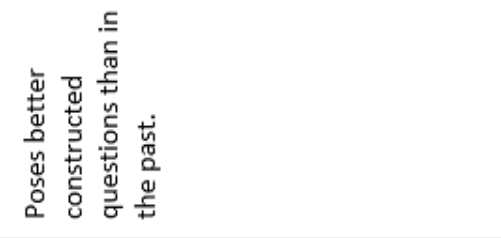 \\
\hline 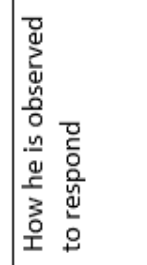 & 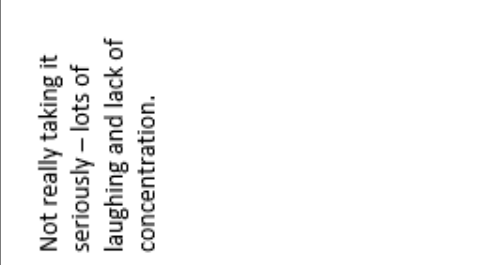 & 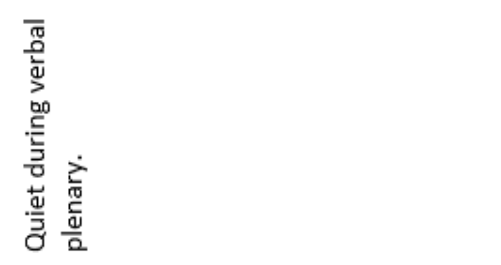 \\
\hline 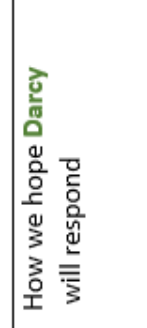 & 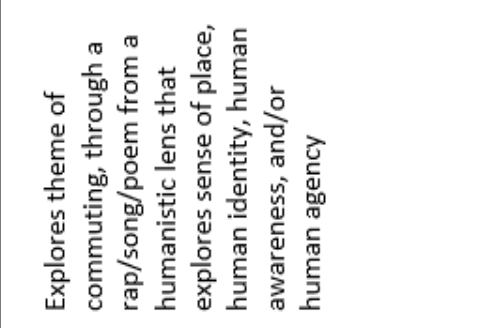 & 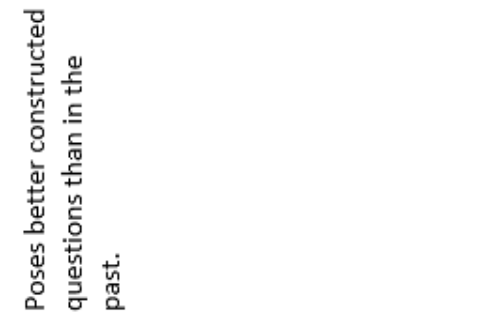 \\
\hline 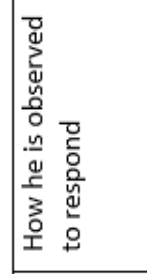 & 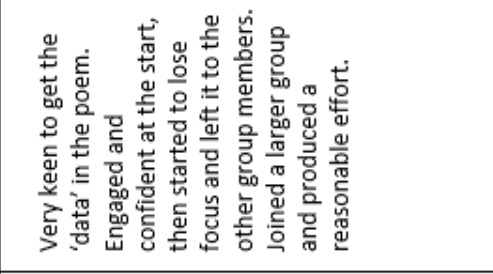 & 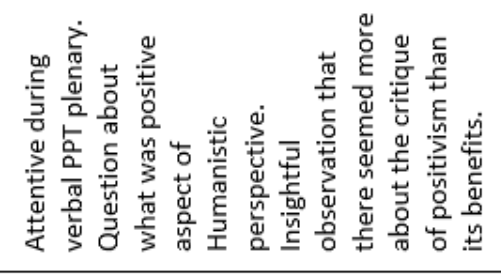 \\
\hline 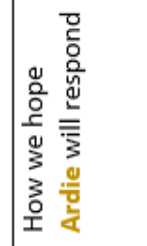 & 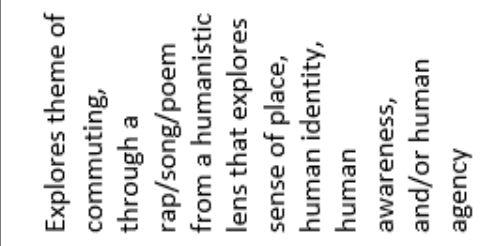 & 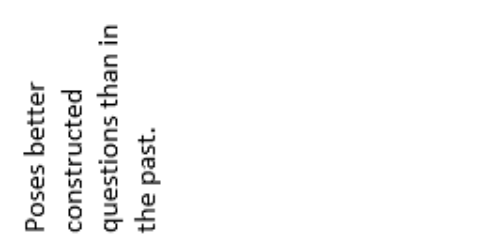 \\
\hline 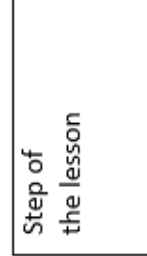 & 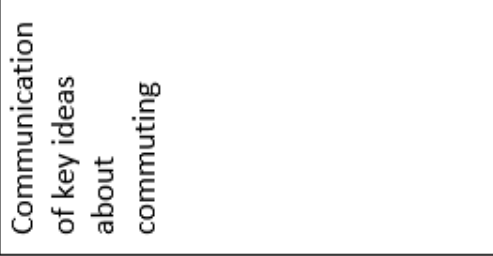 & 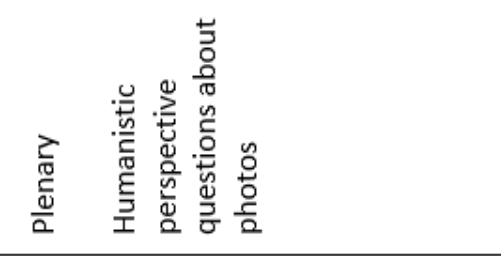 \\
\hline
\end{tabular}


Lesson \#3 Analysis Record

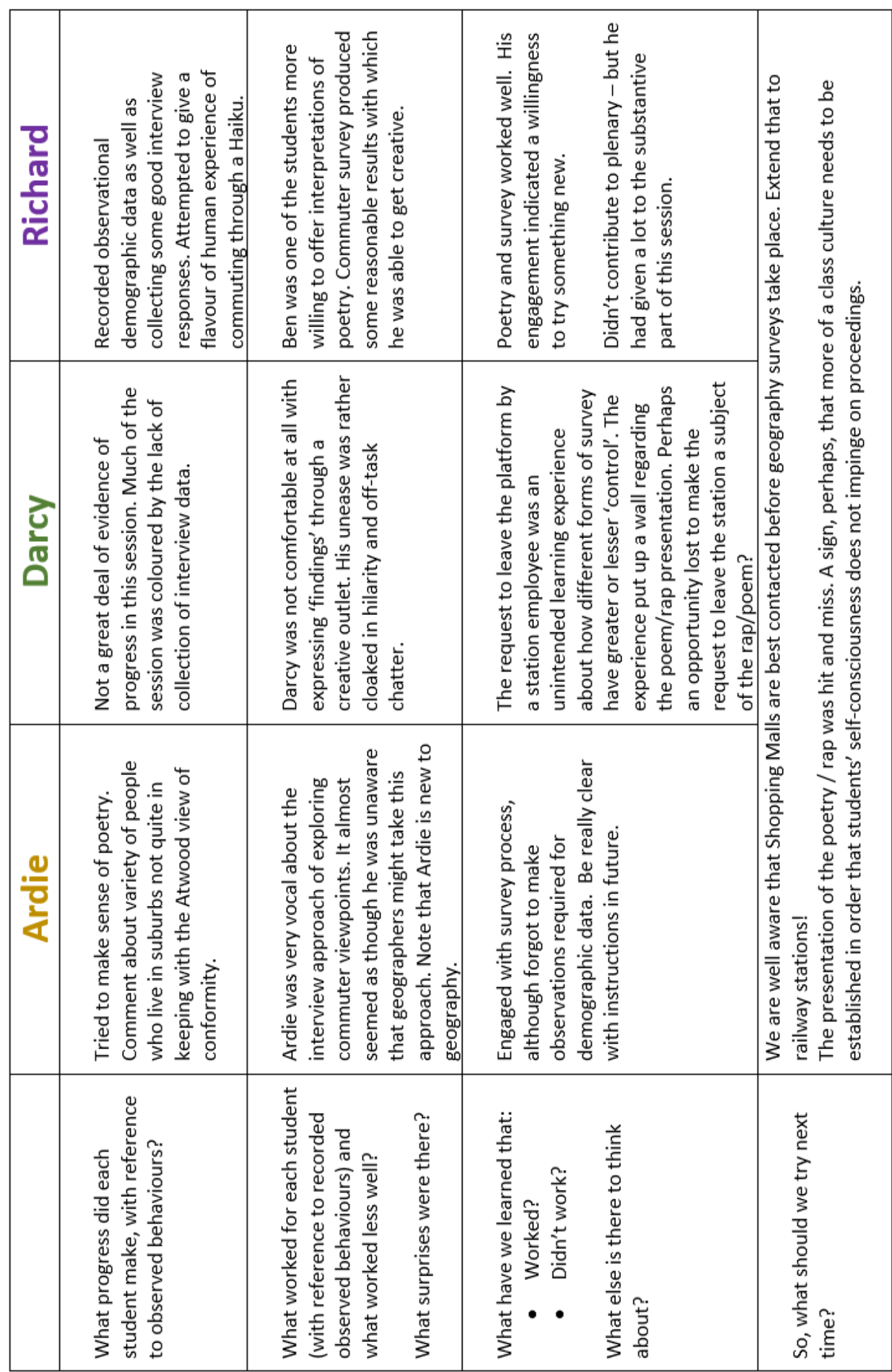




\section{Appendix I iv continued}

Lesson Study \#4 [Observation Key: Red= Michelle; Black = Sasha; Green = Mike]

\begin{tabular}{|c|c|c|c|}
\hline 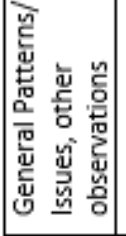 & 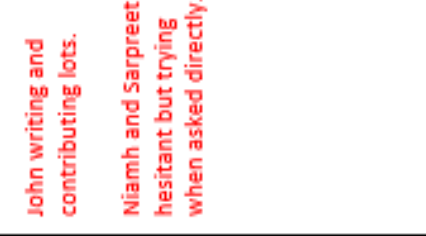 & 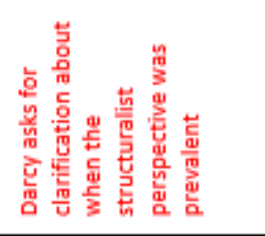 & \\
\hline 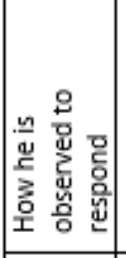 & 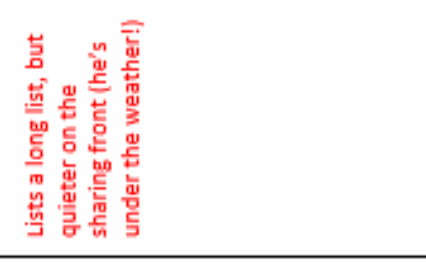 & 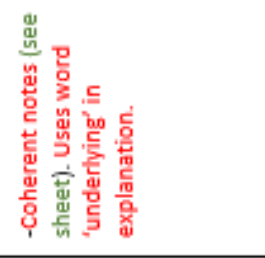 & $\begin{array}{l}\text { 总 } \\
\text { हूँ } \\
\text { हn }\end{array}$ \\
\hline 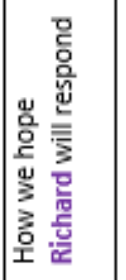 & 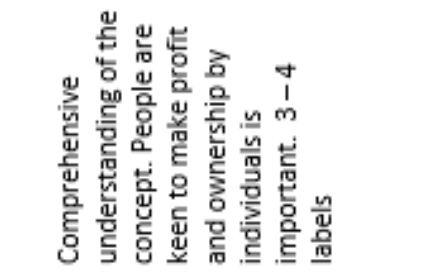 & 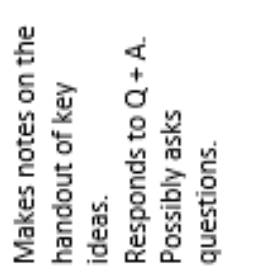 & 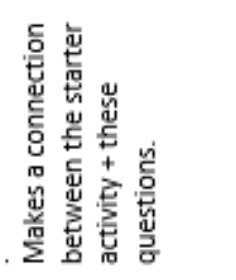 \\
\hline 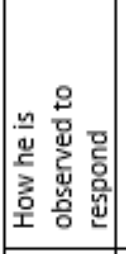 & 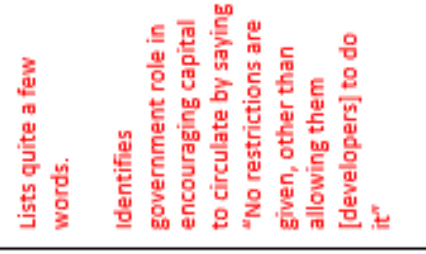 & & 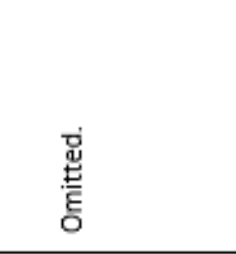 \\
\hline 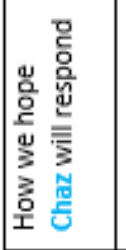 & 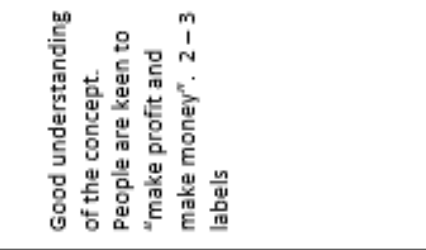 & 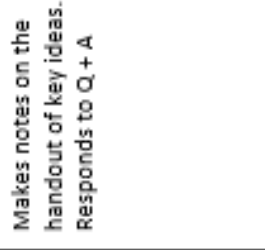 & 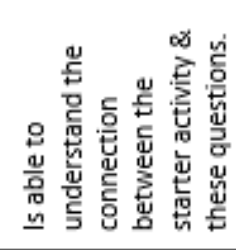 \\
\hline 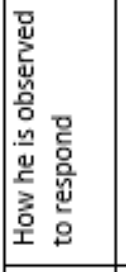 & 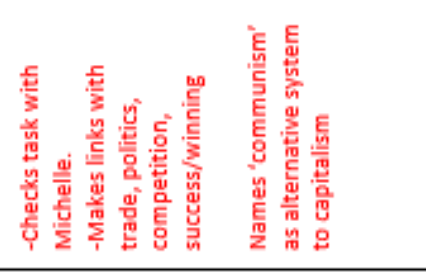 & 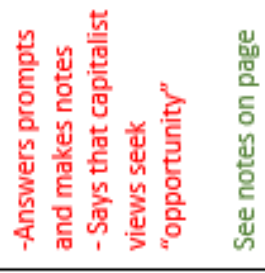 & 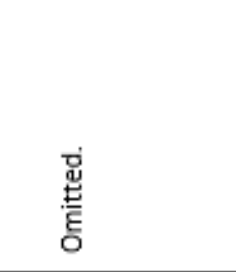 \\
\hline 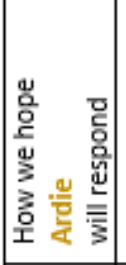 & 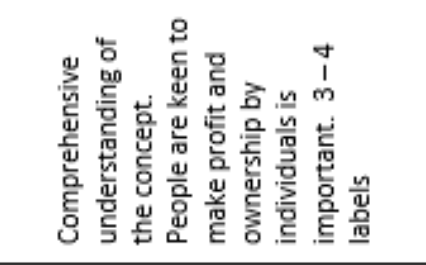 & 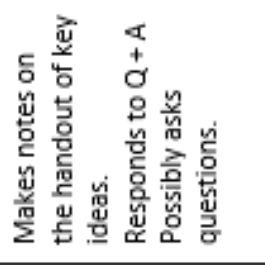 & 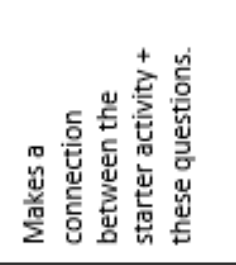 \\
\hline 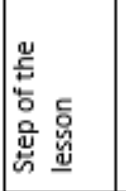 & 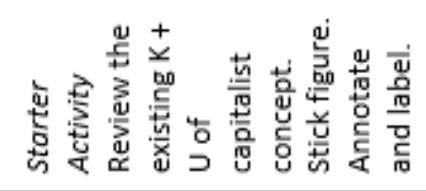 & 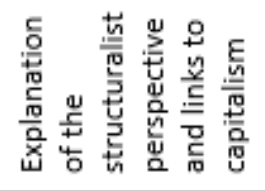 & 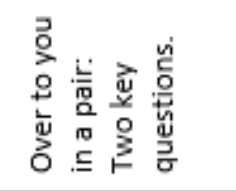 \\
\hline
\end{tabular}


Lesson Study \#4 Observation and Annotation Sheet continued...

\begin{tabular}{|c|c|c|c|c|}
\hline 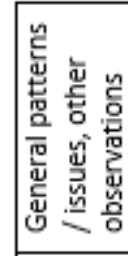 & & 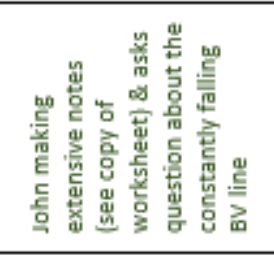 & & \\
\hline 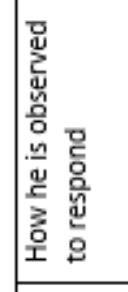 & 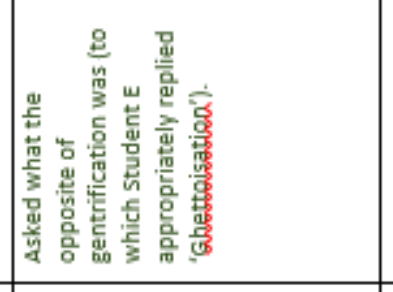 & 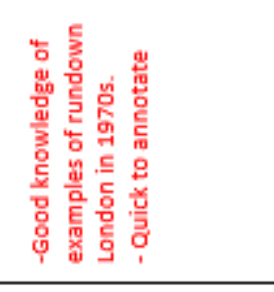 & 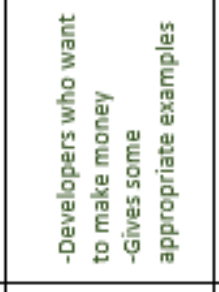 & 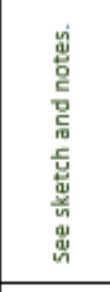 \\
\hline 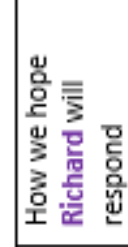 & & 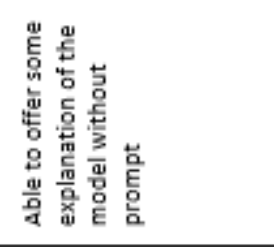 & 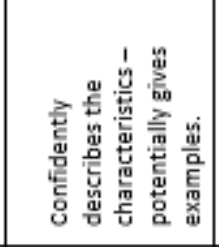 & 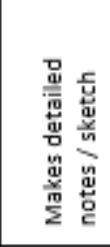 \\
\hline 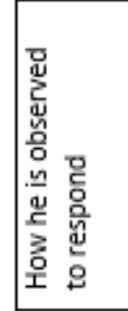 & 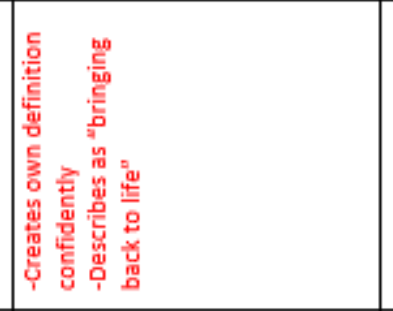 & 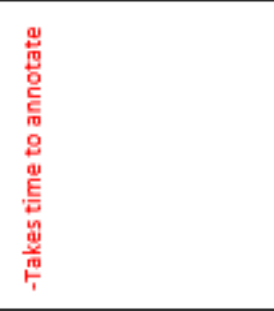 & 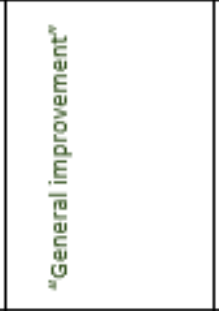 & 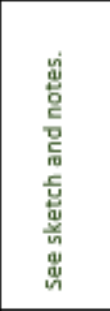 \\
\hline 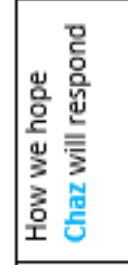 & 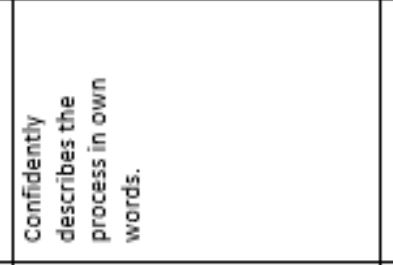 & 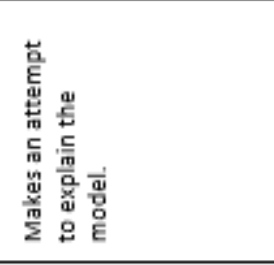 & 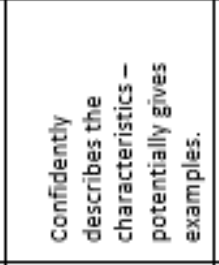 & 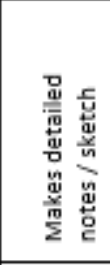 \\
\hline 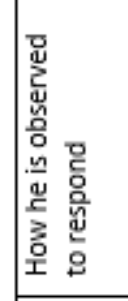 & 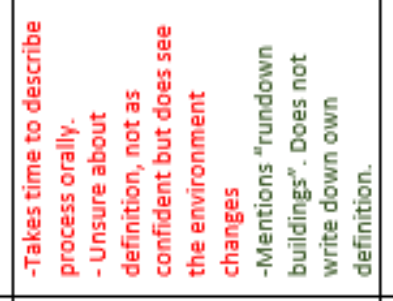 & 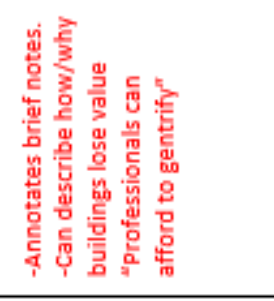 & 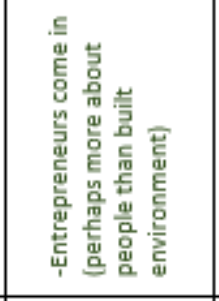 & 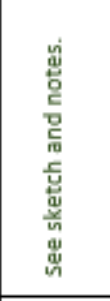 \\
\hline 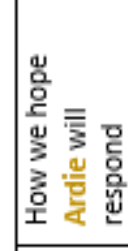 & 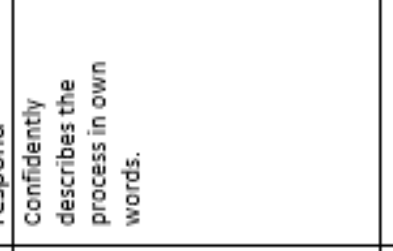 & 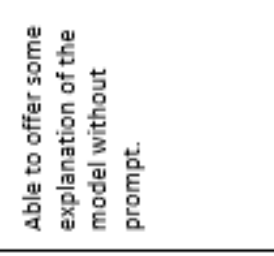 & 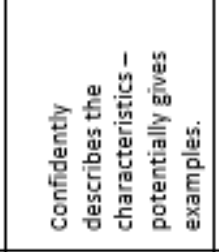 & 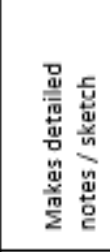 \\
\hline 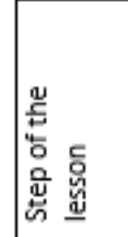 & 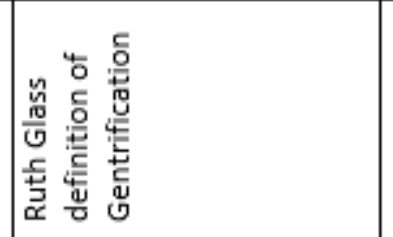 & 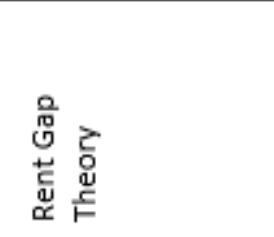 & 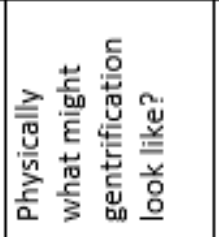 & 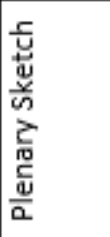 \\
\hline
\end{tabular}



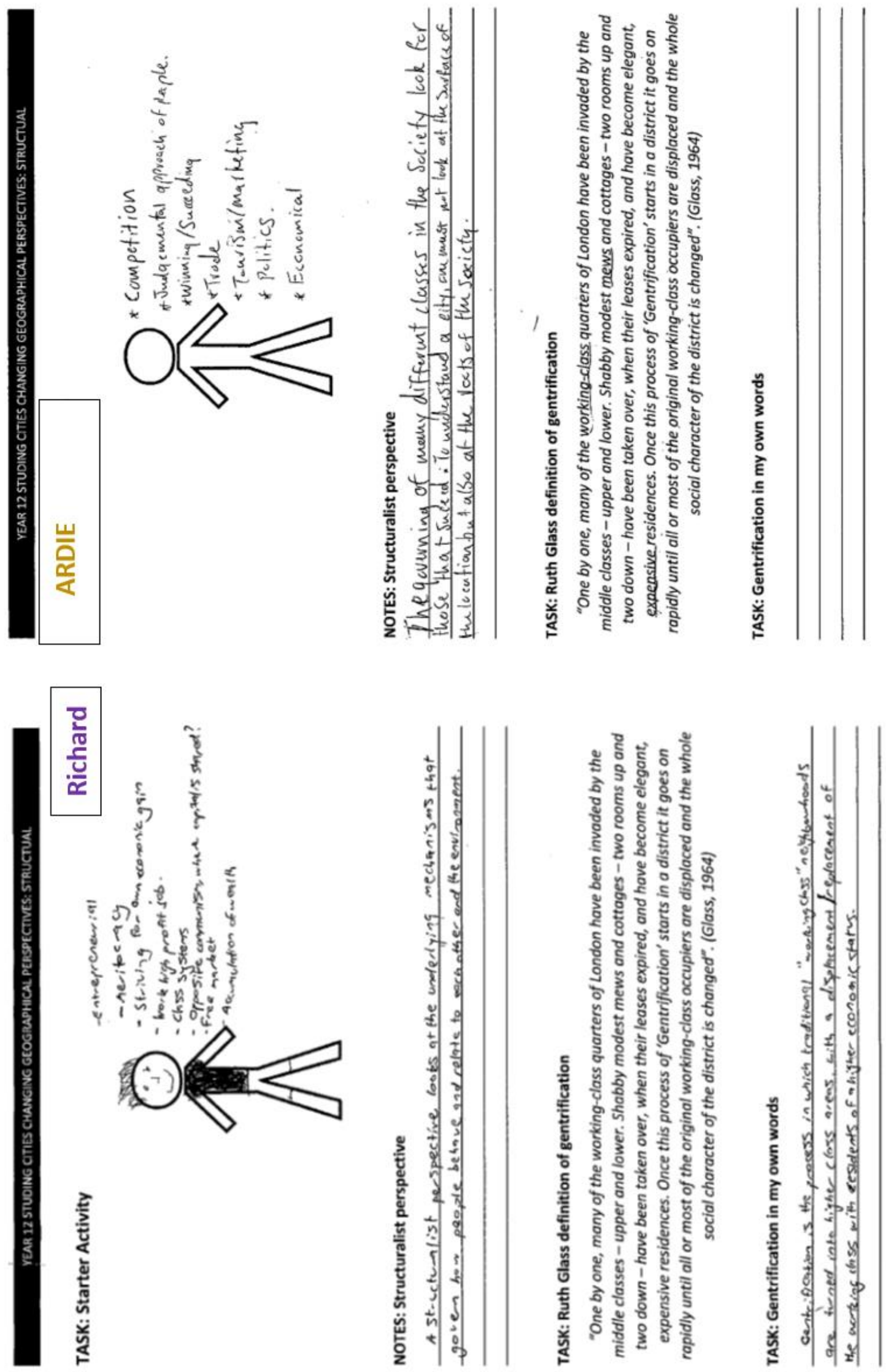
Lesson \#4 Analysis Record

\begin{tabular}{|c|c|c|c|c|c|c|}
\hline$\frac{\overline{0}}{\frac{0}{0}}$ & 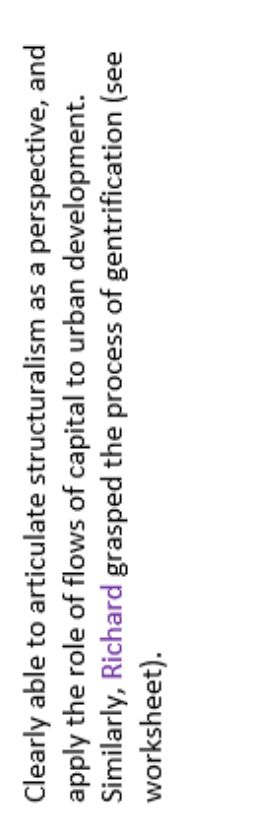 & \multicolumn{2}{|l|}{ 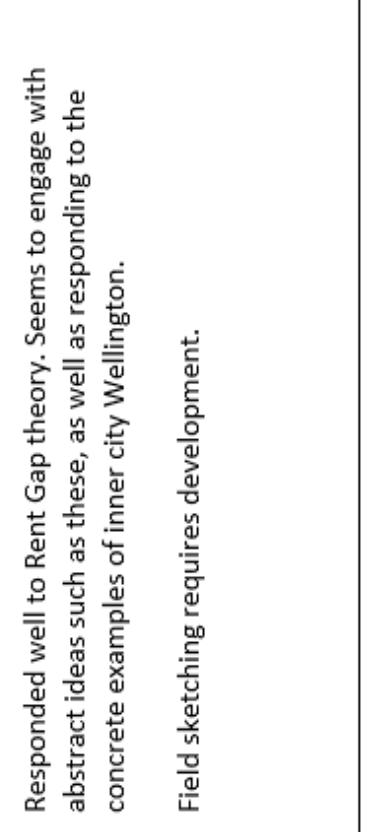 } & \multicolumn{2}{|c|}{ 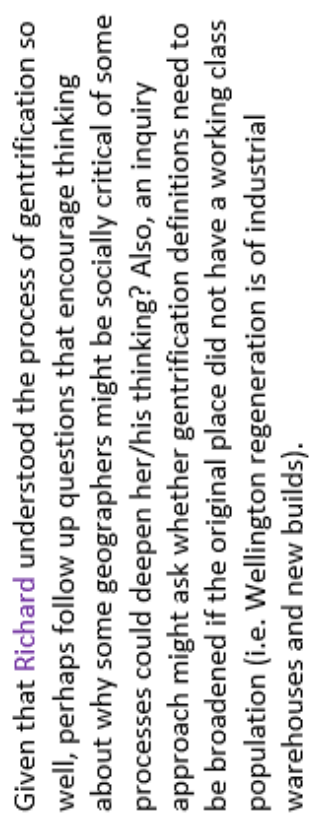 } & \multirow{4}{*}{ 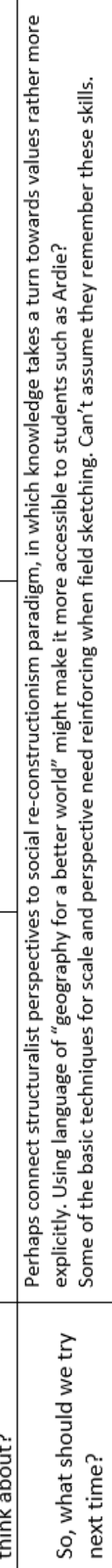 } \\
\hline & 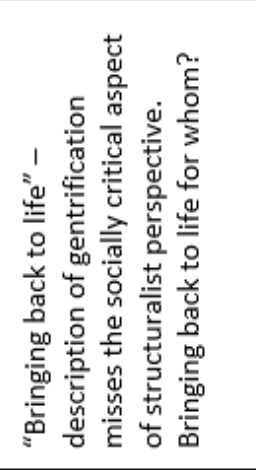 & 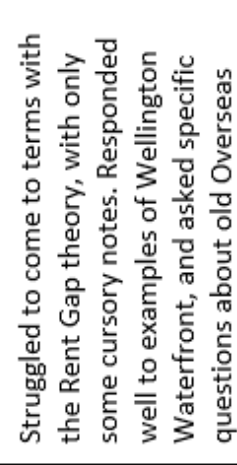 & 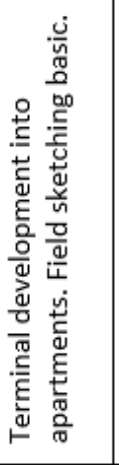 & 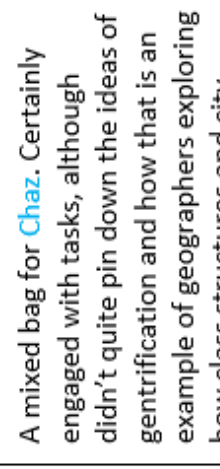 & 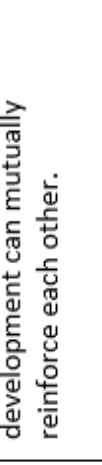 & \\
\hline$\frac{\stackrel{0}{0}}{\frac{0}{4}}$ & 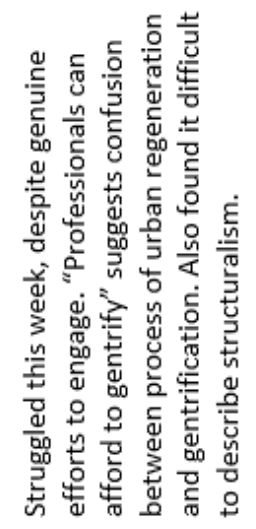 & 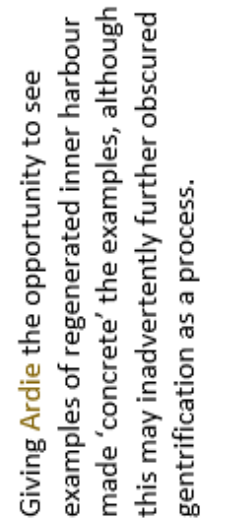 & 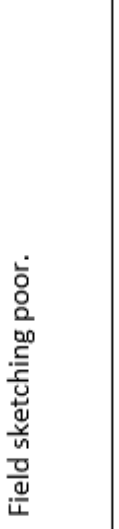 & 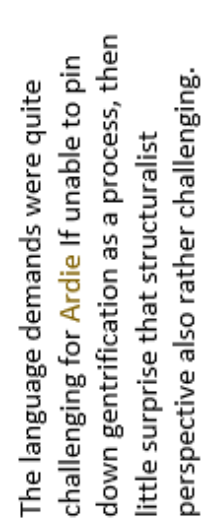 & & \\
\hline & 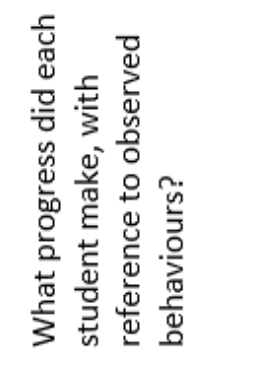 & 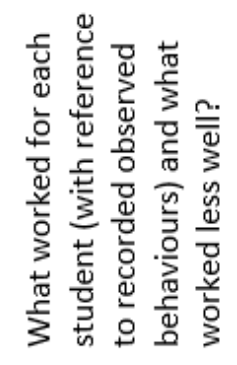 & 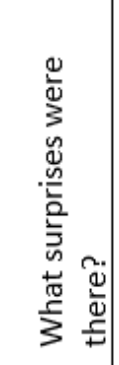 & 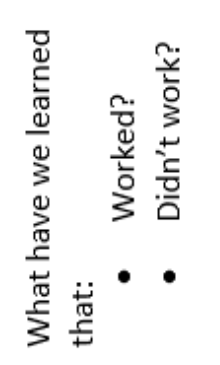 & 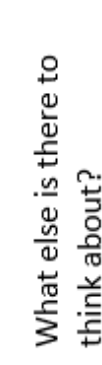 & \\
\hline
\end{tabular}




\section{Appendix IV}

Lesson Study \# 5 [Observation Key: Black - Sasha; Green - Mike]

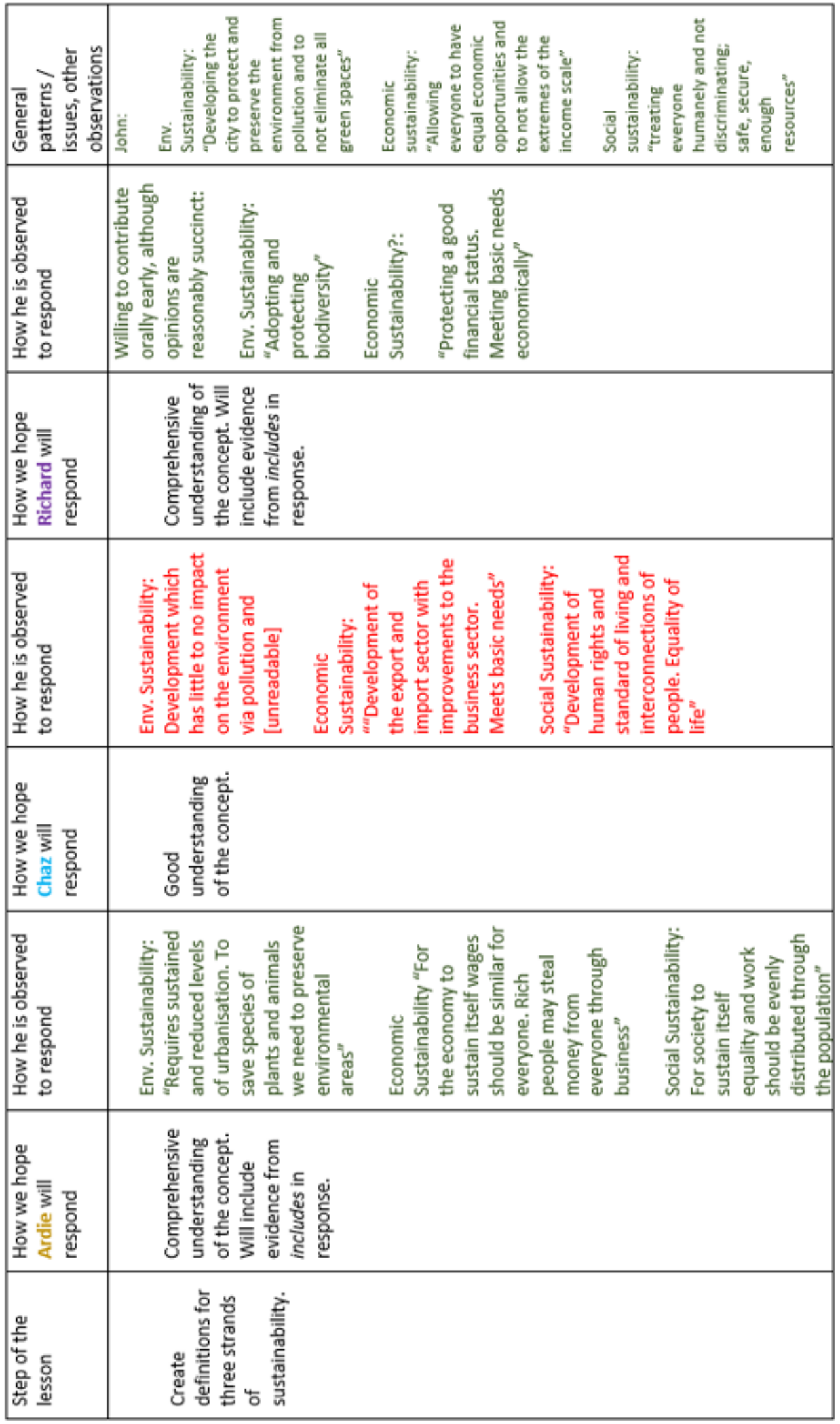


Lesson Study \#5 Observation and Annotation Sheet continued...

\begin{tabular}{|c|c|c|}
\hline 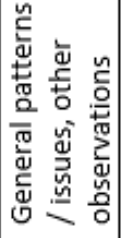 & 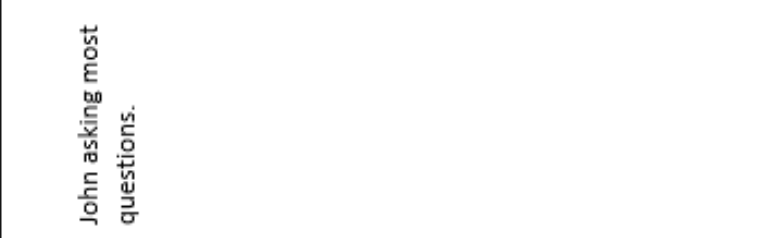 & \multirow{7}{*}{ 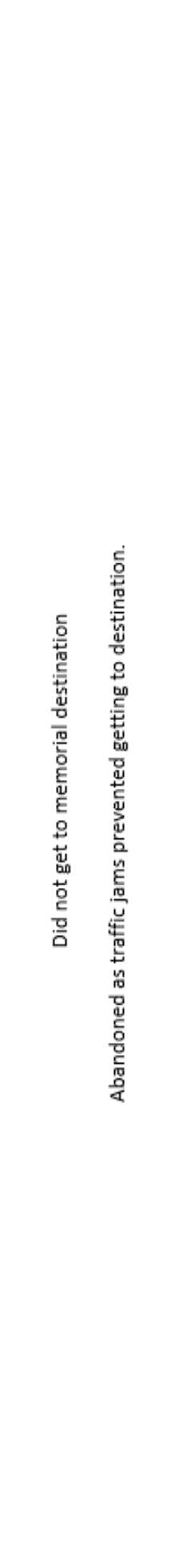 } \\
\hline 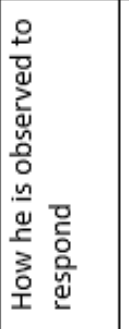 & 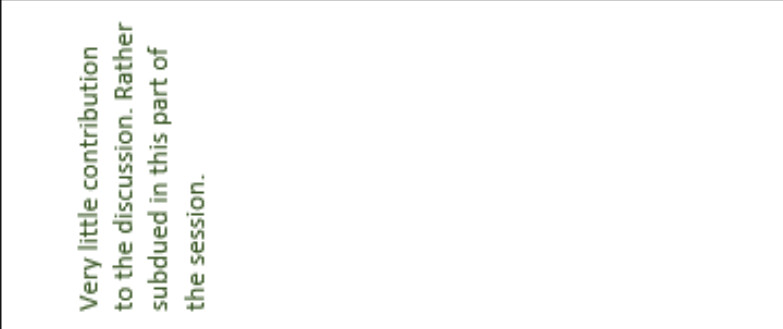 & \\
\hline 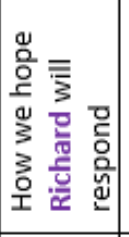 & 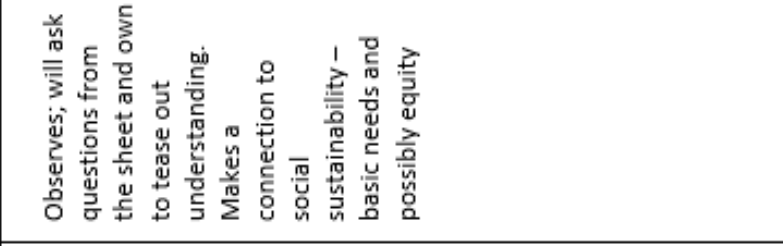 & \\
\hline 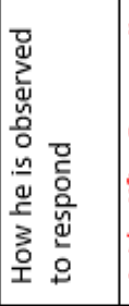 & 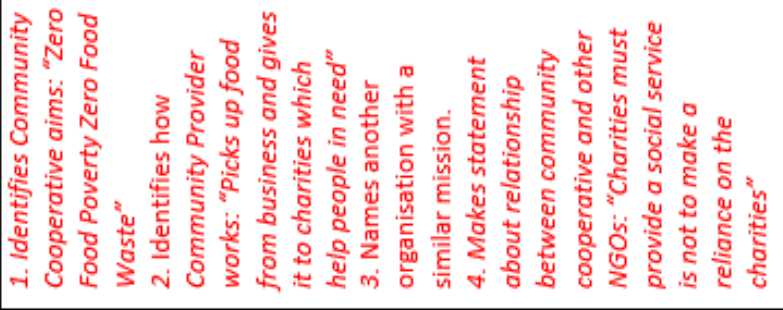 & \\
\hline 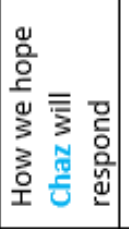 & 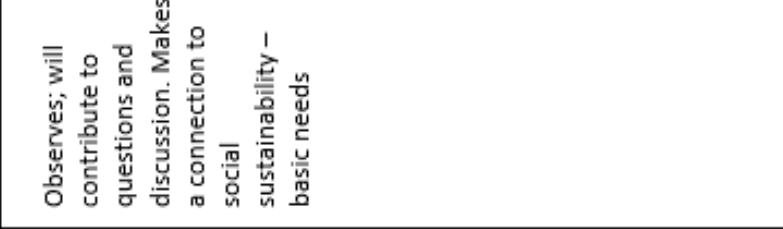 & \\
\hline 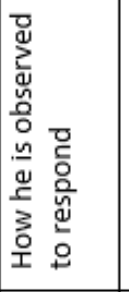 & 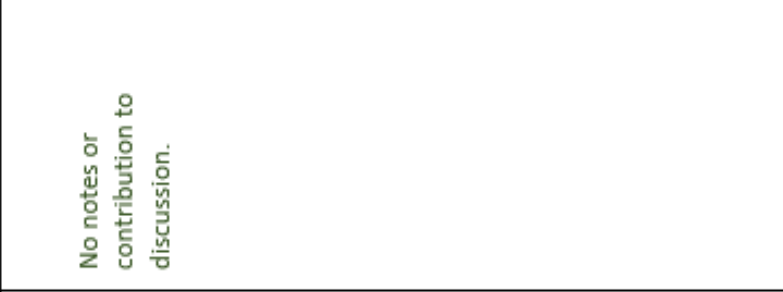 & \\
\hline 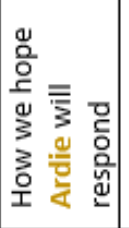 & 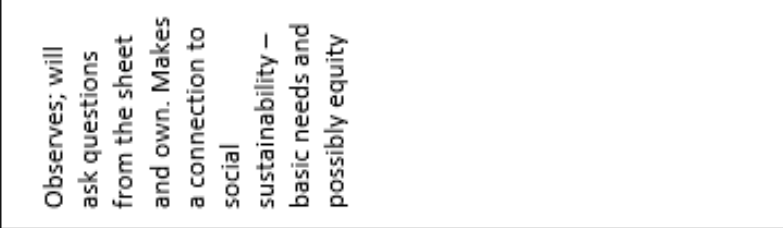 & \\
\hline 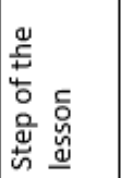 & 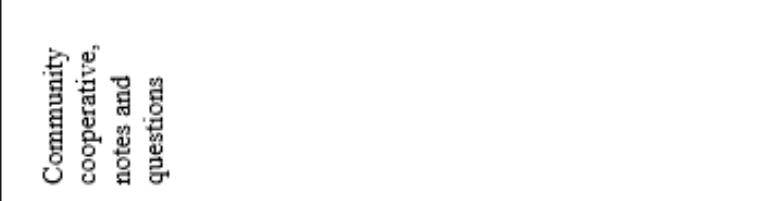 & 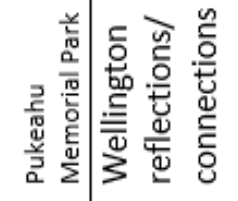 \\
\hline
\end{tabular}


Lesson \#5 Analysis Record

\begin{tabular}{|c|c|c|c|c|c|}
\hline $\begin{array}{l}\frac{0}{0} \\
\frac{0}{0} \\
\frac{0}{\alpha} \\
\end{array}$ & 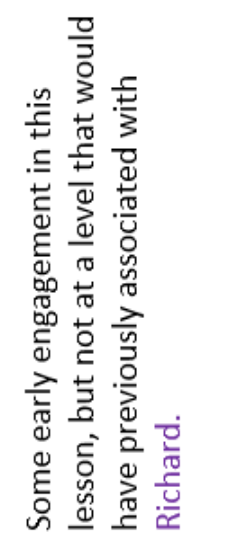 & 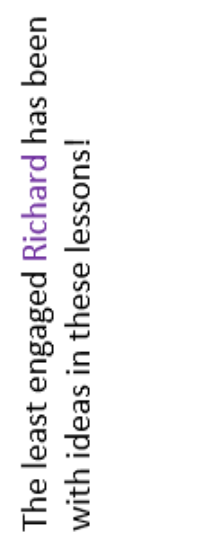 & & \multirow{3}{*}{ 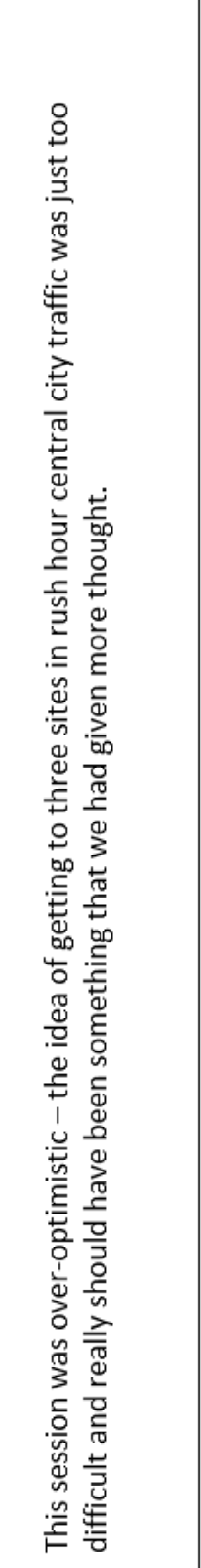 } & \multirow{3}{*}{ 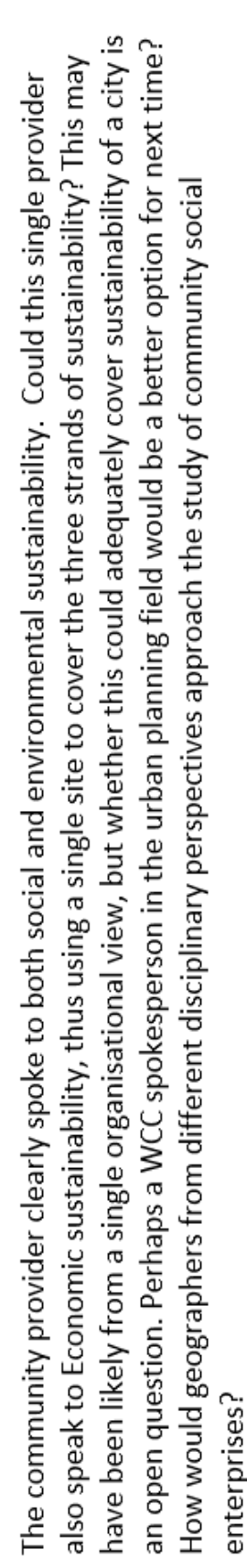 } \\
\hline & 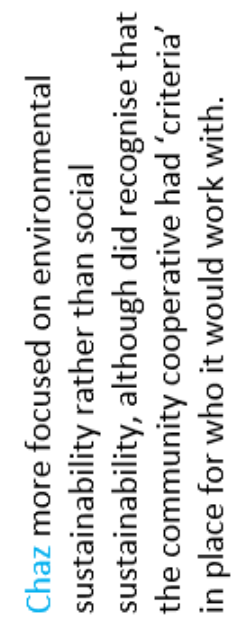 & 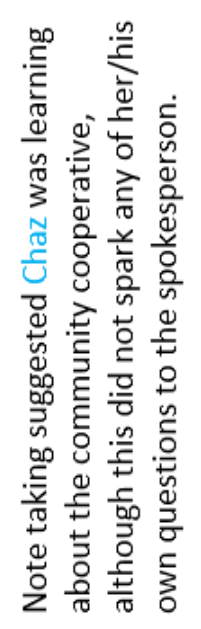 & & & \\
\hline$\frac{\text { 은 }}{\frac{0}{2}}$ & 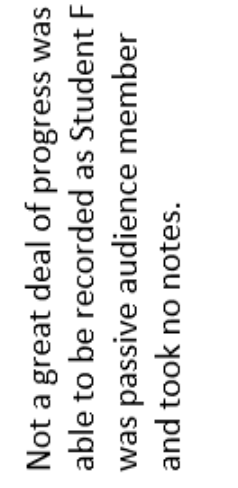 & 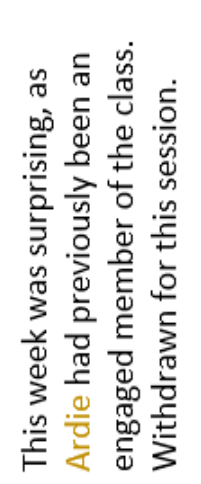 & & & \\
\hline & 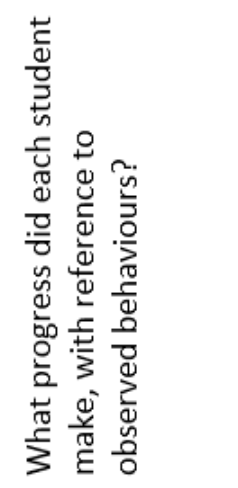 & 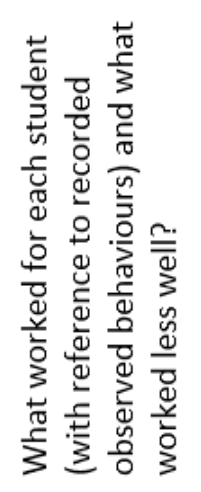 & 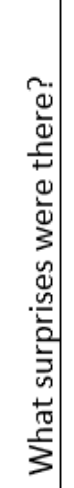 & 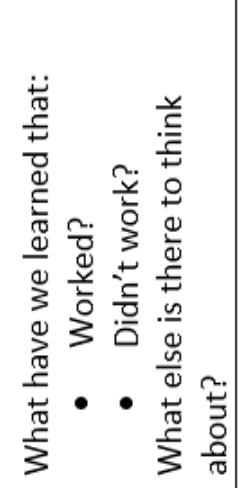 & 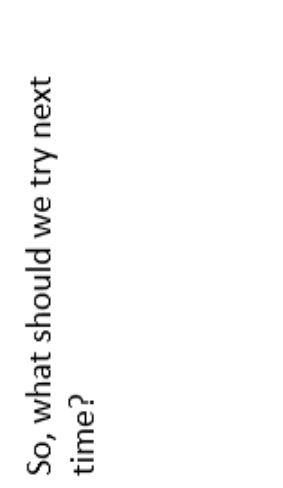 \\
\hline
\end{tabular}




\section{Appendix J: Student Focus Exit Schedule}

\section{Focus Group Exit}

These questions are designed to be asked in focus group discussion(s) approximately 3-4 weeks after the conclusion of the after school extension programme. The focus group meetings will take place on the school site, at a time and place that minimises the chances of disruption.

As an introduction to the focus group, I will thank the students for their contributions to the extension programme, and remind them that this focus group was part of the research that they had agreed to participate to. I will, however, remind the students that they have the freedom to withdraw from the research up until the end of this focus group discussion, without the need to explain why. I will remind the students that the focus group will be digitally recorded, and that I will send them copies of the transcript for them to check that it is a true and accurate record of what they said.

I will remind them that the length of the focus group will be approximately 45 minutes, that the seven broad questions are designed to encourage participation across all members of the focus group, and that my role is largely to facilitate that group participation. Students will also be reminded of the confidential nature of the discussion.

\section{Indicative Schedule}

1. Please comment on your original questions from the tasks we set you before the lessons Which perspectives did they seem to be coming from?

2. What did you enjoy learning about perspectives? What was your key learning?

3. What's hard about learning about perspectives?

4. Please read one of these four texts about the Christchurch rebuild. Annotate the text to identify which geographical perspective the author seems to be coming from.

5. What can you tell me about geography's different disciplinary/theoretical perspectives?

6. What are your thoughts on having three teachers in the room when exploring disciplinary perspectives?

7. At the end of focus group discussion, thank students for their time and wish them well in their future studies.

8. What advice would you give someone about the lesson study process?

9. Is there anything else you would like to comment on about our focus on disciplinary perspectives?

10. What did you think worked or didn't work in our lesson study process?

Thanks etc 


\section{Appendix K: Teacher Exit Interview Schedule \\ Exploring Disciplinary Perspectives in Geography}

The interview will begin with a statement of appreciation for the lesson study collaboration, followed by a reinforcement of what the focus of the interview is about: insights from the teacher about what they have learned from our lesson study collaboration about disciplinary perspectives in geography.

1. In response to prompt card: (below)

How do you relate what we did about perspectives to Firth's idea of geography being a 'multi-paradigmatic discipline'? [Further prompts about perspectives and paradigms if required]

Prompt Card

\section{The nature of Geographical knowledge}

"Geography and Geographers are differentiated from the inside out... Geography is a multi-paradigmatic discipline and geographers work with different concepts of scientific knowledge and its development".

Firth (2011) Making geography visible as an object of study in the secondary school curriculum. Curriculum Journal 22(3), 289-316

2. Are you able to think of other geographic topics in which you could apply disciplinary perspectives to?

3. What worked well for our teaching about perspectives?

4. What do you think could have been improved for our teaching about perspectives?

5. Is there anything our collaboration has sparked off about your own learning of disciplinary perspectives?

6. What advice would you give a new teacher about the concept of perspectives?

7. How do you see perspectives influencing geographical research? 


\section{NCEA Level 2}

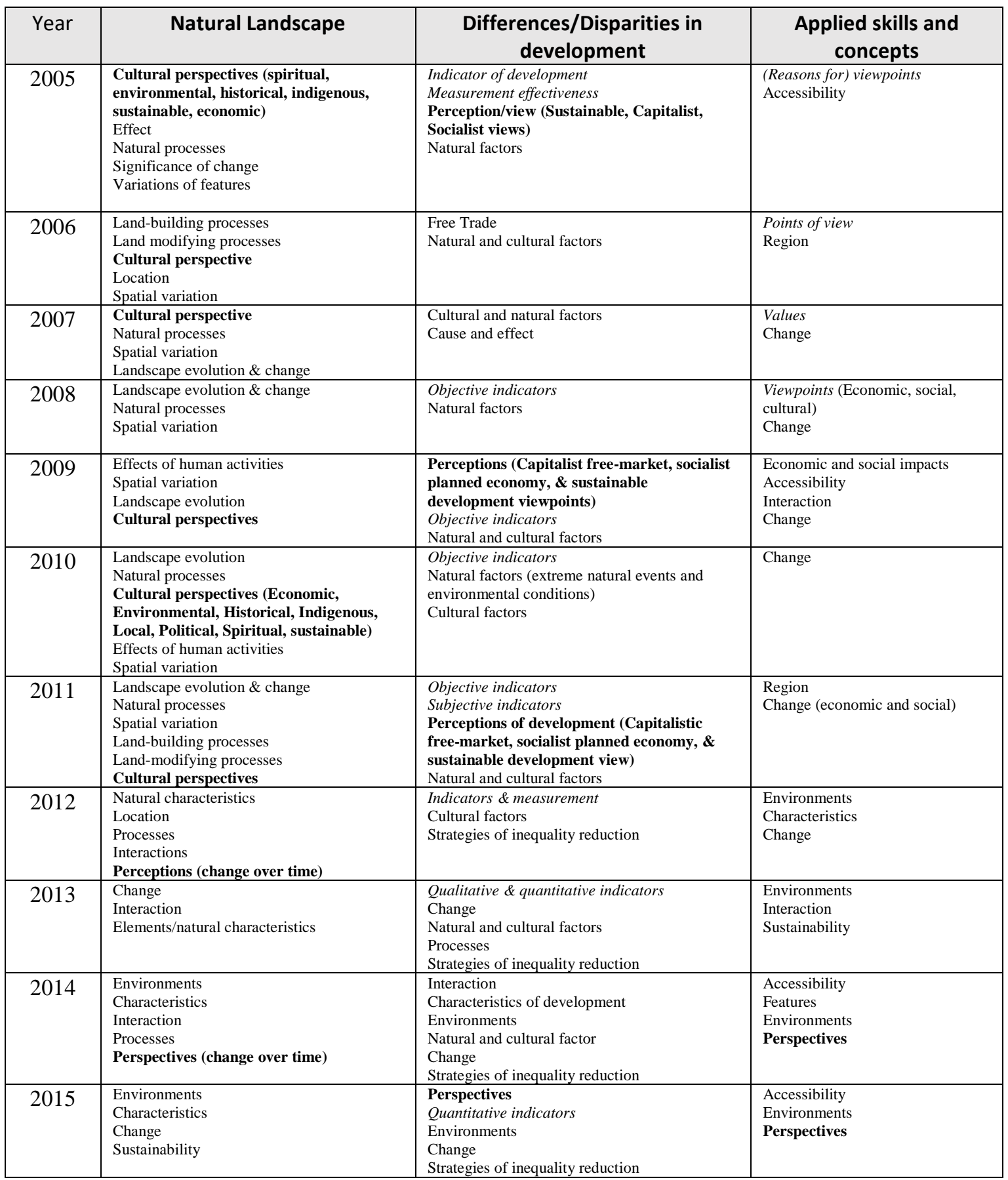

${ }^{25}$ The key concepts are those explicitly highlighted in each exam question (using bold or stated as definitions). Some examination questions require students to focus on a single concept, while others offer a range of concepts from which students may select. 
NCEA Level 3

\begin{tabular}{|c|c|c|c|}
\hline Year & Interacting Natural Processes & Cultural Processes & $\begin{array}{c}\text { Applied skills and } \\
\text { concepts }\end{array}$ \\
\hline 2005 & $\begin{array}{l}\text { Operation of processes } \\
\text { Kaitiakitangi (Stewardship) } \\
\text { Interaction }\end{array}$ & $\begin{array}{l}\text { Change } \\
\text { Operation of processes }\end{array}$ & $\begin{array}{l}\text { Change } \\
\text { Systems }\end{array}$ \\
\hline 2006 & $\begin{array}{l}\text { Temporal variation } \\
\text { Modification of process } \\
\text { Distribution } \\
\text { Formation }\end{array}$ & $\begin{array}{l}\text { Spatial variation } \\
\text { Manaakitanga } \\
\text { Location } \\
\text { Pattern } \\
\text { Operation of process }\end{array}$ & $\begin{array}{l}\text { Patterns } \\
\text { Processes } \\
\text { Regions } \\
\text { Culture \& perception }\end{array}$ \\
\hline 2007 & $\begin{array}{l}\text { Formation } \\
\text { Location } \\
\text { Interaction } \\
\text { Characteristics } \\
\text { Effects } \\
\end{array}$ & $\begin{array}{l}\text { Location } \\
\text { Change } \\
\text { Operation of processes }\end{array}$ & Geographic perspectives \\
\hline 2008 & $\begin{array}{l}\text { (Human) Modification of processes } \\
\text { Formation of features }\end{array}$ & $\begin{array}{l}\text { Spatial variation } \\
\text { Effects of process } \\
\text { Operation of process }\end{array}$ & $\begin{array}{l}\text { People's appraisal } \\
\text { Interaction }\end{array}$ \\
\hline 2009 & $\begin{array}{l}\text { Distribution } \\
\text { Temporal variation } \\
\text { Human modification }\end{array}$ & $\begin{array}{l}\text { Operation of process } \\
\text { Spatial variation } \\
\text { Pattern } \\
\text { Temporal variation }\end{array}$ & Perceptions \\
\hline 2010 & $\begin{array}{l}\text { Location } \\
\text { Formation of feature } \\
\text { Spatial variation } \\
\text { Temporal variation } \\
\end{array}$ & $\begin{array}{l}\text { Change } \\
\text { Spatial variation } \\
\text { Temporal variation }\end{array}$ & Kaitiakitanga \\
\hline 2011 & $\begin{array}{l}\text { Human modification } \\
\text { Outcomes } \\
\text { Formation } \\
\text { Distribution } \\
\text { Features } \\
\end{array}$ & $\begin{array}{l}\text { Effects } \\
\text { Elements/features } \\
\text { Operation of process } \\
\text { Spatial variation }\end{array}$ & $\begin{array}{l}\text { Location } \\
\text { Process } \\
\text { Change }\end{array}$ \\
\hline 2012 & $\begin{array}{l}\text { Location } \\
\text { Human modification } \\
\text { Spatial variation } \\
\end{array}$ & $\begin{array}{l}\text { Operation } \\
\text { Economic factors } \\
\text { Effects }\end{array}$ & $\begin{array}{l}\text { Pattern } \\
\text { Location } \\
\text { Region } \\
\end{array}$ \\
\hline 2013 & $\begin{array}{l}\text { Characteristics } \\
\text { Interaction } \\
\text { Spatial variation } \\
\end{array}$ & $\begin{array}{l}\text { Spatial pattern } \\
\text { Temporal pattern } \\
\text { Operation } \\
\end{array}$ & $\begin{array}{l}\text { Interaction } \\
\text { Change } \\
\text { Sustainability } \\
\end{array}$ \\
\hline 2014 & $\begin{array}{l}\text { Spatial variation } \\
\text { Temporal variation } \\
\text { Interaction }\end{array}$ & $\begin{array}{l}\text { Features } \\
\text { Characteristics } \\
\text { Outcomes } \\
\text { Impacts }\end{array}$ & $\begin{array}{l}\text { Environments } \\
\text { Change } \\
\text { Perspectives }\end{array}$ \\
\hline 2015 & $\begin{array}{l}\text { Scale } \\
\text { Rates } \\
\text { Operation of processes }\end{array}$ & $\begin{array}{l}\text { Elements/features } \\
\text { Characteristics } \\
\text { Temporal variation } \\
\text { Impacts } \\
\text { Operation of process }\end{array}$ & $\begin{array}{l}\text { Interaction } \\
\text { Change } \\
\text { Perspectives } \\
\text { Patterns } \\
\text { Environments }\end{array}$ \\
\hline
\end{tabular}




\begin{tabular}{|c|c|c|c|}
\hline Axial Code & $\begin{array}{c}\text { Codes } \\
\text { (Participants) }\end{array}$ & $\begin{array}{l}\text { Open } \\
\text { coding }\end{array}$ & Exemplar Statements \\
\hline \multirow{10}{*}{$\begin{array}{l}\text { Multiple } \\
\text { purposes }\end{array}$} & $\begin{array}{l}\text { Widening } \\
\text { View } \\
\text { (EW2; TBA1; TBA2; } \\
\text { CA1; CA2; CA3; } \\
\quad \text { PDP1; ITE1) }\end{array}$ & $\begin{array}{l}\text { Understanding } \\
\text { different } \\
\text { perspectives }\end{array}$ & $\begin{array}{l}\text { "Recent research shows that what some call "framing", and some } \\
\text { might think of as "spin" is much more important in understanding } \\
\text { how the thoughts and views of others can influence our thinking, } \\
\text { understanding and actions both individually and collectively"; } \\
\text { "Because an understanding of perspectives enables students to } \\
\text { grasp different ways of seeing the geographic world"; } \\
\text { "Being able to understand that the world is not just seen through } \\
\text { one lens is vital to geographic study"; }\end{array}$ \\
\hline & \multirow[t]{4}{*}{$\begin{array}{l}\text { Critical } \\
\text { Thinking } \\
\text { (CA1; CA 3; CA4; } \\
\text { EW2; PDP1; ITE2) }\end{array}$} & Critically & $\begin{array}{l}\text { "Without students being introduced to a range of perspectives } \\
\text { during their studies they may not be challenged to think differently, } \\
\text { critically or beyond the cultural lens into which they were } \\
\text { born/acculturated"; "I would see the progression linked to } \\
\text { increasing levels of critical thinking, with students considering the } \\
\text { impacts of wider political, social, economic, cultural, technological, } \\
\text { scientific, environmental, feminist etc. forces..."; "A key part of } \\
\text { critical thinking is the ability to look at multiple viewpoints and } \\
\text { why those view are held." "If we do not awaken our students to } \\
\text { these perspectives then it is likely we will create young citizens less } \\
\text { likely to challenge and question what is happening within } \\
\text { communities, our urban areas and to our planet because of the } \\
\text { decisions that have been made. A good geographic education } \\
\text { should develop the critical thinking skills of our young people - to } \\
\text { be the critical conscience of our nation!" }\end{array}$ \\
\hline & & $\begin{array}{l}\text { Critical } \\
\text { theory }\end{array}$ & $\begin{array}{l}\text { "I see critical thinking not just as advantages and disadvantages, but } \\
\text { as critical theory. What larger social, political, cultural, gender, } \\
\text { environmental etc. forces are operating to impact on decision } \\
\text { making about socio-geographic issues?" }\end{array}$ \\
\hline & & Weighting & $\begin{array}{l}\text { "understanding weighting of different perspectives in different } \\
\text { societies and cultures" }\end{array}$ \\
\hline & & Analyse & $\begin{array}{l}\text { "At Y13 they should be more ready to analyse the perspectives seen } \\
\text { within readings, documentaries or when speakers come in"; }\end{array}$ \\
\hline & \multirow[t]{3}{*}{$\begin{array}{l}\text { Personal } \\
\text { positionality } \\
(\mathrm{EW} 2 ; \mathrm{CA} 3 ; \mathrm{CA} 4 ;)\end{array}$} & Own position & $\begin{array}{l}\text { "Being able to identify the position of others helps us to understand } \\
\text { and continually redefine our own position"; "A capable Y13 } \\
\text { student should be able to understand the perspective through which } \\
\text { they view the world..."; }\end{array}$ \\
\hline & & $\begin{array}{l}\text { Conflict with } \\
\text { home }\end{array}$ & $\begin{array}{l}\text { "...our students may find themselves in conflict with ethics or } \\
\text { perspectives of their homes, churches or peer groups. While } \\
\text { consciousness raising we also need to be teaching how to listen, be } \\
\text { open to the perspectives of others, to accept diversity..." }\end{array}$ \\
\hline & & $\begin{array}{l}\text { Live with } \\
\text { perspectives }\end{array}$ & $\begin{array}{l}\text { "Students live with perspectives and studying them creates a greater } \\
\text { awareness of them, maybe even greater tolerance of them." }\end{array}$ \\
\hline & \multirow[t]{2}{*}{$\begin{array}{l}\text { Active } \\
\text { Citizenship } \\
\text { (CA4; PDP1; TBA1;) }\end{array}$} & $\begin{array}{l}\text { Decision } \\
\text { making and } \\
\text { solving }\end{array}$ & $\begin{array}{l}\text { "Very important for Geographers who are involved in decision } \\
\text { making and planning processes to be aware of different } \\
\text { perspectives and their own without negating either their own or } \\
\text { others understandings"; } \\
\text { "Understanding different perspectives will help students solve some } \\
\text { of the world's biggest issues" }\end{array}$ \\
\hline & & $\begin{array}{l}\text { Debating } \\
\text { skills }\end{array}$ & $\begin{array}{l}\text { "work with a class on building their interactive discussion skills so } \\
\text { that they are ready to listen \& debate hard issues" }\end{array}$ \\
\hline
\end{tabular}




\begin{tabular}{|c|c|c|c|}
\hline Axial Code & $\begin{array}{c}\text { Codes } \\
\text { (Participants) }\end{array}$ & $\begin{array}{l}\text { Open } \\
\text { coding }\end{array}$ & Exemplar Statements \\
\hline \multirow{11}{*}{$\begin{array}{l}\text { Framing of } \\
\text { perspectives }\end{array}$} & \multirow{4}{*}{$\begin{array}{l}\text { Stakeholder } \\
\text { orientation } \\
\text { (TBA1; TBA2; } \\
\text { CA1; CA2; CA3; } \\
\text { CA4; PDP1; } \\
\text { PDP2; EW1; } \\
\text { ITE1; ITE2) }\end{array}$} & $\begin{array}{l}\text { Growing } \\
\text { diversity }\end{array}$ & $\begin{array}{l}\text { "....as our country has a growing number of different } \\
\text { nationalities/ethnicities coming to live in New Zealand and } \\
\text { interacting with New Zealand in a number of different ways, } \\
\text { students need to understand the different perspectives that these } \\
\text { different groups might take towards a range of different issues." }\end{array}$ \\
\hline & & $\begin{array}{l}\text { Peoples' } \\
\text { perceptions }\end{array}$ & $\begin{array}{l}\text { "Of course, how people have perceived and used the } \\
\text { environments in which they live lends itself to perspectives } \\
\text { learning"; } \\
\text { "How to consider different perspectives when making decisions } \\
\text { and to understand reasons for people's perspectives e.g. cultural } \\
\text { influences."; "Students need to understand what and why people } \\
\text { have different perspectives..." }\end{array}$ \\
\hline & & $\begin{array}{l}\text { Particular } \\
\text { context }\end{array}$ & $\begin{array}{l}\text { "Main starting point for an area of study is the particular context } \\
\text { usually, and stakeholders are important for this. This allows } \\
\text { better grounding for students in what they know about/are } \\
\text { familiar with." }\end{array}$ \\
\hline & & Organisations & $\begin{array}{l}\text { "Talk to the local government a lot!"; “...modern day } \\
\text { perspectives to focus on real organisations" }\end{array}$ \\
\hline & \multirow{3}{*}{$\begin{array}{l}\text { Relationship } \\
\text { to viewpoints } \\
\text { and values } \\
\text { (TBA2; CA1; } \\
\text { CA2; PDP2; } \\
\text { ITE1; ITE2) }\end{array}$} & $\begin{array}{l}\text { Range of } \\
\text { viewpoints }\end{array}$ & $\begin{array}{l}\text { "Ability to interpret a range of viewpoints - requires initial } \\
\text { understanding of perspectives"; "A capable year } 13 \text { geography } \\
\text { student should be able to consider the range of different } \\
\text { viewpoints that people have about their responses to and } \\
\text { interactions with a range of different environments." }\end{array}$ \\
\hline & & $\begin{array}{l}\text { After } \\
\text { viewpoint }\end{array}$ & $\begin{array}{l}\text { "After clearly stating a person's viewpoint, they need to ask: } \\
\text { what is the lens this person is looking through (e.g. economic, } \\
\text { environmental, feminist, political, humanitarian ...)?" }\end{array}$ \\
\hline & & $\begin{array}{l}\text { Viewpoint, } \\
\text { value, } \\
\text { perspectives }\end{array}$ & $\begin{array}{l}\text { "Year 11: describe the viewpoint and the reasons a person gives } \\
\text { to justify their viewpoint Year 12: as above plus what has } \\
\text { influenced the person to hold this view Year 13: as above plus } \\
\text { description of the lens and factors that might change the views" }\end{array}$ \\
\hline & \multirow[t]{2}{*}{$\begin{array}{l}\text { Worldview } \\
\text { (TBA1; CA1; } \\
\text { CA3; PDP2; } \\
\text { ITE2) }\end{array}$} & Worldview & $\begin{array}{l}\text { "Other words used to describe these underlying influences are } \\
\text { world views and philosophical theories. Social science need to } \\
\text { understand these "forces" and their influence on human society"; } \\
\text { "As geography is about both the environment and people we } \\
\text { need to have an appreciation of how different peoples have } \\
\text { perceived and used the environment informed by a world view } \\
\text { or perspective." }\end{array}$ \\
\hline & & Lenses & $\begin{array}{l}\text { "Vast opportunities to awaken our students to a world beyond } \\
\text { their own - that not everyone sees the world through the same } \\
\text { lens and that often the world-communities within which we live } \\
\text { have been shaped both spatially \& temporally by certain world } \\
\text { views/perspectives i.e. Judeo-Christian, Capitalist."; "It is } \\
\text { important that students realise that the subject matter of } \\
\text { geography can be viewed through the lenses of different } \\
\text { ideologies/worldviews and educational traditions." }\end{array}$ \\
\hline & \multirow[t]{2}{*}{$\begin{array}{l}\text { Disciplinary } \\
\text { orientation } \\
\text { (CA1; PDP1; } \\
\text { EW2; ITE2) }\end{array}$} & $\begin{array}{l}\text { Disciplinary } \\
\text { stance }\end{array}$ & $\begin{array}{l}\text { “...an understanding of perspectives enables students to grasp } \\
\text { different ways of seeing the geographic world, other than the } \\
\text { scientific perspective they are most often exposed to...Human } \\
\text { geography appears easier to apply an understanding of } \\
\text { perspectives. However, I do wish that the perspective being used } \\
\text { in physical geography was overtly named for students as a } \\
\text { scientific perspective, and that students [developed] an } \\
\text { understanding of the nature of scientific inquiry ... as opposed to } \\
\text { teaching physical geography as inert fact." }\end{array}$ \\
\hline & & Primary data & $\begin{array}{l}\text { "Issues and Research. Lends itself to collecting primary data, } \\
\text { which is geography in a nutshell!" }\end{array}$ \\
\hline
\end{tabular}




\begin{tabular}{|c|c|c|c|}
\hline Axial Code & $\begin{array}{c}\text { Codes } \\
\text { (Participants) }\end{array}$ & $\begin{array}{l}\text { Open } \\
\text { coding }\end{array}$ & Exemplar Statements \\
\hline \multirow{13}{*}{$\begin{array}{l}\text { Pedagogical } \\
\text { approaches }\end{array}$} & \multirow{4}{*}{$\begin{array}{l}\text { Issues } \\
\text { based } \\
\\
\text { (TBA1; TBA2; } \\
\text { CA1; CA3; } \\
\text { CA4; PDP1; } \\
\text { PDP2; EW2; } \\
\text { ITE1; ITE2) }\end{array}$} & Issues & $\begin{array}{l}\text { "Any issue-based approach that allows inclusion of } \\
\text { gendered or Māori perspectives seem to be 'natural' area } \\
\text { for perspectives based teaching and learning"; "Through } \\
\text { geographic issue that have both social, economic and } \\
\text { environmental aspects. E.g. resource use, approaches to } \\
\text { geographic issues etc." }\end{array}$ \\
\hline & & Named issues & $\begin{array}{l}\text { "Most suitable: global and local deprivation; } \\
\text { migration/population studies; tourism issues"; } \\
\text { "Contemporary geographic issues, Planning and } \\
\text { decision-making, Responses to crises, Development } \\
\text { studies. Any topic that involves people's interpretation } \\
\text { of events." "Find a local issue to keep it interesting } \\
\text { (skateboard park to open down the road), too many fast } \\
\text { food shops located at a local intersection etc.)." }\end{array}$ \\
\hline & & Real people & $\begin{array}{l}\text { "refer to REAL and SPECIFIC people to support or } \\
\text { highlight the perspective - bring these to life with video } \\
\text { or meet in person - making a connection to REAL } \\
\text { people important" }\end{array}$ \\
\hline & & Conflict & $\begin{array}{l}\text { "Considering world conflicts resulting from different } \\
\text { groups having different viewpoints to the same issue." }\end{array}$ \\
\hline & \multirow[t]{2}{*}{$\begin{array}{l}\text { Identifying } \\
\text { perspectives } \\
\text { (TBA1; CA3; } \\
\text { CA4; PDP1; } \\
\text { EW2; ITE1; ITE2) }\end{array}$} & Named/matched & $\begin{array}{l}\text { "...a good understanding of other perspectives like a } \\
\text { Western scientific or gender perspectives"; "They } \\
\text { should be able to match perspectives to labels such as } \\
\text { political, social, and environmental"; "The concepts are } \\
\text { probably most accessible in relation to ecological, } \\
\text { feminist/gender, cultural and globalization } \\
\text { perspectives." }\end{array}$ \\
\hline & & Identify & $\begin{array}{l}\text { "They should be able to easily identify different } \\
\text { perspectives from text or digital media"; } \\
\text { "...identification of changing perspectives over } \\
\text { time/space" }\end{array}$ \\
\hline & \multirow[t]{2}{*}{$\begin{array}{l}\text { Analyse } \\
\text { Perspectives } \\
\text { (TBA1; TBA2; } \\
\text { CA1; CA3; } \\
\text { PDP2; ITE1) }\end{array}$} & Analyse & $\begin{array}{l}\text { "the good old tried \& true example of looking at an } \\
\text { incident using three different news reports written } \\
\text { through three different political lenses."; "What reasons } \\
\text { are they giving? What has influenced their ideas? Have } \\
\text { their ideas changed? Are they likely to change? What } \\
\text { might influence their view?" }\end{array}$ \\
\hline & & Explain & $\begin{array}{l}\text { "One way to do this is to share different explanations } \\
\text { for the same geographic issue, that are drawn from } \\
\text { different perspectives." } \\
\text { "For example, they should be able to explain how a } \\
\text { feminist perspective on shopping centre design and } \\
\text { layout differs from that of the dominant commercial } \\
\text { capitalist corporate (globalised) retailing perspective"; } \\
\text { "Writing a paragraph explaining a perspective" }\end{array}$ \\
\hline & \multirow{2}{*}{$\begin{array}{l}\text { Application } \\
\text { of } \\
\text { perspectives } \\
\text { (TBA1; CA1; } \\
\text { CA2; CA3; } \\
\text { CA4; PDP1; } \\
\text { ITE1) }\end{array}$} & Transfer & $\begin{array}{l}\text { "be able to transfer their understanding to a scenario } \\
\text { they have been provided to analyse or comment on" }\end{array}$ \\
\hline & & Apply & $\begin{array}{l}\text { "Ability to apply to increasingly unfamiliar and abstract } \\
\text { situations." } \\
\text { "....use case studies of different perspectives before they } \\
\text { apply these to a range of different issues" } \\
\text { "...be able to apply a perspective different from their } \\
\text { own when analysing a scenario..." }\end{array}$ \\
\hline & \multirow{3}{*}{$\begin{array}{l}\text { Future focus } \\
\text { (TBA1; CA3; } \\
\text { EW1; PDP1; } \\
\text { PDP2; ITE1; ITE2) }\end{array}$} & Decisions & $\begin{array}{l}\text { "Much conflict is caused by lack of understanding of } \\
\text { how other people think and feel. Perspectives and } \\
\text { understanding them will make for better 'planning' } \\
\text { decisions" }\end{array}$ \\
\hline & & Responses & $\begin{array}{l}\text { "Explaining responses to issues...when evaluating } \\
\text { potential impacts of events or actions" }\end{array}$ \\
\hline & & Consequences & $\begin{array}{l}\text { "What are the societal consequences of different groups } \\
\text { having different perspectives?" }\end{array}$ \\
\hline
\end{tabular}




\begin{tabular}{|c|c|c|c|}
\hline Axial Code & $\begin{array}{c}\text { Codes } \\
\text { (Participants) }\end{array}$ & $\begin{array}{l}\text { Open } \\
\text { coding }\end{array}$ & Exemplar Statements \\
\hline \multirow{13}{*}{$\begin{array}{l}\text { Challenging } \\
\text { concept to } \\
\text { unpack }\end{array}$} & \multirow{8}{*}{$\begin{array}{l}\text { Difficulty of } \\
\text { interpreting } \\
\text { the concept }\end{array}$} & Scholarship & $\begin{array}{l}\text { "Some of the 'best candidate' scholarship exemplars provide } \\
\text { statements that represent good understanding of perspectives." } \\
\text { "Don't start with perspectives in year 11, but wait for the } \\
\text { scholarship opportunity." }\end{array}$ \\
\hline & & Too difficult & $\begin{array}{l}\text { "Positivist [perspective] too difficult"; "Theoretical } \\
\text { perspectives are often beyond the understanding of many } \\
\text { secondary students." } \\
\text { "Stakeholders or organisations are tangible and easier for } \\
\text { students to identify with. Intangibles are harder."; “...the } \\
\text { second one is not strongly linked to the current curriculum and } \\
\text { generally requires a more critical level of thinking" }\end{array}$ \\
\hline & & Tertiary level & $\begin{array}{l}\text { "My gut feeling is that some of the perspectives listed in this } \\
\text { survey sit better at tertiary level"; "I don't feel very confident } \\
\text { here in assisting my student teachers make the links between } \\
\text { their tertiary learning of different paradigms in geography and } \\
\text { what does and can happen in school geography." }\end{array}$ \\
\hline & & $\begin{array}{l}\text { Conflation/ } \\
\text { confusion }\end{array}$ & $\begin{array}{l}\text { "Perspectives is still, all too often, conflated with viewpoints"; } \\
\text { "It is confusing for students when many terms are used e.g., } \\
\text { values/viewpoints/perspectives/opinions etc."; "I think that } \\
\text { teachers need to work hard to get beyond the viewpoint and } \\
\text { values language they have been using from Yr1!" }\end{array}$ \\
\hline & & Theoretical & $\begin{array}{l}\text { "[It's] quite theoretical - need to unpack this into kid 'friendly' } \\
\text { terminology"; "This is quite a sophisticated idea... I once tried } \\
\text { to briefly introduce feminist geography in an all girls' school } \\
\text { and it fell very flat!" }\end{array}$ \\
\hline & & Unfamiliarity & $\begin{array}{l}\text { "Managerialist - I am unclear what exactly this means"; "not } \\
100 \% \text { sure what it is"; "Unsure what it means!"; "Post-Fordist } \\
\text { - what even is this? Marxist - Historical perspective?" }\end{array}$ \\
\hline & & Pre-dates & $\begin{array}{l}\text { "Teachers will have limited understanding of what these } \\
\text { mean. For those of us who completed geography degrees in } \\
\text { the } 1970 \text { s and } 80 \text { s our study pre-dates many of these terms. } \\
\text { The challenge is how to upskill teachers' knowledge"; }\end{array}$ \\
\hline & & $\begin{array}{l}\text { Taking easy } \\
\text { route }\end{array}$ & $\begin{array}{l}\text { "I realise I have taken the easy route and mainly addressed the } \\
\text { multiple perspectives as per the social inquiry process and not } \\
\text { as ways of knowledge making." }\end{array}$ \\
\hline & \multirow{2}{*}{$\begin{array}{c}\text { Lack of } \\
\text { pedagogic } \\
\text { guidance } \\
\text { (CA1; CA2; TBA1; } \\
\text { TBA2; EW2; ITE2) }\end{array}$} & $\begin{array}{l}\text { Need for } \\
\text { quality } \\
\text { resources }\end{array}$ & $\begin{array}{l}\text { "I think there is a real need to develop quality resources and } \\
\text { material for students to work from as well as to show teachers } \\
\text { how this area might be taught"; "Unfortunately there is still a } \\
\text { lack of good material on this readily available to teachers"; } \\
\text { "I haven't found a 'textbook' that goes close to meeting the } \\
\text { needs of geographers in NZ - recommendations welcome! PD } \\
\text { has been weak as well, in my view, particularly beyond urban } \\
\text { centres/clusters, but this is a resourcing issue (perhaps?)" }\end{array}$ \\
\hline & & $\begin{array}{l}\text { Lack of } \\
\text { specifics }\end{array}$ & $\begin{array}{l}\text { "However, not specific in how this may best be done."; "I } \\
\text { think this statement indicates what is meant by a } \\
\text { perspectivised approach to geography, but it is not content or } \\
\text { pedagogical guidance. I wonder how many geography teachers } \\
\text { would feel confident to teach a range of perspectives...I can } \\
\text { see how easily this could be relegated to the 'too hard' basket, } \\
\text { largely because there is such minimal support for teachers } \\
\text { beyond a definition for perspectives." }\end{array}$ \\
\hline & \multirow[t]{3}{*}{$\begin{array}{l}\text { Boundary } \\
\text { maintenance } \\
\text { (CA3; CA4; TBA1; } \\
\text { PDP1; ITE2) }\end{array}$} & $\begin{array}{l}\text { Geog or } \\
\text { other } \\
\text { subjects? }\end{array}$ & $\begin{array}{l}\text { "humanistic [is] more suited to psychology than geography." } \\
\text { "If more abstract or very social perspectives are used students } \\
\text { can confuse geography with other social sciences" "I think } \\
\text { that geography does have a unique perspective as outlined in } \\
\text { the National Geographical article in the Geog Guidelines. But } \\
\text { the perspectives we are encouraging are also now very } \\
\text { influential in all fields of knowledge." }\end{array}$ \\
\hline & & Hijack & $\begin{array}{l}\text { “...possibility of Geography becoming "hijacked" by non- } \\
\text { geographers”; }\end{array}$ \\
\hline & & $\begin{array}{l}\text { Maintain } \\
\text { focus on geo }\end{array}$ & $\begin{array}{l}\text { "Challenge is to ensure that students maintain a focus on the } \\
\text { geography." }\end{array}$ \\
\hline
\end{tabular}


Appendix N: Teacher analysis of diagnostic tasks

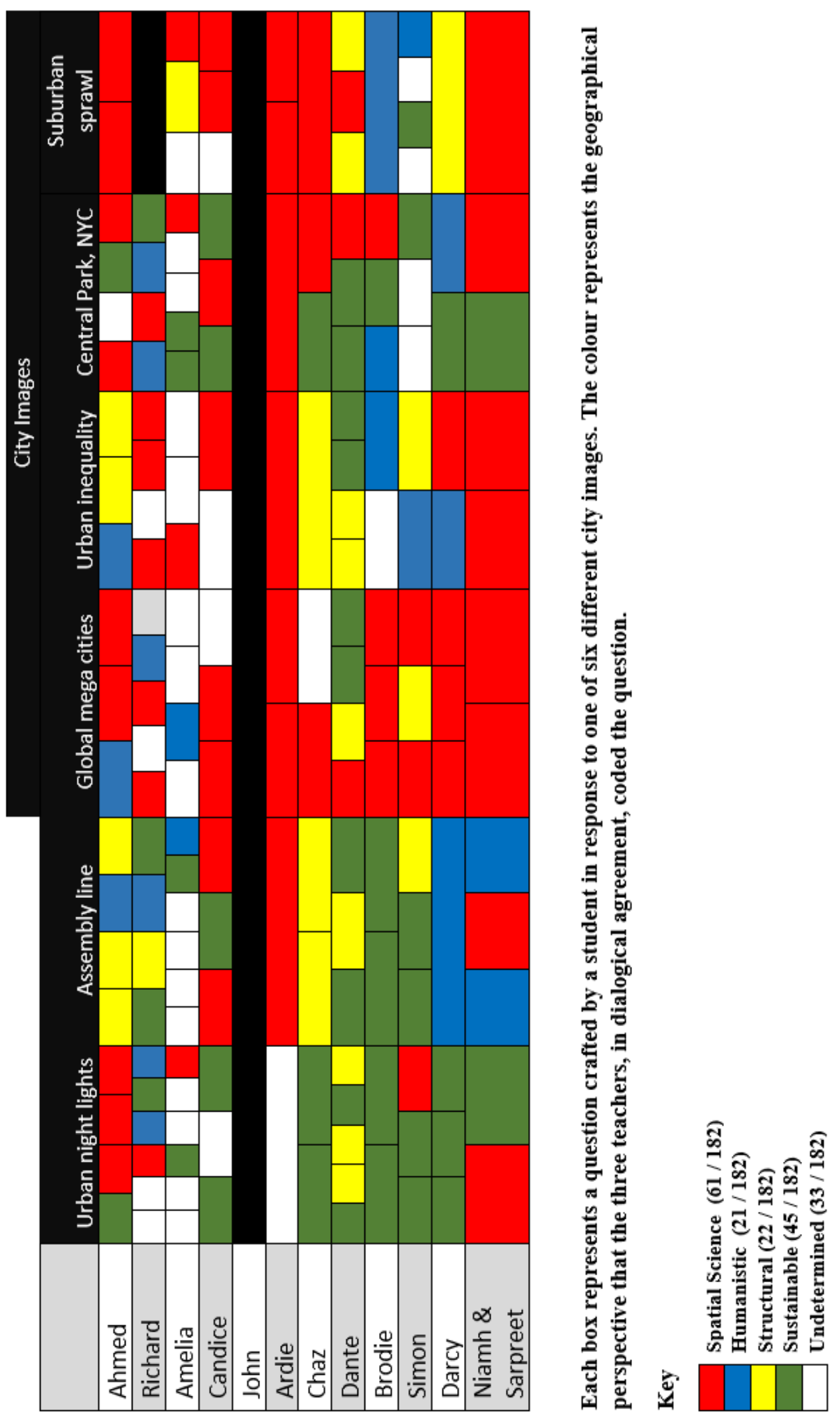




\section{Appendix N continued}

Categorisation of questions: Examples

\begin{tabular}{|l|l|}
\hline $\begin{array}{l}\text { Assigned } \\
\text { Perspective }\end{array}$ & \multicolumn{1}{|c|}{ Examples of Student Posed Questions } \\
\hline Spatial Science & $\begin{array}{l}\text { Does the presumably high population density increase local crime rates and if so } \\
\text { why? [Ahmed] } \\
\text { Is the development of a country proportional to the number of megacities this } \\
\text { country has? [Candice] } \\
\text { What do you think was covering the terrain prior to the urban / industrial settlement } \\
\text { of humans? [Ardie] }\end{array}$ \\
$\begin{array}{l}\text { How does population concentration affect urbanisation and these areas? [Chaz] } \\
\text { Do areas like this have transport systems in place to make sure that those living in } \\
\text { suburban environments can easily access the CBD? [Dante] } \\
\text { Why is there a high density of mega cities in Asia? [Darcy] }\end{array}$ \\
\hline Humanistic & $\begin{array}{l}\text { Does the photograph accurately represent the working conditions in the factory, or } \\
\text { was it staged by the company for self-gain? [Ahmed] } \\
\text { What are some different perspectives people might hold about these workers?[Ben] }\end{array}$ \\
$\begin{array}{l}\text { How does the community interact with one another? [Simon] } \\
\text { How does the lifestyle differ between these two groups (rich and poor)? [Darcy] }\end{array}$ \\
\hline Structural & $\begin{array}{l}\text { Has outsourcing the factory to Asia negatively impacted the economy of the } \\
\text { company's homeland? [Ahmed] } \\
\text { Does urbanisation create a class divide? [Chaz] } \\
\text { Has the development of the tourist industry positively or negatively affected those } \\
\text { from a low socio-economic background? [Dante] }\end{array}$ \\
\hline Sustainability & $\begin{array}{l}\text { Are the buildings safe for earthquake? [Amelia] } \\
\text { How will interaction between human and environment effect this city in the future? } \\
\text { [Brodie] } \\
\text { Is the way that products are made environmentally friendly? [Simon] } \\
\text { Will the development of an urban environment be sustainable for the natural } \\
\text { environment? [Darcy] } \\
\text { Is light pollution a problem? [Niamh \& Sarpreet] }\end{array}$ \\
$\begin{array}{l}\text { What effect is this city having on the rest of the country? [Richard] } \\
\text { What factory work are they doing? [Amelia] } \\
\text { When was the white building shown in the photo built? [Candice] }\end{array}$ \\
\hline
\end{tabular}




\section{What Perspectives Shape Migration Policy?}

\section{Agency perspective}

The government passively observes as different groups seek to control debate about migration. Acts as a 'broker' by responding with policy to address the group who organises most effectively.

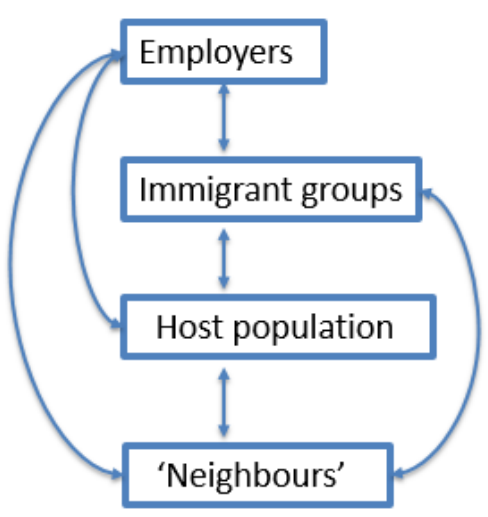

\section{Structural perspective}

Liberalism is embedded across society with the following characteristics:

- freedom from state authoritarianism;

- socially just distribution of welfare resources between citizens;

- moral equality for all humans;

- 'separation of powers' for democratic peace

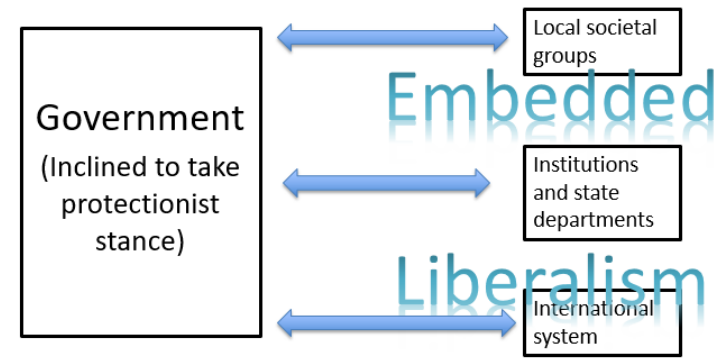

\section{Functional Perspective}

Government is required to complete certain tasks to be seen as credible by voters, otherwise, at the next general election voted out!

\section{Government}

(Required to complete certain tasks to sustain

their legitimacy and

capacity to govern)

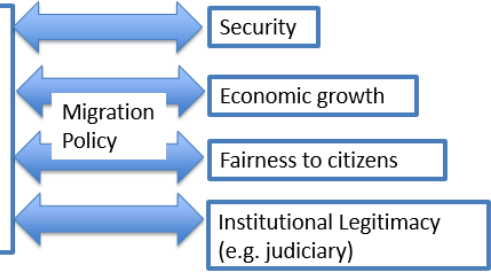




\section{CLASSROOM QUESTIONS}

\section{Learning geography (stakeholder perspectives)}

1. Which perspective do you thing drives Trump U.S. administration migration policy? Why?

2. Can you find quotes from Donald Trump that support your answer to \#1?

3. Name some groups or organisations that oppose current (2018) U.S. migration policy and describe how they come from a different perspective

\section{Learning about Geography (disciplinary-consciousness):}

1. What type of data would a geographer need to collect to research two of these migration policy perspectives? Justify your answer.

2. Which of these perspectives might also be described to be humanist? Why?

3. Why might the structural perspective be considered 'western centric'?
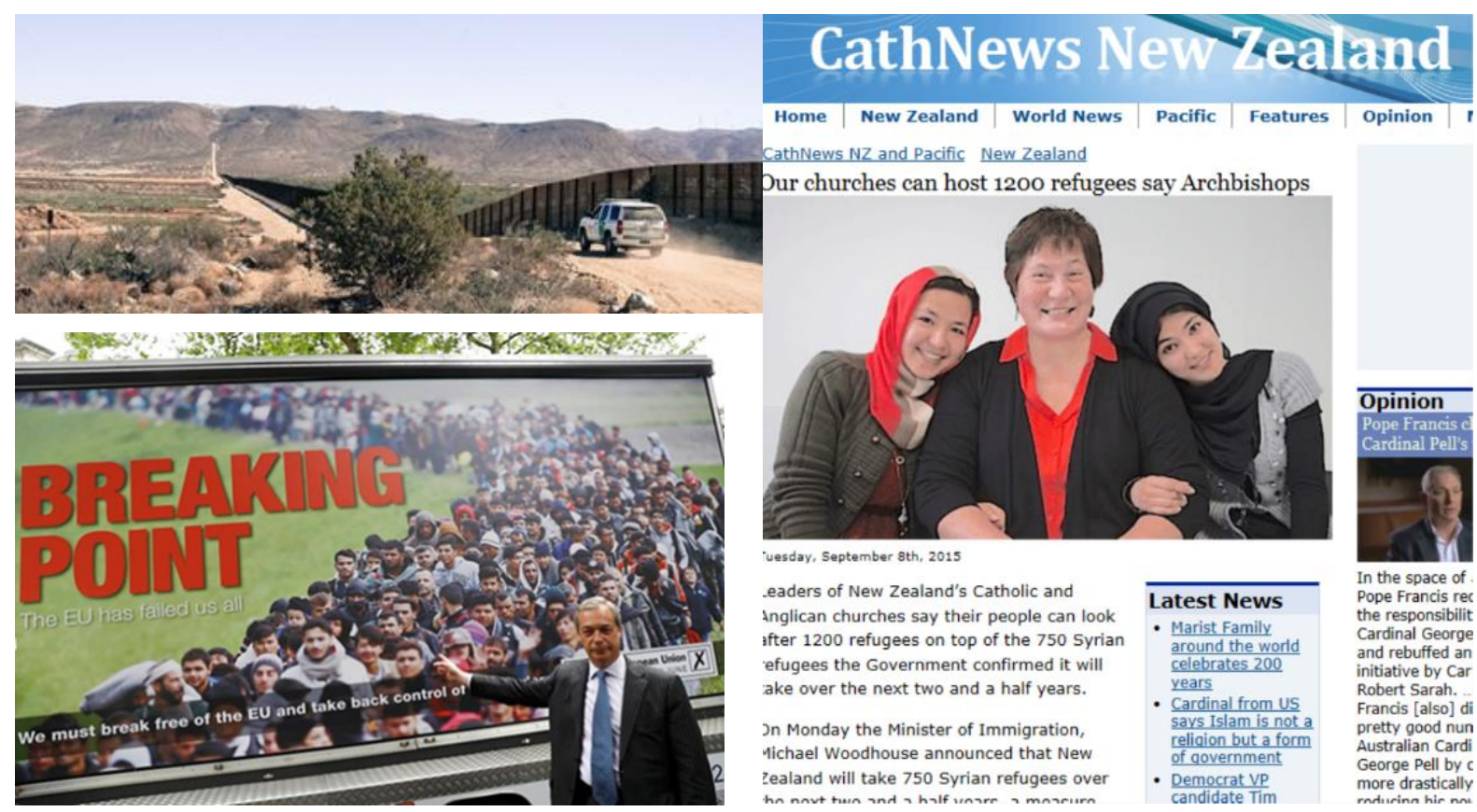